ifornia onal ity

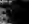




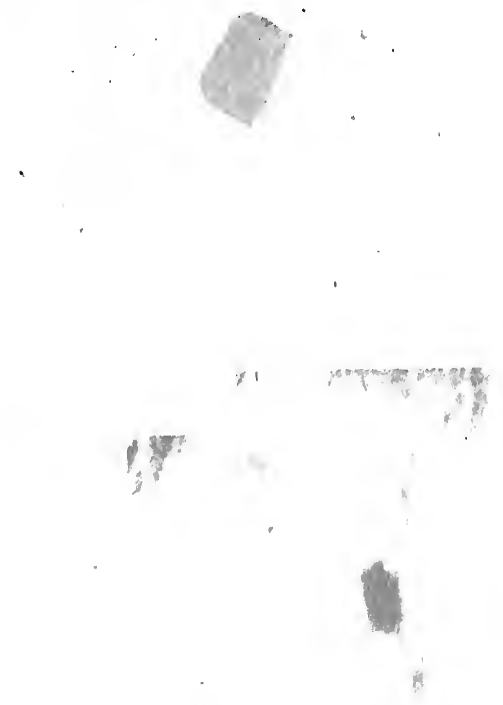

,

i. 
SOUTHERN BRAN

UHUVESTTY OF CALIFGA:Ih, LIRRARY,
LOS ANGELES, CALIF. 
y 
SOUTHEFN ERAN UHIVESUTY OF CALITL:Allh, LIRRARY. LOS ANGELES, CALIF. 



\section{T R A D E T E S T S}

THE SCIENTIFIC MEASUREMENT OF TRADE PROFICIENCY

\section{BY}

\section{J. CROSBY CHAPMAN}

B. A. (Cantab.), D.Sc. (London), Рh.D. (Columbia)

ASSOCIATE PROFESSOR OF EDUCATIONAL PSYCHOLOGY, YALE UNIVERSTTY; MEMBER OF THE NATIONAL RESEARCH COUNCIL, SUB-COMMTTEE ON SELECTION OF MEN WITH SPECIAL

SKILLS; MEMBER OF THE COMMTTEE ON CLASSIFICATION OF PERSONNEL, ARMY

TRADE TEST DIVISION; CONSULTANT TO THE $v$. S. DEPARTMENT OF

LABOR, TRADE INTERVIEW METHOD SECTION; CONSULTING EXPERT

TO WAR DEPARTMENT, TESTS AND STANDARDS SECTION.

WITH THE ASSISTANCE OF

DAISY ROGERS CHAPMAN, M. A.

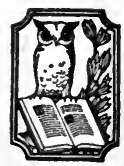

NEW YORK

HENRY HOLT AND COMPANY

I92I

40461 
Copyright, 192I

BY

Henry Holt and Company 


\section{T73 \\ C36t}

THE MEMBERS OF THE COMMITTEE ON CLASSIFICATION OF PERSONNEL, ASSOCIATED WITH THE ARMY TRADE TEST DIVISION, WHOSE CO-OPERATIVE WORK DEVELOPED THE INSTRUMENT DESCRIBED IN THIS BOOK 



\section{PREFACE}

There is a universal demand for increased production; a more economical use of material and man power is the only way in which the world can be rapidly restored to a normal condition. It is obvious to all that greater economy in the use and adaptation of material resources is greatly needed, but it is by no means so clearly recognized that the human resources of the country, and indeed of the world, must be equally husbanded. Depleted man-power is the sad aftermath of war.

d Although this country has not suffered great losses on the field $\gamma$ of battle, although the number of our skilled men has not been ? lowered appreciably, there is no doubt that, as time advances, $\because$ reduced immigration will cause inconvenient labor shortage. \& No industry can afford, at the present juncture, to overlook is any device or method which gives promise of more scientific $\ddot{\gamma}$ selection, placement and training of its employees:

$\checkmark$ At a time when the human resources of the country were $\checkmark$ taxed to the uttermost, the War Department, to meet the $\checkmark$ problem of placement of its skilled personnel, undertook exten$\zeta$ sive researches. One of the important outgrowths of this experimentation was the Trade Test. This instrument was devised and constructed to make it possible for a trained examiner, unskilled in any particular trade, to measure in objective terms the trade standing of any recruit claiming skill in any of the several hundred trades necessary to the work of the army. The success of this work, undertaken by the Committee on Classification of Personnel, was largely due to the whole-hearted coöperation given by a large number of industrial plants, in the three centers where the Army Trade Test Division was established. 
During the war, for obvious reasons, it was impossible to make public the results of the investigation, and to give back to industry the methods and the instruments, the development of which were so largely due to the unstinted help of employers and tradesmen alike. Large industrial organizations, trade unions, small shops and private individuals made great sacrifices, both of time and of money, to further the trade test work. With the closing of hostilities it is possible to repay, in some small measure, the debt of gratitude which the Committee on Classification of Personnel owes to those who contributed so generously to the construction of the trade test instrument.

If the ideas contained in this book serve to stimulate thought and to suggest a method of attack on some recurring problems of industrial management, the function of this book will have been fulfilled. The trade test movement is only in its infancy, but the methods that have been evolved will prove a firm foundation upon which an elaborate superstructure can safely be built. Under the normal conditions of peace, for the simple reason that it would have been impossible to obtain the assistance of the various industries, these foundations could not have been laid. If the principles of army trade test construction are adapted to the needs of the industrial plant, many of the problems of selection, placement and training of skilled personnel will be more easily solved.

The author is indebted not only to the large number of employers and tradesmen who formed a vital part of the vast experiment, but to every member of the Committee on Classification of Personnel who was connected with the Army Trade Test Division. This obligation is inadequately expressed in the dedication of the book. The author is no more responsible for the development of the underlying ideas than were many of his colleagues. The Trade Test was a coöperative product; no use- 
ful purpose would be served by assigning individual credit for particular instruments.

Without making any invidious distinctions, special mention may be made of two men who conceived and guided the movement from its beginnings. To outline the history of the work of Dr. E. L. Thorndike and Colonel Walter Dill Scott is to recapitulate the development of the application of psychology to this group of human problems. With these names the author wishes to couple that of Dr. W. V. Bingham, at whose suggestion this book was prepared.

It is my pleasure to express my gratitude for the helpful suggestions made by Dr. D. E. Rice who read the manuscript.

In the assembly of the contents of this book the author has been greatly aided by material furnished by the following: Mr. Roger Evans, Mr. A. W. Kornhauser, Dr. C. R. Mann, Mr. F. Meine, Mr. D. G. Paterson, Mr. J. A. Randall, Dr. E. S. Robinson, Dr. B. Ruml, Dr. L. L. Thurstone, Mr. H. A. Toops and Mr. Max Watson.

I am under obligation to the Adjutant General of the United States Army for permission to reproduce a considerable body of material prepared by the Army Trade Test Division of the Committee on Classification of Personnel.

In the writing of this book, I have been greatly helped by my wife. Her intimate association with the Army Trade Test Division from its inception, and her close contact with both the experimental work in the laboratory and the administration of the tests within the industrial plants have made her contribution such that the only adequate method of recording this obligation has been the open sharing of authorship.

War Department,

J. Crosby Chapman

WASHINGTON, D.C. 



\section{CONTENTS}

CHAPTER

SECTION I - INTRODUCTION

PAGE

I. The Nature of the Army Problem.............. 3

Section II - The Oral Trade Test

II. The Construction of the Oral Trade Test.........

(General Discussion)

III. Construction of an Oral Trade Test............ 80

(Detailed Procedure)

IV. admintstration and Scope of the Oral Trade Test.... i i66

. Section III - The Picture Trade Test

V. The Picture Trade Test Method............... 185

Section IV - The Performance Trade Test

VI. The General Nature of the Performance Test Method. 259

VII. The Construction of a Performance Test.......... 272

Section V - A Written Group Trade Test

VIII. The Written Group Trade Test Method.

Section VI - The Place of the Trade Test in Industry IX. The Analogy between the Army and the Industrial Employment Problem..................... 347

$\longrightarrow \mathrm{X}$. Problem of Occupational Analysis.............. 367

XI. What the Trade Test Is Not............... $37 \mathrm{I}$

XiI. The Use of the Various Types of Trade Tests...... 376

XiII. The adaptation of Trade Test Methods to the Training

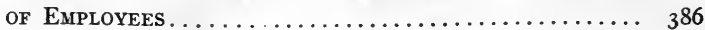

XIV. The Installation of Trade Tests . . . . . . . . 413

XV. Some Further Applications of Trade Test Methods... 420

BIBLIOGRAPHY............................ 43 I

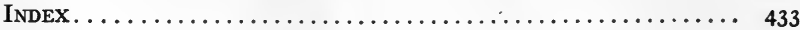




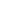


SECTION I

INTRODUCTION 


\section{TRADE TESTS}

\section{CHAPTER I}

\section{THE NATURE OF THE ARMY PROBLEM}

The Necessity for More Exact Knowledge of the Trade Abilities of Workmen

When the scale of production, which the necessities of the world make imperative, is begun, industry will be in desperate need of more men, and particularly skilled men. Without the strictest economy in the use of human resources, the process of adjustment may be indefinitely prolonged. The decline in the quantity of labor available must eventually mean the introduction of a more effective method of using the knowledge and skill of each man employed.

Industry has long been dissatisfied with the manner in which it appraises the skill and knowledge of its human material. Upon these more than on any other factors depend such questions as the selection of men, placement of men, transfer of men and promotion of men. If there is waste in any of these processes, the result is bound to tell on production, which under present conditions is the final gauge of success. To those who have been handling personnel it has long been apparent that what is urgently required is more detailed information concerning the attainments of each employee or prospective employee. Until devices have been evolved which will secure 
such information we can expect a continuance of the enormous waste which the more far-seeing employers of to-day are attempting to minimize. Industry has realized the unsatisfactory state of affairs, but it has been content, in fact forced, to muddle through, substituting the use of greater quantities of labor, wrongly selected and poorly placed, for a less quantity of labor, scientifically selected and strategically placed. Increasing personnel, however expensive the procedure, is the only possible solution, unless industry is willing to make radical alterations in the methods of hiring, assigning, transferring and training men. To effect these alterations the most careful attention will have to be given to the related problem of training the employee and of measuring objectively the degree of his proficiency. Maximum production goes hand in hand with correct placement.

Strict economy, while necessary at the present moment, was of overwhelming importance during the war, when the country was putting vast numbers of men into the field. The strategic use of personnel, at this period, translated itself into losses minimized and battles won. The exigencies of the personnel situation, within the army, forced a crisis which called into existence a new method of attacking an old problem. As already pointed out, until the crisis arose, old methods and old devices were considered "good enough." Blinding its eyes to its own wasteful methods, industry struggled on as best it could. In spite of alarming increases in labor turnover, the pressure of production prevented serious scientific experimentation in the field of employment methods. In the handling of personnel in the army the wastefulness and inefficiency of the old devices for determining trade skill and status caused such enormous inconvenience and delay that new instruments had to be devised to meet the problem. These instruments, forged 
in the heat of conflict for the exclusive use of the army, are now available for general service.

\section{The Army Situation with Relation to Skilled Personnel}

While the ordinary commercial industry, under normal conditions, is able to make up for mistakes in the selection of its personnel by hiring more personnel, the army at the outbreak of the war, and more particularly later, was not in position to apply this easy but highly wasteful remedy. Man power for the army was by no means inexhaustible, for industry was at the same time sorely pressed to maintain its production. It was incumbent upon the army to use the knowledge and skill of each member to the best advantage, for the industrial situation was such that the number of skilled men the army could call upon was strictly limited. It was under this urgent necessity that the army in I9I 7 turned to industry to see if any methods in use at that time for determining the skill of workmen would help it to meet its placement problems.

To appreciate the difficulties of the situation it will be necessary to consider briefly how the ways of handling personnel in the army differed from those found in the ordinary industrial plants. The most outstanding factors were the largeness of the enterprise and the speed with which the whole must be set in operation. The army, within itself and for its own specific purposes, required men of all degrees of skill in several hundred fairly definite occupations. To train for a large number of these occupations was wholly out of the question. To train for any of them, when skilled men were already present in the army, was a course involving great waste and delay. To be engaged in training men to do general automobile repair, for example, while first-rate auto mechanics were learning to drill and dig trenches, was clearly absurd, and yet exactly this situa- 
tion was inevitable unless there was at hand some ready method of determining the trade ability of each man entering or already enrolled in the army.

The first and most rapid method of getting information with regard to the trade ability of each recruit was to interview him and make a note or check on the qualification card, later described, which listed the larger number of important army occupations. The number of years during which the particular trade had been followed gave significant information and an approximate idea of the degree of proficiency. There were, however, two factors which minimized greatly the reliability of this trade qualification record.

In the first place the bluffer of commerce did not seem to change his spots when he entered the army. Many men who in fact had no significant trade experience claimed to be experts, while others, without conscious deception, either overestimated or underestimated their ability, thereby making their records of little value. In the first rush it was necessary to fill the requisitions for men as they came in, 'using at its face value the information supplied by the qualification card. When these men were assigned to active service, the inadequacy of the method became patent. After having been shipped to France on the basis of these records, men failed when confronted with the jobs in those trades in which in the camps they had claimed skill. On investigation of these cases many men openly confessed that they had made misstatements as to their ability, and others admitted that they had grossly overestimated the ability which they possessed. Herein lay one of the great differences between conditions in the army and those in the industrial plant. In the latter, if a wrong assignment is made, the preliminary trial, usually coming immediately after the interview, reveals the fact, though often not without a considerable 
waste of time as well as of material. Into each camp there came a constant stream of men skilled in all varieties of trades. When it is remembered that the services of men representing not less than four hundred distinct occupations were required for the successful operation of the army, it will be seen how impossible it was to have in every center a body of men who could, of their own personal knowledge, estimate trade proficiency in this great variety of occupations. It would have required an army of experts who were needed for purposes other than that of merely testing and examining an occasional recruit who claimed trade ability. In commercial industries the man who hires usually has some acquaintance with the trades which he is handling; if not, he is at least able to refer the applicant to the foreman or to others who have such acquaintance. The army, handicapped in this respect, demanded a method which would enable, if necessary, a single examiner with assistants to determine and rate the trade ability in each of the four hundred trades.

Another factor which rendered the usual industrial method of interview by a foreman or skilled man very unsatisfactory when used in the army was the variation in judgment between different interviewers as to what constituted trade skill. One examiner was willing to call a man a tradesman if he showed the least knowledge of the trade, whereas another would refuse to classify a man as such unless he was familiar with all branches of the work. The result was that ratings on the qualification cards did not have the same meaning from camp to camp, and even varied within the same camp where different interviewers examined for the same trade.

Let us briefly summarize the demands which the army made on the methods devised for measuring trade ability. The more important of these are listed below: 
(I) The methods must be applicable to all trades.

(2) The methods must be such that they can be employed by an intelligent examiner who has no personal knowledge of the trade.

(3) The methods must yield a rating of a man which is independent of the examiner's individual judgment, in other words, the test must be objective and not subjective.

(4) The methods must be rapid, and in most cases must not require the use of tools or apparatus.

These were the major requirements. Several minor details which had to be borne in mind by those who attempted the solution of the problem need not be considered here.

It was to meet these rather exacting requirements that the so-called trade test was devised. The general theme of the whole book must serve as the answer to the question: "What is a trade test?" It seems advisable, however, before proceeding further, to give a preliminary or partial definition of this term. Essentially, the trade test is a measuring rod which can be used without trade knowledge on the part of the examiner, for rating in objective, quantitative terms the degree of trade ability possessed by the person under examination. In many scientific fields we are familiar with the use of accurate measuring devices. The whole of physics depends on standard scales for measuring mass, length, and time and other quantities from which these are derived. Thus the micrometer of the machinist is merely a refined method of testing length; the ammeter of the electrician merely serves to measure the amount of current. These sciences have passed through the stage where a mere qualitative judgment is sufficient; we refuse to accept estimates based on the eye, the touch and other equally variable factors. If in dealing with physical materials we demand accu- 


\section{NATURE OF THE ARMY PROBLEM}

rate measurements to eliminate waste, even more in the case of human material we require for effective use all the measuring rods which science can devise..

\section{Objective versus Subjective Ratings}

The idea of measuring such a human trait as trade ability by an objective scale is of such recent date that it calls for some discussion. We have become so accustomed to such phrases as excellent workmen, good workmen, average workmen, poor workmen, that we are tempted to believe that the terms, "good," "average," "poor," stand for something quite definite in the sense that ten pounds, six pounds, and four pounds stand for definite amounts of weight. When we analyze the meaning of these terms we find that the designation "good," used by different individuals may mean very different degrees of trade ability; that is, the judgment is subjective. In opposition to these subjective judgments, which depend almost entirely upon the opinion of the individual, we get such measures as we have mentioned, where the unit employed is a pound or a similar standardized unit upon which all are agreed. The distinction between the subjective scale, which rates in terms of excellent, good, poor, bad, and the objective scale, which expresses ability in terms that are constant in value and universally understood, cannot be too clearly made. In the case of a perfectly objective scale all competent persons agree, while in the case of a perfectly subjective scale, all competent persons disagree, save by chance.

From certain portions of the account here given it may seem to the nonscientific reader that a disproportionate amount of time and energy has been spent in securing refinements of this scientific measuring-rod. This, however, is the price which must be paid for accurate results. If such time and energy are not given, the product will fail to stand up under the strain to 
which it is subjected in practice. It would have been possible in a very short time to construct scales for measuring trade ability which would have worked fairly well and given moderately accurate results. Under many conditions of industry nothing more than a rough measurement of trade ability is necessary. The care which should be given to the construction of a trade test depends wholly on the decisions which are to be made therefrom. In the army the decisions made were most important, and often involved the shipment of a tradesman to France. Under these conditions an accurate measuring instrument was a vital necessity. In industry, where much less important decisions are made, where the decision is distinctly tentative, and where an immediate try-out is often possible, it may well be that no such refinement in measurement is desirable. In this respect, as in many others which will be mentioned later, the army method is not immediately applicable in its present form to use in industry. The army methods were devised to meet a very specific situation; where conditions change as they must from industry to industry, and from time to time, these methods will have to be adapted to the particular situation. There is, however, not the slightest doubt that the experimental methods which under very favorable conditions were given such extensive try-out by the army have yielded results and devices which either in their present form or in a slightly adapted form, may be used to advantage in industry in the immediate future. Long experience has taught mankind to be extremely skeptical when simple devices are offered as solutions for perplexing problems. Particularly in this true when the purpose of the device is to measure some human achievement or quality. While there is in every one some remnant of credulity upon which the soothsayer, the fortune teller, the character analyst and the so-called "consulting psychologist" may fatten, there 
have been in industry, within recent years, so many attempts at exploitation of this sort that it is difficult at times to get a fair hearing even for most rigid scientific methods.

Not only must any new idea meet the skepticism which has been thus created, but it must also combat the reasonably cautious conservatism of those already engaged in practical work. In attempting to present the ideas contained in this book no claim is made that the instruments which have been devised can be immediately applied to all phases of employment work involving trade ability, but it is claimed that devices have been constructed and have been successfully used for measuring such ability under particular conditions. It is further claimed that even where the devices as they now exist are not directly applicable, the principles upon which they are based can be used with great profit in the solution of a large number of problems in connection with the process of selecting and measuring skilled personnel. The value of a scientific instrument or method must be gauged by its performance. The task of the writer who undertakes to explain the instrument is merely one of careful description. If in his enthusiasm he makes extravagant claims, he at once ceases to be a scientist and degenerates into a propagandist. Great care will be taken to avoid this danger; both the merits and defects of the method will be pointed out, for a clear recognition of its short-comings affords the best assurance of its successful application.

\section{The Meaning of Terms}

Some account of the way in which the words trade and ability are used will clarify our thought and simplify the presentation. By trade, as used in this book, we shall mean what is more commonly designated as "occupation"; thus within trade we shall include such diverse callings as those of surveyor, cook, 
turret lathe operator, statistician, typist. This is perhaps at variance with the ordinary usage of the term, which emphasizes the opposition to a profession. The chief restriction on the meaning of the term "occupation" as here used, is that it does not include activities primarily concerned with the exchange of goods; by occupation we mean rather a calling in which it is necessary to acquire facility in the use of certain tools, instruments and machines in order to produce certain physical results. A further restriction on the use of "occupation" is that this acquired facility or skill is for the most part considered to be a combination of a complex set of intellectual and muscular coordinations, such as is commonly found in carpentry, interior wiring, auto-repairing, telephone repair, etc., and not to be made up of a very narrow range of simple and oft-repeated coördinations such as are characteristic of the standardized operations of much of the highly specialized factory production. If the reader will bear in mind this inclusive meaning of the term trade, it will save the use of many descriptive terms, such as "occupational test" and "professional test," which would complicate the presentation.

The word "ability" is used to signify the power which a tradesman has of meeting the varied situations which arise within his occupation. The term "trade ability," therefore, signifies what is commonly meant by a man's competency to follow his trade, occupation or profession. In more scientific language it refers to any complex set of coördinations which are acquired in a fairly definite order and which characterize all men skilled in a given trade, thereby segregating them as a homogeneous group. The reader must not confuse this with the ability to answer certain questions or perform certain tasks, which is measured only in order to give an indication of true trade ability according to the above definition. 


\section{Existing Industrial Methods of Securing Information} Concerning Skill of Tradesmen

It has already been said that any new method is merely a skilful combination of devices which have been employed before. When a small subcommittee of the Committee on Classification of Personnel met in order to discuss ways and means of solving this new problem which army conditions had presented, the first inquiry that was made was relative to the practice that then existed in the large industrial plants. In these plants the conditions more closely paralleled those of the army; in many cases there was a central office where all matters of employment and selection were handled. The methods used in these central offices were found to be very diverse. In some cases the men in charge of the employment offices, who did the interviewing, were mere clerks who made no attempt to go back of the statements of the applicants but merely referred the latter to the various foremen in the plant. When so referred to the foreman, three forms of procedure are commonly followed. The first consists of a few questions relative to the trade. In the second the applicant is given some simple job to perform and his suitability is determined by his skill in doing the job. The third method, which is by far the most common, consists in trying out the applicant on the actual job which later he is to perform, and for employment in which he is being considered. Although these three methods require an expert tradesman as the examiner, the second procedure, that of assigning a simple job to the applicant, was distinctively suggestive. It subsequently developed into the performance trade test which will be described later. These methods the author, from personal experience, knows to be both uneconomical for the plant and unjust to the applicant. 
Another method which has also been extensively used, especially in the more progressive plants, has been to have in the employment office, or to release for certain hours of the day for work in the employment office, skilled workmen representing the various trades in which hiring takes place. It is the business of these skilled tradesmen to interview all applicants claiming trade ability. The interview covers the common ground of type of work done, length of experience, places where employed, etc. In many cases, in order to verify the statements of the applicant, specific trade questions are asked.

It may be well to discuss some of the disadvantages of this common method. In the first place, the men who are doing the interviewing are chosen, usually, not because they are skilled interviewers, but rather on account of their skill in their own trade. For this reason their attitude toward the men often results in failure to extract the knowledge which the applicant possesses. Secondly, the questions asked by the interviewer are frequently catch questions or else questions involving a knowledge of a very detailed and perhaps local process; frequently found also are questions which can be answered by a mere yes or no, without signifying any trade ability on the part of the applicant, who merely guesses. The questions upon which the "hiring and firing" depends are rarely clearly formulated, and in no cases are definite marks given for definite answers. In many cases which came under the writer's notice the examiners seemed more eager to show their own superiority than to determine the trade ability of the applicant. As a crude method of distinguishing the skilled workman from the bluffer this procedure, generally speaking, fulfills its function. It was, however, of no service from the standpoint of the army problem. Its greatest disadvantage was the fact that it required the services of skilled tradesmen as interviewers. The second dis- 
advantage was that the ratings given, on account of the lack of standardization of questions and answers, were essentially subjective and not objective. The first disadvantage in itself ruled out the possibility of its use in army camps. Skilled workmen were required for skilled work; they could not possibly be spared in such numbers as the above method would demand, merely to serve as a selective or placement force.

Another method used, though not so extensively, in employment bureaus and large plants was to have, in the main, trained clerical assistants in the employment office, but the interviewing force, by contact with foremen, was given facilities to discover the nature of the various occupations and the general processes involved. In some few cases the interviewer secured from the foreman a certain number of questions which might reasonably be supposed to test trade ability. Sometimes the interviewer knew enough about the trade to tell whether the answer given to the question was correct or not, but often he merely judged by the general attitude of the applicant and his readiness to reply, the extent to which he was familiar with trade terms and trade processes. Such questions as "Can you read a mic?" and "Are you acquainted with a blue print?" "What make of machines have you worked on?" "What is a template?" "What is a burring machine?" etc., may be taken as examples. The disadvantages of this type of question are apparent. In the first place, the questions asked in most cases do not call for any definite or detailed information. Any intelligent tradesman who has the least acquaintance with his trade can satisfactorily fulfill the requirements of many examinations of this type. A machinist's apprentice could answer the questions in the majority of cases quite as well as the expert mechanic. Bluffing is at a premium, for often the men know that the interviewer has no definite information with regard to the 
trade. Another important defect from the standpoint of army demands was the lack of a definite objective rating at the end of the examination. Although it was distinctly likely that this method would distinguish the novice from the skilled workman, the probability that it would differentiate between the twoyear apprentice, the ordinary journeyman and the skilled expert was remote. Even if in some exceptional cases it did serve to distinguish between these types, there was no definite mark which could be given that would mean the same thing to all persons, in all places, and at all times.

This general method, while not suited immediately to the army requirements because of its vagueness, possessed certain characteristics which were most suggestive to those studying the ways and means whereby certain phases of the selective work of the army could be met. Its most important feature was the fact that it did not require skilled tradesmen as interviewers. As will be seen later, this method of examination, when greatly modified and systematized, developed into the oral trade test.

\section{The Adaptation of These Methods}

The problem therefore that confronted the army was to adapt these methods to meet the requirements that have been cited. The first essential was that the method be such that it should not require a skilled tradesman as an examiner, and the other equally important consideration was that the examination or interview should yield $a^{*}$ definite objective rating.

During the five years prior to 1917 , a great deal of work had been done in connection with a somewhat related educational problem. Just as it is necessary for industry to have rapid and accurate methods of determining the skill and knowledge of its workmen, so it is equally necessary for the school, if it is 
to be efficient, to have methods of determining the skill and knowledge of its pupils. All instruction exists to produce changes in those taught. The success or failure of this instruction is measured by the rate at which skill is acquired or information assimilated. To place and direct each pupil to the best advantage and to have some check on the instruction demands the construction of objective scales or tests for school subjects. Such objective tests have been worked out in many of the common school branches, of which the most important are those in writing, reading, and arithmetic. Less successful attempts have been made to measure manual dexterity and other school factors more nearly related to trade skill. While some of these scales are far from satisfactory, the point of interest in connection with the army problem is that certain well-known methods have been evolved which eliminated the subjective factor in the estimation of abilities. No longer do we need to use the subjective terms excellent, good, fair, poor with regard to a specimen of writing; it is possible to state that its quality is I4, I3 or II on an objective scale of achievement. Here the qualities I4, I3 or II are not arbitrary, but are as clearly defined and have as precise meanings as the marks of a ruler. The way in which these methods were evolved from physics and psychology and applied to these particular problems cannot be treated here. The field of educational measurements made the maximum contribution. In fact the trade test movement is virtually the story of the refinement of the ordinary selective methods of industry by application of the statistical and other devices which have grown up largely within the realm of educational measurements.

If we leave for one moment the army requirements that the test be such that it can be administered by a nontradesman, there are two fundamental criteria which a trade test must satisfy: 
(I) It must differentiate between men of varying trade abilities and know edge.

(2) Its ratings must be objective.

No test can be considered satisfactory unless, in the first place, it distinguishes the person with no specific trade experience, whom we may call the novice, from the apprentice who has spent some little time in his trade. It must also distinguish the ordinary apprentice or learner or helper from the average skilled workman. In addition, if the test is to have its maximum usefulness, it should also enable us to differentiate the ordinary tradesman from the workman who is exceptionally skilled or has had exceptional experience. The ability which a test has to make these distinctions may be called its differentiating power. Whenever the word "differentiating" is used, we must bear in mind that it is a relative term. When we say that a trade test must differentiate, all that is implied is that it must distinguish between individuals who differ by a certain amount in trade ability. Thus, for example, a test may well serve to differentiate between the individual who has one year's trade experience and the individual who has five years' trade experience, but it may be expected to fail to differentiate between the individual who has had eighteen months and another who has completed nineteen months. We shall, therefore, find it necessary at a later stage to define with great exactness precisely the groups between which we expect the tests to distinguish. Any method of testing ability which will make this differentiation between the novice, apprentice, journeyman and expert has the widest application in the realms of selection and promotion within the industry.

The second requirement, which we shall refer to as that of objectivity, is so closely related to the first that it is only necessary to consider them separately chiefly for convenience in 
thought. Unless a test is objective, the rating which is given will vary from examiner to examiner. The ratings which are made at one time and at one place will not correspond with the ratings at another time and place. Thus while the measuring rod may be used to divide men roughly into three classes tall, medium and short - thereby fulfilling the differentiating function, much of the advantage of the measurement is lost unless for each individual or group of individuals the specific measurements are given and are recorded in units or in terms upon which all are agreed.

\section{Outline}

With this general introduction we are in a position to discuss the various types of trade test which were employed in the army. The succeeding chapters will, therefore, deal in order with

(I) Oral trade test methods

(2) Picture trade test methods

(3) Performance trade test methods

(4) Written trade test methods

An attempt will be made to show the gradual development of technique in the construction and use of each of these instruments. The application of trade test methods, within the industrial field, to such problems of personnel as selecting, placing, transferring and promoting will be discussed in later chapters. 

SECTION II

\section{THE ORAL TRADE TEST}





\section{CHAPTER II}

\section{THE CONSTRUCTION OF THE ORAL TRADE TEST (General Discussion)}

\section{Fundamental Assumption Underlying the Oral Question Method}

THE oral question is a time honored method of testing ability, particularly when this ability is of an informational kind.

If this ability consisted of nothing more than the possession of certain information in regard to the trade, the oral or written question would be the obvious method of measuring proficiency. But the simplest analysis of trade ability shows that it consists of two factors, which for the purposes of emphasis can be separated. These are:

(1) Certain skill or technique in performing operations.

(2) Certain knowledge or information.

The two are closely interrelated; without a considerable amount of information with regard to the trade, the performance of many of its operations is out of the question; likewise, assuming the presence of certain information, only the minimum of manual dexterity is required to perform the operation. If there is a very close correlation between degree of skill and amount of information possessed, then an examination which would test the amount of knowledge of the trade, would serve also as an indication of the degree of skill. If, however, there is no relation between information possessed and corre- 
sponding skill, then any examination which tested merely information would be doomed to failure, for it would give no indication of the first important factor in trade ability, namely, skill in carrying out the various operations. Before oral questions can be used to test trade ability, this crucial problem must be faced: To what extent can total trade ability be measured merely by testing the information of a workman with regard to his trade, without witnessing his dexterity in trade operations, or observing the products of his work?

Obviously the question and answer method does not, and never can, measure trade skill directly. What then does it measure? The answer is patent - it measures the information which the man has with regard to certain elements of his trade. Only in so far as information is the reflection of experience in the trade, obtained at first hand, will the question method give us any indication of skill.

At the time when the method of examination was under discussion, there was a most marked division of opinion concerning this, the critical point, upon which the whole procedure depends. Men of experience in industry were divided into two distinct camps. The first camp, which was by far the larger, was insistent that the manner in which a man answered questions had no relation to his skill in the trade. They cited dozens of concrete cases of men who, they said, were first-rate workmen, and who, in their opinion, would be unable to answer a single question with regard to their trade. They instanced the predominance of the exclusively motor-minded type of tradesman who could do the job with his hands, but could not talk about it in words. They remembered possibly one workman out of thousands they had known, who was completely tongue-tied. The recollection of the isolated case outweighs the multitude of normal cases. The ordinary mind is fascinated and paralyzed by the magical 
power of the isolated case. To hold to the truth of the general law and to maintain an even temper, when extreme cases are paraded as proofs by the skeptical, require not only the genius of the scientist, but the forbearance of the saint. In fact, some foremen would make it appear that it is almost a mark of distinction for the workman to be unable to answer any questions with regard to his trade. The workman, in their minds, is a bundle of mechanical skills or habits. They feel that the exercise of these skills or habits is so automatic in a good workman that it is a positive mark of his superiority to lack any power of describing in words the elements of the processes. To reduce their argument to scientific terms would be to say that there is little relationship between information of the trade, which can be expressed in words, and skill in performing its processes.

The other group, which was much in the minority, held that, with the ordinary workman, all the information which he has in regard to his trade has been obtained through actual trade experience. They claimed that if questions were skilfully worded, if they used the language of the shop, if they concerned themselves with familiar processes, the larger percentage of the workmen who could perform the operations must be able to talk in trade terms, provided, of course, that the examiner and the applicant speak the same language. While this group maintained the proposition of the close correspondence between skill and information, they still recognized that a small percentage of tradesmen, of high proficiency and skill, might be unable to meet the demands of the oral question. Admitting that this controversy can only be settled by actual experiment, it may be useful to note a few of the points which were raised at the time of the discussion. It has been said that the information which the ordinary workman possesses, with regard to his trade, is the outcome of his actual performance of the processes 
of his trade. It is, so to speak, the residue or the precipitate of his experience. While it may be true that the workman occasionally will be unable to describe in words processes in which he has taken part, it will very rarely happen that he can give information with regard to an operation he has never performed. If the majority of workmen had received technical training in their occupation, it is probable that the statement would not be so true. Only the theorist thinks that the knowledge which the ordinary workman possesses is the result of intellectual toil by midnight oil. Generally speaking, for ninety-nine per cent of workmen, what information they possess has come from the sweat of their own brow and the labor of their own hands. Their school is that of experience, not of books. If this position is accepted, it alters the attitude towards the effectiveness of the oral question method. The oral question will, under these circumstances, give us a measure of the skill of the workman, not directly, but indirectly. Information being merely the result of experience in the trade operation, any series of well-chosen questions which test information cannot, at the same time, fail to measure experience or effectiveness. An illustration will perhaps make this point clear. Suppose this question "Of what material is the float in the carburetor made?" is put to an automobile mechanic. All that is called for is certain facts, but granted that the majority of workmen acquire these facts from experience, a correct answer signifies that the workman has had experience with the operation; otherwise, he would not have the necessary factual information. Assumptions of this kind are constantly made in everyday life. If at a convention we hear any man, save a college professor, read a paper on some employment problem which contains what we know to be correct information, and if, in addition, he answers intelligently all the questions we put to him, we at once assume 
that he has had experience in employment work. If we do not make this assumption we are at a loss to know the reason for his knowledge. In this case there is, of course, a possibility that the information is theoretical, because the employment manager is increasingly consulting others and reading in connection with his subject, but we may safely suppose that such is not the case with the large majority of workmen.

It was realized, however, that no amount of dogmatism or argument could settle this question. The decision depends on evidence alone. If oral questions do, as a matter of fact, differentiate between various degrees of trade ability, then the assumption of a close correspondence between skill and information is correct; if they fail to differentiate, such an assumption is untenable. The question is one which can be solved by trial or experiment, and by this method alone. The distinction between the scientific method and the popular method lies in this very point. The scientific method necessitates caution, suspended judgment and prolonged experimentation before it gives a decision. The popular method uses heated arguments and dogmatic statements in place of cool experimentation and guarded generalizations. It rushes in where angels fear to tread, with confusion as the outcome. The reader will bear in mind that the great amount of the detail which is about to be described is the price which has to be paid for following the long but clearly marked scientific high road.

Before we can show concretely the method of attacking this problem we must first consider the type of question which can be emplcyed to satisfy the requirements laid down.

\section{The Nature of the Question}

There is no limit to the scope of a question. It can demand for its answer the widest information on the one hand, or it 
may merely concern itself with the most specific detail. Examples of questions of both of these types may be given. An extreme of the first type would be: "Suppose a car was left in a garage for repair, and you were not told what was wrong. How would you proceed?" An illustration at the other extreme would be: "What joint is there between the differential and the transmission?" A complete answer to the first question would involve a lengthy description of the majority of the processes in automobile repair. The answer, to be tolerably full, might well consume several hours. No two mechanics would answer the question in the same manner. Again, consider how such an answer could be rated. Suppose ten points were to be assigned to this question. What would constitute a score of Io, $8,6,4$, o? Contrast this first question with the second question. To the latter one word, and one word only is the correct reply "Universal." The question calls for a most specific answer, no two examiners can disagree on the rating. If instructions call for a credit of two points for the answer "universal," and zero for all other answers, there is no room for doubt concerning the credit to be given.

Take again two examples, neither of which is so extreme as those just given; both will be taken from the field of the general machinist. The first question that we will consider is, "What kind of work can be done on a universal milling machine?" Here the answer called for is much more definite than the first example cited. But there is still room for a considerable variation in answers given by two highly skilled machinists. No two examiners, even if both were skilled examiners and skilled tradesmen, would agree on the credit to be assigned to the same answer. In addition, the workman would never know when he had given a complete reply. The question of the other type which we will consider is: "When starting a hole on a drill press, if the 
drill runs out of center what do you commonly do?" Here the answer cannot be as definite as in the case of reply to the question which calls for the joint between the differential and transmission but the limits of the possible correct answer are clearly defined. The only suitable one would be somewhat as follows: "Use a gauge." "Try it with a chisel." "Draw over with a gauge." "Draw over with a chisel." If it was agreed that provided the workman mentioned "chisel," "gauge" or. "draw it over" a credit of four would be given for the answer, the marking could be quite definite. All examiners must agree when the directions are so specific. Note that we do not claim that this is an ideal trade question; in fact, we use it as an illustration because it lacks the precision of a perfect question.

\section{The Multi-answer versus Single-answer Question}

The contrast between these two types of questions will now be clearer. For purposes of convenience we shall designate them according to the answer called for as (I) multi-answer questions; (2) single-answer questions. It may be well to consider the advantages and disadvantages of these two types of questions from the standpoint of their application to the army problem. The multi-answer question is by far the more familiar; whenever the question and answer method was being employed in industry, it was this type which was found. Employment offices, trade unions, and examining bodies such as Civil Service Commissions had, in a large number of trades, series of these questions which were available for any purposes. Moreover, this kind of a question enables the examiner to discover whether the workman understands the whole process; there is no restriction as to the ground covered. So much for the advantages of the multi-answer question; its great drawbacks are, first, that it requires for satisfactory use an examiner who has trade knowl. 
edge, and second, that it is absolutely impossible to standardize the answers to the question, so that examiners at different places and under different conditions would give the same rating for the same answers.

The single-answer question, on the other hand, does not necessitate trade information on the part of the examiner. Where the question is so worded that there is only one possible reply, any examiner who can read is capable of conducting the examination. What is more, there can be no disagreement concerning the credits given. The disadvantages of the method, from the standpoint of adoption in the army, were twofold. In the first place, there had been no systematic attempt, before I9r7, to try out questions of this type. There were no sets of questions available, constructed on these lines. In addition, it appeared very doubtful whether specific questions, which had merely a single answer, would fulfill the main function for which the tests were to be given, namely, to differentiate between different degrees of trade ability. No method, however suitable for nontechnical examiners, however objective the results it might yield, could be employed unless, with a considerable degree of precision, it separated workmen into classes, according to their general trade knowledge and practical usefulness.

It may be well to mention at this point the similarity between the multi-answer question and the single-answer question. They are not essentially different types of questions, they merely differ in degree. Whereas the multi-answer question demands for its answer a large number of elements or pieces of information, the single-answer question concentrates on one particular element of information. For example, contrast the two questions, "What do you do when turning a taper in steel on a lathe?" and "How high would you set the tool when turning a taper in steel on a lathe?" The first question calls for a long 
answer, descriptive of the whole process; it would be difficult to know just when to begin and when to stop in the outline of the operation. The second question simply picks out one of the most important elements in the process and confines itself to extracting information with regard to this essential part of the operation. It may reasonably be supposed, if the answer "At center" or "A little above center" is given, that the workman in all probability has a knowledge of the whole operation. Again consider the two questions, "What is a singlephase lighting transformer?" and "What are the names" of the two windings in a single-phase lighting transformer?" Here the wider question gives no clear indication of the kind of answer required. Does it call for an account of the uses or construction of the transformer? How detailed is the information required? Is it necessary to describe from the very beginning the building up of the apparatus? In contrast with this vagueness is the clear-cut question which asks merely for the names of the two windings. The assumption again is that if these names are known, there is a great probability that a considerable amount of further knowledge is present with reference to the properties and uses of the instrument. It will be necessary, when we consider the selection of questions, to return to this point as to the probability or likelihood that a single element of the process will give an indication of knowledge or ignorance, on the part of the workman, of the whole process. It may be pointed out, however, that an assumption of this kind is made, consciously or unconsciously, in every type of examination. When to test a workman the foreman gives him a specific job to do, other than that for which he is to be employed, he is assuming that success or failure in the single operation will give some indication of power in a host of operations which are not involved in the specific job. 
To summarize, then, we may say that the single-answer question is the most feasible oral method which can be used to satisfy the requirements of the army situation. The multi-answer question, whatever its other advantages, does not admit of being handled and marked objectively by an examiner who is not skilled in the trade in which he is giving the test.

It cannot be too clearly recognized that up to this point we have made no assumption that questions of the single-answer type will serve to differentiate between workmen of different degrees of skill. All that we have established is the fact that the single-answer question is a method which fulfills the necessary requirements of yielding an objective rating by an unskilled examiner. The demonstration of the extent to which the most specific type of question will differentiate between various levels of ability will be considered in full in a succeeding section.

It may be well, however, to point out at this stage that the two requirements of army procedure which we have now mentioned, namely, that the test can be given by a nonskilled examiner, and that there can be no disagreement in marking, are not characteristic merely of tests used in the army.

In a large number of industries it is very desirable to have methods of examining applicants which do not involve the services of a skilled trasdesman. In many employment offices the large number of trades handled makes it an utter impossibility to have individuals in the office who are skilled in all the trades in which there happen to be openings. It is apparent that it is a source of great waste to have skilled mechanics in an employment office when a clerk could perform the same service. The proper post for a skilled mechanic is in the shop: he is not in the strategic place, when he is conducting routine interviews. Even when the employment office merely refers applicants to the foreman in the shop, there is great waste of 
time and energy, unless some type of trade examination can be given before the reference is made.

An illustration will make this last point clearer. The author recently was in the employment office of a large plant where a man was being interviewed who claimed to be a general lathe operator. He had given information with regard to his experience, and the interviewer was satisfied that it was worth while to refer him to the foreman of the department for which he was applying. Just after the man had been given the card of reference to the foreman and was about to be conducted to the department in question, permission was asked to give the applicant a trade test which had been constructed for lathe operators. The first question, which was of the very simplest order, was answered correctly. But the following questions were quite beyond his range of knowledge. After six out of the possible eighteen questions had been given, the man admitted quite frankly that he was not a general lathe operator. He said he had been engaged on a lathe entirely on production work of the most routine kind, and that he knew nothing about running a lathe except in this particular operation. His closing remarks were very significant: - "I knew when I came in that I was no lathe operator, but I guessed I would be able to get away with it. You have certainly called my bluff." The applicant was of course told that he did not qualify, and he went away apparently quite satisfied that he had received a very fair deal. If there had been no trade test to apply, the man would undoubtedly have consumed the time of a highly skilled workman for some little period before the true extent of his knowledge was discovered. With the use of the simplest form of trade test the actual state of affairs was discovered by a nontechnical examiner in three minutes.

Not only in the employment office itself is there great scope 
for the application of these methods, but they also will have a great field of usefulness when hiring has to be done out of town, or away from the plant. A large number of concerns find it necessary to send highly skilled workmen to interview applicants. Especially is this the case when transportation is furnished. With a method which obviates the necessity of using a trained tradesman as examiner, any clerk can be sent, and what is more, he can handle any number of trades in which men are to be hired.

\section{Attempts to Meet the Interview Problem, Prior to the Introduction of the Single-ANSWER Question}

The significance of the single answer question will be more fully understood, when the inadequacy of the previous methods of interview are realized.

In describing the question with a single-word answer we have rather forestalled the conclusions of a long process of experimentation which was gone through by the army prior to the introduction of the standarized trade question test.

As soon as shipments and transfers of tradesmen were made, it became apparent that it was absolutely impossible to rely merely on the information given by the soldier himself. As has been already said, men were actually shipped to France who admitted on their arrival that they had merely bluffed as to their trade knowledge in order to see service abroad. It was absolutely necessary for the army to act at once in the matter and to provide the personnel officers in the camps with some method of checking up the claims of the men. To meet this requirement series of questions for a large number of trades were collected. These were published under the title, "Aids for Interviewers." Samples of these questions in a number of trades are appended. The general arrangement of each interview is 
obvious. There are three questions which it was supposed would be suitable for apprentices in the trade, these being marked with letter " $\mathrm{A}$ "; three intermediate questions marked with letter "J," which might be considered to test the average workman, followed by a series of questions ranging in number from three to five, which were supposed to be suitable for men of exceptional trade ability. The following directions were given to the interviewers:

\section{AIDS FOR INTERVIEWERS}

I. These AIDS are for use in the preliminary interview of recruits.

2. It is not expected that these questions will be used with all tradesmen, but only when the interviewer is in doubt about the preliminary classification, and wishes to question the recruit more closely about his trade.

3. CAUTION. Do not expect answers which correspond word for word with the answers printed in the AIDS. The answers are primarily for the benefit of the examiner. He will often find it necessary to supplement questions given with other questions in order to draw out the information desired.

4. As an arbitrary means of classifying according to degree of knowledge or skill of candidate, all questions have been divided into three groups:

a. Questions designated by "A" are intended to determine the knowledge of the candidate on such subjects as come under an Apprentice's experience or one with only a moderate amount of training and experience.

b. Questions designated by " $\mathrm{J}$ " cover such knowledge as might be expected from a Journeyman, or one who has completed a period of preliminary training.

c. Questions designated by "JE" cover such knowledge as might be expected from a journeyman who could be considered an expert and capable of acting as a foreman or boss or having advanced training and experience.

[These interviews are reproduced by permission of the Adjutant General.] 


\begin{tabular}{|c|c|}
\hline . & $\begin{array}{l}\text { MACHINIST } \\
\text { (GENERAL) }\end{array}$ \\
\hline & $\begin{array}{l}\text { Q. (a) Name six types of machine tools and (b) describe the work } \\
\text { that each is adapted for. }\end{array}$ \\
\hline & $\begin{array}{l}\text { A. (a) (I) Engine lathe, (2) planer, (3) shaper, (4) grinders, (5) drill } \\
\text { press, (6) milling machine. Most others a re a modified form of } \\
\text { one of these: (b) (I) Engine lathe: Training and boring, } \\
\text { threading - internal and external. (2) Planer: Planing work } \\
\text { to a flat surface. (3) Flat planing on small work. (4) Grinding } \\
\text { to smooth and close dimensions. (5) Drill press: Drilling and } \\
\text { boring holes. (6) Milling machine: Cutting keyways, gears, } \\
\text { and work which with the use of cutters can be more efficiently } \\
\text { and accurately handled on this machine than on other tools. }\end{array}$ \\
\hline & \multirow{2}{*}{$\begin{array}{l}\text { Q. What tools should be used in measuring (a) inside diameters, } \\
\text { (b) outside diameters? } \\
\text { A. (a) (I) Inside calipers, (2) inside micrometer, and (3) plug gauge. } \\
\text { (b) (I) Outside calipers, (2) outside micrometer, and (3) snap } \\
\text { gauge. }\end{array}$} \\
\hline & \\
\hline : A & $\begin{array}{l}\text { Q. Name the different common classes of gearing used in machines. } \\
\text { A. (I) Spur, (2) bevel, (3) spiral, (4) worm, (5) herring bone. }\end{array}$ \\
\hline \multirow{2}{*}{$\mathrm{J}$} & $\begin{array}{l}\text { Q. What is meant by (a) "rake" and (b) "clearance" on a lathe } \\
\text { tool? }\end{array}$ \\
\hline & $\begin{array}{l}\text { A. (a) Angle or clearance given the cutting face of tool at the cutting } \\
\text { edge which would cause the tool to cut, curl and clear the chip. } \\
\text { (b) The angle ground on the sides and front to keep all but } \\
\text { the cutting edge of the tool from rubbing the work. }\end{array}$ \\
\hline \multirow[b]{2}{*}{ : J } & $\begin{array}{l}\text { Q. (a) How much metal should be removed by using a straight } \\
\text { fluted reamer. (b) Name some other types of reamers. }\end{array}$ \\
\hline & $\begin{array}{l}\text { A. (a) Not more than one sixty-fourth inch. (b) (I) Taper, (2) ex- } \\
\text { panding, (3) chucking, (4) rose, (5) sheli, (6) fluted. }\end{array}$ \\
\hline & $\begin{array}{l}\text { Q. What are some coatings on which lines may be made for scribing } \\
\text { or marking on metals? }\end{array}$ \\
\hline & $\begin{array}{l}\text { halk, (2) powdered chalk mixed with alcohol, (3) rub- } \\
\text { h sulphate of copper, (4) white lead and turpentine. }\end{array}$ \\
\hline
\end{tabular}




\begin{tabular}{|c|c|c|}
\hline \multicolumn{2}{|r|}{ STANDARD } & $\begin{array}{cc} & \text { MACHINIST } \\
\text { Page } 2 & \text { (GENERAL) }\end{array}$ \\
\hline \multirow{2}{*}{$1: \mathrm{JE}$} & \multicolumn{2}{|c|}{$\begin{array}{l}\text { Q. (a) What is the value of the clapper box on a shaper, slotter and } \\
\text { planer? (b) What is the effect of moving the clapper box holder } \\
\text { to either side of the shaper and planer? }\end{array}$} \\
\hline & \multicolumn{2}{|c|}{$\begin{array}{l}\text { A. (a) It prevents wearing away of the cutting edge of tool by drag- } \\
\text { ging on the quick return. (b) The moving of holder in same } \\
\text { direction as cut destroys the value of the clapper box, and mov- } \\
\text { ing in opposite direction to cut increases its value on heavy } \\
\text { cuts. }\end{array}$} \\
\hline \multirow{2}{*}{ 2: JE } & \multicolumn{2}{|c|}{ Q. What are the most common standard tapers in use? } \\
\hline & \multicolumn{2}{|c|}{ A. (1) Morse, (2) Brown \& Sharpe, (3) Jarno, (4) S. A. E. } \\
\hline \multirow{2}{*}{$3: \mathrm{JE}$} & \multicolumn{2}{|c|}{ Q. What kind of work can be done on a universal milling machine? } \\
\hline & \multicolumn{2}{|c|}{$\begin{array}{l}\text { A. (I) Cutting pieces to form, by using special shaped rotary cutters. } \\
\text { (2) Facing off flat surfaces. (3) Cutting spiral grooves, such } \\
\text { as twist drills and milling cutters. (4) Dividing circles into } \\
\text { a given number of parts by use of dividing head. }\end{array}$} \\
\hline
\end{tabular}




\begin{tabular}{|c|c|}
\hline & $\begin{array}{l}\text { AUTO REPAIRER } \\
\text { (ENGINE) } \\
\text { Page } 1\end{array}$ \\
\hline \multirow{2}{*}{ 1:A } & Q. What kind of bearings are used in motors? \\
\hline & A. (I) Ball, (2) babbit, or (3) bronze faced with babbit. \\
\hline \multirow{2}{*}{ 2:A } & Q. How should carbon be removed from cylinder and piston heads \\
\hline & $\begin{array}{l}\text { A. (r) Remove cylinder or cylinder head and scrape off, or (2) burn } \\
\text { out with oxygen. }\end{array}$ \\
\hline \multirow{2}{*}{ 3:A } & Q. How should engine valves be ground in? \\
\hline & $\begin{array}{l}\text { A. (1) Remove valve springs, }(2) \text { coat valve surface with grinding } \\
\text { compound, }(3) \text { turn back and forth with screw-driver with very } \\
\text { little pressure, (4) lift valve frequently and give half turn while } \\
\text { off seat. Continue this operation until there is an even surface } \\
\text { all around and no rings or ridges. }\end{array}$ \\
\hline \multirow{2}{*}{$1: \mathrm{J}$} & Q. How should fit be tested after fitting new connecting rod bearings? \\
\hline & $\begin{array}{l}\text { A. (I) Take hold of connecting rod at wrist pin and (2) try play at } \\
\text { different positions all the way around crankshaft. }\end{array}$ \\
\hline \multirow{2}{*}{$2: J$} & Q. What should be done to "scrape in" a connecting rod bearing? \\
\hline & $\begin{array}{l}\text { A (I) Coat the crank pin very slightly with prussian blue or carriage } \\
\text { blue, (2) put bearing and cap in place, }(3) \text { bolt together, } \\
\text { (4) work connecting rod back and forth on crank shaft, (5) re- } \\
\text { move, and (6) scrape away metal carefully where blue paint } \\
\text { appears on bearing and cap. (7) Set bearing up so that it is } \\
\text { slightly tight. }\end{array}$ \\
\hline \multirow{2}{*}{ 3: J } & \multirow{2}{*}{$\begin{array}{l}\text { Q. What is the relation of the speed of the cam shaft to that of the } \\
\text { crank shaft in a six cylinder motor? } \\
\text { A. The cam shaft turns one-half a revolution while the crank shaft } \\
\text { turns once. }\end{array}$} \\
\hline & \\
\hline \multirow{2}{*}{$1: \mathrm{JE}$} & Q. What are indications of wear in a ball bearing? \\
\hline & $\begin{array}{l}\text { A. (I) They may be heard to drop and become noisy, }(2) \text { the races } \\
\text { also become rough by flaking off of the metal. If the races are } \\
\text { not sufficiently hardened they may groove without flaking. } \\
\text { (3) Crankshaft will have play in the bearing which can be } \\
\text { located by lifting crank shaft with a jack. }\end{array}$ \\
\hline
\end{tabular}




\begin{tabular}{|c|c|c|}
\hline \multicolumn{2}{|r|}{ STANDARD } & $\begin{array}{l}\text { AUTO REPAIRER } \\
\text { (ENGINE) } \\
\text { Page } 2\end{array}$ \\
\hline \multirow{2}{*}{ 2: JE } & \multicolumn{2}{|c|}{ Q. Does the diameter of the piston head vary from that of the bottom? } \\
\hline & \multicolumn{2}{|c|}{$\begin{array}{l}\text { A. In some the variation is about two thousandths of an inch; in } \\
\text { others there is no difference. }\end{array}$} \\
\hline \multirow{2}{*}{$3: \mathrm{JE}$} & \multicolumn{2}{|c|}{$\begin{array}{l}\text { Q. What clearance should be allowed between ends of the rings in } \\
\text { fitting new piston rings? }\end{array}$} \\
\hline & \multicolumn{2}{|c|}{ 1. Two thousandths of an inch for each inch diameter of piston. } \\
\hline \multirow{2}{*}{$4: \mathrm{JE}$} & \multicolumn{2}{|c|}{ Q. How should a magneto be timed? } \\
\hline & \multicolumn{2}{|c|}{$\begin{array}{l}\text { A. (I) Place the crankshaft in the proper position, (2) have the } \\
\text { magneto in a position where it will deliver a spark, (3) then } \\
\text { mesh the gears or connect the coupling. Care should be taken } \\
\text { to determine whether the magneto runs clockwise or anti- } \\
\text { clockwise. }\end{array}$} \\
\hline \multirow{2}{*}{$5: \mathrm{JE}$} & \multicolumn{2}{|c|}{$\begin{array}{l}\text { Q. What is the gear ratio of the magneto shaft to the crankshaft on } \\
\text { (a) four cylinder motor, (b) six cylinder, (c) eight cylinder, } \\
\text { (d) twelve cylinder? }\end{array}$} \\
\hline & \multicolumn{2}{|c|}{$\begin{array}{l}\text { A. (a) One to one. (b) One and one-half to one. (c) Two to one. } \\
\text { (d) Three to one, unless a double distributor is used when it } \\
\text { will be one-half to one. }\end{array}$} \\
\hline
\end{tabular}




\begin{tabular}{|c|c|}
\hline & $\begin{array}{l}\text { MOTION PICTURE } \\
\text { OPERATOR } \\
\text { Page } 1\end{array}$ \\
\hline \multirow{2}{*}{ 1:A } & Q. Which side of the film should be toward the light? \\
\hline & A. The emulsion side. \\
\hline \multirow{2}{*}{ 2: A } & Q. What is the standard projection speed? \\
\hline & $\begin{array}{l}\text { A. (I) Ten pictures per second, (2) one foot per second, (3) sixteen } \\
\text { to seventeen minutes per reel of one thousand feet }\end{array}$ \\
\hline \multirow{2}{*}{ 3: A } & Q. How should a film patch be made? \\
\hline & $\begin{array}{l}\text { A. (I) Cut film on floor line, (2) leave one-eighth of an inch margin } \\
\text { on one strip and scrape off emulsion, (3) cement together so } \\
\text { that perforation holes are in alignment. Cement should be } \\
\text { applied to celluloid side only. }\end{array}$ \\
\hline \multirow{2}{*}{ 4:A } & Q. What is the use of the revolving shutter? \\
\hline & A. To cut off light from screen while one picture is shifting to a nother. \\
\hline \multirow{2}{*}{$1: \mathrm{J}$} & $\begin{array}{l}\text { Q. What is the lowest practical voltage required to maintain a direct- } \\
\text { current arc? }\end{array}$ \\
\hline & A. About forty volts. \\
\hline \multirow{2}{*}{ 2: J } & $\begin{array}{l}\text { Q. Which arc requires the larger current for the same intensity of } \\
\text { light - A. C. or D. C.? }\end{array}$ \\
\hline & A. A. C. \\
\hline \multirow{2}{*}{ 3: J } & Q. Why does a picture appear distorted on the screen? \\
\hline & A. Screen and line of projection not being set at right angles. \\
\hline \multirow{2}{*}{$4: J$} & Q. What size and style wire should be used for connecting arc? \\
\hline & A. Number six B. \& S. or larger, asbestos covered. \\
\hline \multirow{2}{*}{$1: \mathrm{JE}$} & Q. How should a direct current arc be connected? \\
\hline & $\begin{array}{l}\text { A. (I) Positive wire to the upper carbon, (2) and negative wire } \\
\text { to the lower carhon of lamp. }\end{array}$ \\
\hline
\end{tabular}




\begin{tabular}{|c|c|}
\hline & $\begin{array}{l}\text { MOTION PICTURE } \\
\text { OPERATOR } \\
\text { Page } 2\end{array}$ \\
\hline \multirow{2}{*}{$2: \mathrm{JE}$} & Q. What causes condenser lenses to break? \\
\hline & $\begin{array}{l}\text { 1. (I) Arc too close to condenser. (2) Lens fitting holders too tight. } \\
\text { (3) Cold air striking hot condenser. }\end{array}$ \\
\hline \multirow[b]{2}{*}{ 3: JE } & $\begin{array}{l}\text { Q. What size carbons should be used on: (a) thirty-five amperes, } \\
\text { D. C., (b) sixty amperes D. C., (c) thirty-five amperes A. C., } \\
\text { (d) sixty amperes A. C.? }\end{array}$ \\
\hline & $\begin{array}{l}\text { A. (a) Five-eighths inch cored positive and one-half inch solid } \\
\text { negative. } \\
\text { (b) Three-quarters inch cored positive and five-eighths solid } \\
\text { negative. } \\
\text { (c) Five-eighths inch cored upper and lower. } \\
\text { (d) Three-quarters inch cored upper and lower. }\end{array}$ \\
\hline \multirow{2}{*}{$4: \mathrm{JE}$} & $\begin{array}{l}\text { Q. How is the focal length of lens found, if given the distance from } \\
\text { machine to screen and the size picture wanted? }\end{array}$ \\
\hline & $\begin{array}{l}\text { A. (I) Multiply the distance between machine and screen by width } \\
\text { of film gauge, (2) and divide by the width of picture. This } \\
\text { will give the focal length of lens. }\end{array}$ \\
\hline
\end{tabular}




\begin{tabular}{|c|c|}
\hline & STANDARD \\
\hline & Q. What is a bench mark? \\
\hline 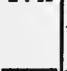 & $\begin{array}{l}\text { A. A permanent point whose elevation is accurately determined with } \\
\text { reference to some fixed datum. }\end{array}$ \\
\hline & Q. What is the degree of curvature of a curve? \\
\hline 2.8 & $\begin{array}{l}\text { A. The angle at center, subtended by a chord of one hundred feet. } \\
\text { It is expressed by the number of degrees and minutes in that } \\
\text { angle. }\end{array}$ \\
\hline & $\begin{array}{l}\text { Q. (a) What equipment is necessary for a transit to be used as a } \\
\text { leveling instrument? (b) What adjustments should be made? }\end{array}$ \\
\hline 3:A & $\begin{array}{l}\text { A. (a) A level tube on the telescope. (b) Axis of bubble should be } \\
\text { adjusted parallel with line of sight. }\end{array}$ \\
\hline & $\begin{array}{l}\text { Q. (a) What is meant by azimuth? (b) If the bearing of a line is } \\
\text { South thirty-five degrees West, what is the azimuth of the line, } \\
\text { taking North as zero azimuth? }\end{array}$ \\
\hline & $\begin{array}{l}\text { A. (a) The angle that a horizontal line forms with the magnetic } \\
\text { meridian, the angle being measured in a clock wise direction } \\
\text { from Lero to three hundred and sixty degrees, taking zero } \\
\text {. either at the North point or at the South point. (b) Thirty- } \\
\text { five degrees plus one hundred and eighty degrees equals two } \\
\text { hundred and fifteen degrees. }\end{array}$ \\
\hline & $\begin{array}{l}\text { Q. How can the leveler determine when the rodman is holding the } \\
\text { rod vertically? }\end{array}$ \\
\hline $2: J$ & $\begin{array}{l}\text { A. By means of the vertical hair the leveler can tell whether the rod } \\
\text { is in the vertical plane of the line of sight. To be sure that the } \\
\text { rod is actually vertical he has the rodman sway the rod gently } \\
\text { toward and away from the instrument and ngtes the smallest } \\
\text { reading obtained on the road. This gives the vertical position. }\end{array}$ \\
\hline 3 & $\begin{array}{l}\text { Q. (a) In leveling what is meant by datum? (b) What is a grade } \\
\text { line? }\end{array}$ \\
\hline & $\begin{array}{l}\text { A. (a) A datum is a level surface, assumed or actual, to which the } \\
\text { elevations of other points are referred. It is the plane of zero } \\
\text { elevation. (b) The grade line represents the finished surface } \\
\text { of a road, railroad, etc. It shows the rate of rise or fall. }\end{array}$ \\
\hline
\end{tabular}




\begin{tabular}{|c|c|c|}
\hline \multicolumn{2}{|r|}{ STANDARD } & SURVEYER \\
\hline \multirow{2}{*}{$4: \mathrm{J}$} & \multicolumn{2}{|c|}{$\begin{array}{l}\text { Q. What will be the elevation of grade at stations sixty-five and } \\
\text { seventy with one per cent ascending grade, if the elevation of } \\
\text { grade at station sixty is one hundred and sixty-two feet? }\end{array}$} \\
\hline & \multicolumn{2}{|c|}{$\begin{array}{l}\text { A. Since the grade is one foot to every hundred feet, the elevation } \\
\text { at Station Sixty-five will be one hundred and sixty-two feet } \\
\text { plus five feet, or one hundred and sixty-seven feet, while at } \\
\text { Station Seventy the elevation will be one hundred and sixty- } \\
\text { two feet plus ten feet, or one hundred and seventy-two feet. }\end{array}$} \\
\hline \multirow{2}{*}{$1: \mathrm{JE}$} & \multicolumn{2}{|c|}{$\begin{array}{l}\text { Q. What will be the position of the vernier when the angle read is } \\
\text { eighty-four degrees thirty-four minutes when the smallest } \\
\text { graduation of the limb of a transit is one-half degree or thirty } \\
\text { minutes, and the vernier reads to single minutes? }\end{array}$} \\
\hline & \multicolumn{2}{|c|}{$\begin{array}{l}\text { A. The zero of the vernier will be just past eighty-four degrees thirty } \\
\text { minutes on the limb, and the graduation marked four on the } \\
\text { vernier will coincide with a graduation mark on the limb. }\end{array}$} \\
\hline \multirow{2}{*}{ 2: JE } & \multicolumn{2}{|c|}{$\begin{array}{l}\text { Q. Explain the method of prolonging a line from a given backsight } \\
\text { by double centering. }\end{array}$} \\
\hline & \multicolumn{2}{|c|}{$\begin{array}{l}\text { A. (1) Set up on line, (2) direct line of sight to backsight, }(3) \text { reverse } \\
\text { telescope and set a point ahead, (4) revolve on vertical axis and } \\
\text { sight again to backsight, (5) reverse telescope, set another } \\
\text { point ahead, (6) take mean of two forward points. }\end{array}$} \\
\hline & \multicolumn{2}{|c|}{ Q. Name any method of computing the area of a closed survey } \\
\hline o: & \multicolumn{2}{|c|}{ A. (I) Double meridian, (2) coördinates, $(3)$ dividing into triangles. } \\
\hline
\end{tabular}




\begin{tabular}{|l|l|}
\hline STANDARD & TIRE REPAIRER \\
(RUBBER)
\end{tabular}




\begin{tabular}{|c|c|c|}
\hline \multicolumn{2}{|r|}{ STANDARD } & $\begin{array}{l}\text { TIRE REPAIRER } \\
\text { Page } 2 \quad \text { (RUBBER) }\end{array}$ \\
\hline \multirow{2}{*}{$3: \mathrm{J}$} & \multicolumn{2}{|c|}{$\begin{array}{l}\text { Q. What would be the cause of an outside repair swelling or blister- } \\
\text { ing when removing tire from mold or cavity? }\end{array}$} \\
\hline & \multicolumn{2}{|c|}{$\begin{array}{l}\text { A. (I) Caused by not removing moisture before applying cement, } \\
\text { or (2) not allowing cement to dry before applying mat erial. }\end{array}$} \\
\hline \multirow{2}{*}{$4: \mathrm{J}$} & \multicolumn{2}{|c|}{$\begin{array}{l}\text { Q. (a) What should be done with tire if the outside repair swelled } \\
\text { or blistered when removing from mold or cavity? (b) Would } \\
\text { tire require any further attention or treatment? } \\
\text { would be the result? }\end{array}$} \\
\hline & \multicolumn{2}{|c|}{$\begin{array}{l}\text { A (a) (I) Dip tire in cold water until blister disappears, (2) then } \\
\text { prick repair with brad awl to allow steam or vapor to escape. } \\
\text { (b) After it is fairly cooled off put back into mold and recure } \\
\text { about half the time necessary to complete the full cure. (c) Re- } \\
\text { pair would come off shortly after tire is put into use. Vulcani- } \\
\text { zation not being completer, the two surfaces would not stick } \\
\text { together. }\end{array}$} \\
\hline \multirow{2}{*}{$1: \mathrm{JE}$} & \multicolumn{2}{|c|}{$\begin{array}{l}\text { Q. What are some of the causes for honey-combing of rubber during } \\
\text { vulcanization? }\end{array}$} \\
\hline & \multicolumn{2}{|c|}{$\begin{array}{l}\text { A. (1) Not allowing the cement sufficient time to dry, (2) dampness } \\
\text { in the repair material, (3) lack of internal pressure in the air } \\
\text { bag. }\end{array}$} \\
\hline \multirow[b]{2}{*}{$2: \mathrm{JE}$} & \multicolumn{2}{|c|}{$\begin{array}{l}\text { Q. How can it be determined whether or not rubber is properly } \\
\text { vulcanized? }\end{array}$} \\
\hline & \multicolumn{2}{|c|}{$\begin{array}{l}\text { 1. (a) When rubber is overvulcanized it becomes brittle and chips } \\
\text { or breaks easily. (b) When under vulcanized it becomes dead } \\
\text { and has no come-back when stretched. (c) When properly } \\
\text { vulcanized it has snap - you can tell by pushing a pencil or } \\
\text { sharp instrument into it; if the depression fills up readily it is } \\
\text { properly cured. }\end{array}$} \\
\hline \multirow{2}{*}{$3: \mathrm{JE}$} & \multicolumn{2}{|c|}{$\begin{array}{l}\text { Q. How should fabric broken casings (caused by blow-out) be built } \\
\text { up? }\end{array}$} \\
\hline & \multicolumn{2}{|c|}{$\begin{array}{l}\text { A. (I) By overlapping with rebuilding fabric as many layers as } \\
\text { were removed, and (2) applying an extra layer of fabric at } \\
\text { least two inches beyond the last stepped-up layer. }\end{array}$} \\
\hline
\end{tabular}




\begin{tabular}{|c|c|}
\hline & $\begin{array}{l}\text { BRICK-LAYER } \\
\text { Page } 1\end{array}$ \\
\hline \multirow{2}{*}{$1: A$} & Q. Why should brick be wet before using? \\
\hline & $\begin{array}{l}\text { A. Because dry brick absorbs water from the mortar, thereby injur } \\
\text { ing the binding qualities of the mortar. }\end{array}$ \\
\hline \multirow{2}{*}{ 2: A } & Q. What is meant by tempering mortar? \\
\hline & $\begin{array}{l}\text { A. Working over mortar, which has become stiff, to a proper con } \\
\text { sistency for use. }\end{array}$ \\
\hline \multirow{2}{*}{ 3: A } & \multirow{2}{*}{$\begin{array}{l}\text { Q. What is meant by (a) courses, (b) stretchers and (c) headers? } \\
\text { A (a) Courses are the horizontal layers of brick. (b) Stretcher i } \\
\text { the term applied to a brick laid as the wall runs. (c) Heade } \\
\text { is the term applied to the brick laid in the direction of the } \\
\text { thickness of a wall. }\end{array}$} \\
\hline & \\
\hline \multirow{2}{*}{ 1: $\mathrm{J}$} & Q. Name the different blockings used in brick-laying. \\
\hline & $\begin{array}{l}\text { 1. (I) Gable end blocking, (2) party wall blocking (3) three cours } \\
\text { blocking and toothing. }\end{array}$ \\
\hline \multirow{2}{*}{ 2: J } & $\begin{array}{l}\text { Q. (a) How should a door or window opening be "topped out" } \\
\text { (b) Describe arrangement. }\end{array}$ \\
\hline & $\begin{array}{l}\text { A. (a) Either by an arch or a lintel. The style arch usually em } \\
\text { ployed is the segmental. (b) The lintel may be of stone, iron } \\
\text { or steel. If it is narrower than the wall in thickness, a second } \\
\text { lintel, generally of wood with an arch turned over it, is placed } \\
\text { on the inside. }\end{array}$ \\
\hline \multirow{2}{*}{ 3: J } & Q. What qualities should good brick possess? \\
\hline & $\begin{array}{l}\text { A. (I) Hardness; (2) uniformity of color; (3) freedom from lumps; } \\
\text { (4) edges sharp and angles square; (5) a clear ringing sound } \\
\text { when struck with the trowel. }\end{array}$ \\
\hline \multirow{2}{*}{$4: J$} & Q. Give some of the reasons why walls become unsafe. \\
\hline & $\begin{array}{l}\text { A. (I) Insufficient foundations; (2) use of inferior mortar; (3) walls } \\
\text { out of plumb; (4) improper bonding; ( } 5 \text { ) laying brick with } \\
\text { uneven courses and leveling up with thick joints of mortar; } \\
\text { (6) not anchoring walls properly; (7) racking walls while } \\
\text { putting on beams. }\end{array}$ \\
\hline
\end{tabular}




\begin{tabular}{|c|c|c|}
\hline \multicolumn{2}{|r|}{ STANDARD } & $\begin{array}{ll}\text { BRICK-LAYER } \\
\text { Page } 2 & \end{array}$ \\
\hline \multirow{2}{*}{$1: \mathrm{JE}$} & \multicolumn{2}{|c|}{ Q. Describe the different types of bond in brick work? } \\
\hline & \multicolumn{2}{|c|}{$\begin{array}{l}\text { A. (1) English Bond - Alternate courses of headers and stretchers. } \\
\text { (2) Flemish Bond - A header and stretcher in succession on } \\
\text { every course. } \\
\text { (3) Common Bond - Five courses of stretchers to one of headers. }\end{array}$} \\
\hline \multirow{2}{*}{$2: \mathrm{JE}$} & \multicolumn{2}{|c|}{$\begin{array}{l}\text { Q. If you had to do masonry work in freezing weather what precau- } \\
\text { tions would you take to obtain best results? }\end{array}$} \\
\hline & \multicolumn{2}{|c|}{$\begin{array}{l}\text { A. (I) Heat the sand and water. (2) Protect the work from the } \\
\text { front, covering with tarpaulin, straw, etc., until the cement is } \\
\text { thoroughly set. }\end{array}$} \\
\hline \multirow{2}{*}{$3: \mathrm{JE}$} & \multicolumn{2}{|c|}{ Q. How are foundation walls protected from dampness? } \\
\hline & \multicolumn{2}{|c|}{$\begin{array}{l}\text { A. (I) Give two coats of an approved waterproofing paint, (2) apply } \\
\text { one inch of waterproofed cement mortar, (3) a course of com- } \\
\text { mon brick instead of the mortar or (4) a course of hollow brick } \\
\text { plastered with cement mortar. }\end{array}$} \\
\hline \multirow{2}{*}{$4: \mathrm{JE}$} & \multicolumn{2}{|c|}{ Q. What are curtain walis? } \\
\hline & \multicolumn{2}{|c|}{$\begin{array}{l}\text { A. Outer masonry walls used in buildings of skeleton type which } \\
\text { are usually supported at every story or every other story by } \\
\text { the steel framework and carry nothing but their own weight. }\end{array}$} \\
\hline
\end{tabular}




\begin{tabular}{|l|l|l|} 
STANDARD & SHEET METAL WORKER \\
(GENERAL)
\end{tabular}




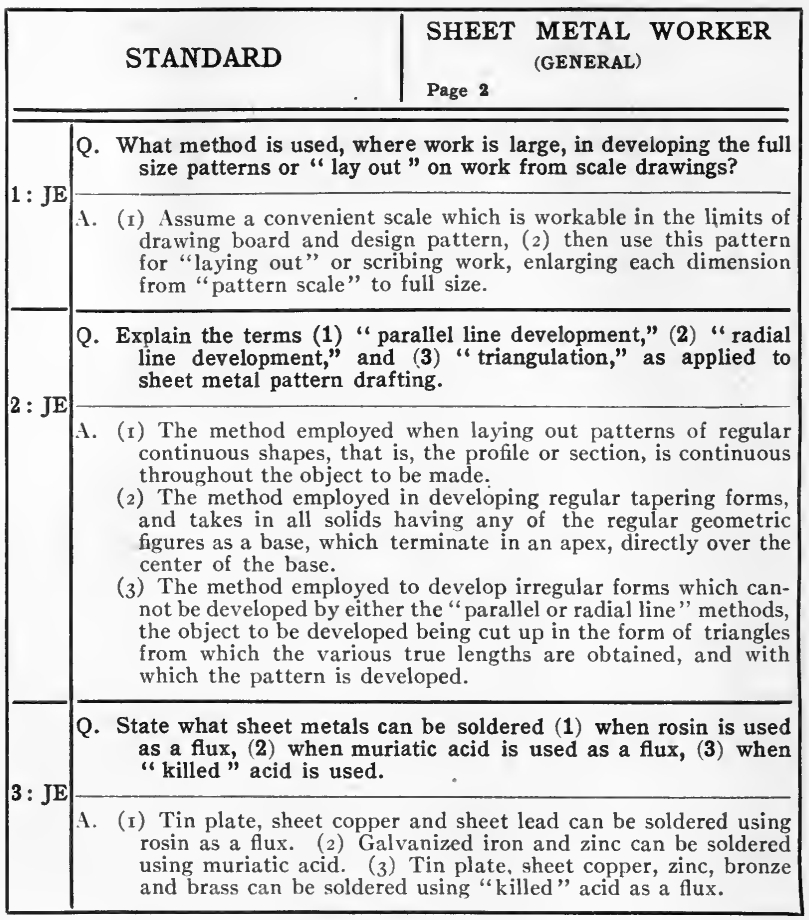




\begin{tabular}{|c|c|c|}
\hline \multicolumn{2}{|r|}{ STANDARD } & $\begin{array}{c}\text { ELECTRICIAN } \\
\text { Page } 1\end{array}$ \\
\hline \multirow{2}{*}{$1: A$} & \multicolumn{2}{|c|}{ Q. How should the head of nail be protected from splitting the knob? } \\
\hline & \multicolumn{2}{|c|}{ A. By using "leather heads." } \\
\hline \multirow{2}{*}{ 2: A } & \multicolumn{2}{|c|}{$\begin{array}{l}\text { Q. How high from the finished floor should ordinary flush or snap } \\
\text { switch outlets be placed? }\end{array}$} \\
\hline & \multicolumn{2}{|c|}{ A. Four to four and one-half feet. } \\
\hline \multirow{2}{*}{ 3: A } & \multirow{2}{*}{\multicolumn{2}{|c|}{$\begin{array}{l}\text { Q. Describe the proper method of cutting and threading a piece of } \\
\text { conduit. } \\
\text { A. (I) Cut the conduit with a hack saw, (2) ream the end thor } \\
\text { oughly until no burrs or sharp edges remain, }(3) \text { then proceed } \\
\text { to cut thread, (4) thoroughly oiling the dies with lard oil. }\end{array}$}} \\
\hline & & \\
\hline \multirow{2}{*}{$1: \mathrm{J}$} & \multicolumn{2}{|c|}{$\begin{array}{l}\text { Q. What is the maximum allowable load of the branch circuits of a } \\
\text { lighting panel? }\end{array}$} \\
\hline & \multicolumn{2}{|c|}{ A. Six hundred and sixty watts. } \\
\hline \multirow{2}{*}{$2: J$} & \multicolumn{2}{|c|}{$\begin{array}{l}\text { Q. What size conduit would be used for the following combination } \\
\text { of wires : (a) number fourteen duplex and number fourteen } \\
\text { double braided rubber covered single conductor, (b) four } \\
\text { pieces of number twelve double braided rubber covered single } \\
\text { conductor, (c) three pieces of number six double braided rubber } \\
\text { covered single conductor. }\end{array}$} \\
\hline & \multicolumn{2}{|c|}{$\begin{array}{l}\text { A. (a) One-half inch conduit. (b) three-quarter inch conduit } \\
\text { (c) one and one-quarter inch conduit. }\end{array}$} \\
\hline \multirow{2}{*}{$3: \mathrm{J}$} & \multicolumn{2}{|c|}{ Q. Give proper method of installing entrance switch and fuses. } \\
\hline & \multicolumn{2}{|c|}{$\begin{array}{l}\text { A. (1) Should be so installed that fuses are toward the line, (2) en- } \\
\text { trance switch so placed that gravity tends to open switch, } \\
\text { (3) blades of switch "dead" when in open position. }\end{array}$} \\
\hline \multirow{2}{*}{$4: J$} & \multicolumn{2}{|c|}{$\begin{array}{l}\text { Q. How are conductors supported in a vertical riser to take the } \\
\text { strain off the contacts? }\end{array}$} \\
\hline & \multicolumn{2}{|c|}{$\begin{array}{l}\text { A. (I) By the use of approved junction boxes, or (2) ninety degree } \\
\text { bend in riser. }\end{array}$} \\
\hline
\end{tabular}




\begin{tabular}{|c|c|}
\hline & $\begin{array}{l}\text { ELECTRICIAN } \\
\text { Page } 2\end{array}$ \\
\hline & $\begin{array}{l}\text { Q. How would you protect the lamps on the low current side from } \\
\text { being burned out (due to an unusual load condition) on a one } \\
\text { hundred and ten - two hundred and twenty volt, three-wire } \\
\text { "Edison system," with an unbalanced lamp load? }\end{array}$ \\
\hline & $\begin{array}{l}\text { A. (I) By "blocking in" the neutral fuse, or (2) running the neutral } \\
\text { straight through without a fuse. }\end{array}$ \\
\hline \multirow{2}{*}{$: \mathrm{JE}$} & $\begin{array}{l}\text { Q. How many transformers and what transformer capacity should } \\
\text { be used for fifteen horse-power, two hundred and twenty volt, } \\
\text { three-phase induction motor? }\end{array}$ \\
\hline & $\begin{array}{l}\text { A. Either one fifteen-kilovolt ampere, three-phase transformer or } \\
\text { two seven and one-half kilovolt ampere single-phase trans- } \\
\text { formers. }\end{array}$ \\
\hline & Q. What are the methods most frequetly used in inside wiring? \\
\hline & $\begin{array}{l}\text { A. (I) Knob and tube, (2) rigid iron conduit, (3) flexible iron con- } \\
\text { duit, (4) "B. X." conductor, (5) metal moulding. }\end{array}$ \\
\hline \multirow{2}{*}{$\mathrm{JE}$} & $\begin{array}{l}\text { Q. What advantage is gained by the use of a three-phase trans- } \\
\text { mission line as compared with a single phase? }\end{array}$ \\
\hline & $\begin{array}{l}\text { A. (I) Reduction in the size of copper for transmitting the same } \\
\text { amount of power, and (2) a better balanced load condition. }\end{array}$ \\
\hline
\end{tabular}

While undoubtedly these aids were of considerable value and a great improvement upon the previous state of affairs, where no examination was attempted, the method when put into operation broke down for the following reasons.

First, it was discovered that many of the questions covered such a wide field that a large number of correct answers given by highly skilled tradesmen were not included in the answers supplied to the interviewer. Under these conditions it was repeatedly found that the interviewers were refusing to accept answers which were not given in the manual, in spite of the fact that these answers were sometimes better than those furnished there. 
Second, the method failed to furnish any objective rating. Even if all the questions were given by a highly intelligent examiner, it was impossible to decide the degree of ability of the tradesman. While undoubtedly these interviews served to eliminate bluffers, they could, from their very nature, give no standardized rating of ability. For these reasons other methods of oral examination had to be sought.

Third, the relative difficulty of each question was not known; some of the journeymen questions were, as a matter of fact, easier than the apprentice questions, and vice versa.

\section{The Development of the Single-word Answer Question}

The defects of the general method outlined in "Aids to Interviewers" served as the starting-point for the conscious development of the final oral trade test method. If skilled tradesmen could not be employed as examiners, if a standardized rating was essential, it was absolutely necessary to eliminate all questions of the multiple-answer type. This step, which has been described so briefly, involved, before its final adoption, a vast amount of "trial and error" experimentation. Most of those who were working with the problem felt that the reduction of questions to the single-answer type involved a dangerous narrowing of the content of the questions which could be employed. The restrictions placed upon such questions, it was felt, might conceivably damage their value to such an extent that they would fail to satisfy the differentiating requirement. It is perfectly obvious that a large number of questions which might well be employed by an expert tradesman cannot be used when unskilled examiners have to give objective ratings. One of the first tests in which the impossibility of the use of the older type of question became apparent was in connection with the trade of rubber tire repairer. 
The first type of interview is shown. It can readily be seen that such an interview cannot be handled successfully by an examiner who has no knowledge of the process of vulcanizing. A cursory examination of the questions reveals the weakness of the method. Even the simplest question framed requires a lengthy and involved answer. This seems to be necessary when questions pertaining to processes are concerned. Take for example the question marked IJ. A complete answer to this question should cover, according to the examination, the nine points mentioned. Within many of these points there is possibility of considerable elaboration. A complete answer to such a question embraces so many items that the examiner must of necessity become confused. In addition, there is the difficulty that even if the examiner knows the trade, he is still in doubt as to what to accept as the complete answer. If questions are to be reduced to the single-answer type, the processes must be examined in order to discover what are the significant elements. Concerning these elements it is perfectly feasible to ask very specific questions; in fact, if the questions are carefully worded and well selected, it is often possible to reduce the answer to a single word. In addition, if elements in the process are chosen concerning which there is no variation in practice, the single answer will be the reply given by all tradesmen who have information with regard to that process. Without anticipating the full description of a trade test, the above statement can be illustrated by the following questions, of the type which eventually replaced the method above described.

Sample single-answer questions for tire repair workers:

Question 1. What tool is used in skiving?

Answer. Knife.

Question 2. How long do you vulcanize when making a sectional repair on a tire at usual pressure? 
Answer. 40-60 minutes.

\section{Question 3. What is meant by buffing?}

Answer. Roughening (cleaning, scraping) the surface.

Question 4. Where is cushion stock commonly used?

Answer. Between tread (breaker strip) and carcass (body) (fabric).

\section{Limitations of the Single-answer Questions}

To forestall objections it may be observed that the requirement of objectivity in the scoring, which virtually necessitates a single-answer form of question, limits materially the scope of the question. It prevents absolutely what up to the present has been the stock form of question, namely, that which calls for a more or less complete description of a process. Only with regard to one element in the process can the single-answer form of question test information. When, however, this single element is well chosen, because it is highly significant of the total procedure, the presence or absence of this element of information may be an exceedingly reliable index of the presence or absence of the knowledge of the total operation. Even assuming that this is true, the single-answer question still suffers from another serious drawback. It is commonly recognized that one of the best tests of knowledge in a field is the manner in which a large variety of ideas, or pieces of information are brought together and focussed in the attempt to solve a complex problem. Each idea may have little value in itself, as a revealer of knowledge, but the manner in which it is combined and fused with other ideas is most indicative. While it may be claimed that occasionally even a single-word answer question may call for the marshalling of facts and the weighing of evidence, it must be admitted that the large majority of these questions make no such demand. But this does not mean that merely 
isolated pieces of information are all that is required. If the questions are well selected, they will center around the important jobs and operations of the trade, and the element concerning which the question is framed will be so intimately and conclusively related to this operation that a correct answer will be forthcoming only from a workman who has successfully performed the operation. The best form of examination, from certain points of view, is that in which the examiner gives a problem to the examinee, and judges the power of the latter by the way in which the problem develops and enlarges, as time advances. Such a process is the true revealer of mind to mind; but it necessitates a highly trained examiner, and frustrates all attempts at objective scoring.

We may conclude by saying, quite frankly, that the singleanswer form of question is far from ideal as a test of degree of information, but it is the best instrument so far devised for testing this factor, when objective scoring by an unskilled examiner is a requirement.

Obviously the success of this new method of examination depends on the skilful selection of questions. There is a technique in connection with the construction of good single-answer questions which will have to be discussed in much detail later. In the interest of proving to the reader that this specific type of question does serve to differentiate between men of different degrees of skill, we will pass on to describe the method used for testing the suitability of the questions.

General Description of Method of Testing the Differentiating Power of Single-answer Question Method

The differentiations which it was expected that any method of examination must perform were more or less laid down by army 
requirements. The army distinguishes in any particular trade between four types of men:
I. Novice,
2. Apprentice,
3. Journeyman,
4. Expert.

It is impossible to define exactly what is meant by each of these terms. While the novice is an intelligent adult who has had no experience in the trade, the apprentice is supposed to possess the information and skill of the man who has spent a reasonable amount of time as a learner or helper in the trade. At first the army defined the Apprentice as a "man who has had not more than four years in the trade." While this definition is sound for a great many of the older trades, such as carpenter, machinist, pipe fitter, etc., it breaks down completely for the newer trades, such as vulcanizing or radiator repairing, acetylene welding, oxy-acetylene welding, and others of a similar nature. In these occupations the period of learning is comparatively short. With reasonable intelligence a year, or even less, converts a novice into a workman of average skill. Any definition of an apprentice designating a period of four years' service is out of the question. As a matter of fact, the army system of classification is archaic, for the old apprenticeship system upon which it was founded has largely ceased to exist.

The journeyman was defined as an individual who has passed the apprentice stage, whatever may be the period which this apprenticeship occupied. In addition, the journeyman, according to army usage, must not have had exceptional experience or possess a thorough, all-round knowledge of the trade. When this is the case, the army defines the standing by a special term, 
which is unknown in industry. The term is the so-called expert rating. An expert, by army definition, is "a man who has had not less than five years' experience as a journeyman and who has shown a superior knowledge of the trade, or such other qualifications as are required of a foreman."

The general method of testing the differentiating power of any set of questions was to administer them to 20 novices, 20 apprentices, 20 journeymen and 20 experts. The questions were given individually to these $80 \mathrm{men}$, distributed in three centers, Newark, Pittsburg and Cleveland. The answer of each man to each question was taken down in short-hand, that is, a complete verbatim report was obtained. This complete report gave at once information in two important directions. In the first place, it served to show whether the question itself was effective, particularly whether it yielded a single answer or a large number of possible correct answers. Where the question was ambiguous, where a local term was involved, where the phrasing of the question was incomplete, the answers thereto showed at once its unsuitability. The additional important information which these verbatim answers furnished was with regard to the relative difficulty of each question for novices, apprentices, journeymen, and experts. Without entering into technical details at this time it is obvious that the ideal type of question must fulfill the following requirements:

I. It must be such that practically no novices are able to answer it correctly. If novices do succeed, the question does not test genuine trade knowledge.

2. Apprentices as a group must be inferior to journeymen as a group in their power to answer the question, while the experts, as a group, must show distinct superiority to the journeymen in their answers.

3. In addition the question must be such that it is answered 
by a very large percentage of experts. If this is not the case, the question is distinctly too difficult for the purpose for which it is intended.

The method of selection of the 80 men who were given the examination is of the greatest importance. It cannot be too clearly recognized that during this process, which we have just described, we are not measuring the trade standing of the workmen, but we are merely testing out our own method of procedure. The trade standing of every man who was examined was known; only men who, according to the classification of foremen under whom they worked, fell well within one of the divisions of apprentice journeyman, or expert, were examined. Where there was doubt with regard to trade experience or standing the individual was rejected. In this way the trade or industry furnished men who were known to have three distinct levels of ability. These levels of ability served as the standard for measuring the value and efficiency of the method of examination. We were compelled to assume that the ratings given by foremen in consultation were correct. Given these three levels of trade ability, the feasibility of the questions was tested by the extent to which they were answered correctly by an increasing proportion of men as passage was made from the novice class, through the apprentice and journeyman group to the expert class.

Another method, used at the beginning of the experiment, of testing the efficiency of such a series of questions is of interest. Throughout the process of the standardization of the series of questions ${ }^{1}$ from which was to be selected the final set of questions, several experiments were made to gain some rough idea of the extent to which the whole group of questions differen-

${ }^{1}$ The method of collection of these questions will be discussed in the following chapter. 
tiated between various levels of trade ability. The usual method of procedure, where such an attempt was made, was to ask the foreman or superintendent, before the examination was given, to rank the men according to their usefulness as tradesmen. Those who did the ranking were warned not to consider such traits as punctuality, loyalty, etc., but merely to rank the men according to their practical trade ability. This ranking, made either by the foreman or superintendent, alone or in consultation, was retained by them, not being shown to those who were to administer the trade test. The thirty or forty questions were then administered in a routine way to the tradesmen who had already been ranked. In this way two rankings were secured. The first was the result of expert supervision extending over several years; it was based upon close contact, under the actual conditions of the job. The second was a ranking given by a nontechnical examiner, as the result of twenty minutes examination. The crucial test of the method is found in the degree in which these two rankings coincide. It was unfortunate that the method could not be tried out within a single plant on thirty or forty workmen who could be rated. This was, however, for reasons given later, contrary to the practice, it being the rule not to examine more than seven to ten men in one plant. Such ratings as were obtained involved therefore but 'few cases: the results however show the close correspondence between the foreman's ratings and those given by the test.

Pending the presentation of full evidence in the next chapter, it may be dogmatically stated that the Oral Trade Test succeeded remarkably well in differentiating between men of different degrees of ability as found in the trade. By selecting the most suitable questions it was possible to construct an examination in which the novices, apprentices, journeymen or experts reached different levels of score. That is to say, the experts 
Table Showing Correspondence between Rating of Foreman (F) and the Rating by the Oral Test (T)

\section{Lineman Test}

\begin{tabular}{cccccccccc}
\multicolumn{1}{c}{ Group I } & \multicolumn{2}{c}{ Group II } & Group III & \multicolumn{2}{c}{ Group IV } & \multicolumn{2}{c}{ Group V } \\
F. & T. & F. & T. & F. & T. & F. & T. & F. & T. \\
I & 2 & I & I & I & I & I & I & I & I \\
2 & I & 2 & 2 & 2 & 2 & 2 & 2 & 2 & 2 \\
3 & $4 \cdot 5$ & 3 & 3 & 3 & 4 & 3 & 3 & 3 & $3 \cdot 5$ \\
4 & $4 \cdot 5$ & 4 & 4 & 4 & 5 & 4 & 4 & 4 & $3 \cdot 5$ \\
5 & 3 & 5 & 7 & 5 & 3 & 5 & 5 & 5 & 5 \\
6 & 6 & 6 & 6 & 6 & 6 & & & & \\
7 & 8 & 7 & 5 & 7 & 7 & & & & \\
8 & 7 & & & & & & & &
\end{tabular}

as a group scored higher than the journeymen, the journeymen higher than the apprentices, and the apprentices higher than the novices. This does not mean that a few journeymen did not occasionally score as high as the lowest of the experts, and a few apprentices as high as the lowest of the journeymen, but in no case was there any great difficulty in drawing dividing lines between the classes, so that the overlapping was small. This process of deciding the critical scores for each level of trade ability is termed calibrating the test. When this calibration is completed on men of known trade ability, it can then be used for the purpose of ascertaining the standing of men whose proficiency in the trade is unknown.

To make the meaning of these critical scores perfectly clear* the journeyman rating, 57-74, means simply this: when the set of twenty-one questions was administered to a group of average journeymen, in different plants and in different cities, the large majority of them scored between fourteen and eigh* See following trade test:-Telephone Repairer Switchboard, p. 74 
teen answers, with credit of 4 points for each. This record is not a matter of opinion, nor is it the estimate of an expert. It is the actual performance of typical men engaged in the trade. Suppose then that the examination is given to an unknown workman, who answers fifteen questions correctly, or in other words scores sixty points. Under these conditions we may, with a high degree of probability, assume that his proficiency corresponds with that of the average journeyman engaged in the trade. If, however, he had scored thirty-six points or seventy-eight points, we should have been justified in rating him as an apprentice in the first place, an expert in the second.

It seems desirable at this point, even though the reader will not understand in detail the process by which the trade test has been constructed nor the method by which the standards have been deduced for the various trade levels, novice, apprentice, journeyman and expert, to present several complete trade tests. A careful examination of these tests will serve as the best introduction to the study of the intricate experimental process which has to be gone through in order to compile such a test. If the reader could try out some of these tests upon actual tradesmen ${ }^{1}$ before reading further, it would not only establish his confidence in a method concerning which he may be skeptical, but it would also afford a very good basis for understanding the discussion which is to follow. The danger of inserting these tests before a full description of their method of construction has been given lies in the possibility of the

1 The reader is cautioned against assuming that the content of an army trade is identical with the trade of the same name in civil industry. In more directions than one the ways of the army are past finding out. Certainly the strange trade names which they give within the army afford a proof of the above statement. For example, by an armature winder in civil life is commonly meant a person who merely does the winding of coils, whereas the army meaning of the term is much more nearly covered by the civil occupation of electrical repair man. 
reader thinking that a trade test is any set of questions, thrown together at random. Succeeding chapters will correct this notion, for it will reveal the fact that the construction of a measuring device for trade ability involves the most rigorous application of scientific method. 


\section{TRADE TEST \\ PAINTER. - General}

\section{ORAL}

COMMITTEE ON CLASSIFICATION OF PERSONNEL IN THE ARMY

Trade Test Division

Reproduced by permission of the Adjutant General

\section{QUESTION 1}

Q. What do you do to knots and sappy places before painting?

A. Shellac.

Score 4

\section{QUESTION 2}

Q. When is the puttying done on new wood-work?

A. After priming (first coat).

Score 4

\section{QUESTION 3}

Q. What is the brightest yellow used?

A. Chrome.

Score 4

\section{QUESTION 4}

Q. What is a finishing coat mixed with if a flat surface is required?

A. Turpentine.

Score 4

QUESTION 5

Q. What is the best paint to use on wrought iron to keep it from rusting?
A. (I) Red lead.
Score 4
(2) Graphite.
Score 4

QUESTION 6

Q. What do you call the lower portion of a wall which is painted a darker color?

A. Dado.

Score 4 


\section{QUESTION 7}

Q. What hard wood besides mahogany is best for a mahogany finish?

A. Birch.

\section{QUESTION 8}

Score 4

Q. What do you use to clean the surface of the wood after using paint remover?

A. (I) Benzine (gasoline).

Score 4

(2) Alcohol.

Score 4

(3) Vinegar. Score 4

\section{QUESTION 9}

Q. What do you use to bleach an exposed oak door before refinishing?

A. Oxalic acid.

Score 4

\section{QUESTION 10}

Q. What do you use for rubbing down enamels for a dull finish?

A. Pumice.

\section{QUESTION 11}

Score 4

Q. What is used to dissolve oxalic acid?

A. Water.

Score 4

QUESTION 12

Q. What do you call the operation of pouring paint from one bucket into another?

A. Boxing.

Score 4

QUESTION 13

Q. What device is used for working just outside of a single window on a high building?

A. Jack.

Score 4

\section{QUESTION 14}

Q. What is the proper way to clean off an alligatored surface on the inside of a hardwood door?

A. Paint (varnish) remover.

Score 4

QUESTION 15

Q. What is applied first on porous wood to get a natural finish?

A. Filler.

Score 4 


\section{QUESTION 16}

Q. How would you care for a paint brush after being used for the first time?

A. Lay out.

Score 4

\section{QUESTION 17}

Q. What stain do you get by mixing Van Dyke brown, ground Japan, rose lake and rose pink?

A. Mahogany.

Score 4

\section{QUESTION 18}

Q. Why is a small quantity of blue or black added to white?

A. (I) Bleach (whiten).

Score 4

(2) Keep from turning yellow.

Score 4

\section{QUESTION 19}

Q. What color must be used in stain to get a brown mahogany finish?

A. Van Dyke brown.

Score 4

\section{QUESTION 20}

Q. What color is Dutch pink?

A. Yellow (ochre) (mustard).

Score 4

\section{RATING THE CANDIDATE}

Score

Rating

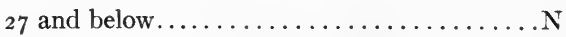

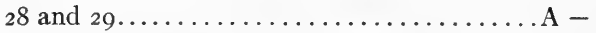

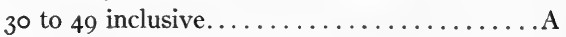

50 and $51 \ldots \ldots \ldots \ldots \ldots \ldots \ldots \ldots \ldots \ldots \ldots \ldots \ldots+$

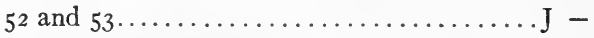

54 to 65 inclusive................... J

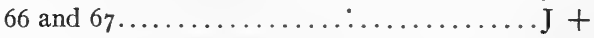

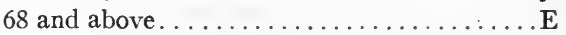

There is no $\mathrm{E}-$ or $\mathrm{E}+$ rating. 


\section{TRADE TEST}

\section{BLACKSMITH. - Forger, Hammersmith ORAL}

\section{COMMITTEE ON CLASSIFICATION OF PERSONNEL IN THE ARMY \\ Trade Test Division}

Reproduced by permission of the Adjutant General

\section{QUESTION 1}

Q. What keeps the top die from slipping back and forth?

A. Key (pin) (dowel).

Score 4

\section{QUESTION 2}

Q. What anvil tool do you use for smoothing off the surface of a forging?

A. Flatter.

Score 4

\section{QUESTION 3}

Q. To what is the top die fastened?

A. Ram (head).

Score 4

\section{QUESTION 4}

Q. How are the handles of large forge tongs held together while carrying work?

A. Link (ring).

Score 4

\section{QUESTION 5}

Q. What do you use for measuring the size of work while forging?

A. Calipers.

Score 4

\section{QUESTION 6}

Q. To what color do you draw a cold chisel for cutting cast iron? A. Blue. 


\section{QUESTION 7}

Q. What is the shape of the hole in a bolster for making a flatter?

A. Square.

Score 4

\section{QUESTION 8}

Q. What is the man called who has charge of the work while it is in the fire?

A. Heater.

Score 4

\section{QUESTION 9}

Q. When using top and bottom dies to make a forging, what is the waste material called which forms around the forging?

A. Fin (flash) (flange) (scale).

Score 4

\section{QUESTION 10}

Q. What kind of oil is used for tempering?
A. (I) Fish.
(2) Linseed.

Score 4

Score 4

\section{QUESTION 11}

Q. What do you put on bottom dies so the billet will not be hammered below a desired thickness?

A. Sizer (peg) (snap-block) (gauge).

Score 4

\section{QUESTION 12}

Q. What will happen to a billet in a hollow fire if a piece of coke gets on it?

A. Burn hole.

Score 4

\section{QUESTION 13}

Q. What tool do you use to cut off the end of a billet on a half circle?

A. Gouge (circle cutter) (circle hack).

Score 4

\section{QUESTION 14}

Q. In drawing out a long, heavy bushing what tool do you use inside of the bushing?

A. Mandrel.

Score 4 


\section{QUESTION 15}

Q. What kind of tongs do you use for pulling light pieces from the fire?

A. Pick-up.

Score 4

\section{QUESTION 16}

Q. What tool do you use under the hammer to make a 2-inch circular hole in a disk 1 inch thick?

A. Punch.

\section{RATING THE CANDIDATE}

Score

Rating

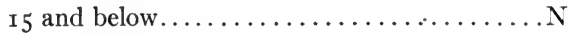

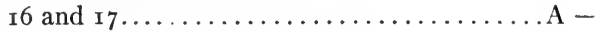

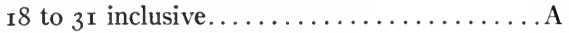

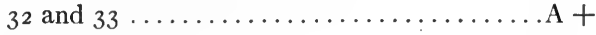

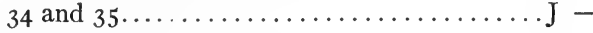

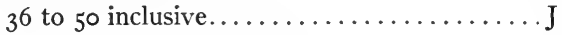

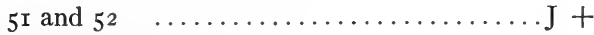

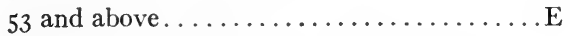

There is no $\mathrm{E}-$ or $\mathrm{E}+$ rating. 


\section{TRADE TEST}

\section{CARPENTER. - Cabinet Maker}

ORAL

\section{COMMITTEE ON CLASSIFICATION OF PERSONNEL IN THE ARMY \\ Trade Test Division}

Reproduced by permission of the Adjutant General

\section{QUESTION 1}

Q. How can a bruise in a piece of wood be raised?

A. (I) Wet.

Score 4

(2) Hot iron on damp cloth. Score 4

\section{QUESTION 2}

Q. What is used to close the pores of open-grained wood before finishing?

A. Filler.

\section{QUESTION 3}

Q. How can a bevel be cut with a circular saw?

A. (I) Tilting (setting) table (top).

(2) Gauge (guide).

Score 4 Score 4

\section{QUESTION 4}

Q. With what do you set the cut of the blade on a metal smoothing plane?

A. Screw.

Score 4

\section{QUESTION 5}

Q. With what kind of a joint is a table leg fastened to the rail of the table?

A. (I) Mortise (tenon).

Score 4

(2) Dowel. 


\section{QUESTION 6}

Q. How is an oak log sawed to get the best effect of the grain?

A. Quartered.

Score 4

\section{QUESTION 7}

Q. What is the name of the largest plane commonly used?

A. Joint (fore).

Score 4

QUESTION 8

Q. What does the number of a saw mean?

A. Number of teeth to the inch.

Score 4

\section{QUESTION 9}

Q. What hand-saw would you use to cut a round piece out of a board?

A. Compass (key-hole).

Score 4

\section{QUESTION 10}

Q. What is done to the surface of the veneer and core before gluing to make the glue stick?

A. Roughened (scratched) (tooth-planed).

Score 4

\section{QUESTION 11}

Q. What is fastened across the width of the board to keep it from warping?

A. Batten (cleat).

Score 4

\section{QUESTION 12}

Q. What plane do you use to plane the end of a small board across the grain?

A. Block (butt).

Score 4

\section{QUESTION 13}

Q. How is veneer $\frac{1}{4}$ of an inch thick treated before gluing?

A. Heated (steamed).

Score 4

\section{QUESTION 14}

Q. What is meant by shakes in wood?

A. Cracks (splints) (checks). 


\section{QUESTION 15}

Q. What are two kinds of joints used for the front of a drawer in fine cabinet work?

A. (I) a. Dovetail. Score 4

b. Rabbet (lap) (tongue and groove).

\section{QUESTION 16}

Q. Why are doors made up of panels?

A. Allow for shrinkage (swelling) (warping).

Score 4

\section{QUESTION 17}

Q. What is used for roughing down varnish or shellac besides sandpaper or pumice stone?

A. Steel wool (wire hair).

Score 4

\section{RATING THE CANDIDATE}

Score

Rating

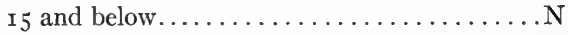

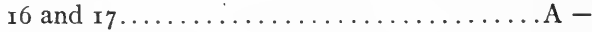

I8 to 29 inclusive..................... A

30 and $3 \mathrm{r} \ldots \ldots \ldots \ldots \ldots \ldots \ldots \ldots \ldots \ldots \ldots \ldots \ldots+$

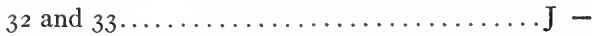

34 to 53 inclusive................... J

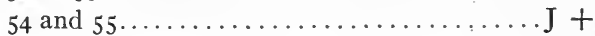

56 and above.........................

There is no $\mathrm{E}-$ or $\mathrm{E}+$ rating. 


\section{TRADE TEST}

\section{AUTO MECHANIC. - Auto Repairer, General ORAL}

COMMITTEE ON CLASSIFICATION OF PERSONNEL IN THE ARMY

Trade Test Division

Reproduced by permission of the Adjutant Gencral

\section{QUESTION 1}

Q. What are steering column bushings made of?

A. (I) Bronze (brass).

Score 4

(2) Steel.

(3) Babbitt.

Score 4

(4) Cast iron.

Score o

Score o

\section{QUESTION 2}

Q. What joint is there between the differential and the transmission?

A. Universal.

Score 4

\section{QUESTION 3}

Q. What is the best way to repair a badiy cracked cast-iron transmission housing?

A. (I) Weld (braze).

Score 4

(2) Rivet on a patch (plate).

Score 2

(3) Solder.

Score o

\section{QUESTION 4}

Q. What damage would be caused if an engine became much overheated through lack of water?

A. (I) Score cylinders.

(2) Pistons seize (freeze).

Score 4

(3) Burn out bearings.

Score 4

(4) Burn (warp) valves.

Score 4

Score 2 


\section{QUESTION 5}

Q. What are distributor brush-holder covers made of?

- (I) Rubber (hard rubber).

Score 4

(2) Fibre.

Score 4

(3) Bakelite.

Score 4 Any metal, Score o

QUESTION 6

Q. What regulates the height of gasoline in the carburetor?
A. (I) Float.
Score 4
(2) Float valve.
Score 4

\section{QUESTION 7}

Q. What happens to the breaker points if the condenser is bad?

A. Burn (pit) (foul) (carode).

Score 4

\section{QUESTION 8}

Q. What two metals are cam-shaft bearings usually made of?

A. (r) a. Bronze (brass).

Score 4

b. Babbitt (white metal).

\section{QUESTION 9}

Q. How are body springs fastened to the spring seats?

A. (I) Clips (U-bolts).

Score 4

(2) Shackles.

Score o

\section{QUESTION 10}

Q. What part of the carburetor governs the speed of the motor?
A. (I) Butterfly (throttle) (shutter).
Score 4

(2) Air valve. Score o

\section{QUESTION 11}

Q. What are two ways of driving the cam-shaft?

A. Chains and gears.

Score 4

\section{QUESTION 12}

Q. What is the most common way to hold the wrist-pin in position? A. Set screw (cap screw). 


\section{QUESTION 13}

Q. What is the result if the wrist-pin set screw works loose?

A. (I) Score (groove) cylinder. $\quad$ Score 4

(2) Pin drop out.

Score o

\section{QUESTION ' 14}

Q. What should be done in regard to the temperature of the motor before making any permanent adjustment on the carburetor?

A. Warm it up.

Score 4

\section{QUESTION 15}

Q. What will happen if the timing gear teeth bottom or mesh too deeply?

A. (I) Make noise (grind) (roar).

Score 4

(2) Break teeth. Score o

\section{QUESTION 16}

Q. What are the two windings in an armature or coil?

A. (I) a. Primary (low) (low tension).

Score 4

b. Secondary (high) (high tension).

RATING THE CANDIDATE

Score

Rating

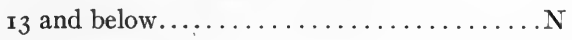

14 and $15 \ldots \ldots \ldots \ldots \ldots \ldots \ldots \ldots \ldots \ldots \ldots \ldots \ldots \ldots \ldots \ldots$

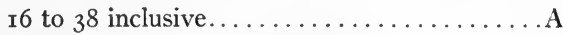

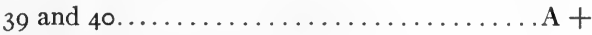

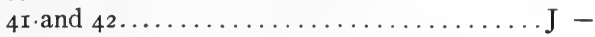

43 to 55 inclusive................ J

56 and $57 \ldots \ldots \ldots \ldots \ldots \ldots \ldots \ldots \ldots \ldots \ldots \ldots \ldots \ldots \ldots \ldots \ldots$

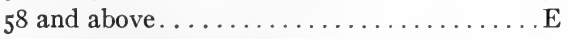

There is no $\mathrm{E}-$ or $\mathrm{E}+$ rating.

\section{SUPPLEMENTARY QUESTIONS}

These questions are inserted to provide the examiner with a means of guarding against the candidate's coaching for the examination. The Supplementary Questions should be used only when necessary. Not all of these questions should be asked any one tradesman. 


\section{QUESTION A}

Q. What are the marks on the fly-wheel used for?

A. (I) Timing (timing engine) (timing motor)

Score 4 (timing valves) (timing ignition).

(2) Setting valves (setting cams)

Score 4 (setting cam-shaft).

\section{QUESTION B}

Q. If a cylinder is scored from overheating what repairs are necessary to put it in good condition?

A. (I) Rebore.

(2) Regrind.

Score 4

Score 4

\section{QUESTION C}

Q. What is the best material to use to show the high point when scraping a bearing?

A. (I) Blue (Prussian blue).

Score 4

(2) Lamp black.

Score 4 


\section{TRADE TEST}

\section{TELEPHONE MAN. - Telephone Repairer.}

\section{Switchboard}

ORAL

COMMITTEE ON CLASSIFICATION OF PERSONNEL IN THE ARMY

Trade Test Division

Reproduced by permission of the Adjutant General

\section{QUESTION 1}

Q. How does the wire chief notify the subscriber that his receiver is off the hook?

A. Howler.

Score 4

\section{QUESTION 2}

Q. What voltage is used on a common battery system exclusive of - ringing?

A. 22 to 48 .

Score 4

QUESTION 3

Q. What insulating material is use between the carbon plates of a protector or lightning arrestor?

A. Mica.

Score 4

QUESTION 4

Q. Where are the plugs inserted in a switchboard?

A. Jacks.

Score 4

QUESTION 5

Q. What gauge wire is generally used for cross connections or jumpers?

A. (I) 20 .

Score 4

(2) 22.

Score 4

(3) 24 .

Score 4 


\section{QUESTION 6}

Q. What kind of current can flow through a condenser?

A. (I) A. C. (alternating current).

Score 4

(2) Pulsating.

Score 4

\section{QUESTION 7}

Q. Through what part of the protectors do lightning discharges pass to the ground?

A. Carbon.

Score 4

QUESTION 8

Q. What metal are switch board relay contacts made of?

A. (I) Platinum.

(2) Silver.

Score 4

(3) German silver.

Score 4 Score 4

QUESTION 9

Q. With what instrument do you measure a condenser kick?

A. Voltmeter.

Score 4

\section{QUESTION 10}

Q. What are cable skinners always treated with to keep out moisture?

A. (I) Wax.

(2) Paraffin.

Score 4

(3) Shellac.

Score 4

Score 4

QUESTION 11

Q. What does E.M.F. mean?

A. Electromotive force.

Score 4

\section{QUESTION 12}

Q. What do the marks 2 M.F. on a condenser mean?

A. 2 microfarads.

Score 4

\section{QUESTION 13}

Q. What is the voltage of a dry cell?

A. I to $I \frac{1}{2}$.

Score 4 


\section{QUESTION 14}

Q. What is meant by I.D.F. in a large telephone office?

A. Intermediate distributing frame.

\section{QUESTION 15}

Q. Name in order the first five colors in the switchboard cable color code.

A. (I) a. Blue.

Score 4

b. Orange.

c. Green.

d. Brown.

e. Slate.

Note: All required. No partial credits.

\section{QUESTION 16}

Q. What is the voltage of a one-cell storage battery?

A. 2 to 2.6 .

Score 4

\section{QUESTION 17}

Q. What part of the station apparatus prevents the flow of direct current through the circuit?

A. Condenser.

Score 4

\section{QUESTION 18}

Q. What is the name of the third talking circuit where only two pairs of wires are used?

A. Phantom.

Score 4

QUESTION 19

Q. Why are wires twisted in pairs?

A. (I) Prevent induction.

Score 4

(2) Prevent cross talk.

Score 4

\section{QUESTION 20}

Q. What is the usual resistance of a magneto telephone receiver? A. 65 to 100 . Score 4 


\section{QUESTION 21}

Q. At a temperature of $80^{\circ}$ Fahrenheit what allowance should be made in hydrometer reading?

A. 3 .

\section{RATING THE CANDIDATE}

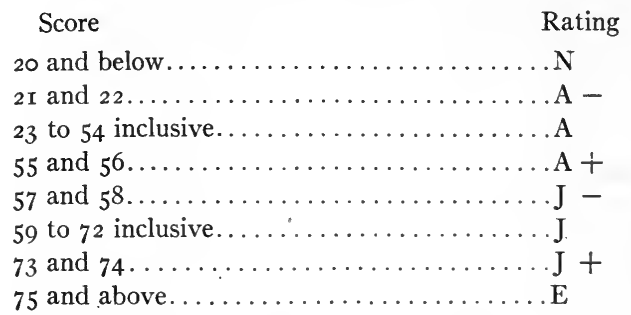

There is no $\mathrm{E}-$ or $\mathrm{E}+$ rating. 


\section{CHAP'TER III}

\section{CONSTRUCTION OF AN ORAL TRADE TEST (DETAILED PROCEDURE)}

\section{Random Sampling of Ability}

IN any examination of trade ability, certain implicit assumptions are made. It is advisable to see clearly just what these assumptions are, and the extent to which they limit the possibilities of an adequate examination. The statement has already been made that trade ability is a resultant of the combination of (I) certain skills; (2) certain elements of information. In oral tests we are making the somewhat broad assumption that the amount of skill can be measured indirectly by a determination of the amount of information possessed by the tradesman. In addition to this assumption made in the oral test, there is another which is common to all types of examination, whether of the oral, picture, written or performance kind. It is obvious that whether we are striving to measure skill or information, it is utterly out of the question to examine the tradesman in all the trade processes in which he is skilled; likewise it is impossible in a single examination to cover all the knowledge which is possessed by the tradesman. Only observation of actual work in a thousand and one jobs would enable any adequate estimate to be made of the majority of the "skills" possessed by the workman, while it would require a test of several thousands of questions in most trades, to cover the larger part of the information possessed by an expert.

Under these conditions we have to resort to what is tech80 
nically known as the "Procedure of Sampling." To sample means merely to test or examine by means of a portion or specimen. A sample is a portion taken at random out of a quantity supposed to be homogeneous, the assumption being that the properties or qualities of the sample may reasonably be expected to be found in the whole. This process is so familiar that a single illustration will make the meaning of the formal definition patent. Suppose a large plant receives from the same source several trainloads of what is supposed to be the same kind of steel. Before it can be used it is necessary to verify (I) whether its composition agrees with those qualities demanded by the specification; (2) whether all of the various loads are of the same kind, or whether, in other words, the material is homogeneous. Before answer is made to these two questions, the common procedure is to take samples from this batch, and from that batch, at random; to submit these samples to chemical analysis, and from this analysis of perhaps not more than a few ounces, the whole material, running into hundreds of thousands of tons, is taken or rejected. The accuracy of the final judgment, provided the analyses themselves are correct, depends on the degree to which the few samples taken are representative of the whole material, or as the definition has it, the extent to which "the properties or qualities of the samples may reasonably be expected to be found in the whole."

When, therefore, an attempt is made to measure general trade ability, either by oral questions, performances, or pictures, it is essential that the elements of information asked for or the skills which are tested, be representative as far as possible of the total range of ability. Where a thousand questions would by no means cover the ground, twenty questions have to be chosen with great circumspection, if there is to be a reasonable sampling of the total information. 
The questions must be scattered among the various processes of the trade - no two questions should involve the same process. In this case the correct answer to the one question often gives an almost certain probability of the correct answer to the second. What is required where only twenty questions are to form the final test is to have each question not only taken from twenty different important processes of the trade, but also cover the element in the process concerning which adequate knowledge is the most indicative of information with regard to the other elements which constitute the complete process. Twenty questions chosen carefully, from this point of view, may well cover a range of ground which several hundred less carefully selected might not touch. Especially when an attempt is made to conform to the single-word answer question, and the questions are secured merely from one shop or one expert, there is very apt to result a group of questions concerning a single process stressed in that one shop, or by that one expert. This group of questions must be replaced by the single most significant question, the significance of the question being dependent on the degree to which a correct answer is an almost certain indication of the presence of the other information concerning which there are no questions.

As will be seen later, in the case of the performance test, the difficulty is greater. In the oral question a comparatively large area can be touched; in fact, in the time consumed by the ordinary performance test it would be feasible to ask several hundred questions covering varied branches of the occupation. From the nature of the performances, the time consumed by the examination of the skill on a single job is such that, if several days are not given the examination, only one or two special skills can be examined. Under these conditions it is almost impossible to choose two or three typical tests which can be 


\section{AN ORAL TRADE TEST}

fairly taken as representative of the whole range of skills possessed by the expert workman.

It is now possible to discuss, in more detail, the essential stages through which a trade test must pass before it can be used as a satisfactory measuring device for trade ability. The various stages are:

I. The compilation of the proposed questions,

2. The preliminary testing of questions with elimination and revision,

3. The final testing of questions for purposes of standardization,

4. Statistical treatment of results,

5. Selection of final questions and calibration of the test.

Each one of these stages will now be considered separately. It is the object of the description of these processes to enable the reader to construct for himself, with the minimum of wasteful experimentation, an oral trade test for any occupation in which he may desire to hire men.

\section{Compilation of the Questions}

Paradoxical as it may seem, the success of the trade test method was largely due to the fact that those who compiled the questions were not expert tradesmen. This necessitated constant contact with trade conditions. By far the most important source of information consisted of experts who were actually, at the time, engaged in the occupation. While the compiler of the question took advantage of the literature on the trade, the larger number of the questions came directly from foremen and experts. Even when a question was suggested by books or previous examinations in the trade, it was always talked over with numerous practical tradesmen before it was included in 
the first trials. The work of the compiler and the tradesman was usually complementary. While the trade expert furnished the necessary knowledge of the processes of the trade, the questions that he propounded were usually of the vague, multianswer type. It was only in the rare case that the expert framed questions of the kind required for the purposes of an objective trade test. Such being the case the business of the compiler was, on his side, to analyze and examine the questions and problems proposed in order to convert them into questions which elicited only a single answer.

Had the compilers themselves been familiar with the trade, there is little doubt that the questions would have savored more of the polished desk and the quiet office, than of the forge and bench. It was the enforced consulation, at the very beginning of the assembly of the questions, with foremen and expert tradesmen, in their own shops, surrounded by the machines and tools with which they were working, that guaranteed the practical nature of the instrument.

As soon as it was decided to work on a particular trade, the first problem was to determine the feasibility of a test in this field. Was it of such a nature that it contained the necessary informational elements. Did it permit of grading according to degrees of skill? In some trades it was found that the occupation required simply the performance of a single set of operations: there were no gradations among the members of the trade. A large number of the so-called occupations which modern production methods of industry have called into existence, are examples of occupations in which there is almost no gradation in skill; the operation can be done or not done; there is no middle path. When it was decided that the trade was such that the oral method could be applied, the next stage involved the collection of practical information upon which 
the questions were to be based. This information was secured by visiting plants and talking with the men in the shop. Áfter explaining the general nature of the problem to a foreman, a question which the author often put to the tradesman will illustrate the procedure. "Suppose you were hiring a man out of town, away from your shop and tools, what are some good trade questions you would ask, to be sure that the man had the trade ability he claimed?" Usually this question served to open up negotiations and question after question was forthcoming. Where this method was not successful in eliciting the information, the compiler would watch work in operation, and ask questions himself with regard to tools and operations. Nearly always, after a few minutes even the most secretive foreman became a ferment of questions. Most of them, however, were in a form totally unsuited to the purpose of the examination. The important thing is that this process furnished material upon which the compiler could work and which was not the result of the study of books or theory, but came out of the practical experience of the man on the job.

The type of question which was commonly proposed is well illustrated by the examples which are cited in the "Aids to Interviewers" on page 35-5I. Questions of this type have to be analyzed into their elements by the compiler, and reduced to a simpler form requiring a single answer. To illustrate this process some specific examples may be given with advantage, as indicating some of the more outstanding difficulties which were met. The common faults of the simpler forms of questions were found either in their vagueness or in the chance they afforded even a nontradesman of guessing the answer. Especially was this the case in those questions to which the answer was merely "Yes" or "No." As examples of the first type thousands of questions, as they came from the foremen, could be 
given verbatim. The most common was the question calling for a description of a long process. "How should a spring be removed from a car?" 'This can be answered in a large number of ways and it cannot be scored objectively. In many questions both faults were present, as, for instance, in a question proposed for blue printers. "Which is better, to overexpose or underexpose a print? Why?" The first part of the answer is a guess: the second part calls for a long explanation which only the expert could understand and no man living could score objectively. As an example of guess questions we may take the following: "Which way should the front wheels be turned, if the rear wheels are skidding to the right?" Here the answer - "To the right" — can obviously be guessed with a fifty per cent chance of accuracy. Or again a question of this type, in which the fact is less obvious. "In making a solid cylinder pattern, on which side would you put the tapered core print?" The pattern maker with the least knowledge of his trade knows that it must be either on the cope or drag side. Even though he has never seen the process, he has a fifty per cent chance of a correct answer if he guesses. A third example, requiring no trade knowledge whatsoever for a correct guess half the number of times, is "Can a milling machine be used for the spacing of holes without a layout?" The answer is merely "Yes" or "No." It.will be seen that the questions of this type were framed without reference to the way in which they would meet the army problem. In nearly all cases, where the questions did not admit of guessing, the answers were so long and involved that they could not be scored objectively, or in many cases even understood by the nontechnical examiner. It becomes an easy matter after a little practice to convert a large number of these vague and guess questions, elicited from the foreman, to a form in which they can be employed. If instead 
of asking for information concerning the whole process, an essential element of the process is isolated, and a question framed with regard to this element, usually a definite objective answer may be secured. Often skilful rewording will convert a useless guess question into a most serviceable one.

As many readers will be likely to construct series of questions for trades within their own industry, the following points, which were the outcome of many months practical work, will be of value.

\section{Guides for the Compilation of Oral Trade Questions with the Aid of Experts}

I. Analyze with the aid of experts the actual jobs in the trade.

Watch the common processes of the trade and become familiar with the terms. It is absolutely necessary to have an understanding of the typical operations of the trade, to ensure the correct choice of questions.

2. The information secured from watching tradesmen performing their jobs should be supplemented by the study of trade manuals but great care must be taken to see that the trade manuals are of a practical nature. Furthermore, if any suggestions are received from the study of the manual, before these suggestions are employed, they should be talked over with expert tradesmen, to discover their suitability.

3. With the aids above described, construct a few typical questions covering the important elements of the trade. Remember that the expert is ignorant of trade test methods; while he knows his trade, he does not realize what type of question is wanted. A few sample questions will show him what is being sought. After he has grasped the method, elements of the trade which seem most obvious will often furnish the best type of trade question. 
4. Do not expect the expert to formulate the question. $\mathrm{He}$ can supply the information, but he can rarely word the question to fulfill the rigid requirements of the examination. The compiler himself must word the question from the information he receives.

5. The wording of the question cannot be too simple. The author well remembers one which ran as follows: "What is the function of the float in the carburetor?" Two mechanics examined in succession commented: "If you tell me what "function' is, I'll answer the question."

6. The terms of the question should be as far as possible in the vocabulary of the shop. It is absolutely necessary to talk in the language of the tradesman.

7. Avoid catch questions. They make the applicant suspicious. Use the simplest possible language in the question. The test is to measure trade ability and not power to use the English Language.

8. Make your question clear. It is impossible to be too specific.

9. Whenever it is feasible in a trade, questions should be framed which demand precise numerical answers. If sufficient care is taken by the assembler to make the desirability of numerical answers obvious to the expert, there are few trades in which some of the questions cannot be of this type.

I0. Avoid questions yielding a numerical answer to which there are limits. Such limit questions are very difficult to score, because of different practices in the trades. For example, in the question, "How much stock should be left in a one and onequarter inch hole for hardening and grinding?" the most common answer is five to eight thousandths of an inch, but from job to job there will be variations, depending on particular conditions, which make the " 5 to 8 thousandths" only one of many 
possible answers. It is almost impossible with questions of this limit type to get sufficient uniformity in answer to enable a nontradesman to score correctly.

II. Questions should have only one part, and the answer should be such that a single word is sufficient. In this connection a very good help is to decide the trade term that is desired for the answer, and then frame the question so that it will fit the answer decided upon and yield no other possible answer.

12. As a rule questions beginning with the word "how" should be avoided. They usually call for a description of a process which is lengthy. Such questions do not permit objective marking.

I3. Be very careful in the use of the word "kind" or "type." Such questions are apt to be vague. For example, "Name four kinds of reamers." Here, the answer called for may be the names of makers, or sizes, or hand, machine, rose, expansion; etc. The same criticism applies to a question of this type: "What type of socket should be used when wiring in damp places?" Here the answer called for is "weather proof or porcelain," but as the question is framed a maker's name will often be secured.

14. In order to avoid local terms, try the question out on workmen who have had very diverse training and experience. A question may appear to be fair for all the men in one plant, but incomprehensible to experts in other plants.

15. The questions must be so chosen that they represent all degrees of difficulty, otherwise they cannot be expected to measure the three grades of trade ability.

I6. Questions must be avoided which are either included or assumed in other questions.

I7. Aim to secure a good balance in the number of questions on each aspect of the trade. The number of questions covering 
each aspect should vary with the importance of that element of the trade. Avoid questions which are concerned with a highly specialized branch of the trade, or found only in a particular type of work.

I8. A consideration which must be borne in mind at all times is that any question, however important, from the standpoint of bringing out the principle of the trade, is useless if it calls for a long and rambling answer. The short, concise answer, with a single cue-word, is the great desideratum.

r9. Having secured questions from an expert, take advantage of every opportunity to try out these questions on the other experts, with whom consultation takes place. If the questions are not "fool-proof," this fact will be readily discovered.

To return to the army procedure, it was usually necessary to consult at least five experts, in different plants, working under different conditions, to secure seventy or eighty questions which fulfilled the requirements stated above. By a more careful application of these requirements and others of less importance, the seventy or eighty questions were sifted down to approximately fifty. These were then compiled into a set known as "The Preliminary Try-out Questions." A description of this first testing of the questions is given in the next section.

\section{The Preliminary Testing of Questions}

The fifty or sixty questions which remained, after the first selection, were then administered to a number of tradesmen, usually from nine to twelve, the apprentice, journeymen and experts being about equally represented.

The method of giving the examination was completely standardized. Though detailed instructions as to the administration of a trade test will be given later, the general directions may be briefly outlined here. The examiner read the question just as 
it stood; even though experience showed that the first wording was wrong, no change was allowed in the question during the preliminary try-out. No help by gesture or emphasis was to be given the tradesman. The examiner was allowed however to use certain "follow up" questions when the answer given by the tradesman seemed to be to the point but did not correspond with that given in the test. These standardized follow-up questions were:

(I) Anything more?

(2) Any other name for it?

(3) Any other way of saying the same thing?

(4) Any other way of doing it?

The full answer to each question was recorded verbatim, together with any of the above "follow up" questions, which were employed to elicit further information. Full notes also were taken of any significant comments made by the tradesman.

It has been said that in this preliminary try-out tradesmen from different shops or plants were examined, in order to eliminate questions dependent on specialized methods or modes of expression confined to a single plant. In addition, to get the benefit of more than one point of view for revision, at least two examiners worked on each set of questions at this stage.

A careful examination of the answers given by the apprentices, journeymen and experts offered a ready means of checking each question for the following points:

I. Is it applicable to the trade?

II. Does it represent good trade practice?

III. Does it need to be modified, supplemented to yield a suitable answer, or must it be eliminated.

IV. Does it differentiate between the three different levels of trade ability? 
Further, the examination of the questions as a group showed the extent to which there was a representative sampling of the range of trade processes.

In the light of these answers, the fifty or sixty odd questions were then examined carefully one at a time. Certain questions were eliminated for one reason or another. Some were reworded or changed in form and in others additional answers were added which the try-out had shown were correct alternatives to the original answer. This process reduced the questions to a small enough number, usually thirty to forty, to admit of easy standardization. Care was taken to see that the remaining questions were sufficiently wide in scope to represent different degrees of trade ability. These questions, with their answers, were then ready for the next stage of the process, namely the final try-out for purposes of accurate standardization.

\section{Final Testing of Questions}

The final testing of the question was merely an elaboration of the method used in the preliminary testing, which has just been described. Instead, however, of using three apprentices, three journeymen and three experts, the test was now administered, in full, in each one of the four groups, to twenty men who were known to be typical representatives of the four classes novice, apprentice, journeyman and expert. Extreme care was taken to secure correct information concerning each man before he was rated as a typical representative of his group. The novice must be a man of good intelligence and good general knowledge, but he must have had no specific trade experience. The apprentice must have had sufficient experience to lift him out of the novice class, but at the same time he ought not to have had a sufficient period in the trade to acquire the experience of an ordinary journeyman. For this purpose in those trades where 
four years is the usual length of apprenticeship it was customary to examine men who had had not less than nine months or more than two years' experience. The journeyman, for the same reason, was not considered typical if he had that degree of intelligence and experience which might reasonably be considered the mark of an expert. Under ordinary conditions no man of more than four years' experience as a journeyman was taken as a representative of his group. The greatest difficulty in assigning the proper trade status was encountered in the case of the expert. While a minimum of six or eight years as a journeyman was considered essential, mere length of experience was no criterion. In choosing men as representatives of the trade levels, apprentice, journeyman or expert, the joint judgements of several foremen, and that of the employer were used. Seeing that at this stage we were really testing the test by the extent to which these men of known trade ability were able to answer the questions, it can be seen how essential was the accuracy of these trade ratings. In all cases the examiner was compelled to classify the men before the examination commenced. This was done to avoid being influenced by the manner in which the tradesmen answered the questions.

In order to obtain as wide a sampling of tradesmen as possible, the general rule was established that not more than six men should be examined in one plant. In addition to this precaution, three testing stations were used, one in Cleveland, one in Newark, and one in Pittsburg. This was done to get the benefit of wide geographical distribution. By this means any questions which involved the use of local terms could be detected and eliminated. In view of the fact that the trade tests were to be applied in all parts of the country, this freedom from geographical bias was essential.

The procedure of the examination was precisely the same as 
that which was to be used later in the camps, with this exception - whereas in the camps the answers were not recorded but merely scored, in the final try-out, as in the preliminary one, a full verbatim record of the answer to each question was made. The examiner, in addition to being responsible for giving the question in the exact form and seeing that the answer given was recorded correctly by the stenographer, was also charged with the duty of scoring the question. The credits allowed for each question were from zero to four. The reason for the introduction of this graded system of scoring grew out of the rather vague type of question which, in the beginning of the work, was used in the examination. Later when the single-answer question was reduced in most cases to a single-word answer, the reason for the graded scoring ceased to exist. At the very beginning of the work there was much opposition on the part of the author to the use of partial credits, on the ground that this complicated the issue, permitting great subjectivity in the scoring. It was, however, contended that a question which was partially correct must be given a partial credit. This was largely a concession to common opinion. Extensive experiments in the realms of educational measurement had shown before rgr 7 the inadvisability of using partial credits. As the one-word answer trade test evolved, the whole system was reduced virtually to an "all or none" method of scoring. An answer was either perfect and given a credit of four, or else it was wrong, in which case it was assigned zero.

The answer furnished with the questions was in many cases merely a key-word. It was not expected that the tradesman would-limit himself in his answer merely to a single word, though in the better form of trade question this was largely the case. The examiner scored the question perfect, provided the answer included the key-word. An illustration will make this clearer. 
In the test for Brass Melters this question is asked, "What is done to the core to let out the gas when pouring?" The answer given in the test is "vented." In this case, provided the man in a descriptive answer used the term "vented," he was given full credit. though in many cases his answer would be a very short description of the process. Where there were two or more possible correct answers to a question, the most likely answer was given first, and the alternative answers were placed in parenthesis. In this case any one of the answers was acceptable and scored four. The candidate was not expected to give both answers. The following questions for the Printing Press Operator illustrates this point.

Question, "Where do the form rollers get ink?"

Answer, "Slab (plate), (table)."

This procedure furnished very full information with regard to each question. In certain cases, when the material had been collected and carefully examined, it was discovered from a study of the journeyman or expert replies to certain of the questions that the original answers were incomplete. In this case the alternative answers were inserted. The particular questions in which this took place were then remarked, in the light of these alterations. This had to be done, otherwise the scoring in the standardization process would have differed from that eventually used in the camps. In view of the fact that the performance of the eighty men of known trade standing was establishing norms, it was absolutely essential to have the standards constant. A question for Lithographic Pressmen at the commencement of final testing was as follows: "What is put on the blanket cylinder after it has been cleaned?"

Answer, Sulphur (score 4)

Chalk (Score 4)

When the answers of the Experts were examined it was dis- 
covered that it was common practice to use soapstone. This alternative was, therefore, added to the possible answers and the records of the eighty men were remarked, to make the scoring coincide with this addition. This remarking necessitated in those cases where the men had only answered "Soapstone," a change of credit from zero to four.

It cannot be too clearly emphasized that at this stage it was absolutely impossible to attempt to alter the form or wording of the question. Additions could be made to the answers, for this involved merely remarking, but even the slightest alteration in the form of the question would have nullified all the evidence obtained. Where a question was wrongly worded, elimination was the only alternative. The question could not be altered without administering it again to the eighty men. The verbatim answers of the eighty men to all the proposed questions being assembled, the next stage in the process was the statistical treatment, from which resulted the selection of the final questions, and establishment of the standards of achievements.

\section{Statistical Treatment of Results}

The first step before commencing the statistical treatment proper was to examine roughly the answers to each of the questions. A rapid examination of this kind revealed, at once, that some questions could not be employed. The most common causes of this rejection were:

r. Correct answers to the questions were so varied that it was impossible to conform to the objective requirement of marking.

2. The process in the trade upon which the question was based, on further examination, proved to be doubtful practice.

3. The question proved to be suitable for one locality, but 
was not suitable for general use. Thus, a question might be well answered at Newark and fail to function in Cleveland and Pittsburg.

4. On further examination a certain ambiguity would be revealed in the question.

The rejections on the above points usually reduced the questions by ten or more, leaving as a rule thirty to thirty-five questions, which were then subjected to routine statistical analysis.

The objective of the statistical analysis was to make careful study of the answers and scores in each of the remaining questions, in order to determine the relative value of each individual question and its suitability for selection as a part of the final test.

In order to make clear this somewhat complex process of standardization, the chart containing the full statistical data for a typical test is reproduced. For economy of space only the results for the twenty final questions are recorded. Each dot denotes a correct answer for which a score of four points was given. There were no partial scores allowed in this test. The chart with the footnotes is self-explanatory.

A careful study of this chart will facilitate an understanding of the whole statistical process.

Generally speaking, if a trade test is good, a known expert when tested is able to answer all or nearly all the questions correctly; a journeyman is able to answer the majority; an apprentice a smaller part, and a novice practically none. This does not mean that each question should be answered correctly by all the experts, a majority of the journeymen, some apprentices, but no novices. It is only a few of the more ideal questions which show this gradual increase in difficulty, as we pass from level to level. The method by which this increase in difficulty was graphically represented will be now described. 

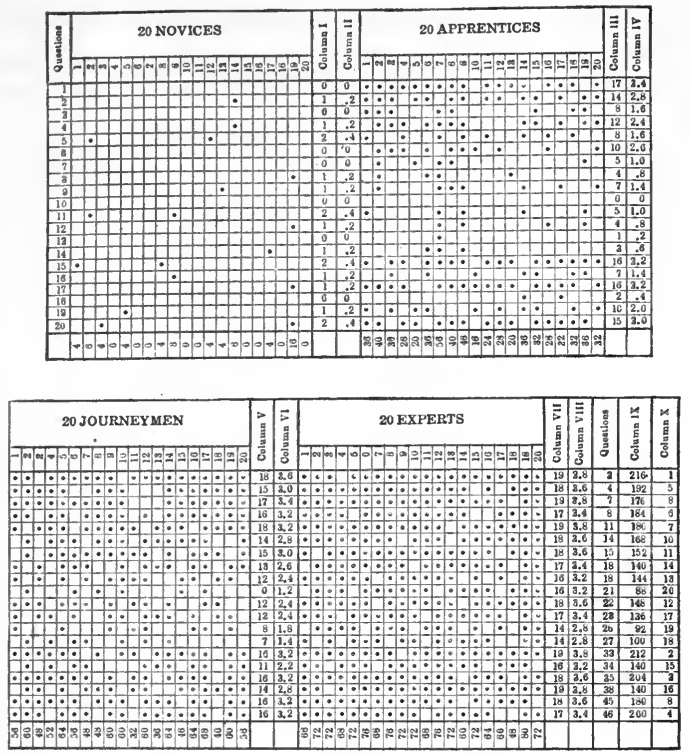

This chart shows all the statistical data used in the making of the test. Of the 50 questions originally assembled and used in the samplings, all but the 20 shown were rejected for various reasons. Each dot denotes a correct answer having a score value of 4 . There were no partial scores allowed in this test.

Column I shows the number of correct answers to each question by Novices. (Columns III, V and VIII show similar facts for Apprentices, Journeymen and Experts respectively.)

Column II shows the average score of Novices for each question. Column I shows that on question 5,2 out of 20 Novices scored 4 each, making a total Novice score of 8 . Dividing by 20 gives an average of .4 as shown in Column II. (Columns IV, VI and VIII show similar facts for Apprentices, Journeymen and Experts respectively.)

Column IX shows the total score of Novices, Apprentices, Journeymen and Experts combined for each question, obtained by adding, in each case, Columns I, III, V, and VII, and multiplying by 4 . The highest score indicates the easiest question, number $\mathrm{I}$ in Column $\mathrm{X}$.

The unnumbered column signifies number of questions in original series.

Column X shows the 20 selected questions as they will appear in the completed test, arranged in ascending order of difficulty. 
For the purposes of clearness in presentation, we shall suppose that the test was given to exactly twenty novices, twenty apprentices, twenty journeymen, and twenty experts. The information shown in the table was collected with regard to each question. For an ideal type of question, the first horizontal line in the table would read as follows: Of the twenty novices, not a single one got the answer correct. Of the twenty apprentices, seven answered the question; thus the twenty apprentices scored among them 28 points, four points being given for each correct answer. Their average score, therefore, on that question was I.4. This is obtained by dividing the twenty-eight points by the number of apprentices tested. Similarly, the bottom line would read as follows: all the experts examined answered the question correctly, thereby scoring, on the basis of four points for a question, eighty points. This made the average score of the experts exactly 4.0 .

The graphical representation of this table is shown in Fig. I. In this graph, the novice, apprentice, journeyman, and expert are distributed at equal distances ${ }^{1}$ along the abscissa. The ordinate axis, rating from $\circ$ to 4 , records the average performance of the four groups examined. Thus, for example, an average score

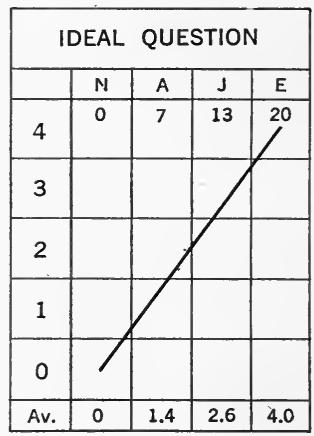

Fig. I. of one on the question, by a group of twenty, implies that

1 To the statistically trained reader it will be obvious that these equal distances imply equal increments of total trade ability from class to class. This assumption is, of course, erroneous, but the convenience justifies this method, provided the reader keeps in mind that these distances, truly represented, would be by no means equal. 
five of the twenty individuals gave correct answers. In the graph itself it is shown that the average apprentice scores I.4,

\begin{tabular}{|c|c|c|c|c|}
\hline \multicolumn{5}{|c|}{ QUESTION No. 5} \\
\hline & N & A & J & E \\
\hline 4 & 2 & 8 & 16 & 19 \\
\hline 3 & & & & \\
\hline 2 & & & & \\
\hline 1 & & & & \\
\hline 0 & & & & \\
\hline Av. & .4 & 1.6 & 3.2 & 3.8 \\
\hline
\end{tabular}

Fig. 2. the journeyman, 2.6, and the experts, 4.0. The question just described in which there is a gradual increase in difficulty as we pass from class to class is of course never obtained. It is, however, from certain points of view the ideal question, but, like most ideal things, is rarely found. Types of questions which approximate more or less closely to this, are, however, of common occurrence. In Figs. 2 to 9 typical curves for single answers are given. These curves represent various types of questions. The curve in Fig. 2 indicates that this particular question approximates very closely to the ideal type where

\begin{tabular}{|c|c|c|c|c|}
\hline \multicolumn{5}{|c|}{ QUESTION No. 1} \\
\hline & N & A & J & E \\
\hline 4 & 0 & 17 & 18 & 19 \\
\hline 3 & & & & \\
\hline 2 & & & & \\
\hline 1 & & & & \\
\hline 0 & 7 & & & \\
\hline Av. & 0 & 3.4 & 3.6 & 3.8 \\
\hline
\end{tabular}

Fig. 3 .

\begin{tabular}{|c|c|c|c|c|}
\hline \multicolumn{5}{|c|}{ QUESTION No. 18} \\
\hline & N & A & J & E \\
\hline 4 & 20 & 2 & 14 & $\begin{array}{c}19 \\
\text { (1) }\end{array}$ \\
\hline 3 & & & & \\
\hline 2 & & & & \\
\hline 1 & & & & \\
\hline 0 & & & & \\
\hline Av. & 0 & .4 & 2.8 & 3.8 \\
\hline
\end{tabular}

Fig. 4.

there is a gradual increase of difficulty from group to group. Question 5 is a "trade question," so-called, because it differen- 
tiates very strongly between novice and tradesman. It does not, however, serve to differentiate, in any very high degree,

\begin{tabular}{|c|c|c|c|c|}
\hline \multicolumn{5}{|c|}{ QUESTION No. 10} \\
\hline & N & A & J & E \\
\hline 4 & 0 & 0 & 6 & 16 \\
\hline 3 & & & & \\
\hline 2 & & & & \\
\hline 1 & & & & \\
\hline 0 & & & & \\
\hline Av. & 0 & 0 & 1.2 & 3.2 \\
\hline
\end{tabular}

Fig. 5 .

\begin{tabular}{|c|c|c|c|c|}
\hline \multicolumn{5}{|c|}{ QUESTION No. 25} \\
\hline & N & A & J & E \\
\hline 4 & 6 & 18 & 20 & 18 \\
\hline 3 & & & & \\
\hline 2 & & & & \\
\hline 1 & & & & \\
\hline 0 & & & & \\
\hline Av. & 1.2 & 3.6 & 4.0 & 3.6 \\
\hline
\end{tabular}

Fig. 6.

between apprentice, journeyman and expert. Question $I$ is an example of an "apprentice-journeyman question," so-called, because it differentiates sharply between the novice and apprentice class on the one hand, and the journeyman and expert group on the other.

Question ro is distinctly an "expert question," its most marked differentiation being between the journeyman and expert class. Question 25 shows a rather high novice score and no differentiation between apprentice, journeyman and expert; in fact the experts are distinctly inferior to the journeymen. For this reason such a

\begin{tabular}{|c|c|c|c|c|}
\hline \multicolumn{5}{|c|}{ QUESTION No. 30} \\
\hline & N & A & J & E \\
\hline 4 & 2 & 1 & 7 & 7 \\
\hline 3 & & & & \\
\hline 2 & & & & \\
\hline 1 & & & & \\
\hline 0 & & & & \\
\hline Av. & .4 & .2 & 1.4 & 1.4 \\
\hline
\end{tabular}

Fig. 7 . question must be rejected. Question 30 is, of course, much too difficult, even for the journeymen and experts. It does not 
differentiate sufficiently between the four classes. Questions of this kind cannot be used. Question $3^{I}$ is of interest; here the experts as a group fall distinctly below the journeymen. For this reason such questions must be avoided. Question 42 shows no differentiation between the novice and the apprentice and the small rise in the curve indicates that the question was distinctly too hard for the journeymen and experts. Even in the expert group only one man in four was able to answer it.

Questions of the first five types may be employed in the final

\begin{tabular}{|c|c|c|c|c|}
\hline \multicolumn{5}{|c|}{ QUESTION No. 31 } \\
\hline & N & A & J & E \\
\hline 4 & 3 & 7 & 19 & 14 \\
\hline 3 & & & & \\
\hline 2 & & & & \\
\hline 1 & & & & \\
\hline 0 & & & & \\
\hline Av. & .6 & 1.4 & 3.8 & 2.8 \\
\hline
\end{tabular}

Fig. 8.

\begin{tabular}{|c|c|c|c|c|}
\hline \multicolumn{5}{|c|}{ QUESTION No. 42} \\
\hline & N & A & J & E \\
\hline 4 & 0 & 0 & 3 & 4 \\
\hline 3 & & & & \\
\hline 2 & & & & \\
\hline 1 & & & & \\
\hline 0 & & & & \\
\hline Av. & 0 & 0 & .6 & .8 \\
\hline
\end{tabular}

Fig. 9.

examination. It has been indicated that each kind of question has its value in the test. The main requirement is that the tendency of the curve should be upward, but it is by no means necessary that it should approximate to the straight line. Such a linear relationship between score on question and trade status is, in many cases, not to be expected. In fact it may be very desirable to construct questions which do not show such a relationship. When it is necessary, for example, to differentiate sharply between journeymen and experts, the question which shows little differentiation between novice, apprentice and 
journeyman, but showing a rapid rise when the expert class is reached, is of great value. Questions where there is a distinct line of cleavage between the various groups must be selected to form a proper balance; that is, if we select a question primarily because it differentiates between novice and apprentice, in spite of the fact that the differentiation between journeyman and expert is small, we must take care that balancing questions are introduced which differentiate sharply between the two lastnamed classes. It will be remembered that a cursory examination of the collected answers quite apart from any statistical study, eliminated some of the questions. For all questions not so eliminated, the graphs were drawn by the method described above. A detailed study of these graphs eliminated for the reasons given above a further number of questions. The remainder were then combined into the final form of the test. The only process which is left for description is that of the calibration of the test.

\section{Calibration of the Test}

When the final selection of questions has been made, the only problem that remains is that of establishing the standards which shall be considered characteristic of the expert, journeyman, apprentice and novice classes. Using the physical analogy, the process is commonly called "calibrating" the test. Usually in the army the final test consisted of fifteen to twenty questions. This, however, is a purely arbitrary number chosen for purposes of speed in assembly and ease in administration. What was required of the army instrument was primarily speed. There is no reason why fifteen to twenty questions should not be replaced by forty or fifty questions, if such an addition furnishes valuable information with regard to the trade standing of the workman. 
The problem of calibrating the test would be an easy one if the following two conditions were fulfilled.

r. If the classifications of the eighty men tested were perfectly accurate indices of each man's total trade ability.

2. If at each level of trade ability there was a distinct standard of performance, with no overlapping of the various groups. Neither of these conditions was, however, fulfilled. It must be borne in mind that the classification into the four levels of ability was based on rather arbitrary standards. It depended on a combination of length of experience, type of work done, general intelligence, and a foreman's rating. In general the classification was reasonably reliable. It was certainly accurate enough to serve as a very good test of the trade test itself. It could not be expected, however, that the ratings would be perfectly objective. We should expect to find that a few men rated as high class journeymen might well belong, if rated perfectly accurately, to the expert class. Similarly, it might easily happen that a man was rated as an expert, where an omniscient rating would have placed him in the journeyman class. The same is true of all the divisions with the exception of the novice. What constitutes the novice in a trade is fairly objective.

Again, even if the men were correctly classified according to their trade standing, we should still expect to find overlapping in the achievement of the various levels. It might be expected that a young, ambitious journeyman of, say, two years full standing in his trade, who could by no chance be rated as an expert, might well outrank a tradesman who was classified as an expert largely because of extreme skill in one operation, or on account of ability as a foreman which, in the last analysis, was due rather to power over men than to high trade ability.

These two considerations would make us rather expect a small overlapping in the performances of the various groups. 
When imperfection exists in the rating of the tradesman, as apprentice, journeyman or expert, the more accurate the trade test, the more certain would be overlapping. What has been said, however, must not be taken to mean that we cannot measure the efficiency of a trade test by the extent to which it differentiates the tradesmen at the three known levels of ability. In the large majority of cases, it must show that the greater number of men are placed by their score in the trade test at a level corresponding to their estimated ability in the trade, but it is not to be expected that all men will be rated by their score in the test at their real trade level. An occasional exception to a general rule is bound to occur; the theory of statistics teaches us not to be daunted by such exceptions, and provides a method whereby the correct weight can be given to the exception. Each question in the test was allowed four points. On this basis, all that is necessary is to determine how many points indicate an expert, how many a journeyman, how many an apprentice, and how many a novice. Obviously the way to do this is to note how many points were scored by the men who were rated experts in the trade when they were tested; similarly the number of points scored by the journeyman, apprentice and novice so rated. The manner in which this information concerning the scores of each man was collected graphically is shown in the accompanying figure. The base line shows the scores on the test, varying from zero to eighty, eighty being the maximum on the basis of four points for each of the twenty questions. The apprentices, journeymen and experts are then arranged separately on four distribution curves, each black square representing one man's position in the test, or his score. According to the different vertical levels it is known to which class this individual belongs. A glance at this table shows that the experts as a group score higher than the journeymen, and the 
journeymen higher than the apprentices. As was to be expected, however, a few of the experts are as low as some of the journeymen. The extent of the overlapping is brought out very clearly by the graph. When a diagram such as the typical one above has been constructed for each test, the problem is to draw the dividing lines between the various classes, so that the overlapping shall be a minimum. The method of determining the position of these dividing lines is that of "trial and error." Imaginary lines are drawn at several places, and that line is

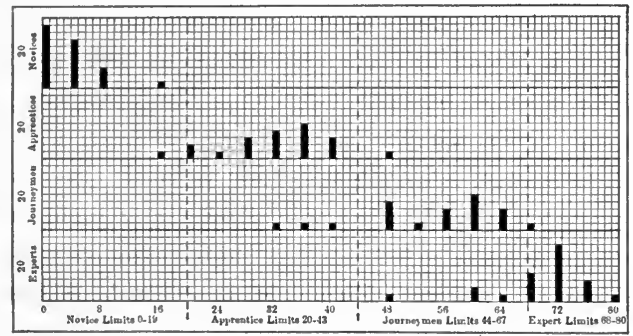

This chart shows the distribution according to individual total scores of the 8o subjects used in standardization. Each square represents one man. The limits shown are the ones finally used in army testing.

chosen which places the maximum number of men, according to their score in the test, in their correct known trade classification. Thus, for example, placing the dividing line between novice and apprentice at ig makes the critical score of the novice group such that it included every novice that is tested. Only one out of the twenty apprentices, under these conditions, fell within the limits of score of the novice group. Similarly placing the point of differentiation between the journeyman and apprentice class at 44 , rated one apprentice as a journeyman on 
the test, and three journeymen were rated as high apprentices. The differentiating line between journeyman and expert being placed at 68 correctly classified sixteen of the experts and only altered the journeyman rating of one of the tradesmen. When these "critical scores," as they are usually called, were established, the test was ready for final assembly and printing.

\section{Final Assembly of Test}

Other things being equal it is advisable to arrange the questions in the test in the order of their difficulty. This serves the double purpose of establishing, by starting with easy questions, the confidence of the person under examination, even though he may be an expert, while in the case of the apprentice, it prevents discouragement due to early contact with questions which are quite outside his range of information.

It has already been made clear that no alteration in the form of the question during this final assembly is permissible. Even the smallest verbal alteration can change the difficulty of a question sufficiently to make restandarization necessary. In a previous section it has been mentioned that even after the final testing has taken place, it is possible, providing the necessary remarking is done, to alter the answer, but when the critical scores have been established on the basis of these altered answers, no further changes are feasible. The matter becomes merely clerical, and any modification invalidates the accuracy of the test.

The following tests taken from various fields, including among others the building, electrical, foundry and machinist trades, are reproduced to illustrate the wide application of this method of examination:

Bricklayer. General.

Pipe Fitter. General (Low pressure). 
Pipe Fitter. Plumber (General).

Structural Steel Worker. Iron Worker, Erector.

Electrician. Generator and Switchboard Tender (D. C.).

Lineman and Cableman. Telegraph and Telephon

Foundryman. Cupola Tender.

Foundryman. Brass Melter.

Machinist and Mechanic. Automatic Screw Machine Operator.

Machinist and Mechanic. Die Sinker.

Blacksmith. Drop Forger.

Butcher.

Instrument Maker and Repairer. Typewriter (Remington).

Printer. Compositor.

Surveyor. General.

Tailor.

Telegrapher and Wireless Operator. Radio Operator.

Welder. Cutter. (Oxy-Acetylene Operator.) 


\section{TRADE TEST \\ BRICKLAYER. - General \\ ORAL}

COMMITTEE ON CLASSIFICATION OF PERSONNEL IN THE ARMY

Trade Test Division

Reproduced by permission of the Adjutant General

\section{QUESTION 1}

Q. What are headers used for in a brick wall?

A. To bind (bond) (tie).

Score 4

QUESTION 2

Q. What is half of a brick called?

A. Bat.

Score 4

\section{QUESTION 3}

Q. What is used in the middle of a long wall to keep the line level?

A. Twig (twigger) (twigging) (tingle).

Score 4

\section{QUESTION 4}

Q. In coming to a height if there is a course of brick difference in the level, what do you call it?

A. Hog.

Score 4

QUESTION 5

Q. What is a brick called when set on end?

A. Soldier.

Score 4

QUESTION 6

Q. What do you call a course of brick laid lengthwise of a wall?

A. Stretchers.

Score 4 


\section{QUESTION 7}

Q. What is a bond called when a header and stretcher are laid in the same course?

A. Flemish.

Score 4

QUESTION 8

Q. What do you call the top course of stone on a wall?

A. Coping.

Score 4

QUESTION 9

Q. What is a brick called when cut in half lengthwise?

A. Soap (King).

Score 4

QUESTION 10

Q. In setting a sill course how much pitch do you give it?

A. $\frac{1}{4}$ to $\frac{3}{4}$ inch.

Score 4

\section{QUESTION 11}

Q. How do you tie-in the front work of a building in plain bond work if you have no metal ties?
A. (I) Clip (clip course).
Score 4
(2) Blind (secret) header.
Score 4

\section{QUESTION 12}

Q. What is a brick called when set on the narrow edge?

A. Rowlock.

Score 4

\section{QUESTION 13}

Q. What do you call the bond when you have a course of headers first, then a course of stretchers, and then another course of headers?
A. (I) English.
(2) Dutch.

Score 4 Score 4

\section{QUESTION 14}

Q. What is the course called from which an arch starts?

A. (I) Spring (springer) (springing course).

(2) Skew-back.

Score 4 Score 4 


\section{QUESTION 15}

Q. How do you get your courses uniform?

A. (I) Story (gauge) rod.

(2) Story (coursing) pole.

\section{RATING THE CANDIDATE}

Score

Rating

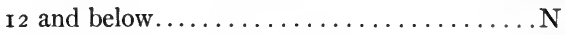

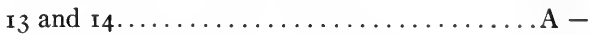

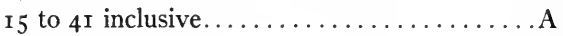

42 and $43 \ldots \ldots \ldots \ldots \ldots \ldots \ldots \ldots \ldots \ldots \ldots \ldots \ldots \ldots \ldots \ldots \ldots \ldots$

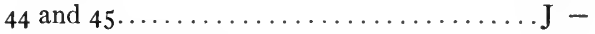

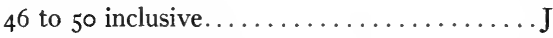

$5 \mathrm{I}$ and $52 \ldots \ldots \ldots \ldots \ldots \ldots \ldots \ldots \ldots \ldots \ldots \ldots \ldots \ldots \ldots \ldots$

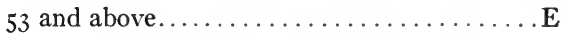

There is no $\mathrm{E}-$ or $\mathrm{E}+$ rating. 


\section{TRADE TEST}

PIPE FITTER. - General. Low Pressure Heating ORAL

\section{COMMITTEE ON CLASSIFICATION OF PERSONNEL IN THE ARMY}

Trade Test Division

Reproduced by permission of the Adjutant General

\section{QUESTION 1}

Q. How can a very short nipple be cut with a die?

A. (I) Use chuck (nipple-holder). $\quad$ Score 4

(2) Reverse the die. Score 4

\section{QUESTION 2}

Q. When ordering a reducing tee, what is the right way to give the size of outlets?

A. (I) a. Run first.

Score 4

b. Side (branch) (bull-head) last.

\section{QUESTION 3}

Q. Name all the sizes of wrought iron pipes up to and including six inches.

A. $\frac{1}{8}, \frac{1}{4}, \frac{3}{8}, \frac{1}{2}, \frac{3}{4}, I, 1 \frac{1}{4}, I \frac{1}{2}, 2,2 \frac{1}{2}, 3,3 \frac{1}{2}, 4,4 \frac{1}{2}, 5,6$. Score 4 Note: Take off one point for each one omitted or wrong.

\section{QUESTION 4}

Q. What is the standard push nipple or slip nipple used for?

A. (I) Radiators.

Score 4

(2) Boilers Score 4 


\section{QUESTION 5}

Q. What is the usual pressure in a low-pressure heating system?

A. (I) I to Io.

Score 4

(2) I to 20.

Score 2

\section{QUESTION 6}

Q. When exhaust steam is used for heating purposes, what takes the grease and oil out of the steam?

A. Extractor (separator).

Score 4

\section{QUESTION 7}

Q. Name two ways that water of condensation is returned to the boilers in large plants where high-pressure boilers are used.

A. Pumps

Traps.

Injectors.

Any two, Score 4

QUESTION 8

Q. How does a direct-indirect radiator differ from a direct radiator?

A. (I) a. Direct-indirect heats air from outside.

Score 4

b. Direct heats air in the room.

\section{QUESTION 9}

Q. What is the difference between dry returns and wet returns?

A. (I) a. Dry above water line.

Score 4

b. Wet below water line.

\section{QUESTION 10}

Q. What is the least allowable fall between the lowest point on a steam main and the water line of a boiler in a small heating system?

A. Io to 24 inches.

Score 4 


\section{QUESTION 11}

Q. Name two kinds of coils made from pipe.

A. Mitre.

Manifold (header).

Corner.

Return bends.

Any two, Score 4

\section{RATING THE CANDIDATE}

Score

Rating

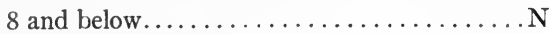

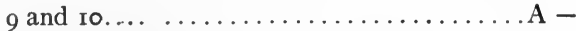

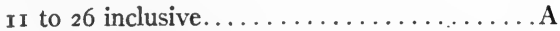

27 and $28 \ldots \ldots \ldots \ldots \ldots \ldots \ldots \ldots \ldots \ldots \ldots \ldots \ldots \ldots \ldots$

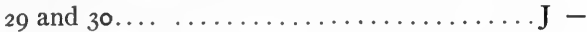

3 I to 39 inclusive................. J

40 and $4 \mathrm{I} \ldots \ldots \ldots \ldots \ldots \ldots \ldots \ldots \ldots \ldots \ldots \ldots \ldots \ldots \ldots$

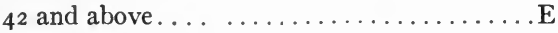

There is no $\mathrm{E}-$ or $\mathrm{E}+$ rating.

\section{SUPPLEMENTARY QUESTIONS}

These questions are inserted to provide the examiner with a means of guarding against the candidate's coaching for the examination. The Supplementary Questions should be used only when necessary. Not all of these questions should be asked any one tradesman.

\section{QUESTION A}

Q. What is the usual distance apart of pipe hangers?

A. (I) 8 to ro feet.

Score 4

(2) 5 to 12 feet.

Score 2

\section{QUESTION B}

Q. How is the contraction and expansion of long straight runs of pipe taken care of?

A. (I) Expansion (slip) joint.

Score 4

(2) Expansion bend (loop).

Score 4 


\section{QUESTION C}

Q. What fitting is used to make a short elbow connection?

A. Street (service) elbow ("ell"). Score 4

\section{QUESTION D}

Q. What is a feed water heater used for?

A. To heat water for the boiler.

Score 4 


\section{TRADE TEST}

\section{PIPE FITTER. - Plumber, General}

\section{ORAL}

\section{COMMITTEE ON CLASSIFICATION OF PERSONNEL IN THE ARMY \\ Trade Test Division}

Reproduced by permission of the Adjutant General

\section{QUESTION 1}

Q. What is used in making joints in cast-iron soil pipes?

A. Oakum and lead.

Score 4

\section{QUESTION 2}

Q. What do you use in bending lead pipe?
A. (I) Spring.
Score 4
(2) Sand.

\section{QUESTION 3}

Q. What are the proportions of metal in the two kinds of solder used by a plumber?

A. (I) a. About 2 parts of tin to 3 of lead (about 40-60). Score 4 b. Equal parts of tin and lead (half and half) (50-50).

\section{QUESTION 4}

Q. What are the two good types of water closet?
A. (I) a. Syphon jet.
b. Wash down (syphon) (flush).

\section{QUESTION 5}

Q. On what kinds of pipe do you get

a. hub or bell-and-spigot ends?

b. threaded ends?

A. (I) a. Cast iron (soil).

b. Wrought iron (brass) (steel). 


\section{QUESTION 6}

Q. What are air chambers used for?

A. (I) Prevent (stop) hammering (pounding). Score 4

(2) Prevent pipes getting air-bound. Score 4

\section{QUESTION 7}

Q. How should the connection be made between a galvanized wrought-iron pipe and a lead pipe?

A. (I) a. Brass nipple

Score 4

b. Wiped joínt.

\section{QUESTION 8}

Q. What pipe takes care of water closet discharge connection?

A. Soil stack (pipe).

Score 4

\section{QUESTION 9}

Q. Why is a four-inch soil pipe better than a larger one for an ordinary house?

A. Scours (cleans) (washes) better.

Score 4

\section{QUESTION 10}

Q. What is an expansion joint used for?

A. (I) Allow for expansion.

Score 4

(2) Allow for contraction. Score 4

\section{QUESTION 11}

Q. (1) a. What is the proper point at which to attach a back vent pipe to a vent stack?

b. Give reason.

A. (I) a. Above the fixtures (from crown of trap). $\quad$ Score 4

b. So vent cannot act as waste pipe.

\section{QUESTION 12}

Q. Why are compression faucets preferable to self-closing faucets or fuller faucets?

A. (I) Prevent water hammers (pounding).

Score 4

(2) Prevent breaking of pipe.

Score 4 


\section{RATING THE CANDIDATE}

Score

Rating

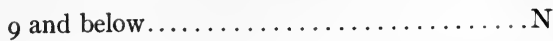

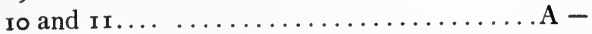

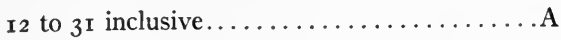

32 and $33 \ldots \ldots \ldots \ldots \ldots \ldots \ldots \ldots \ldots \ldots \ldots \ldots \ldots \ldots \ldots \ldots$

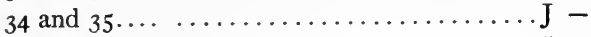

36 to 42 inclusive................... J

43 and $44 \ldots \ldots \ldots \ldots \ldots \ldots \ldots \ldots \ldots \ldots \ldots \ldots \ldots \ldots \ldots$

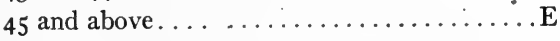

There is no $\mathrm{E}-$ or $\mathrm{E}+$ rating.

\section{SUPPLEMENTARY QUESTIONS}

These questions are inserted to provide the examiner with a means of guarding against the candidate's coaching for the examination. The Supplementary Questions should be used only when necessary. Not all of these questions should be asked any one tradesman.

\section{QUESTION A}

Q. What fall should be given to house drains under the cellar floor? A. $\frac{1}{4}$ inch to the foot. Score 4

\section{QUESTION B}

Q. What is used for soldering galvanized iron or steel?

A. Muriatic acid killed (cut) with zinc.

Score 4

\section{QUESTION C}

Q. How can the seal of a trap be protected against siphonage?

A. Venting (ventilation).

Score 4 


\section{TRADE TEST}

\section{STRUCTURAL STEEL WORKER. - \\ Iron Worker, Erector}

ORAL

COMMITTEE ON CLASSIFICATION OF PERSONNEL IN THE ARMY

Trade Test Division

Reproduced by permission of the Adjutant General

\section{QUESTION 1}

Q. What is a dolly bar used for?

A. Bucking up rivets.

\section{QUESTION 2}

Score 4

Q. Why is a snap used in a riveting hammer?

A. To form the head on the rivet.

Score 4

\section{QUESTION 3}

Q. What should be done if there are bad holes in steel?

A. Ream them.

Score 4

\section{QUESTION 4}

Q. What do you call putting lines through blocks?

A. Reaving.

\section{QUESTION 5}

Score 4

Q. Name two knots you can use to tie the ends of lines together to make a safe hitch.

A. Two bowlines.

A bowline and two half hitches.

Square (hard) (flat) knot.

Fisherman's bend. 


\section{QUESTION 6}

Q. Name two tools used for shearing off rivet heads on heavy work.

A. Buster.

Cutter.

B \& O Punch.

Chisel bar.

Any two, Score 4

\section{QUESTION 7}

Q. Name two tools used for bucking up rivets where you cannot get a straight tool in.

A. Offset bar.

Goose neck dolly.

Spring dolly.

Jam dolly.

Club dolly.

Heel dolly.

\section{QUESTION 8}

Any two, Score 4

Q. What standard stock should be used for driving three-quarterinch rivets into one inch to one and five-eighths inch metal?

A. One and three-eighths to one and seven-eighths inch. Score 4

\section{QUESTION 9}

Q. What is the usual way to reave up a set of triple blocks for a heavy load?

A. From the center.

Score 4

QUESTION 10

Q. What is the name of the single sheave block opening at the hook?

A. Snatch (gate) (foot) block.

Score 4

\section{QUESTION 11}

Q. What is the name of a boom which is attached to the side of a building, reaved from top of boom to building, and swung on a pivot?

A. Chicago. 


\section{RATING THE CANDIDATE}

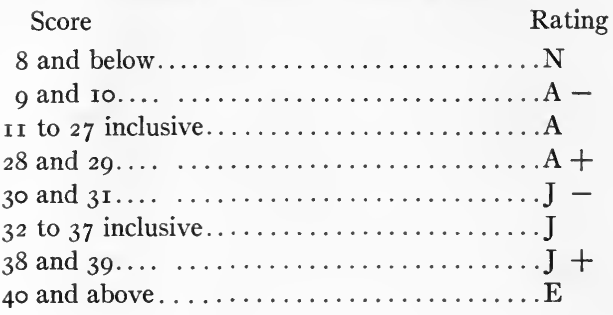

There is no $\mathrm{E}-$ or $\mathrm{E}+$ rating.

\section{SUPPLEMENTARY QUESTIONS}

These questions are inserted to provide the examiner with a means of guarding against the candidate's coaching for the examination. The Supplementary Questions should be used only when necessary. Not all of these questions should be asked any one tradesman.

\section{QUESTION A}

Q. What are drift pins used for?

A. (I) Fairing (pinning) (lining) holes.

(2) Making holes good.

Score 4 Score 4

\section{QUESTION B}

Q. What is a B \& O Punch used for?

A. Backing out.

Score 4

\section{QUESTION C}

Q. What is an "Old Man" used for?

A. Drilling holes.

Score 4

\section{QUESTION D}

Q. When you are reaving up a set of falls what kind of a knot do you end with to bring the blocks together?

A. (I) Becket.

Score 4

(2) Bowline.

Score 4

(3) Two half hitches.

Score 4 


\section{TRADE TEST}

ELECTRICIAN. - Generator and Switchboard Tender, Direct Current (D.C.)

ORAL

\section{COMMITTEE ON CLASSIFICATION OF PERSONNEL IN THE ARMY \\ Trade Test Division}

Reproduced by permission of the Adjutant General

\section{QUESTION 1}

Q. How are commutator coils fastened to commutator bars?

A. Soldered.

Score 4

\section{QUESTION 2}

Q. What do you use to seat a brush?

A. (I) Sandpaper.

Score 4

(2) Emery paper. Score o

\section{QUESTION 3}

Q. How are commutator bars insulated?

A. Mica

Score 4

\section{QUESTION 4}

Q. How is the oil supplied to the bearings of a motor from the well?

A. (I) Ring.

(2) Chain.

Score 4 Score 4

\section{QUESTION 5}

Q. What is used in place of a fuse to break the current in case of an over-load?
A. (I) Circuit breaker.
Score 4
(2) Automatic breaker. 


\section{QUESTION 6}

Q. What are the large copper bars called which are placed behind the switchboard?

A. Bus (bus-bar).

Score 4

\section{QUESTION 7}

Q. What are the three kinds of D.C. motors?

A. (I) a. Series.

b. Shunt.

c. Compound.

Score 4

\section{QUESTION 8}

Q. How should the air space be equalized if unequal?

A. (I) Re-babbit (true up bearings) (line up bearings).

Score 4

(2) Reset magnet frame (pole pieces).

Score 4

(3) Shim up pillar blocks. Score 4

\section{QUESTION 9}

Q. How do you find the neutral point of brushes in a motor when it is running?

A. By shifting rocker ring (holder) (yoke) until sparking at brushes is least.

Score 4

\section{QUESTION 10}

Q. What would you do to cut out a coil of a D.C. armature in an emergency?

A. (I) Use a jumper.

Score 4

(2) Bridge (short-circuit) commutator.

Score 4

(3) Bridge (short-circuit) coil. Score 4

\section{QUESTION 11}

Q. What is the usual purpose of a rotary converter?

A. (I) To change alternating current (A.C.) to direct current
(D.C.).

(2) To change direct current (D.C.) to alternating current
(A.C.). 


\section{QUESTION 12}

Q. What is used between two or more compound generators operating in parallel to take care of the difference in voltage?

A. Equalizer.

Score 4

\section{QUESTION 13}

Q. What kinds of field coils has a compound motor?

A. (I) a. Series.

Score 4

b. Shunt.

\section{QUESTION 14}

Q. What horsepower is generated by a $400 \mathrm{~K}$.W. generator?

A. (I) 400000 divided by (over) 746 .

Score 4

(2) About 535 .

(3) $1 \frac{1}{3}$ times the K.W. (kilowatts). Score 4 Score 4

\section{QUESTION 15}

Q. What do you call the magnetism which remains in the poles after the field current is shut off?

A. Residual.

Score 4

\section{QUESTION 16}

Q. How do you increase the magnetism of the poles in a shuntwound generator?

A. (I) Cut-out resistance (rheostat).

Score 4

(2) Increase field strength (current in field).

Score 4

\section{RATING THE CANDIDATE}

Score

Rating

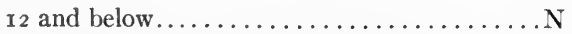

$\mathrm{r}_{3}$ and $\mathrm{r}_{4} \ldots \ldots \ldots \ldots \ldots \ldots \ldots \ldots \ldots \ldots \ldots \ldots \ldots \ldots$



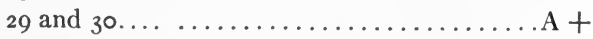

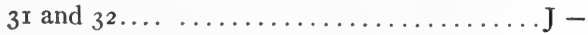

33 to 55 inclusive................. J

56 and $57 \ldots \ldots \ldots \ldots \ldots \ldots \ldots \ldots \ldots \ldots \ldots \ldots \ldots \ldots$

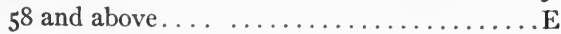

There is no $\mathrm{E}-$ or $\mathrm{E}+$ rating. 


\section{TRADE TEST}

\section{LINEMAN AND CABLEMAN. - Cableman,}

Telegraph and Telephone

\section{ORAL}

COMMITTEE ON CLASSIFICATION OF PERSONNEL

IN THE ARMY

Trade Test Division

Reproduced by permission of the Adjulast General

\section{QUESTION 1}

Q. What is put over a connection of two wires in a cable where they are spliced?

A. Sleeve (tube)

Score 4

\section{QUESTION 2}

Q. What is the ordinary insulation on the wires in a telephone or telegraph cable?

A. Paper.

\section{QUESTION 3}

Score 4

Q. What kind of a lead sleeve is used when it is impossible to slide the sleeve back on the cable?

A. Split.

Score 4

\section{QUESTION 4}

Q. What is the "V"-shaped tool called which is used for cleaning lead sleeves and cables?

A. Shave-hook.

Score 4

\section{QUESTION 5}

Q. If the metal is too fine how do you thicken it?

A. Lead (sleeve). 


\section{QUESTION 6}

Q. What is the joint called where two cables are spliced into one?
A. "Y" (multiple).
Score 4

\section{QUESTION 7}

Q. What distance should a lead sleeve overlap the end of a cable sheath when a splice is made?

A. $I \frac{1}{2}$ to 2 inches.

Score 4

\section{QUESTION 8}

Q. What is put around a sleeve and sheath so that the wipe joint will have an even end?

A. Paster (gum-paper) (sticker).

Score 4

\section{QUESTION 9}

Q. What is the largest gauge wire used in cables?

A. Io to I4.

Score 4

QUESTION 10

Q. From what two materials are insulation sleeves made?

A. (r) a. Paper.

b. Cloth (cotton).

Score 4

\section{QUESTION 11}

Q. What is done to a cloth before it is wrapped around a joint?

A. Boiled.

Score 4

QUESTION 12

Q. How much larger in diameter should the lead sleeve be than the cable in a straight splice?

A. $\frac{3}{4}$ of an inch to I inch.

Score 4

\section{QUESTION 13}

Q. What do you use to get the metal on an upright joint?

A. Stick (paddle).

Score 4

QUESTION 14

Q. What is a Megger used for?

A. Testing (measuring) insulation. 


\section{AN ORAL TRADE TEST}

\section{QUESTION 15}

Q. What flux is used for soldering cables?

A. (I) Stearic acid (styrene).

Score 4

(2) Sperm.

Score 4

(3) Tallow (candle).

\section{RATING THE CANDIDATE}

Score

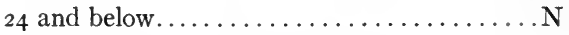

25 and $26 \ldots \ldots \ldots \ldots \ldots \ldots \ldots \ldots \ldots \ldots \ldots \ldots \ldots \ldots \ldots$

27 to 37 inclusive...................A

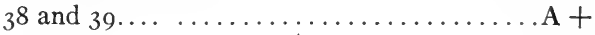

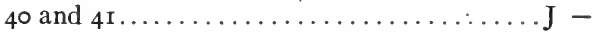

42 to 50 inclusive.....................

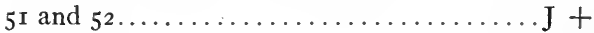

53 and above........................

There is no $\mathrm{E}-$ or $\mathrm{E}+$ rating. 


\section{TRADE TEST \\ FOUNDRYMAN. - Cupola Tender \\ ORAL}

COMMITTEE ON CLASSIFICATION OF PERSONNEL IN THE ARMY

Trade Test Division

Reproduced by permission of the Adjutant General

\section{QUESTION 1}

Q. What is the bottom lined with?

A. Sand.

Score 4

\section{QUESTION 2}

Q. What do you do to the material as soon as the bottom is dropped?

A. Wet (put water on).

Score 4

\section{QUESTION 3}

Q. What is done to the bottom when all the iron has been run out?

A. Drop (knock out).

Score 4

\section{QUESTION 4}

Q. What do you tap a cupola with?

A. Bar (rod).

Score 4

QUESTION 5

Q. How long is it before good iron comes down after the blast is turned on?

A. 15 to 35 minutes.

Score 4

QUESTION 6

Q. What holds up the bottom doors?

A. Bar (rod) (prop). 


\section{QUESTION 7}

Q. Why do you use lime-stone in melting?

A. (I) Make run (fluid) (clean iron).

Score 4

(2) Flux.

Score 4

\section{QUESTION 8}

Q. What tool do you use for chipping out a furnace in the morning?

A. Pick

Score 4

\section{QUESTION 9}

Q. What is usually used in kindling a furnace besides wood?

A. (I) Kerosene (coal-oil)

Score 4

(2) Gas.

Score 4

\section{QUESTION 10}

Q. What might happen if the cupola gases got in the blast pipe?

A. Explode (blow up).

Score 4

\section{QUESTION 11}

Q. How much higher should the bottom sand be at the back than at the front?

A. I to 3 inches.

Score 4

\section{QUESTION 12}

Q. What is the thickness of the lining of a cupola?

A. 6 to 9 inches.

Score 4

\section{QUESTION}

Q. How high above the tuyeres do you fill with coke?

(Pronounced tweers.)

A. I8 to 30 inches.

Score 4

\section{QUESTION 14}

Q. If the tapping hole in the breast is too long what will happen?

A. Freeze (chill) (harden).

Score 4 


\section{QUESTION 15}

Q. What are the tuyeres fastened to?

(Pronounced tweers).

A. (I) Brick.

Score 4

(2) Wind-box. Score 4

(3) Shell.

Score 4

\section{QUESTION 16}

Q. What are the ingredients in cast iron other than pure iron?

A. (I) a. Silicon.

Score 4

b. Carbon.

c. Sulphur.

d. Phosphorus.

e. Manganese.

Note: Take off one point for each one omitted or wrong. QUESTION 17

Q. What will happen if too much phosphorus is used?

A. (I) Hard-spots.

(2) Hard (brittle).

Score 4

Score 4

QUESTION 18

Q. Why is phosphorus added to the mixture?

A. Make fluid (run easier) (liquid).

Score 4

\section{RATING THE CANDIDATE}

Score

Rating

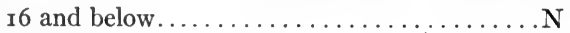

I 7 and $18 \ldots \ldots \ldots \ldots \ldots \ldots \ldots \ldots \ldots \ldots \ldots \ldots \ldots$

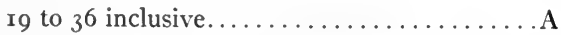

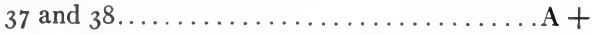

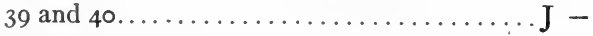

$4 \mathrm{I}$ to 56 inclusive................ J

57 and $58 \ldots \ldots \ldots \ldots \ldots \ldots \ldots \ldots \ldots \ldots \ldots \ldots \ldots \ldots \ldots \ldots .$.

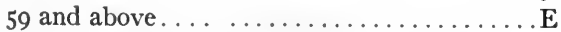

There is no $\mathrm{E}-$ or $\mathrm{E}+$ rating. 


\title{
TRADE TEST
}

FOUNDRYMAN. - Melter, Brass

\author{
ORAL \\ COMMITTEE ON CLASSIFICATION OF PERSONNEL \\ IN THE ARMY \\ Trade Test Division \\ Reproduced by permission of the Adjutant General.
}

\section{QUESTION 1}

Q. What will happen to a crucible if it gets wet before using?

A. Peel (chip) (break) (explode).

Score 4

\section{QUESTION 2}

Q. If bronze scrap is hard to break what do you do with it?

A. Heat.

Score 4

\section{QUESTION 3}

Q. What is the opening in the mold called where the metal is poured in?
A. (I) Sprue.
(2) Gate.

Score 4

Score 4

\section{QUESTION 4}

Q. Why is tin added to a brass mixture?

A. Harden (toughen).

Score 4

\section{QUESTION 5}

Q. What is put on top of the molten metal to keep it from oxidizing? A. Charcoal. Score 4

\section{QUESTION 6}

Q. What will happen if zinc is added when the copper is too hot? A. (I) Fuse (burn). Score 4

(2) Oxidize (volatilize). Score 4 


\section{QUESTION 7}

Q. What is done to the core to let out the gas when pouring?

A. Vented.

\section{QUESTION 8}

Score 4

Q. What is a crucible made of?

A. (I) a. Plumbago (graphite) (black lead). $\quad$ Score 4 b. Clay.

Note: Both required. No partial credits.

\section{QUESTION 9}

Q. What should be done to a new crucible before using?

A. Anneal.

\section{QUESTION 10}

Score 4

Q. In a bronze mixture of eighty-five and three fives what metals are used besides copper?

A. (I) a. Zinc (spelter).

b. Lead.

c. Tin.

Note: All required. No partial credits.

\section{QUESTION 11}

Q. What percentage of tin is used in a mixture for high speed bearings?

A. Io to $\mathbf{r} 6$.

Score 4

QUESTION 12

Score 4

Q. What is the percentage of tin used for standard government bronze?

A. Io.

Score 4

QUESTION 13

Q. What percentage of lead is usually used in a yellow brass mixture?

A. I to 3 .

Score 4

QUESTION 14

Q. How much metal does a No. 40 pot hold?

A. I 20 pounds.

Score 4 


\section{QUESTION 15}

Q. In what bronze mixture is there a small per cent of iron?

A. Manganese.

Score 4

\section{QUESTION 16}

Q. What are the three chief ingredients used in making German silver?

A. (I) a. Copper.

Score 4

b. Zinc.

c. Nickel.

RATING THE CANDIDATE

Score

Rating

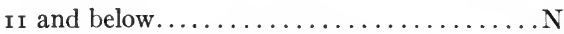

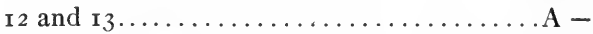

I4 to 22 inclusive....................

23 and $24 \ldots \ldots \ldots \ldots \ldots \ldots \ldots \ldots \ldots \ldots \ldots \ldots \ldots \ldots \ldots$

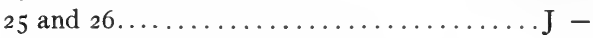

27 to 42 inclusive................... J

43 and $44 \ldots \ldots \ldots \ldots \ldots \ldots \ldots \ldots \ldots \ldots \ldots \ldots \ldots \ldots .$.

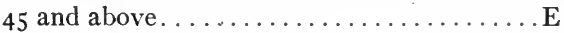

There is no $\mathrm{E}-$ or $\mathrm{E}+$ rating. 


\section{TRADE TEST}

\section{MACHINIST AND MECHANIC. - Automatic Screw Machine Operator}

\section{ORAL}

\section{COMMITTEE ON CLASSIFICATION OF PERSONNEL IN THE ARMY \\ Trade Test Division}

Reproduced by permission of the Adjutant General

\section{QUESTION 1}

Q. When cutting steel where you want a high finish what kind of oil is used?

A. Lard-oil.

Score 4

\section{QUESTION 2}

Q. On what kind of material do you use the highest spindle speed? A. Brass.

Score 4

\section{QUESTION 3}

Q. What are the two most common makes of automatic screw machines?

A. Brown \& Sharpe (B \& S).

Cleveland.

Gridley.

Acme.

Any two, Score 4

\section{QUESTION 4}

Q. How high should the parting tool be set in relation to the stock? A. Center.

\section{QUESTION 5}

Score 4

Q. What do you call the drill you use to start a hole with?

A. Spot (centering) (counter-sink). 


\section{QUESTION 6}

Q. What is apt to be the result if there is not enough spring tension in the chuck?

A. (I) Not release (open).

Score 4

(2) Slip (not feed).

Score 4

QUESTION 7

Q. How many spindles are there on Gridley machines?

A. (I) a. I.

Score 4 b. 4 .

\section{QUESTION 8}

Q. What kind of a die do you use when the work spindle does not reverse?

A. Self-opening (geometric) (automatic).

Score 4

\section{QUESTION 9}

Q. How much material should be left for grinding after hardening?

A. (I) .005 to .015 .

(2) $\frac{1}{64}$

Score 4

Score 4

\section{QUESTION 10}

Q. What kind of tool is used to cut internal grooves in the side of a hole?

A. Recessing (necking) (swing).

Score 4

\section{QUESTION 11}

Q. What is the first thing you would look for if the work came short?

A. (I) Loose feed-finger.

Score 4

(2) Loose chuck.

Score 4

\section{QUESTION 12}

Q. What kind of a tool should be used when the stock is so long that it will not stand a forming cut?

A. (I) Box.

Score 4

(2) Hollow-mill.

Score 4 


\section{QUESTION 13}

Q. How much material should be left for the finishing cut when the roughing cut has been made by a box tool or hollow-mill in steel?

A. .005 to .015 .

Score 4

\section{QUESTION 14}

Q. What make of automatic screw machine requires a special set of cams for each job?

A. Brown and Sharpe.

Score 4

QUESTION 15

Q. What shape of cam is used on a Brown and Sharpe?

A. Disk (circular).

Score 4

\section{QUESTION 16}

Q. If a sharp forming tool is set below center what will it do?

A. Chatter.

Score 4

\section{QUESTION 17}

Q. When a die or thread tool cannot be used what do you use to form a thread in the rear of a shoulder when working brass?

A. Thread-roll (roller-die).

Score 4

\section{QUESTION 18}

Q. What kind of a drill do you use for brass instead of a twist drill? A. Straight fluted (farmer) (flat) (gun).

\section{QUESTION 19}

Q. In making a one-eighth forty fillister head screw, what size in decimals should the body of the screw be before threading? A. .122 to .125 .

Score 4

\section{QUESTION 20}

Q. What would you use instead of a hollow-mill to turn a part of considerable length?

A. Box turner (tool) (mill). 


\section{SCORING THE CANDIDATE}

Score

Rating

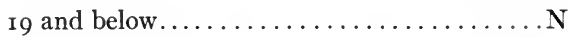

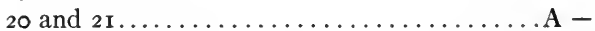

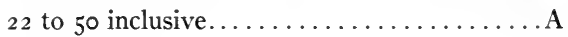

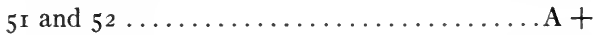

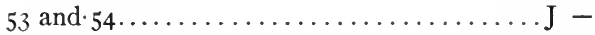

55 to 67 inclusive................... J

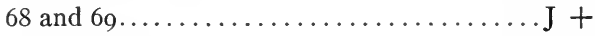

70 and above ..................... E

There is no $\mathrm{E}-$ or $\mathrm{E}+$ rating. 


\section{TRADE TEST}

\section{MACHINIST AND MECHANIC. - Die Sinker}

ORAL

COMMITTEE ON CLASSIFICATION OF PERSONNEL

IN THE ARMY

Trade Test Division

Reproduced by permission of the Adjutant General

\section{QUESTION 1}

Q. What will happen to the dies if they are overheated and cooled too quickly?

A. Crack (break).

\section{QUESTION 2}

Q. With what are die blanks colored for laying out work?

A. Copper sulphate (blue vitriol) (blue stone) (copperas). Score 4

\section{QUESTION 3}

Q. What can be done if a die is accidentally cut too deep?

A. Plane off (cut off).

Score 4

\section{QUESTION 4}

Q. What machine is used for sinking dies of irregular shape?

A. Milling (die sinking) (profiler).

Score 4

\section{QUESTION 5}

Q. What is the ordinary draft given?

A. 7 .

QUESTION 6

Q. Where is the edger located on a die?

A. Side. 


\section{QUESTION 7}

Q. What machine is used for cutting a straight groove between two deep holes?

A. Shaper. .

Score 4

\section{QUESTION 8}

Q. What is used on a type to see if it is bedded?

A. Blue.

Score 4

QUESTION 9

Q. What is the waste metal called that is formed around the forging? A. Flash.

\section{QUESTION 10}

Score 4

Q. What is the end of the forging called where it is joined to the stock?
A. (I) Gate.
(2) Sprue.

Score 4 Score 4

QUESTION 11

Q. What is a small curved file called?

A. Riffler.

Score 4

QUESTION 12

Q. How much per inch should the shrinkage allowance be between a drop forging and the die for trimming the forging cold?
A. (I) .012 to .200
Score 4
(2) $\frac{1}{64}$ to $\frac{3}{16}$.
Score 4

QUESTION 13

Q. What is the usual finish allowance on a drop forging?

A. $\frac{3}{32}$ to $\frac{1}{8}$ of an inch.

Score 4

\section{QUESTION 14}

Q. What is the impression in the die called which is used just before the finishing impression?

A. Blanking (blocking) (roughing).

Score 4

\section{QUESTION 15}

Q. How is the die laid out so that the finished forging will be the right size?

A. Shrinkage. 


\section{QUESTION 16}

Q. What form of a die is used for removing the flash?

A. Trimming.

\section{QUESTION 17}

Q. In making a forging with a large hump on one side why is the deepest impression in the top die?

A. (I) Forms up better than down (fills top easier).

(2) Keeps free from scale.

Score 4 Score 4

\section{QUESTION 18}

Q. How is a die cut so that the forging will not stick?

A. Draft.

Score 4

\section{QUESTION 19}

Q. What is used for packing die blocks when carbonizing?

A. (I) Bone-dust.

(2) Charred leather.

(3) Charcoal.

\section{QUESTION 20}

Score 4

Score 7

Score 4

Q. What carbon steel is used for trimming dies?

A. 60 to 90 .

\section{RATING THE CANDIDATE}

Score

Rating

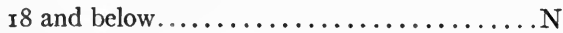

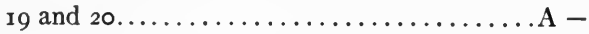

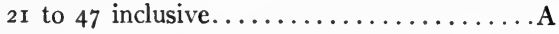

48 and $49 \ldots \ldots \ldots \ldots \ldots \ldots \ldots \ldots \ldots \ldots \ldots \ldots \ldots \ldots \ldots \ldots \ldots \ldots$

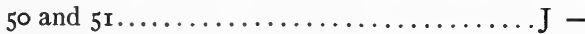

$5^{2}$ to 69 inclusive...................

70 and $71 \ldots \ldots \ldots \ldots \ldots \ldots \ldots \ldots \ldots \ldots \ldots \ldots \ldots \ldots \ldots$

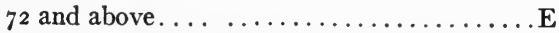

There is no $\mathrm{E}-$ or $\mathrm{E}+$ rating. 


\section{TRADE TEST}

\section{BLACKSMITH. - Forger, Drop}

ORAL

COMMITTEE ON CLASSIFICATION OF PERSONNEL

IN THE ARMY

Trade Test Division

Reproduced by permission of the Adjutant General

\section{QUESTION 1}

Q. What do you call the part of the machine that holds the upper die?

A. Head (ram).

Score 4

\section{QUESTION 2}

Q. What keeps the upper die from shifting back and forth?

A. Dowel.

Score 4

QUESTION 3

Q. What do you call the plate that holds the bottom die?

A. Shoe (sow).

Score 4

\section{QUESTION 4}

Q. What keeps the hammer from falling after it is up?

A. (I) Clamps.

Score 4

(2) Latches.

Score 4

QUESTION 5

Q. What would happen if you would quench chrome vanadium or nickle steel in water, at a high heat?
A. (I) Crack.
Score 4
(2) Break.
Score 4

\section{QUESTION 6}

Q. What is the waste metal called that is formed around the forging?

A. Flash (fin).

Score 4 


\section{QUESTION 7}

Q. What is the crack or seam called which is formed by a fold in the forging?

A. Cold-shut.

Score 4

QUESTION 8

Q. How is the board fastened to the head?

A. Wedges.

Score 4

\section{QUESTION 9}

Q. What is the purpose of pickling a forging?

A. (I) Remove scale.

Score 4

(2) Detect flaws (cracks). Score 4

\section{QUESTION 10}

Q. What raises the hammer?

A. (I) Board.

Score 4

(2) Rolls (spools).

\section{QUESTION 11}

Score 4

Q. What is the impression in the die called which is used just before the finishing impression?

A. Blanking (blocking) (roughing).

Score 4

\section{QUESTION 12}

Q. How is a die made so that the forging will not stick?

A. (I) Draft.

(2) Degrees.

Score 4 Score 4

\section{QUESTION 13}

Q. What kind of wood is the board made of?

A. Maple.

Score 4

\section{QUESTION 14}

Q. What is the end of the forging called where it is joined to the stock?

A. (I) Gate.

(2) Sprue.

Score 4

(3) Tong hold.

Score 4

Score 4 


\section{QUESTION 15}

Q. In making a forging with a large hump on one side why is the deepest impression in the top die?

A. (I) Forms up better than down (fills top easier). Score 4

(2) Keeps free from scale. Score 4

\section{QUESTION 16}

Q. How many times more than the weight of the hammer should the base weigh?

A. I 5 to 20 .

Score 4

RATING THE CANDIDATE

Score Rating

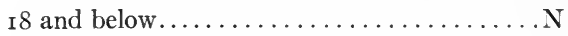

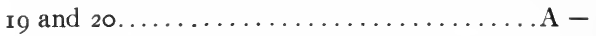

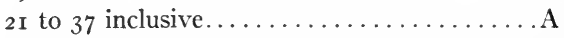

38 and $39 \ldots \ldots \ldots \ldots \ldots \ldots \ldots \ldots \ldots \ldots \ldots \ldots \ldots \ldots \ldots \ldots$

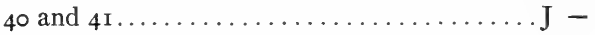

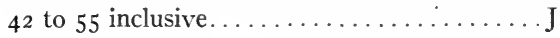

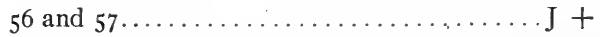

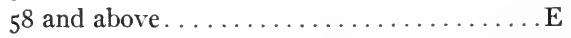

There is no $\mathrm{E}-$ or $\mathrm{E}+$ rating. 


\section{TRADE TEST \\ BUTCHER. - Butcher}

ORAL

COMMITTEE ON CLASSIFICATION OF PERSONNEL

IN THE ARMY

Trade Test Division

Reproduced by permission of the Adjutant General

\section{QUESTION 1}

Q. From what part are pork chops usually cut?

A. Loin.

Score 4

QUESTION 2

Q. How many ribs are cut to a rib of beef?

A. (I) 7 .

Score 4

(2) 8 .

Score 4

(3) 9 .

Score 4

\section{QUESTION 3}

Q. What are two knives which a butcher uses?

A. (I) a. Steak (cutting).

Score 4

b. Boning (trimming).

\section{QUESTION 4}

Q. From what part of the hog do you get picnic or California hams?

A. Shoulder.

Score 4

QUESTION 5

Q. What is located between the first rib and the hip?

A. Loin (porterhouse).

\section{QUESTION 6}

Score 4

Q. What is the average weight of sweet-breads?

A. $\frac{1}{2}$ to $I$ pound.

Score 4 


\section{QUESTION 7}

Q. From what is tripe made?

A. (I) Stomach (belly).

Score 4

(2) Paunch.

Score 4

QUESTION 8

Q. From what part of a hog is salt pork made?

A. Belly.

Score 4

\section{QUESTION 9}

Q. How many ribs are left on a chuck of beef?

A. (I) 4 .

(2) 5 .

Score 4

Score 4

QUESTION 10

Q. What is the average weight of a plate from a 500 pound dressed steer?

A. 20 to 40 .

Score 4

QUESTION 11

Q. About what should a hind quarter of a 500 pound dressed steer weigh?

A. IIO to I30.

Score 4

QUESTION 12

Q. What should a ham weigh from a 150 pound dressed hog, trimmed . to pickle?

A. Io to 15 .

Score 4

\section{QUESTION 13}

Q. What do you call the strip of fat along the back from which the loin has been pulled?

A. Back fat (fat back). Score 4

\section{QUESTION 14}

Q. What is the average weight of a steer liver?

A. 9 to $\mathrm{I} 2$.

Score 4

QUESTION 15

Q. What is the part of a beef between the front legs?

A. Brisket. 


\section{QUESTION 16}

Q. How old should a calf be before it is butchered?

A. 4 to 5 weeks.

\section{QUESTION 17}

Q. What do you call a calf under 7 days old?

A. Bob (slunk).

\section{QUESTION 18}

Score 4

Q. Where is the cross rib located?

A. Shoulder (fore-quarter).

Score 4

\section{RATING THE CANDIDATE}

Score

Rating

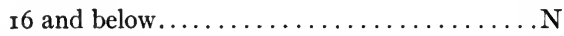

I 7 and $18 \ldots \ldots \ldots \ldots \ldots \ldots \ldots \ldots \ldots \ldots \ldots \ldots \ldots \ldots \ldots$

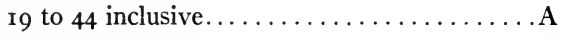

45 and $46 \ldots \ldots \ldots \ldots \ldots \ldots \ldots \ldots \ldots \ldots \ldots \ldots \ldots \ldots \ldots \ldots$

47 and $48 \ldots \ldots \ldots \ldots \ldots \ldots \ldots \ldots \ldots \ldots \ldots \ldots \ldots \ldots \ldots \ldots$

49 to 57 inclusive.................

58 and $59 \ldots \ldots \ldots \ldots \ldots \ldots \ldots \ldots \ldots \ldots \ldots \ldots \ldots \ldots \ldots \ldots$

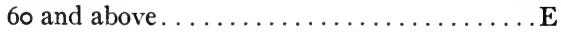

There is no $\mathrm{E}-$ or $\mathrm{E}+$ rating. 


\title{
TRADE TEST
}

\section{INSTRUMENT MAKER AND REPAIRER. -}

\section{Typewriter Repairer}

(Remington)

\section{ORAL}

COMMITTEE ON CLASSIFICATION OF PERSONNEL IN THE ARMY

\author{
Trade Test Division
}

Reproduced by permission of the Adjutant General

\section{QUESTION 1}

Q. How are the feed rolls cleaned?

A. Alcohol.

\section{QUESTION 2}

Score 4

Q. How many feed rolls are there on a Remington No. 10?

A. 6 .

Score 4

QUESTION 3

Q. How many column selector keys are there on a Remington No. 10? A. 5 .

\section{QUESTION 4}

Score 4

Q. What do you use to bend a type bar?

A. A nine-prongs.

Score 4

\section{QUESTION 5}

Q. What would be the result if the teeth on the rack would not mesh with pinion wheel?

A Skipping (jumping) (wrong spacing).

Score 4

\section{QUESTION 6}

Q. How are bell cranks fastened to the segment?

A. Screws. 


\section{QUESTION 7}

Q. How is type fastened to type bars on a Remington No. 10?

A. (I) Pressed in (forced in).

(2) Squeezed in.

Score 4 Score 4

\section{QUESTION 8}

Q. Name the different standard lengths of carriages on a Remington No. 10.

A. (I) a. A $\left(7 \frac{1}{2}\right)$ ( 76 pica).

Score 4

b. B $\left(9 \frac{1}{2}\right)$ (95 pica).

c. $C^{\prime}($ I2) (I 20 pica).

d. D (I6) (I6o pica).

\section{QUESTION 9}

Q. What are metal platens made of?

A. Brass.

Score 4

\section{QUESTION 10}

Q. What mechanism is inside of the governor cup?

A. (I) a. Fan (propeller) (paddle).

Score 4

b. Graphite.

c. Shot.

\section{QUESTION 11}

Q. What is shown by the small marks between letters on the face of the type?

A. Style (name) (size) (kind) of type.

Score 4

\section{QUESTION 12}

Q. How many teeth are there in a regular ratchet head on a Remington No. 10?

A. 29 .

Score 4

\section{QUESTION 13}

Q. What is pitch for pica type?

A. Io.

Score 4 


\section{QUESTION 14}

Q. What are the two kinds of dogs used on the escapement frame?

A. (I) a. Loose (active).

b. Rigid (stationary).

Score 4

\section{QUESTION 15}

Q. What style pitch is used on an elite type machine?
A. (I) I 2 .
(2) $12 \frac{1}{3}$.
Score 4
Score 4

\section{QUESTION 16}

Q. What separates the tabulator blades?

A. Comb.

\section{RATING THE CANDIDATE}

Score

Rating

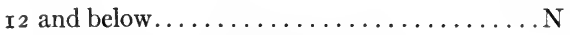

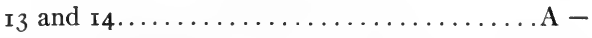

$x_{5}$ to 32 inclusive.....................

33 and $34 \ldots \ldots \ldots \ldots \ldots \ldots \ldots \ldots \ldots \ldots \ldots \ldots+$

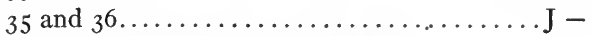

37 to 50 inclusive................... J

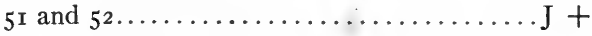

53 and above.................... E

There is no $\mathrm{E}-$ or $\mathrm{E}+$ rating. 


\section{TRADE TEST \\ PRINTER. - Compositor \\ ORAL}

COMMITTEE ON CLASSIFICATION OF PERSONNEL IN THE ARMY

Trade Test Division

Reproduced by permission of the Adjutant General

\section{QUESTION 1}

Q. What does the proof reader's w.f. indicate?

A. Wrong font.

Score 4

\section{QUESTION 2}

Q. What do you call a table on which the form is locked up?

A. Stone.

Score 4

\section{QUESTION 3}

Q. In what do you assemble the type from the cases?

A. Stick.

\section{QUESTION 4}

Q. How are types made so that they can be placed in the stick in the proper way?

A. Nicked.

Score 4

\section{QUESTION 5}

Q. What do you use to get the type perfectly level in the form?

A. Planer.

Score 4

\section{QUESTION 6}

Q. What is the page number called?

A. Folio. 


\section{QUESTION 7}

Q. What space is generally used between words?

A. 3-em.

Score 4

\section{QUESTION 8}

Q. What machine is used to make the rule corners join perfectly?

A. Mitering.

Score 4

\section{QUESTION 9}

Q. What word do you use in proof-reading to show that a portion of type matter marked " out" should be let stand?

A. Stet.

Score 4

\section{QUESTION 10}

Q. What do you call the large size letter that is used at the beginning of a job?

A. Initial.

Score 4

\section{QUESTION 11}

Q. What size type would you use on a 5 by 8 circular of 200 words?

A. (I) (ro-point).

Score 4

(2) (I 2-point).

Score 4

QUESTION 12

Q. What is the standard newspaper measure?

A. (I) $\mathrm{I}_{3}$ ems.

(2) $\mathrm{I} 2 \frac{1}{2} \mathrm{ems}$.

Score 4 Score 4

\section{QUESTION 13}

Q. What size em is used as a unit for measurements?

A. Pica (12-point) (I2).

Score 4

QUESTION 14

Q. What kind of spaces and quads are beveled on the back and front to clear the overhang of the letters?

A. Script.

Score 4

\section{QUESTION 15}

Q. What kind of quads and spaces are used for electrotype?

A. High.

Score 4 


\section{QUESTION 16}

Q. What folio would be placed beside page 2 in locking up a straight 16-page form?

A. 15 .

\section{QUESTION 17}

Score 4

Q. By what name are block letters known?

A. Gothic.

QUESTION 18

Q. What is the square of any body of type called?

A. Em.

\section{QUESTION 19}

Score 4

Score 4

Q. What do you call the half-tone where the background fades away gradually?

A. Vignette.

\section{QUESTION 20}

Score 4

Q. How many 8-point ems in a square inch?

A. $8 \mathrm{r}$.

Score 4

\section{RATING THE CANDIDATE}

Score

Rating

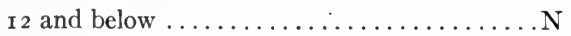

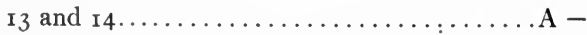

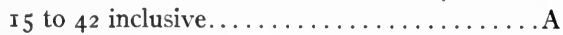

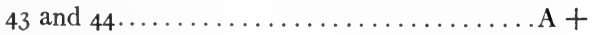

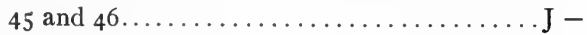

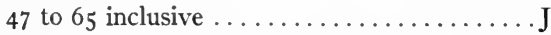

66 and $67 \ldots \ldots \ldots \ldots \ldots \ldots \ldots \ldots \ldots \ldots \ldots \ldots \ldots \ldots \ldots \ldots$

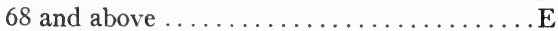

There is no $\mathrm{E}-$ or $\mathrm{E}+$ rating. 


\section{TRADE TEST \\ SURVEYOR. - General}

ORAL

COMMITTEE ON CLASSIFICATION OF PERSONNEL IN THE ARMY

Trade Test Division

Reproduced by permission of the Adjutant General

\section{QUESTION 1}

Q. What is used to find the proper position for holding a chain when it is held above a tack point?

A. Plumb-bob.

QUESTION 2

Score 4

Q. How long are the red and white sections into which a sighting pole is divided?

A. I foot.

Score 4

QUESTION 3

Q. What does a point marked P. T. signify on a railroad curve?

A. Point of tangency.

QUESTION 4

Score 4

Q. What would you do to get past a large tree on a transit line?

A. Off-set.

Score 4

\section{QUESTION 5}

Q. In running a line of levels, what are the permanent elevation points called which are established at various intervals?

A. Bench marks.

Score 4

\section{QUESTION 6}

Q. What method is used to measure the distance across a lake too wide to be chained?

A. Triangulation. 


\section{QUESTION 7}

Q. What is the point called that the levelman sets before changing the location of the instrument?

A. Turning point.

Score 4

QUESTION 8

Q. What is meant by a grade of 2 tenths of 1 per cent?

A. 2 tenths to roo feet.

Score 4

\section{QUESTION 9}

Q. How is the target of a level rod equipped so that readings of less than one hundredth can be made?

A. Vernier.

Score 4

\section{QUESTION 10}

Q. What kind of a curve is used to connect two points of different elevations?

A. Vertical.

Score 4

\section{QUESTION 11}

Q. What is the sight called which a levelman takes to get the H. I.?

A. Back (plus).

Score 4

QUESTION 12

Q. What do you use to turn the bubble adjustment screws on a level?

A. Pin.

Score 4

QUESTION 13

Q. What do you call the lines on topographical maps which connect points of the same elevation?

A. Contour.

Score 4

\section{QUESTION 14}

Q. What data do you have to take to tie-in a point which is not on the line?

A. (r) Distance and angle.

Score 4

(2) Two angles.

Score 4

(3) Two distances.

Score 4 


\section{QUESTION 15}

Q. At what points on a highway should elevation readings be taken to get an accurate profile?

A. Changes in grades (high and low points).

Score 4

\section{QUESTION 16}

Q. What reading has to be taken if a stadia shot is made from the bottom to the top of a hill?

A. Vertical.

Score 4

\section{QUESTION 17}

Q. What kind of a curve is used on railroads to lessen the diffculty of approach?

A. Spiral (transition) (easement).

Score 4

QUESTION 18

Q. What are two methods of finding a true meridian?

A. (I) a. Polaris (north star).

b. Solar (sun).

Score 4

\section{QUESTION 19}

Q. What is the angle called which a line forms with the meridian as measured East or West from a North or a South point?

A. Bearing (azimuth).

\section{QUESTION 20}

Score 4

Q. What would be the azimuth of a line calculated from the North meridian if the bearing of the line is South, 35 degrees West?

A. 215 .

Score 4

\section{RATING THE CANDIDATE}

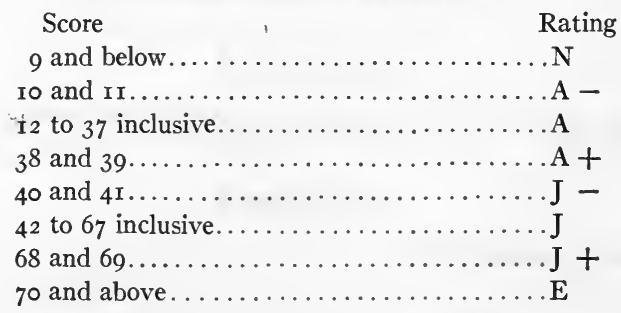

There is no $\mathrm{E}-$ or $\mathrm{E}+$ rating 


\section{TRADE TEST \\ TAILOR. - Tailor}

ORAL

COMMITTEE ON CLASSIFICATION OF PERSONNEL IN THE ARMY

Trade Test Division

Reproduced by permission of the Adjutant General

\section{QUESTION 1}

Q. What is used to hold the front of the coat firm so it can be shaped?

A. (I) Canvas.

(2) Haircloth.

Score 4

(3) Wigging. Score 4

Score 4

\section{QUESTION 2}

Q. What is used on the front edge of a coat to prevent it from stretching?

A. Edge-stay (stay tape) (tape).

Score 4

\section{QUESTION 3}

Q. How should the canvas be cut for the under collar?

A. Bias.

Score 4

\section{QUESTION 4}

Q. What size needles do you generally use for hand sewing?

A. 3 to 9 .

Score 4

QUESTION 5

Q. What is silesia used for?

A. Pockets.

Score 4 


\section{AN ORAL TRADE TEST}

\section{QUESTION 6}

Q. What six measurements must be taken for a pair of pants?

A. (I) a. Outside.

Score 4

b. Inseam.

c. Waist.

d. Hips (seat).

e. Knee.

f. Bottom.

Note: All required. No partial credits.

\section{QUESTION 7}

Q. How is a sleeve lining fastened at the top and bottom in a coat sleeve?

A. Felling.

Score 4

\section{QUESTION 8}

Q. How many yards of 56-inch cloth will it take to make a suit for a man with 38 chest and about 5 feet, 8 inches in height?

A. $3 \frac{1}{4}$ to $3 \frac{1}{2}$.

QUESTION 9

Score 4

Q. How much longer should the sleeve lining be at the top than at the bottom?

A. $\frac{1}{2}$ to $\frac{3}{4}$ of an inch.

Score 4

QUESTION 10

Q. What kind of thread is used to sew on buttons?

A. Linen.

Score 4

QUESTION 11

Q. Where is linen or holland used in a coat?

A. Pockets.

Score 4

\section{QUESTION 12}

Q. What is put on trouser seats to keep them from raveling?

A. Serging (overcast).

Score 4

\section{QUESTION 13}

Q. What is an edge used on overcoats called which is stitched flat without being turned in?

A. Raw.

Score 4 


\section{QUESTION 14}

Q. What is used to cover wadding?

A. Cheese cloth.

Score 4

\section{QUESTION 15}

Q. What kind of edges would you make on a Carrs Melton overcoat? A. Raw.

\section{QUESTION 16}

Score 4

Q. What do you call drawing two pieces of cloth together without a seam?

A. Stoting (stowing).

\section{QUESTION 17}

Score 4

Q. What garment is Kersey mostly used for?

A. Overcoat.

Score 4

\section{RATING THE CANDIDATE}

Score

Rating

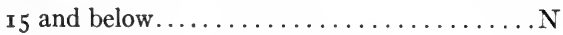

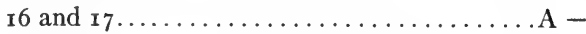

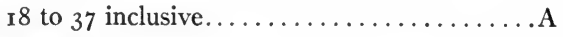

38 and $39 \ldots \ldots \ldots \ldots \ldots \ldots \ldots \ldots \ldots \ldots \ldots \ldots \ldots \ldots \ldots \ldots$

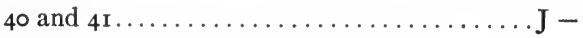

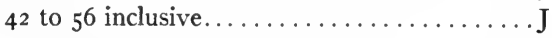

57 and $58 \ldots \ldots \ldots \ldots \ldots \ldots \ldots \ldots \ldots \ldots \ldots \ldots \ldots \ldots \ldots$

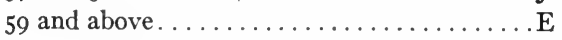

There is no $\mathrm{E}-$ or $\mathrm{E}+$ rating. 


\section{TRADE TEST}

TELEGRAPHER AND WIRELESS OPERATOR. Radio Operator

ORAL

COMMITTEE ON CLASSIFICATION OF PERSONNEL IN THE ARMY

Trade Test Division

Reproduced by permission of the Adjutant General

\section{QUESTION 1}

Q. What two codes are used?

A. (I) a. Morse (American Morse).

Score 4

b. Continental (international).

\section{QUESTION 2}

Q. What is the unit of resistance?

A. Ohm.

Score 4

\section{QUESTION 3}

Q. Name two types of A.C. transformer used in wireless work.

A. (I) a. Open.

b. Closed.

Score 4

\section{QUESTION 4}

Q. What are the two international normal wave lengths for commercial stations?

A. (I) a. 300.
b. 600.

Score 4

QUESTION 5

Q. Name three types of antenna in general use.

A. (I) a. T.

Score 4

b. Inverted L.

c. Umbrella. 


\section{QUESTION 6}

Q. What is used for storing electro-static energy?

A. Condenser.

\section{QUESTION 7}

Score 4

Q. How should a temporary repair be made if a step in the startingbox is burned out?

A. Jumper (short circuit) (bridge) (shunt).

Score 4

\section{QUESTION 8}

Q. How should connections or joints in an aerial be made?

A. Solder.

Score 4

QUESTION 9

Q. What are four common types of spark gap?

A. (I) a. Plain (straight) (fixed) (open) (ordinary).

Score 4

b. Synchronous (synchronous-rotary).

c. Non-synchronous (non-synchronous-rotary).

d. Quenched.

QUESTION 10

Q. What is usually used to clean motor commutators?

A. (I) Sandpaper.

Score 4

(2) Canvas.

Score 4

(3) Emery.

Score o

\section{QUESTION 11}

Q. What is the unit of inductance?

A. Henry.

Score 4

\section{QUESTION 12}

Q. What is included in the bulb of a three-element vacuum valve?

A. (I) a. Filament.

Score 4

b. Grid.

c. Plate (wing).

QUESTION 13

Q. What two things are liable to happen if you try to transmit with the spark gap open too wide?

A. (I) a. Puncture condenser.

Score 4

b. Break down (puncture) transformer (secondary). 


\section{QUESTION 14}

Q. What does the signal Q. R. M. mean?

A. Interference.

Score 4

\section{QUESTION 15}

Q. What is used to find the sharpness of the wave?

A. Wavemeter (decremeter).

Score 4

\section{QUESTION 16}

Q. Name four frequencies usually used in wireless generators. .

A. (I) a. 60 .

b. I20.

c. 240 .

d. 500 .

Score 4

QUESTION 17

Q. What is used for transferring the oscillations from the primary or closed circuit to the aerial or open circuit and to tune both circuits to resonance?

A. Oscillation transformer (helix) (jigger).

Score 4

\section{QUESTION 18}

Q. What are two ways to change D.C. to A.C.?

A. (I) a. Motor generator.

b. Rotary converter (dynamotor).

Score 4

\section{QUESTION 19}

Q. Where is the highest potential strain on the antenna?

A. Extreme (free) (upper) (outer) end.

Score 4

\section{QUESTION 20}

Q. What will happen if a motor is started too slowly?

A. (I) Resistance coils (rheostat) burn out.

Score 4

(2) Starting box burn out.

Score 4 


\section{TRADE TESTS}

\section{QUESTION 21}

Q. What is used to make a ground for a field set in very dry soil?

A. Counterpoise.

\section{RATING THE CANDIDATE}

Score Rating

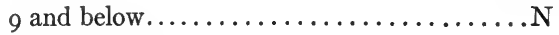

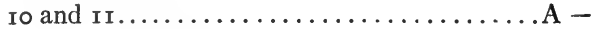

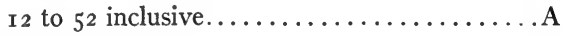

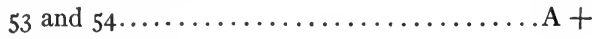

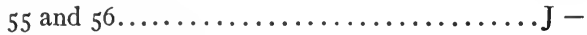

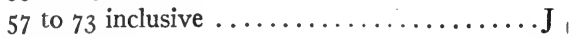

74 and $75 \ldots \ldots \ldots \ldots \ldots \ldots \ldots \ldots \ldots \ldots \ldots \ldots \ldots \ldots \ldots$

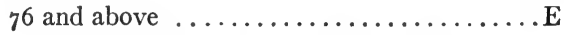

There is no $\mathrm{E}-$ or $\mathrm{E}+$ rating. 


\section{TRADE TEST}

WELDER, CUTTER. - Cutter, Oxy-Acetylene

Operator

ORAL

COMMITTEE ON CLASSIFICATION OF PERSONNEL IN THE ARMY

Trade Test Division

Reproduced by permission of the Adjutant General

\section{QUESTION 1}

Q. What is it called when the edges of metal sheets are welded together in different spots to hold them in place for welding?

A. Tack (spot).

Score 4

\section{QUESTION 2}

Q. What chemical is mixed with water to form acetylene gas?

A. Carbide.

Score 4

\section{QUESTION 3}

Q. What metal do you use to braze brass and cast iron together?

A. Brass (bronze).

Score 4

\section{QUESTION 4}

Q. What will happen if oil gets on the oxygen regulator or hose? A. (I) Explode (blow up).

Score 4

(2) Catch fire (burn up). Score 4

\section{QUESTION 5}

Q. How do you put the flux on the weld on light castings?

A. (I) Dip rod in flux.

Score 4

(2) Put it on rod.

Score 4 


\section{QUESTION 6}

Q. What is the best kind of rod to use when welding cast aluminum?

A. Aluminum.

Score 4

\section{QUESTION 7}

Q. What is done to a casting before welding to lessen the danger of warping when finished?

A. Preheat.

Score 4

\section{QUESTION 8}

Q. How should the edges of thick plates be prepared for welding?

A. (I) Bevel (chamfer) (45 degrees).

Score 4

(2) Vee (V).

Score 4

\section{QUESTION 9}

Q. How hot do you preheat large castings before starting to weld? A. Red.

Score 4

QUESTION 10

Q. How can you tell by looking at the hot metal that too much oxygen is being used in welding?

A. (I) Boil (foam) (spark) (burn).

Score 4

(2) White (shiny). Score 4

QUESTION 11

Q. What is the best kind of flux for brass?

A. Borax.

Score 4

\section{QUESTION 12}

Q. What simple flux can be used for cast iron?

A. (I) Borax.

Score 4

(2) Soda.

Score 4

(3) Salt.

Score 4

QUESTION 13

Q. What is the pressure of a large size oxygen tank?

A. I 500 to 2200 .

Score 4

\section{QUESTION 14}

Q. Why is a casting annealed after welding?

A. (I) Prevent getting hard.

Score 4

(2) Make (keep) soft. 


\section{QUESTION 15}

Q. What is the pressure of an acetylene tank when filled?

A. 200 to 300 .

\section{QUESTION 16}

Score 4

Q. What are the names of two common forms of joints used in welding plates?

A. Lap.

Butt (straight).

Flange.

\section{QUESTION 17}

Any two, Score 4

Q. What is used to line up crank shafts when welding?

A. V blocks.

\section{QUESTION 18}

Score 4

Q. What is put in the acetylene tank to prevent explosions?

A. Acetone.

Score 4

\section{RATING THE CANDIDATE}

Score

Rating

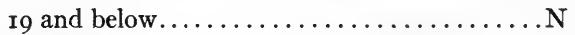

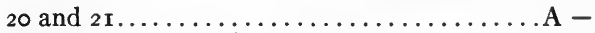

22 to 35 inclusive......................

36 and $37 \ldots \ldots \ldots \ldots \ldots \ldots \ldots \ldots \ldots \ldots \ldots \ldots+$ A +

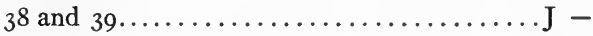

40 to 55 inclusive.................... J

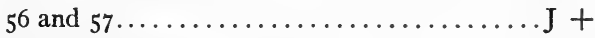

58 and above.......................

There is no $\mathrm{E}-$ or $\mathrm{E}+$ rating. 


\title{
ADMINISTRATION AND SCOPE OF THE ORAL TRADE TEST
}

\author{
Instructions for Giving Oral Trade Tests
}

THE following are the instructions, with slight modifications which were issued for the administration of the oral tests.

\section{INSTRUCTIONS FOR GIVING ORAL TRADE TESTS}

\section{COMMITTEE ON CLASSIFICATION OF PERSONNEL IN THE ARMY \\ Trade Test Division}

\section{GENERAL STATEMENT:}

In order that the Oral Trade Tests may be used effectively, it is necessary that examiners follow to the letter these "Instructions for Giving Oral Trade Tests." Although the tests have been carefully prepared, they will not give uniform results unless examiners use them uniformly. Consequently, no change must be made in the tests themselves, or in the manner of administering them, until official notice is given to that effect. In case a certain answer comes repeatedly to a given question, giving the examiner reason to believe it is a correct answer, even though it is not recorded, the examiner should bring the matter to the attention of the officer in charge at the earliest possible moment.

Even with the use of well-standardized tests under the most carefully controlled conditions the rating of men by this means is subject to error in some cases. This fact is mentioned to warn examiners 
against yielding to the temptation of permitting their judgment of what the candidate knows to influence his score. Provision is made on the test record card for noting any facts which the examiner feels should be made a part of the test record, such, for example, as that the candidate was in unfit physical condition at the time of the testing.

Preliminary to giving the test, the examiner will make a statement to the candidate which must cover and be limited to the following points:

I. Why the test is given.

2. The importance of thinking carefully before answering in order to do as well as possible.

3. The necessity of making the answers brief and to the point.

4. The fact that there are no "catch" questions.

The exact wording is not prescribed because of the obvious difficulty of making it suit all examiners under varying conditions. Note the following sample statement:

"We are going to give you a test to find out how much you know about your trade. Think carefully before you answer so as to do as well as you can. Make your answers brief and to the point. There are no catch questions in this test."

\section{GIVING THE TESTS :}

I. Ask each man all the questions (except the supplementary questions) in the order given.

2. Be very careful to make yourself heard distinctly.

3. Do not change the questions.

4. Do not prompt the candidate in any way.

5. Do not illustrate any terms with gestures. The tendency to illustrate such expressions as vertical, parallel, and the like, is to be particularly guarded against.

6. Give no indication whatever, by comment, facial expression or otherwise, of the quality of the candidate's answers.

7. Give special emphasis to underscored words: e.g., What are metal platens made of? What is the practical limit for vacuum? 
8. Guard against giving any clue to the answer through emphasis on any particular word unless it is underscored.

9. Numbering and lettering of answers:

(a) Each complete answer is numbered.

For example,

Q. What is attached to the ribbon which causes it to reverse?

A. (I) Eyelet.

(2) Stud.

Score 4

Score 4

In such a case either answer is a perfect-score answer and should be scored 4 .

(b) Each required part of an answer is lettered.

For example,

Q. What are the three most common styles of type?

A. (I) a. Pica.

Score 4

b. Elite.

c. Medium Roman.

In such a case all three parts of the answer are required for a perfect-score answer. Any one should be scored 2; any two should be scored 3 .

(c) When the question calls for a specific number of items and more than this number are listed under "A," numerals and letters are omitted and instructions for scoring are given below the last item to the right.

For example,

Q. Name two tools used for shearing off rivet heads on heavy work.

A. Buster.

Cutter.

Chisel bar.

Any two, Score 4

10. Use of answers given:

(a) One or more answers are given to each question as a guide to the examiner. It is not assumed, however, that candidates are always required to answer 
in these terms. In general only the key word is given.

(b) In some cases more than one perfect-score answer is given. These are acceptable answers whose quality cannot be readily inferred from the first answer.

For example,

Q. What lifts the ribbon when printing?

A. (I) Ribbon shield.

Score 4

(2) Oscillating (actuating) arm.

Score 4

(3) Vibrator.

Score 4

(c) In some cases a zero answer is given. Such an answer should be scored o without repetition or follow-up questions. It is in effect a guess answer. The candidate should not be permitted to guess again.

For example,

Q. What kind of a seam is used in heavy pipe?

A. (r) Rivet seam.

Score 4

(2) Lock seam.

Score o

(d) The general rules to be followed are:

(I) In case an answer cannot be scored on the basis of the answer given, repeat the question or use appropriate follow-up questions as indicated in Sections II and I 2 .

(2) In case of doubt as to whether an answer should be scored $\circ$ at once or followed up, always follow up.

II. Repetition of questions:

(a) A question should be repeated, except as noted below in paragraph (b), under such conditions as the following:

(I) When no answer is given, in order to make sure that the candidate heard clearly.

(2) When the candidate says, "I don't understand the question," or the equivalent. 
(3) Whenever the answer cannot be scored and repetition of the question seems the appropriate procedure.

(4) When the candidate is slow in answering.

(b) An answer which is unequivocally wrong should be scored o without repetition or follow-up questions. For example,

Q. When filing cast iron in a lathe, what happens to the cast iron if you run the lathe too fast?

A. (r) Case-hardens it.

Score 4

(2) Glazes it.

Score 4

If the candidate should answer "Softens it," he should be scored o. Repetition in such a case is practically equivalent to saying, "Wrong! Guess again."

12. Use of follow-up questions:

Whenever an answer cannot be scored on the basis of the answers given, the examiner should use one of the following questions according to the particular needs:

(a) Anything more?

(b) Any other name for it?

(c) Any other way of saying the same thing?

(d) Any other way of doing it?

13. An answer which includes the correct answer but with additional statements, is to be given full credit, except when any part plainly negates the correct answer.

For example,

Q. In what direction do the coils run in relation to the laminations on a drum wound armature?

A. (Required answer.) At right angles (across). (Candidate's answer.) At right angles or parallel.

"Parallel" plainly negates "at right angles." Therefore the answer should be scored $o$.

14. When the required answer contains a given number of items and the candidate exceeds this number, the examiner should say: 
"The question calls for (one), (two), (three), (four).

What is your answer?"

For example,

Q. What two metals are cam-shaft bearings made of?

A. (Required answer.) (I) a. Bronze.

b. Babbitt.

(Candidate's answer.) Bronze, babbitt, steel.

(Examiner.) The question calls for two. What is your answer?

15. When the question calls for a name and the candidate answers in terms of a description, the examiner should say:

"The question calls for a name, not a description.

What is your answer?"

I6. Whenever necessary the examiner may ask the candidate to repeat his answer.

I7. Do not permit the candidate to talk endlessly after he has made his answer. Give him the next question.

I8. Use of supplementary questions:

If the examiner has reason to believe that the candidate had knowledge of the questions previous to the testing, he should ask him selected questions from the list of supplementary questions. A candidate who has had trade experience should score at least one-third the possible number of points.

Since these supplementary questions are to be used only as a check, they should be asked only when necessary. No one candidate should be asked all of the supplementary questions. The score attained by the candidate on these questions should not affect his score on the test. Whenever they are used, a note to that effect, together with the score attained on these questions, should be made on the record card.

Note: Supplementary questions discontinued. The above statement, therefore, refers only to the early tests.

\section{SCORING :}

I. Score the answer to each question before giving the next question. 
2. Score a perfect answer

Score a half-perfect answer

Score a failure
4 .

2.

o.

If you cannot decide whether to score 4 or 2 , score 3 .

If you cannot decide whether to score 2 or $\mathrm{O}$, score $\mathrm{I}$.

3. (a) When a question consists of two parts, each part is to be allowed 2 points.

(b) When a question consists of three parts:

One part to be allowed 2 points.

Two parts to be allowed 3 points.

Three parts to be allowed 4 points.

(c) When a question consists of four parts, each part is to be allowed one point.

4. Partial credit scores are to be given only after repetition or follow-up questions fail to bring a perfect-score answer.

5. (a) Alternative terms are enclosed by parentheses.

Those terms in the answer of which the words in parentheses are alternatives, are underscored.

For example,

A. Add inductance (loading) coil.

(b) When all that precedes the parentheses is alternative with that in the parentheses it is not underscored.

For example,

A. Cut off air (choke it).

6. Unless the question specifically calls for a range of values, the candidate is not required to give a range even though the answer is in this form. Either extreme or any value within the limits is accepted.

For example,

Q. What is the usual distance apart of pipe hangers?

A. 8 to ro feet.

Score 4

If candidate answers 8 , or 9 , or ro feet, he is to be scored 4 .

7. In the case of two answers in terms of a range, the first answer represents the best limits, and the second answer the extreme limits.

(a) An answer which falls within the best limits is to be scored 4 . 
(b) An answer which falls outside the best limits but within the extreme limits is to be scored 2 .

(c) An answer which falls outside the extreme limits is to be scored 0 .

(d) When the candidate answers in terms of a range, score each end of the range separately and take the average for the score for the question.

For example,

Q. How much stock should be left in a $1 \frac{1}{4}$-inch hole for hardening and grinding?

A. (I) 5 to 8 thousandths of an inch.

(2) 3 to Io thousandths of an inch.

Score 4

Score 2

Sample answers:

(I) 5 to ro thousandths of an inch.

This should be scored " 3 " on the following basis. 5 - Score 4

Io - Score $2 \quad$ Average score - 3 .

(2) 3 to 12 thousandths of an inch.

This should be scored " $I$ " on the following basis. 3 - Score 2

I 2 - Score $0 \quad$ Average score - I.

8. In all cases score the candidate's answer on the basis of what he says, not on the basis of what you think he knows.

9. The candidate's Oral Test Score is obtained by adding the scores for the individual questions.

I0. The candidate will be rated according to instructions given at the end of each test.

I I. Divisions of trades.

In old well-established trades, trade divisions generally are as follows. Many of the newer trades do not have the divisions well defined.

$\mathrm{N}$ (Novice)

A man with no trade experience.

A (Apprentice)

A man who has had not more than four years' experience in the trade. 
J (Journeyman)

A man who has passed the apprentice stage.

E (Journeyman Expert)

A man who has had not less than five years' experience as a journeyman and who has shown a superior all-round knowledge of the trade, or such other qualifications as are required of a foreman.

It will be noted that under the general directions for scoring, partial credits were allowed. This was necessary, particularly in the earlier form of tests, before the questions were reduced to the single-answer type. There is no doubt that the giving of partial credits is a mistake, for it introduces a subjective element in the scoring which is very undesirable. It was the experience with this type of marking that led to the stricter adherence to the one-word answer method. With the more extensive use of the single-word answer, the giving of partial credits became unnecessary. If the candidate in his answer used the cue word, full credit (4) was given; if he failed to use this word, he was marked zero. In the future work all questions which do not admit of being marked in this way should be eliminated in the process of standardization.

The necessity for the accurate following of these instructions may not be quite clear to those who are unfamiliar with the process whereby the standards of achievements for the three levels of trade ability were established. During this process the directions just given were followed to the letter, and on the basis of this procedure the ratings were determined. If any departure is made from this routine, the standards, carefully established by a laborious scientific process, have no meaning and cannot be used for rating purposes. 


\section{The Attitude of the Tradesman to the Test}

A few words may not be out of place with reference to the attitude of the tradesmen to whom the tests were given. It is a common impression that the average workman resents anything that savors of an examination. The idea was so dominant at the beginning of the trade test experiment that it was seriously debated as to whether it would not be necessary to pay the men who served as the examinees. It was known that the employer would be willing to sacrifice the time of his men, but it was thought necessary to make payment to overcome the opposition of the men themselves. In actual practice the diffculty was not to persuade men to take the tests, but to get away from the plant without examining more men than the nature of the experiment demanded. On many occasions the author, after filling the quota for a particular examination, on the earnest entreaty of the men who had not been tested, proceeded to give them the test, though the records were discarded on leaving the plant. The men who were not tested felt themselves discriminated against. Only in one case out of several thousand was there the slightest objection raised by a tradesman to the procedure; in this case, further inquiry led to the fact that this particular workman was a thorough crank. The common attitude of the employer was also favorable and may be represented by one superintendent who once said on our leaving: "I wish you men would come once a month just to show my boys that they don't know it all."

Whether a similar attitude of mind will be found when these tests are used in the employment offices of the country depends almost wholly on the skill of those who are giving the tests. One thing is certainly true: the trade test, because of its close relation to the man's occupation, will not have to meet the opposi- 
tion which is often found when psychological or skill prediction tests are employed. When a man has claimed trade knowledge, he usually expects, under present conditions, to be given some form of test. The trade test itself is only a more scientific refinement of present trade interview methods. It can be administered in as informal a manner as the other part of the employment interview.

\section{An Alternative Method of Constructing Oral Trade Tests}

The method of calibrating which results in certain ranges of scores determining the various trade levels of ability is perhaps the simplest device for rating. It has, however, certain grave disadvantages. One of these arises from the fact that an inverted statistical process has been used. The standards of achievement were determined by assuming certain trade levels and then determining the ranges of scores which gave the least overlapping. That is, the passage is from known trade level to score; to reverse the process and pass from score to trade level is fallacious. For example-suppose in a particular set of twenty questions the following standards obtained:

$$
\begin{aligned}
& \text { N I-I9, } \\
& \text { A } 20-44, \\
& \text { J } 45-63, \\
& \text { E } 64-80 .
\end{aligned}
$$

The score $45^{-6} 63$ does not mean that all journeymen scored between 45 and 63 and no apprentice or expert fell in this range. It merely means that the range $45^{-6}$ gave the minimum of overlapping. As a matter of fact, it may be true that two of the experts and three of the apprentices fell in this class. A score, therefore, of between 45 and 63 does not indicate necessarily a journeyman ability, but merely a high probability of 
journeyman ranking, a lower probability of expert ranking and a still lower probability of apprentice ranking. It is always a matter of probability. Any range of score does not mean a single level of trade ability but a range of ability.

The other disadvantage of the ratings being based on totals in all questions is found in the fact that the unsuitability of a single question, and the impossibility of its use, throw out the whole scheme of rating. On account of these two disadvantages another possible method of constructing the test in which these two difficulties are obviated may be mentioned.

Suppose we consider three questions of ascending order of difficulty; these questions when administered to twenty novices, twenty apprentices, twenty journeymen and twenty experts give the following results.

Question

$\begin{array}{lrrrr} & \text { N } & \text { A } & \text { J } & \text { E } \\ \text { A } & \text { I } & \text { I } ~ & \text { I9 } & 20 \\ \text { B } & 0 & 2 & \text { I8 } & 20 \\ \text { C } & 0 & 0 & 3 & \text { I5 }\end{array}$

The table indicates that question A was answered correctly by one out of the twenty novices, seventeen out of the twenty apprentices, etc.

From the manner in which question $\mathrm{A}$ is answered it will be apparent that this question is indicative of apprenticeship ability, and it does not serve to differentiate the apprentice from the journeyman ${ }^{-}$or expert. It does, however, separate the novice from the apprentice. The question may, therefore, be taken as typical of the level of ability of the apprentice. That is, a correct answer to the question gives every assurance that the applicant has at least apprenticeship standing.

Similarly question B is characteristic of journeyman standing and question $\mathrm{C}$ indicative of expert standing. 
In this way a group of characteristic apprentice questions could be collected, the answering of each one of the questions giving a high degree of probability that the examinee had at least apprentice standing. The answer of a combination of questions within the group, would give an almost certain verdict as to whether ability characteristic of the apprentice was present. Similarly groups of questions could be assembled for the journeyman and expert levels respectively.

It is of course possible to work out for each question the probability that a correct answer indicates a given level of ability, but this refinement would hardly be necessary for ordinary work.

With such a method of construction, the final form of the test would consist of a large number of questions, each question falling into one of three levels characteristic of the ability of the apprentice, journeyman and expert, respectively. The answering of a certain number of questions within a group would constitute the passing of that stage. The method would be essentially similar to that employed in the well-known Binet Simon Intelligence Test. Here there are groups of questions for each age level; in the trade test, these would be replaced by groups of questions for each trade level.

Analysis of questions also reveals the interesting fact that, while a correct answer may be very significant as an index of class, a failure to answer is of little value for diagnosis, but this phase of the problem must be left.

The advantages of groups of questions characteristic of the three levels are obvious. In the first place, only one or two or three questions within the group need be used to secure an almost certain rating. In the second place there is no need to ask an expert a series of questions which are so simple that the ordinary apprentice can answer them. When examining a 


\section{ADMINISTRATION AND SCOPE}

tradesman who is considered to be an expert, the examination can commence with expert questions, and perhaps three or four questions will settle the case. In the third place if a question proves unsuitable it can be eliminated without throwing out the basis of scoring.

\section{Scope of Oral Trade Test}

At the time when the oral trade test method was first employed it was thought that its general justification lay in the fact that oral tests were of low cost, and that they could be applied to a large number of men in a comparatively short time with the minimum of equipment. It was not anticipated that they would, in many cases, more than distinguish between the presence or absence of trade ability. Certainly at the commencement of the work not even the most optimistic would have ventured to predict the accuracy with which they determined different degrees of ability. Although considered at the first a rough, quick method of measurement, the oral test proved itself, under the gruelling of camp conditions, to be the most accurate method which was used. On the whole it worked with most trades far more satisfactorily than the performance or picture test. However skeptical the reader may be of the idea that a workman's degree of skill can be determined by examinations of this kind, the fact remains that under the most practical of all tests they more than vindicated the reliance which was placed in them.

The oral trade test can be applied to a wide range of occupations. Never was an attempt made to construct a trade test in any occupation which did not finally result in a set of questions which more or less fulfilled the necessary requirements. It is true that in certain trades the differentiation between the four classes, novice, apprentice, journeyman and expert, was much 
less exact than in others, but in no case was there a failure to get sufficient differentiation to justify the use of the method.

The question as to whether this method can rightly be applied to a trade is found in the answer to the question as to the ratio between skill and information, in the particular trade ability. If the trade demands next to no information, and it is almost wholly a matter of dexterity, then the oral test is not suitable. Such trades as typist, truck driver, clerical worker, serve as examples of occupations which are clearly more adapted to the application of the performance test. The distinction between the mediocre and the expert truck driver is not to be found, as can be readily seen, in the greater amount of information possessed by the expert, but rather in the amount of skill with which he can use the little information which is required for handling the truck. At the other extreme we get occupations such as surveyor, power house man, where the whole emphasis is on information, and skill in the carrying out of the processes follows almost automatically from the possession of the necessary information. In these occupations the oral trade test shows to the maximum advantage.

It is interesting to record, however, that trades, which at first sight appear to be almost wholly a matter of skill, can be treated by the question-answer method. The trade upon which the author commenced work with the greatest trepidation, namely, general cook, furnished after more than usual care, a set of questions which differentiated with a fair degree of accuracy between different degrees of cooking ability and knowledge, as found in workers in restaurants, residences and family hotels. This test, in part, is here reproduced, not by any means because it is one of the best, but because it shows the successful application of the oral trade test method to a field where success would hardly have been predicted. The extensive range of 
trades, for which oral tests were successfully constructed, is the best indication of their wide applicability.

For the general guidance of those who may wish to decide whether a particular trade lends itself to being tested by the oral method, the following rule may be laid down. If the trade requires for its successful pursuit any considerable body of information the oral method may be applied. Where, however, the successful pursuit of the trade is dependent on the smallest amount of information and largely dependent on skill or dexterity, use the oral test method with the greatest caution. It is almost certain that a performance test of some kind will here be the only accurate method of measuring trade ability.

\section{Cooks Test (Selected questions)}

I. What is added to milk to keep it from curdling when making creamed tomato soup?

Soda.

2. What do you put on fried sweet potatoes to make them brown? Sugar.

3. What kind of bones are used to flavor bean soup?

Ham.

4. What is put in buckwheat cakes to make them rise when the cakes are mixed with sweet milk?

Baking powder.

5. What vegetables are used in succotash?

Beans and corn.

6. What is the color of the powder used in making lamb curry? Brown (yellow).

7. What do you put in soup stock to make it clear? Egg (egg-shell).

8. What kind of meat is used in Irish Stew? Lamb (mutton).

9. How long do you boil American macaroni? Anywhere from 15 to 30 minutes.

Io. From what part of the beef is porterhouse steak cut? Loin (sirloin) (T-bone). 

SECTION III

THE PICTURE TRADE TEST 


\section{CHAPTER V}

\section{THE PICTURE TRADE TEST METHOD}

\section{The Picture Test Method}

The picture test method resembles so closely that used in the purely oral test that it will be unnecessary to discuss the picture tests at length. The stages passed through in its construction are essentially similar to those which have just been described for the oral tests. The account which is here given will limit itself, therefore, to the consideration of the following topics:

(I) Reasons for the use of pictures.

(II) General description of the construction of the picture test.

(III) Presentation of several typical picture tests.

(IV) Criticism of this method of examination.

Reason for the Use of the Picture Method

Undoubtedly the major reason for the introduction of the form of test in which actual pictures of tools, machines and processes were employed was the attempt to get nearer to the conditions under which the trade is performed. The fact is accepted that the best prediction of ability in any activity is given by that test which in its essential structure most closely resembles the given activity. It is apparent, for example, that the most perfect test for a storage battery man would be that in which the individual under examination was given a number of actual jobs to do which were typical of the trade. This would 
amount to a number of performance tests. In the absence of such a complete reproduction of the conditions of normal work, the next most perfect substitute is that in which the test operations so closely resemble the trade operations that success in the former would be a sure indication of ability in the latter. While admitting that the performance method, given the necessary material and ample time, is ideal, the question arises whether, in the absence of all material and w th a short period of examination, it is not possible to use a form of examination which approximates more closely to the performance test than does the purely oral examination. In the type of test which has been described in the previous chapters, the question was merely stated in words. This involved on the part of the tradesman under examination a translation of these words into a mental picture or a mentally reconstructed situation. An illustration will make this clear. In the wagoner-blacksmith oral test the following question was asked: "With what are the springs fastened to each other at the ends?" In order to answer this question the ordinary workman must first get in his mind a clear picture of the operation; in by far the majority of cases he will see, as we say, "in his mind's eye" a picture of the springs. Without this process of reproduction a correct answer will be impossible, unless the question is so familiar and has been so often answered that no definite picture is necessary. It may be true that in very simple operations there is merely a verbal process, but in by far the larger number of simple operations and in practically all complex processes some kind of mental picture is essential. Contrast now the purely oral question with one in which a picture is shown of the springs fastened to each other at the ends by the shackles with an arrow pointing to the shackles. In this case the question would be, "What do you call the pieces, marked with an arrow, which fasten the springs together at the 
ends?" To answer this question there is no need for a mental picture, as this term is ordinarily used. The second type of question, it is claimed, is a much nearer approach to an actual shop situation where a workman, pointing to the shackles, might well ask for their name.

Where pictures of tools, machines and operations are present, the general impression produced on the tradesman is that the examination is much less abstract; although he is not actually handling the tools or running the machine, he feels much more at home and is more liable to have confidence in himself as well as trust in the examination. It has been already mentioned that one of the difficulties that was anticipated in the use of the oral test method was the presence of so-called "motormindedness" in many tradesmen. That is, there were thought to be tradesmen who would do the job, but were completely unable to answer questions. The results of the oral tests tried out on hundreds of thousands of men have shown that such individuals virtually do not exist or if they do, they form such a small percentage of the total trade population that they need not be given consideration. This, however, does not prevent a large number of employers and workmen from still holding and being influenced by this popular notion. To such employers and tradesmen the picture test method will commend itself. Where they feel that injustice has been done by the oral method, the application of the picture method will serve as a further check. Every examination for its successful functioning demands the whole-hearted coöperation of the examinee. Any element which can be introduced into the test which will establish confidence, both in the man himself and in the method, has great value. One of the difficulties which have to be faced in any plant when introducing any form of intelligence or trade tests centers around this point. Nothing is more essential than 
that at the end of any interview or test the workman leaves with a feeling that he has had the maximum chance to show his ability. The problem of not only giving a square deal to each employee but also of convincing him that he has had a square deal is one upon which it is impossible to lay too much emphasis. A method of selection may be as perfect as possible, but if it arouses antagonism on the part of those who are subjected to it, it is a most dangerous instrument, and will, in the long run, if education does not lessen the antagonism, do much more harm than good. Quite apart from its power of differentiating between different trade abilities, on this score the picture test possesses distinct advantages as compared with the purely oral method.

\section{Picture Tests Admit of More Detailed Questions}

Where a picture is presented, showing at a glance the various parts of the machine or the elements of the process, there is no limit to the detail of the questions which may be asked. Many problems which could not be stated in words, or at best would require a complicated description to be understood, can be asked in the simplest manner when reference can be made to a picture. One of the objections at first made to the oral test question of the single-answer type, was that it would have to be of such a simple order that there would be no possibility of using it to distinguish between the three levels of trade ability. While we know by experiment that this is not the case, there is no doubt in the mind of the writer that the picture method, when used to its limit, would give a much more satisfactory differentiation between experts and journeymen than that which could be expected of the purely oral method.

In addition, there was at its conception another justification for the picture method. It seemed that the assistance fur- 
nished by the pictures might enable a foreigner with language difficulty to be tested when the oral questions without pictures would fail to be understood. It was not anticipated that this kind of test could be used on a tradesman with no knowledge of English, because, even with pictures, the questions are in English. But there was hope that the simpler form of questions which can be used with the pictures would enable a great number of men with only slight language difficulty to do themselves reasonable justice in the absence of a performance test. This expectation, however, was not realized in practice, for reasons which will be stated when we consider at greater length the relative disadvantages of this method of examination.

The method of construction of the pcture or photographic test and the various stages through which it passed before completion are so similar to those used in the building up of the purely oral test, that only a few of the more outstanding points of difference need be mentioned. The only essential point of divergence in the two methods is to be found in the aid given to the subject by the use of photographs and pictures. The same type of answer, preferably the one-word answer, was adhered to; the questions employed were altered both in their form and content to make them suitable for investigating the subject's knowledge of the trade process to which the pictures were related. The picture material was obtained from many sources, of which the following were the most important:

I. Text books and manuals of the trade.

2. Trade journals.

3. Actual photographs, specially prepared.

4. Diagrams and sketches, specially made.

5. Trade catalogues.

The above will furnish an almost unlimited supply of pictures. More often these pictures will be of the tools and ma- 
chines, and less often of the actual process of the trade. Where pictures of processes are required, resort usually has to be had either to more elaborate treatises on the trade, or else to photographs, specially taken.

\section{Method of Construction}

Given this bulk of the material, the essential point was to construct questions with reference to those pictures which had distinct significance in the trade. As may be readily seen, a great many trades use common tools and common processes, of which the simplest illustrations are the hammer, the wrench and the lathe. Obviously, it was necessary, as in the case of the oral question, to choose pictures of those tools, machines and processes which applied specifically to the one trade and to that trade alone. Thus, for example, to present a picture of a micrometer and to ask simply, "What is that?" is putting a question which would apply not to a single trade, but to practically every trade of the machinists' group. The questions that were constructed had to conform to these three material requirements:

I. They must differentiate between the three trade levels of apprentice, journeyman, and expert.

2. They must yield a single answer, preferably one word.

3. They must apply specifically to the trade in question, and that trade alone.

Again, consultation with expert tradesmen in the occupation was the source of information for the construction of questions conforming to the above requirements. While text books. manuals and catalogues give a very good indication as to common tools and practices, it was necessary in every case to verify most carefully any information obtained in this way. Repeatedly it was found that tools and processes described in even the best manuals did not conform to practice in the shops. 
When the tradesmen were questioned with regard to the suitability of a particular question or picture, they would often reply: "Well, I suppose that it could be done that way. In fact, that would be the best way, but we do it in another way, using other tools and other machines." It was only by visiting numerous plants that it was possible to be sure that the question was universally suitable. Again, one of the great difficulties that were met was the differences in machines, turned out by the various makers for accomplishing the same purpose. Although the basic principles of the machines were the same, and the operations involved almost identical, it was discovered that the ordinary workman was at sea, when confronted by a picture of a machine which was slightly different from his own. Even such unessential differences as the power used in running the machine seemed to throw the ordinary workman off the track. When he was accustomed to a belt-driven machine, the fact that a slightly later type of machine, motor-driven, was pictured, was sufficient to cause a great deal of trouble. The workman would look at the picture and reply at once, "This is not the kind of machine that I have seen. The ones that we use don't have this attachment." The same difficulty was met, though to a less degree, in the case of the more complex tools. Even very unessential differences were confusing. Times without number the tradesman when looking at the picture would say: "Give me a little time. I will have to figure this out. The tool I use is quite different from this."

In spite of these obstacles, in the ordinary trades the large majority of the tools, most of the process and a considerable number of the machines, were universally known. Around pictures of these, with the help of expert tradesmen, the questions were devised; as in the case of the oral questions, it was the expert who supplied the necessary trade information, while 
the compilers of the questions were responsible for framing the question so that it conformed to the requirements which we have discussed at great length under the oral trade test method. They will be found on pages $85-88$.

The detailed statement of the method of administration of the test will be given later; here it need only be mentioned in passing that the examiner was supplied with the questions, while the tradesman was provided with a small booklet containing the pictures. The examiner then was responsible for seeing that the attention of the tradesman was directed to that picture concerning which the question was being asked.

From this point on the procedure leading to the completion of the final test was similar to that described for the oral tests. These stages were:

I. The preliminary testing of the questions, with elimination and revision by administration to three apprentices, three journeymen and three experts.

2. The final testing of these questions for purposes of standardization.

3. Statistical treatment of the results.

4. Selection of final questions and calibration of the test.

It is unnecessary to describe the procedure characteristic of each of these stages, for they have already been dealt with in full for a particular set of questions in the oral method.

\section{Instructions for Giving Picture Trade Tests}

\section{GENERAL STATEMENT}

In giving Picture Tests the same instructions govern in the main as for giving Oral Tests. (See Instructions for Giving Oral Trade Tests.) 


\section{GIVING THE TESTS}

(See Instructions for Giving Oral Trade Tests, paragraphs I to 8.)

I. Every Picture Trade Test is prepared in two folders, ${ }^{*}$ one for the examiner and one for the candidate. The Examiner's Folder contains the questions and answers for the test. The Candidate's Folder contains the pictures upon which the questions are based.

2. Place in front of the candidate the folder containing the pictures.

3. Precede each question by stating the number of the picture, to insure that the candidate is looking at the right picture while the question is being asked.

4. The examiner may point to a picture instead of designating it by number if that is found more convenient.

5. Repetition of questions: (See paragraph ira, Instructions for Giving Oral. Trade Tests.)

6. If the candidate gives an incomplete answer, or an answer so different from the correct answer that his knowledge cannot be judged, (See paragraph I2. Instructions for Giving Oral Trade Tests.)

7. If the candidate points to the correct part of the photograph instead of stating the letter notation on that part, his answer is acceptable in that form.

8. The Examiner may, at his own discretion, point to any part of the picture which is mentioned in the question but should be careful not to call attention to any part which will serve to prompt the candidate.

\section{SCORING}

I. In all cases score the candidate's answer on the basis of what he says, not what you think he knows.

2. A perfect answer is scored 4. An imperfect answer is scored 0 .

3. No partial credits are allowed.

4. If a question can be answered in several ways, the acceptable answers are listed and numbered. The note "One sufficient" means that the candidate only needs to give one of the answers in order to obtain a score of 4. The note "Both required" means that the candidate must give both of the listed items in order to obtain a score of 4 .

* Pictures are here reproduced in body of test. 
5. Equivalent words are printed in parentheses. The word in parentheses is equivalent to the word immediately preceding the parentheses.

6. The printed answers are not complete answers in the ordinary sense. The scoring system is based on key words.

7. The candidate must use all the key words in one of the answers listed as correct. He may say more, of course, but should not be permitted to ramble.

8. The candidate is not required to give the key words in the order in which they are printed.

9. Score the answer to each question before giving the next question.

Io. If the candidate gives a satisfactory answer which includes the correct answer for subsequent questions, the Examiner will silently score the candidate " 4 " on those subsequent questions without asking them.

For example,

I. Q. What is that?

A. Arrester.

2. Q. What kind of arrester is that?

A. Aluminum.

3. Q. What is that arrester used for?

A. Protection against lightning.

If the candidate should answer in response to the first question: "Aluminum arrester to protect against lightning," then the Examiner should score the candidate " 4 " on all three questions without stating the last two questions.

\section{RATING}

I. The candidate will be rated according to the instructions given in each test.

\section{Criticism of the Picture Test Method}

Although the picture tests were not used as extensively as were the oral tests, from the experience derived from the process of standardization and from application in the camps it is possible to weigh, in a tentative manner, the relative advan- 
tages and disadvantages of this type of examination. Several of these advantages have been discussed incidentally in connection with the reasons for the adoption of this method of examination. It will, however, be convenient to collect here some of the more valuable features of this method.

\section{Advantages of the Picture Tests}

I. The picture test approximates more closely to the actual situation in the trade.

2. The tradesman has more confidence in the method; it appears to him to be much more practical than the purely oral method.

3. The picture test admits of more intricate questions.

4. It is less subject to coaching.

5. The picture will often call forth a piece of information which the tradesman might be unable to recollect without the association value of the picture.

It may be interesting to state that repeatedly, when oral tests were given, the men themselves suggested that the method of examination would have been improved if pictures had been used. In the opinion of the author, this is the main advantage derived. Generally speaking, the picture tests did not differentiate between different trade levels with any greater degree of accuracy than did the oral questions. They did, however, establish an understanding between the examiner and the tradesman which was sometimes not'ceably lacking in the case of the oral tests. Though in by far the majority of cases the candidates were certain that the oral tests were fair, in a few cases the examiner could not help noticing that the man felt that he had been given a very theoretical examination. Even though, as a matter of fact, this idea was erroneous, in view of the rigorous standardization to which the oral tests were 
subjected, it is a human factor which must not be overlooked. Considering the importance of human relationships in industry it would seem that even a slightly inferior type of examination which appeals to the workman as essentially practical is of greater value than a more accurate measuring device which arouses suspicion as to its fairness or practicality.

\section{Disadvantages of Picture Test}

I. The construction of the test is more laborious in so far as pictures, diagrams or photographs have to be procured.

2. The cost of production is greater.

3. It is more awkward to give, and takes a longer time than an equal number of oral questions.

4. There is a greater danger of unfamiliarity, due to the fact that the machine or tool or process pictured is not identical with that used by the tradesman.

5. The pictures are themselves liable to get out of date; that is, ten years' progress in a trade would throw out a greater proportion of the picture questions than of oral questions.

6. Many men of less intelligence are not accustomed to reading diagrams or interpreting pictures. As we have already stated, a combination of words and pictures might appear to be an easier form of examination than that furnished by words alone. That is, the pictures might clarify the meaning of the words. This assumption, however, was not verified by practice, except in the case of the expert. Often the picture makes it more difficult for the man to focus his attention on the question which is being asked, for he tends to study the whole picture and his thoughts are diffused over a wide area. With the less skilled and less educated, particularly where there is a slight language difficulty, the pictures seem in one way or another to com- 
plicate the mental process. It was found that the lower type of man, in the attempt to direct his attention simultaneously to the words of the question and to the picture, became confused. For such men there is no doubt that the oral method of examination is superior.

7. Where several questions depend on a single picture, the failure to recognize this picture unfairly penalizes the candidate.

It would appear that the advantages of both the oral method and the picture method could be combined. The use of pictures in a few questions would not only establish confidence in the form of examination, but it would also enable certain very valuable questions to be asked which could not be introduced in the oral examination.

These methods of examination are so recent that much further experimentation will be necessary before final judgments can be given. Either method supplies a device which is infinitely superior to any that has been previously employed to meet the conditions, but a correct balance can only be the outcome of much further trial in the every day routine of varied industrial plants.

\section{Representative Picture Tests}

The following picture tests, taken from diverse trades, illustrate the method of application of the principles described:

Carpenter. General.

Electrician. General and Switchboard Tender (A.C.).

Electrician. Lead Storage Battery.

Machinist. Lathe Operator.

Blacksmith. Horseshoer.

Boilermaker. Locomotive.

Leather Worker. Cobbler.

Welder. Gas Welder. 


\section{TRADE TEST \\ CARPENTER. - General}

PICTURE

COMMITTEE ON CLASSIFICATION OF PERSONNEL IN THE ARMY

Trade Test Division

Reproduced by permission of the Adjutant General

\section{PICTÚRE 1}

1. Q. What do you call that?

A. Jack (fore), (joiner) plane.

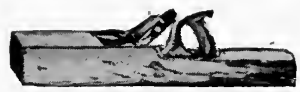

PICTURE 2

2. Q. What do you call that?

A. Spoke shave.

PICTURE 3

3. Q. What do you call that?

A. Saw clamp (vise).

PICTURE 4

4. Q. What do you call that?

A. Draw knife.

PICTURE 5

5. Q. What do you call that?

A. Ripping (prying) chisel.

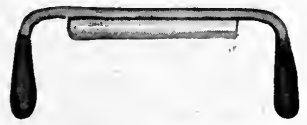


THE PICTURE TRADE TEST METHOD 199

PICTURE 6

6. Q. What do you call that?

A. Center bit.

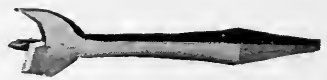

\section{PICTURE 7}

7. Q. What do you call that?

A. Bevel gauge ("fence").

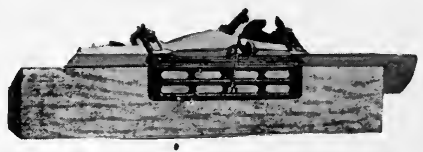

PICTURE 8

8. Q. What do you call that?

A. Scraper.

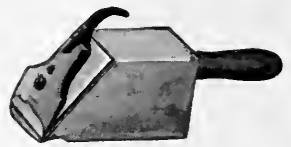

PICTURE 9

9. Q. What do you call that?

A. Saw set.

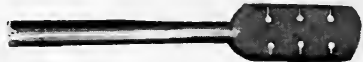

PICTURE 10

10. Q. What kind of a chisel is that?

A. Mortise (frame).

PICTURE 11

11. Q. What do you call that?

A. Mitre.

PICTURE 12
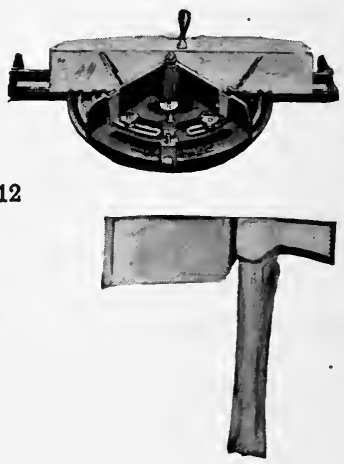

12. Q. What kind of a hatchet is that?

A. Lathe (shingle). 
13. Q. What kind of a joint is that?

A. Halved (cross lap).

\section{PICTURE 14}

14. Q. What kind of nailing do you call that?

A. Toe.
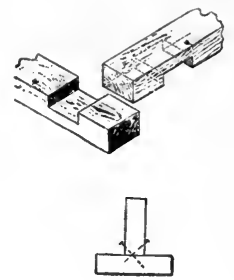

PICTURE 15

15. Q. What does "W.S." mean?

A. Wall stringer.

16. Q. What part of the step is that at $\mathrm{C}$ ?

A. Rise.

17. Q. What do you call the part

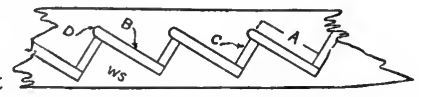
of the step at $B$ ?

A. Tread (run).

18. Q. What do you call D?

A. Nosing.

\section{PICTURE 16}

19. Q. What kind of jointing is that?

A. Slip tongued (feather and grooved, matched).

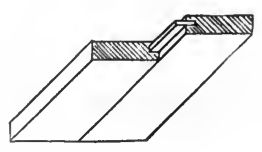

\section{PICTURE 17}

20. Q. What do you call the rafters at "O-A, O-B and O-C"?

A. Valley.

21. Q. What do you call the rafters at "O-D, O-F, and O-E"?

A. Ridge.

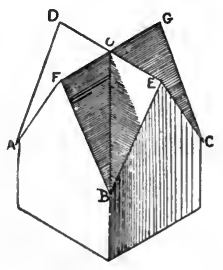




\section{PICTURE 18}

22. Q. Where is the sill?
A. I.

23. Q. Where are the studs?

A. A.

24. Q. Where is the sheathing?

A. C.

25. Q. Where is the water table?

A. H.

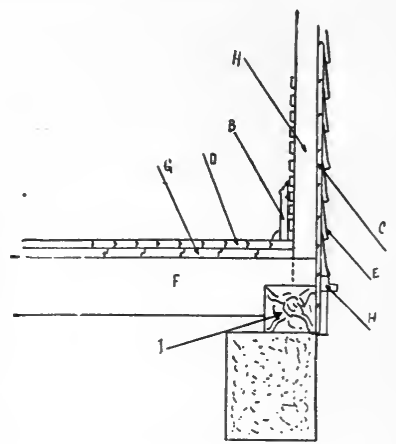

\section{IDENTIFICATION OF DIFFERENT KINDS OF WOOD}

Say to the candidate: "Here are a number of different kinds of wood. Tell me the name of each kind. Begin with number $\mathrm{I}$ and go right through."
26. (I) A. White Pine.
27. (2) A. Hackmatack (Larch) (Tamarack).
28. (3) A. Cypress.
29. (4) A. Basswood.
3o. (5) A. Maple.
31. (6) A. Cherry.
32. (7) A. Elm (Butternut).
33. (8) A. $\overline{\text { Ash. }}$.
34. (9) A. Chestnut.
35. (ro) A. Oak.
36. (I I) A. Red Oak.
37. (I2) A. Gum (Hazel) wood.
38. (I3) A. Walnut.
39. (I4) A. Mahogany (Baywood).
40. (I 5) A. Teak (Pasanda). 


\section{INSTRUCTIONS TO THE RATER}

\section{Score}

Rating

I08 to 160 both inclusive..............E

60 to 107 both inclusive............... J

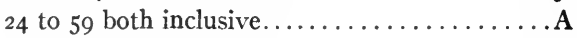

o to 23 both inclusive............... 
THE PICTURE TRADE TEST METHOD 203

\section{TRADE TEST}

\section{ELECTRICIAN. - Generator and Switchboard Tender}

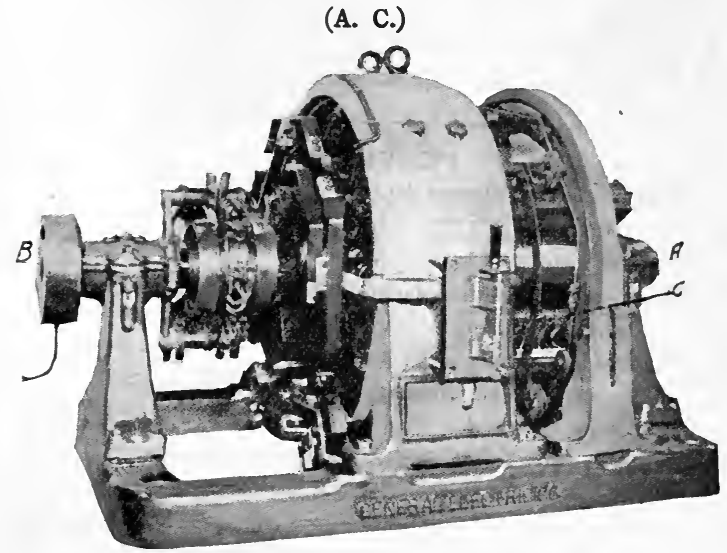

COMMITTEE ON CLASSIFICATION OF PERSONNEL IN THE ARMY

Trade Test Division

Reproduced by permission of the Adjulant General

\section{PICTURE 1}

1. Q. What is that machine used for?

A. (I) To convert Direct Current (D.C.) into Alternating Current (A.C.).

(2) A.C. to D.C.

(One sufficient)

2. Q. How do you know that the A.C. end is at B?

A. (I) Slip rings.

(2) Connecting rings.

(One sufficient)

3. Q. How many phases has that machine?

A. Three. 


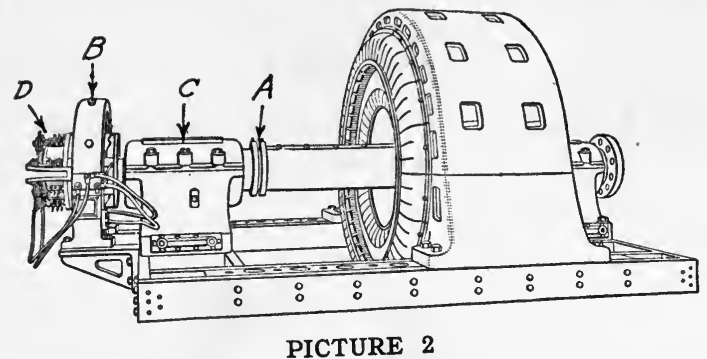

4. Q. What does that picture represent?
A. (I) Alternator.
(2) Generator.
(One sufficient)

5. Q. What do you call the machine at "B"?

A. Exciter.

6. Q. What is the exciter used for?
A. (I) To supply field current.
(2) Excite the field.
(One sufficient)

7. Q. Where is the exciter current put into the field?

A. (I) At "A."

(2) Slip rings.

(One sufficient)

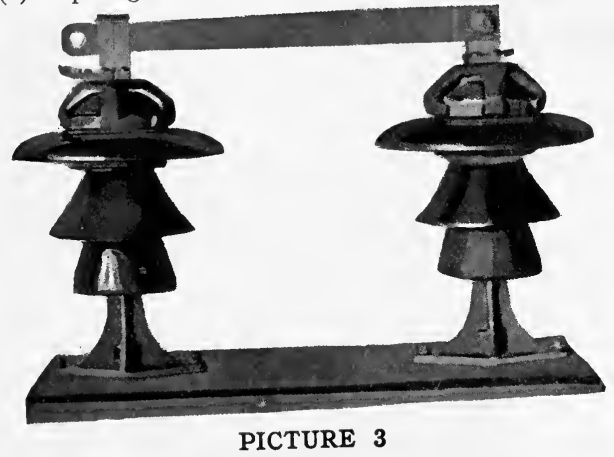

8. Q. What do you call that?

A. (I) Disconnecting switch. 
THE PICTURE TRADE TEST METHOD 205

(2) Knife switch.

(3) High tension switch.

(One sufficient)

9. Q. What kind of insulator is that?

A. Petticoat.

10. Q. What is the purpose of the irregular surface of an insulator?

A. (I) To increase the creepage distance.

(2) Long path.

(3) To increase surface.

(4) Moisture.

(One sufficient)

PICTURE 4

11. Q. That diagram shows two alternators to be synchronized.

How would you tell when to close the main switch?

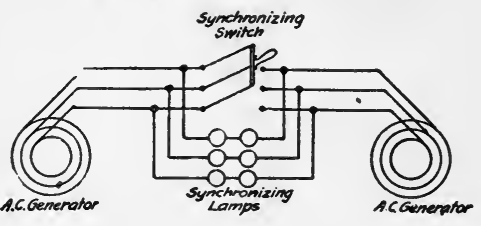

A. When lamps are dark.

\section{PICTURE 5}
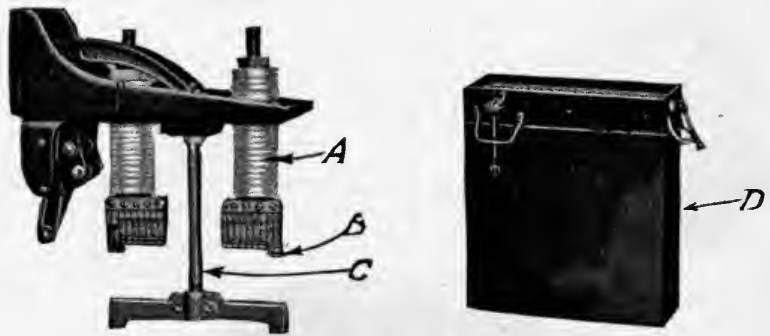

12. Q. What does that picture represent?

A. (I) Oil switch.

(2) Circuit breaker.

(One sufficient)

13. Q. What is shown at "A"?

A. Insulator.

14. Q. What is the rod at " $\mathrm{C}$ " made of?

A. Wood. 


\section{PICTURE 6}

15. Q. What do you call that?

A. Regulator.

16. Q. What is shown at " $\mathrm{A}$ " in that picture?

A. Motor.

\section{PICTURE 7}

17. Q. What is that?

A. Circuit breaker.
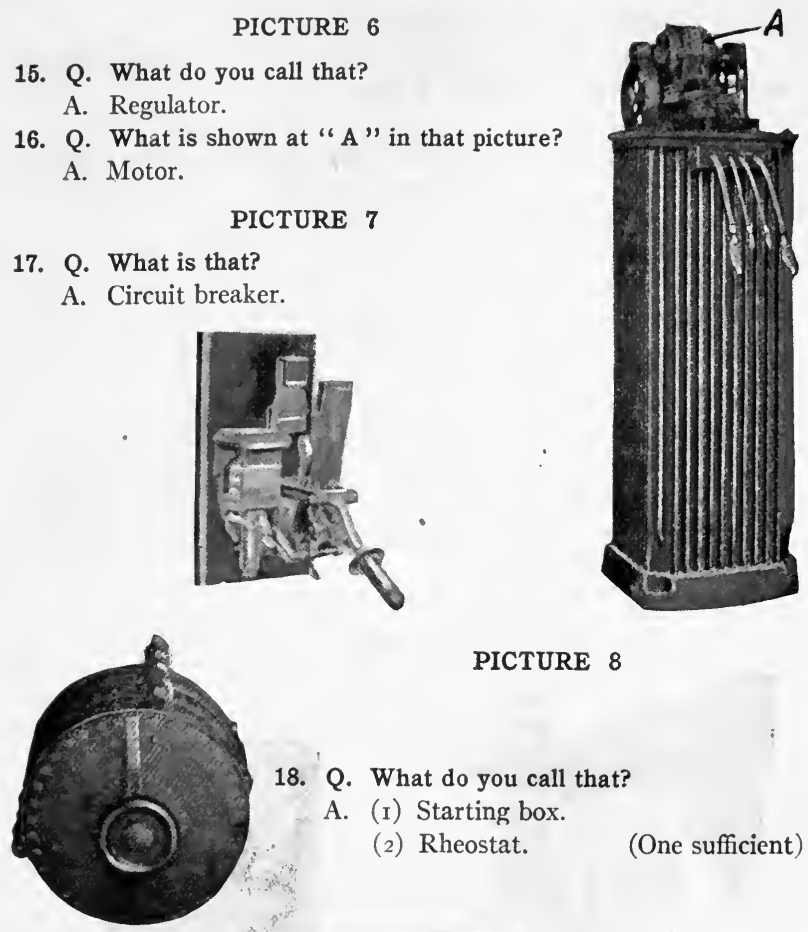

PICTURE 8

18. Q. What do you call that?

A. (I) Starting box.

(2) Rheostat.

(One sufficient)

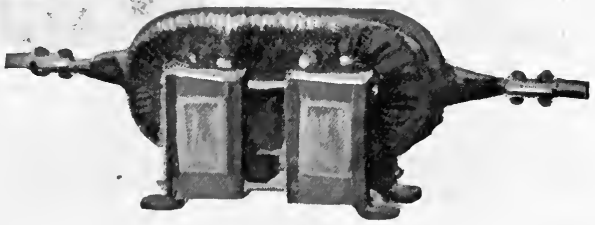

PICTURE 9

19. Q. What kind of transformer is that?

A. Current transformer. 
THE PICTURE TRADE TEST METHOD 207

\section{PICTURE 10}

20. Q. What kind of transformer is that?

A. (I) Potential transformer.

(2) Voltage transformer.

(One sufficient)

PICTURE 11

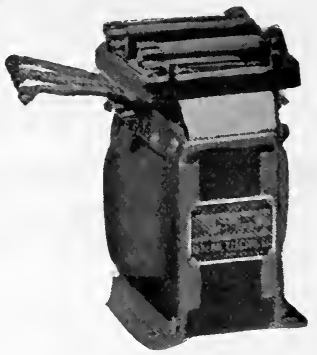

21. Q. What do you call that?

A. Shunt.

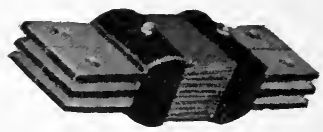

PICTURE 12

22. Q. What do you call that?

A. Choke coil.

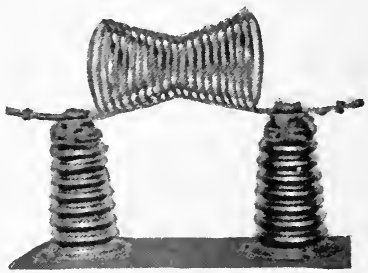

\section{PICTURE 13}

23. Q. What is the part at "A" used for?

A. Tighten belt.

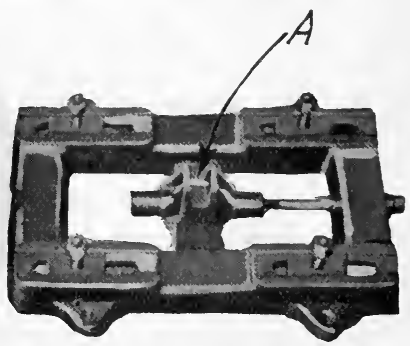


24. Q. What kind of wattmeter is that?

A. (I) Recording.

(2) Integrating. (One sufficient)

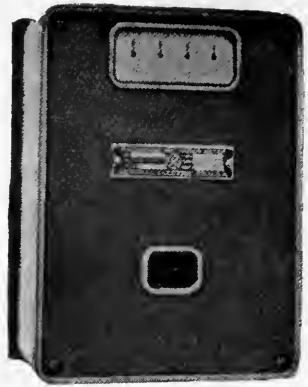

PICTURE 15

25. Q. What is that?

A. Field coil.

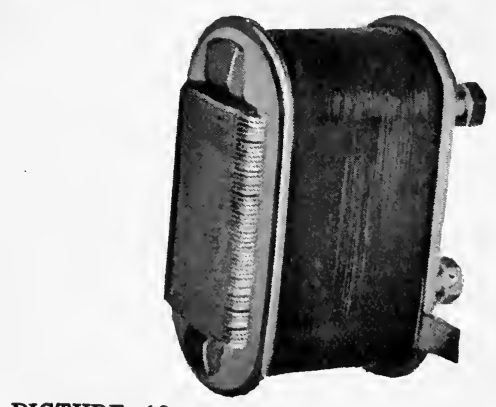

\section{PICTURE 16}

26. Q. What do you call that instrument?

A. (I) Synchroscope.

(2) Synchronism indicator. (One sufficient)

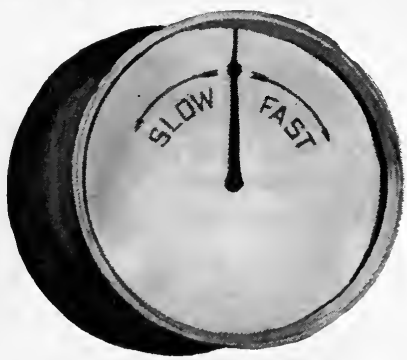


THE PICTURE TRADE TEST METHOD 209

\section{PICTURE 17}

That is a wiring diagram for a three-phase generator panel. Study the connections and identify the following parts:

27. Q. What is shown at "A "?

A. Field switch.

28. Q. What is shown at "B"?

A. Field rheostat.

29. Q. What is shown at " C"?

A. Shunt.

30. Q. What is shown at "D"?

A. Voltmeter.

31. Q. What is shown at "E"?

A. Ammeter.

32. Q. What is shown at " F"?

A. Field ammeter.

33. Q. What is shown at " G"?

A. Current transformer.

34. Q. What is shown at " $\mathrm{K}$ "?

A. Oil switch.

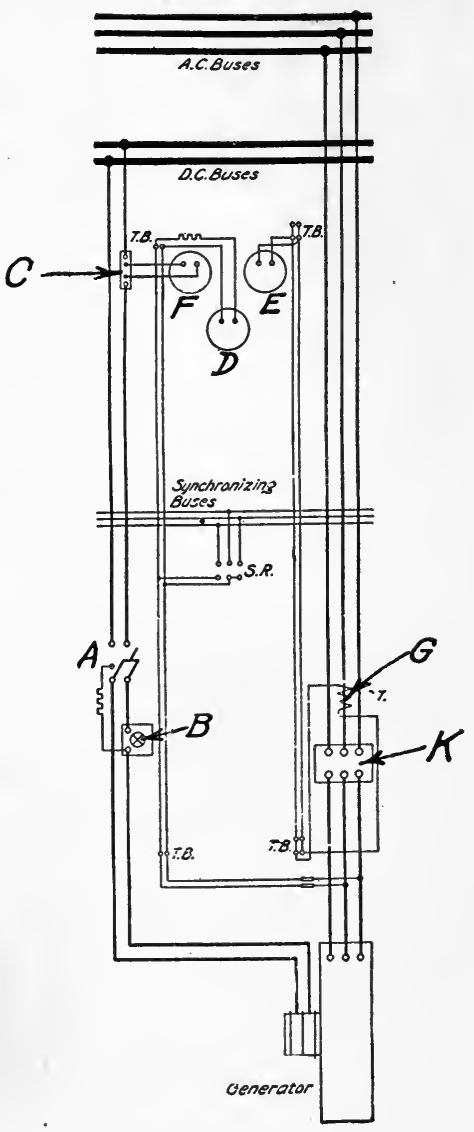




\section{PICTURE 18}

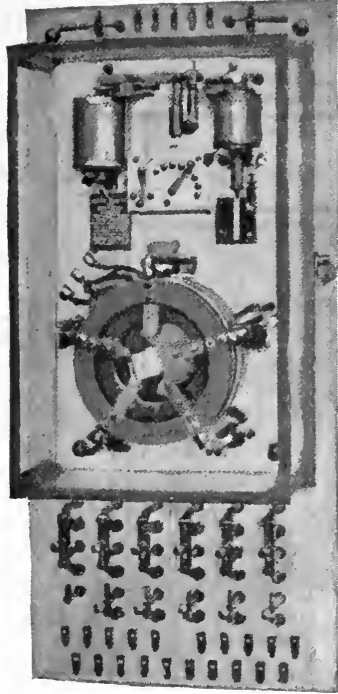

35. Q. What kind of regulator is that?

A. Tirrill.

\section{PICTURE 19}

36. Q. What do you call that?

A. Arrester.

37. Q. What kind of an arrester is that?

A. (I) Aluminum.

(One sufficient)

(2) Electrolytic.

38. Q. What is it used for?

A. (I) Lightning protection.

(2) High tension short circuits.

(One sufficient)

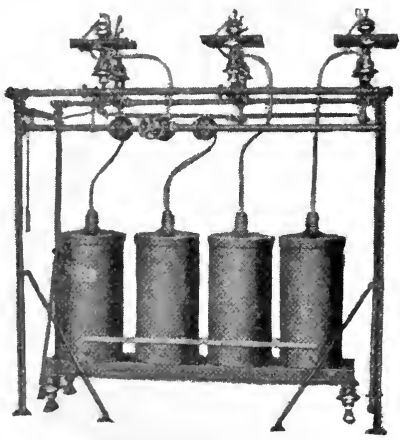




\section{THE PICTURE TRADE TEST METHOD 211}

\section{RATING THE CANDIDATE}

\section{Score}

Rating

○ to $\mathrm{I} 6$ inclusive...................... Novice

20 to 60 inclusive.................... Apprentice

64 to 124 inclusive ..................... Journeyman

I 28 to $\mathrm{I}_{5} 2$ inclusive .................. Expert 


\section{TRADE TEST}

\section{ELECTRICIAN. - Lead Storage Battery PICTURE}
COMMITTEE ON CLASSIFICATION OF PERSONNEL IN THE ARMY
Trade Test Division

Reproduced by permission of the Adjutant General

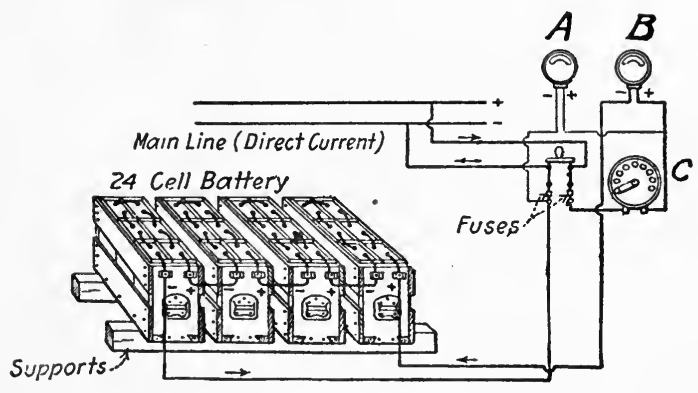

PICTURE 1

1. Q. What is being done in that picture?

A. Charging.

2. Q. What is at "A "?

A. Voltmeter. (Note: "Voltmeter or ammeter" is wrong.)

3. Q. What is at " $B$ "?

A. Ammeter. (Note: "Voltmeter or ammeter" is wrong.)

4. Q. What is at " $\mathrm{C} "$ ?

A. (I) Rheostat.

(2) Resistance.

(One sufficient)

(Note: "Starting box" or "Controller" is wrong.) 


\section{PICTURE 2}

5. Q. What is that apparatus used for?

A. Burning.

6. Q. What is supplied at " $A$ "?

A. (I) Gas.

(2) Hydrogen.

(One sufficient)

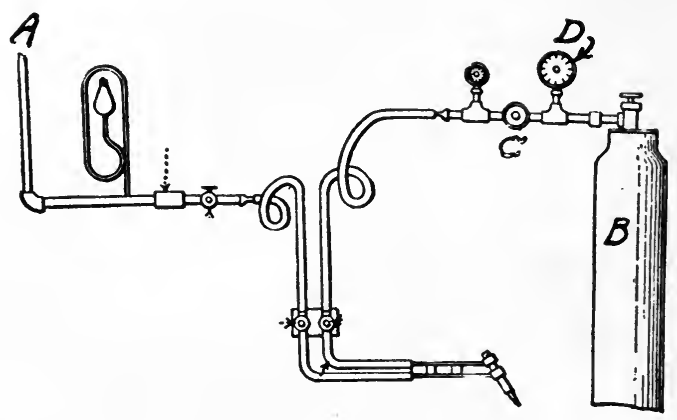

7. Q. What is in the tank at " $B$ "?

A. (I) Oxygen.

(2) Air.

8. Q. What is at " $D$ "?

(One sufficient)

A. (I) Pressure gauge.

(2) Pressure meter.

(3) Pressure indicator.

(One sufficient)

(Note: "Pressure regulator" is wrong.) 


\section{PICTURE 3}

9. Q. How many volts would you get from that arrangement if each cell gives two volts?

A. Two.

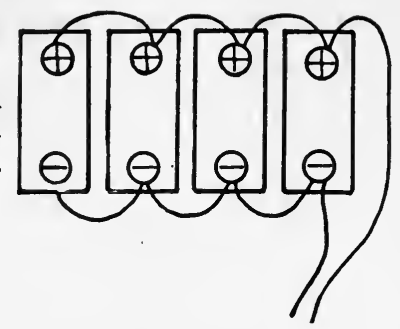

\section{PICTURE 4}

10. Q. How many volts would you get from that arrangement if each cell gives two volts?

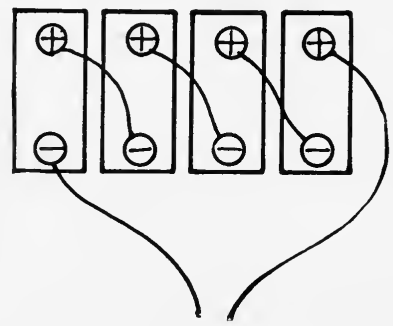

PICTURE 5

11. Q. How many volts would you get from that arrangement if each cell gives two volts?

A. Four.

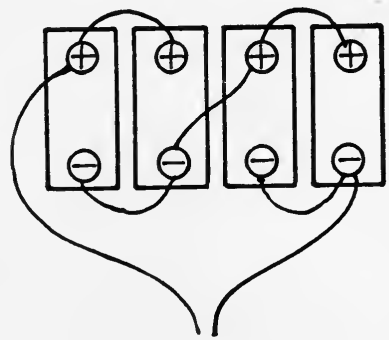


THE PICTURE TRADE TEST METHOD 215

\section{PICTURE 6}

12. Q. How many volts would you get from that arrangement if each cell gives two volts?

A. Four.

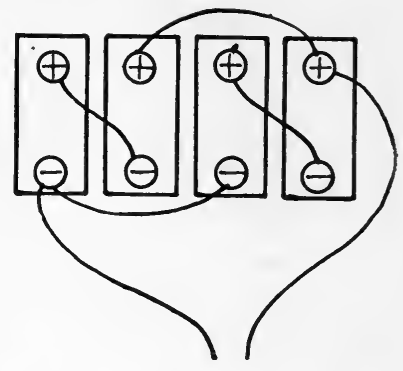

PICTURE 7

13. Q. What is that?

A. Handle.

PICTURE 8

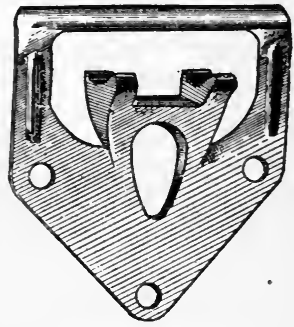

14. Q. What make of battery are those plates for?

A. Edison.

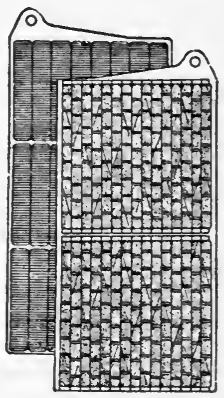




\section{PICTURE 9}

15. Q. What is that?

A. Vent.

\section{PICTURE 10}

16. Q. What do you call those cross pieces at the bottom of the jar?

A. (I) Bridge.

(2) Ribs.

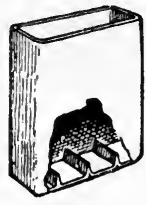

17. Q. What is the purpose of those cross pieces at the bottom of the jar?

A. (I) Collect sediment.

(2) Prevent short circuit (Short).

(One sufficient)

PICTURE 11

18. Q. What kind of wrench is that?
A. (I) Ratchet.
(2) Socket.

(Cne sufficient)

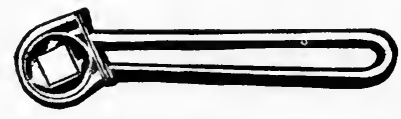

\section{PICTURE 12}

19. Q. What car has that assembly of batteries?

A. Maxwell.

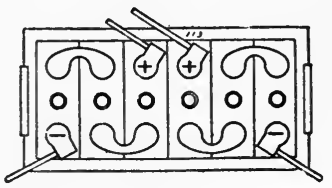

PICTURE 13

20. Q. What car has that assembly of
batteries?
A. Packard. 
THE PICTURE TRADE TEST METHOD 217

PICTURE 14

21. Q. What is that?

A. Separator.

22. Q. What is that separator made of? A. Wood.

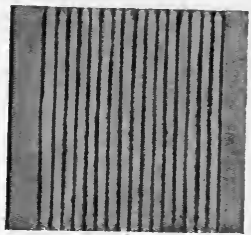

\section{PICTURE 15}

23. Q. Why is that torch applied at the top of the jar?

A. (I) To soften compound.

(2) To remove the plates.

(One sufficient)

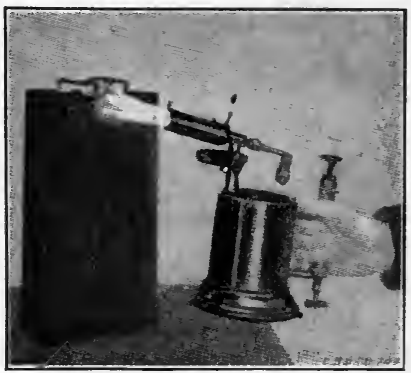

\section{PICTURE 16}

24. Q. What caused the damage to that plate?

A. (I) High temperature.

(2) Short circuit.

(3) Overload.

(4) Heavy charge or discharge.

(5) Sulphation.

(6) Separator broken.

(7) Frozen battery.

(8) Overcharging.

(9) Undercharging.

(Io) Vibration.

(One sufficient)

(Note: "Age" is insufficient.)

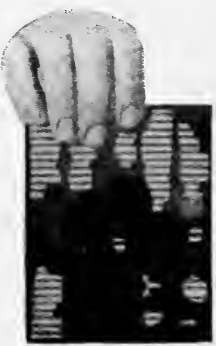

25. Q. What would you do with a plate like that?

A. Discard it. 


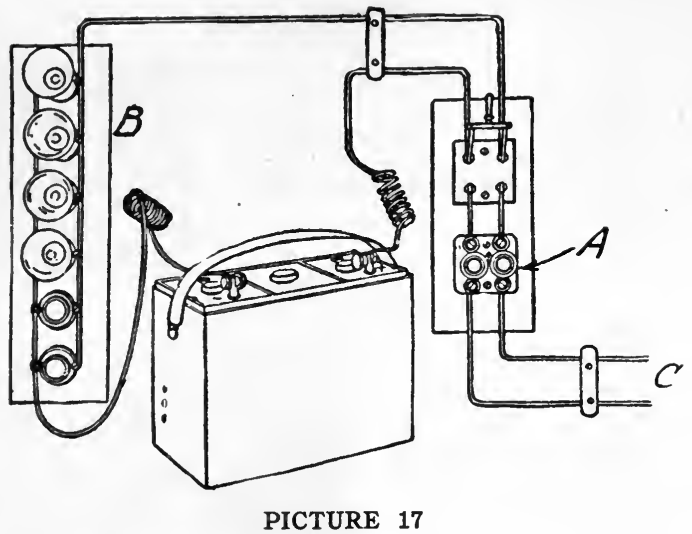

26. Q. What is shown at "A "?

A. Fuse.

27. Q. What are the lamps at "B " used for?

A. (I) Resistance.

(2) Rheostat.

(3) Regulate current.

(One sufficient)

28. Q. What kind of current is supplied at " $\mathrm{C}$ "?

A. Direct current (DC).

\section{PICTURE 18}

29. Q. What is that?

A. Rectifier.

30. Q. What kind of rectifier does that picture show?

A. (I) Mercury.

(2) Cooper-Hewitt. (One sufficient)

31. Q. What is a rectifier used for?

A. To change alternating current (AC) to direct current (DC) or vice versa.

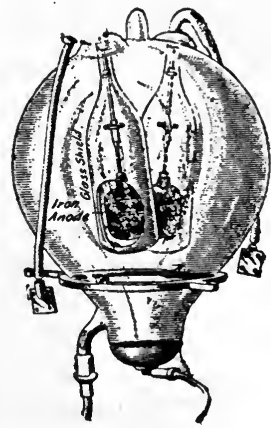




\section{RATING THE CANDIDATE}

o to 32 inclusive - Novice.

36 to 64 inclusive - Apprentice.

68 to 96 inclusive - Journeyman.

I00 to I 24 inclusive - Expert. 


\section{TRADE TEST \\ MACHINIST. - Lathe Operator \\ PICTURE}

COMMITTEE ON CLASSIFICA ION OF PERSONNEL IN THE ARMY

Trade Test Division

Reproduced by permission of the Adjutant General
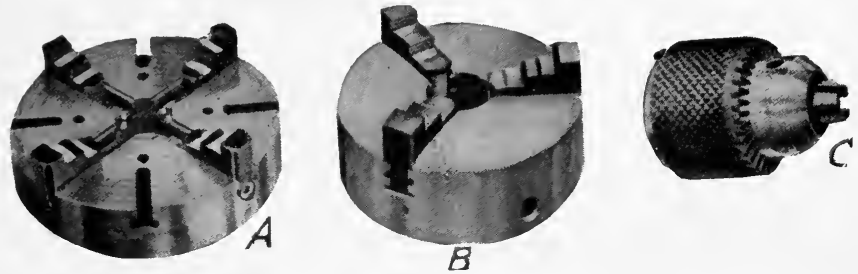

\section{PICTURE 1}

1. Q. What do you call those chucks?

A. (a) 4-jaw chuck (Independent).

(b) 3-jaw chuck (Universal).

(c) Drill chuck.

(All three required)

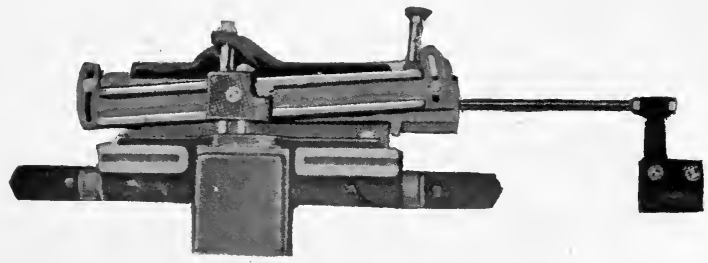

PICTURE 2

2. Q. What do you call that mechanism?

A. Taper attachment. 
THE PICTURE TRADE TEST METHOD 22]

\section{PICTURE 3}

3. Q. What is the purpose of those two gears $\mathbf{A}$ and $\mathbf{B}$ ?

A. Reverse.
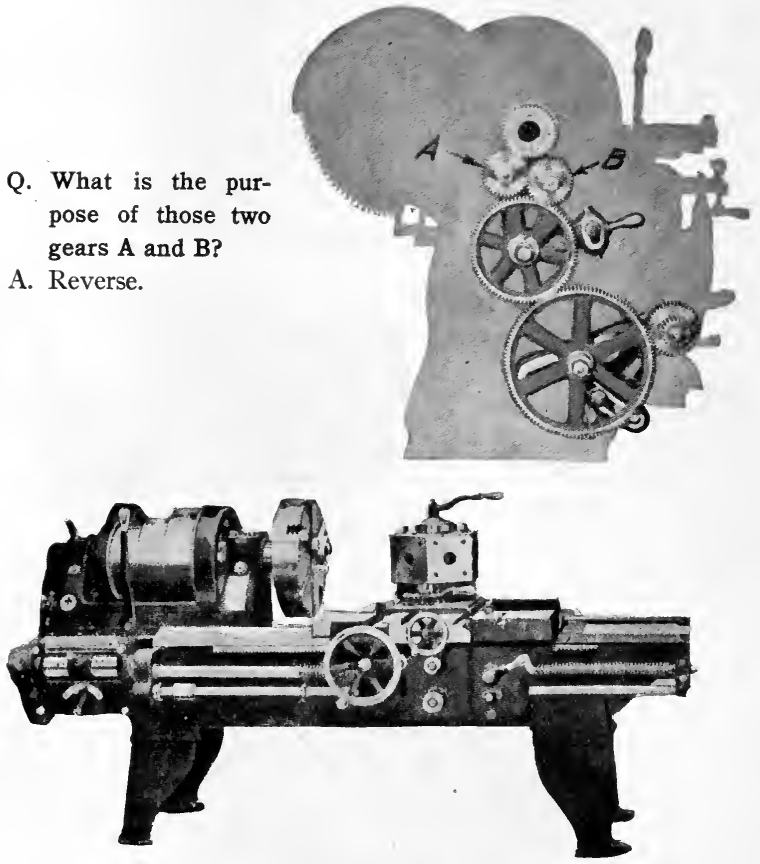

PICTURE 4

4. Q. What kind of lathe is that?

A. Turret.

PICTURE 5

5. Q. What kind of chuck is that?

A. (I) Spring chuck.

(2) "Draw-in" chuck.
(3) Collet.
(4) Split.

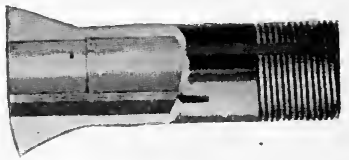

(One sufficient) 


\section{PICTURE 6}

6. Q. What is being done in that picture?

A. Locating center.

7. Q. What do you call the device at $\mathrm{B}$ ?

A. V-block.

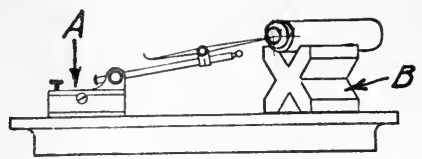

\section{PICTURE 7}

8. Q. Why do you have the two gears at $\mathrm{A}$ and $A$ ?

A. (I) Reverse feed.

(2) Right and left hand thread.

(One sufficient)
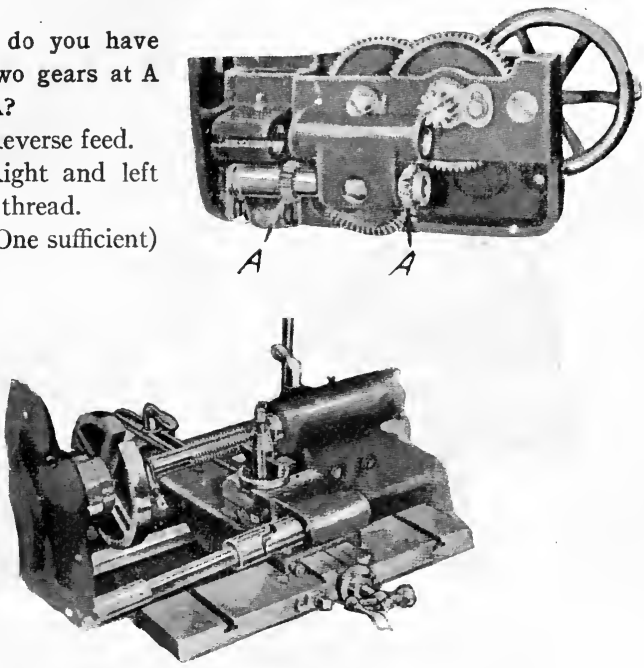

PICTURE 8

9. Q. What do you call the tool between the centers?

A. Tap.

10. Q. What is the attachment on that lathe used for?

A. (I) "Backing off."

(2) Relieving.

(3) Clearance.

(One sufficient) 
THE PICTURE TRADE TEST METHOD 223 SCALE.

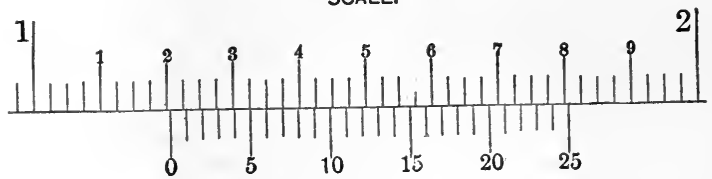

\section{PICTURE 9}

11. Q. What is the reading on that vernier?

A. (I) 1.205 to 1.207.

(2) 205 to 270.

(One sufficient)

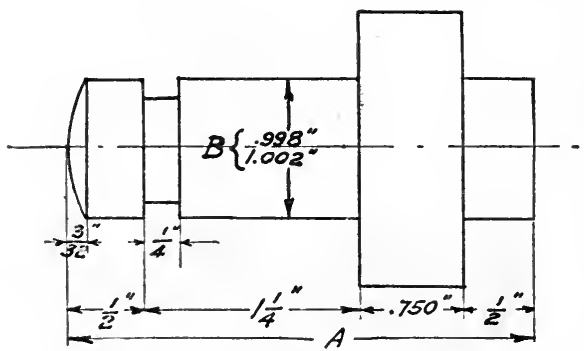

PICTURE 10

12. Q. What should be the dimension at $\mathrm{A}$ ?

A. $3^{\prime \prime}$.

13. Q. Why do they have two dimensions at B?

A. (I) Maximum and minimum.

(Note: Accept any equivalent answer.)

(2) Tolerance.

(3) Allowance of $0.004^{\prime \prime}$.

(4) For limit gages. 


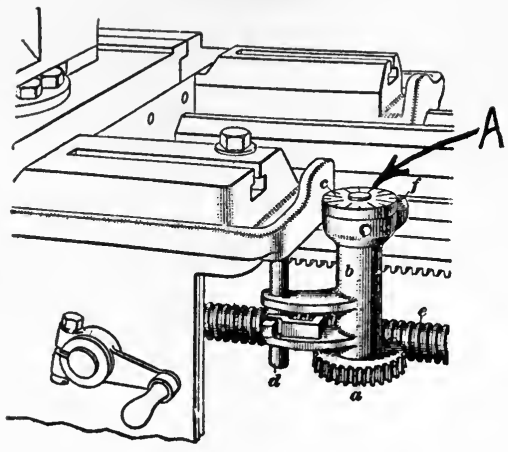

\section{PICTURE 11}

14. Q. For what kind of work do you use the dial at A? A. Cutting threads.

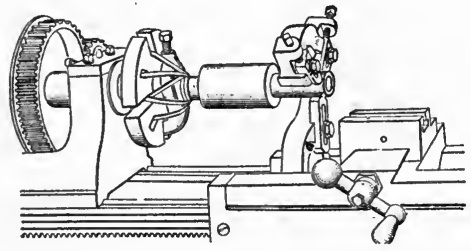

PICTURE 12

15. Q. How do you get the lace tight on the face plate?

A. Loosen face plate before lacing. 
THE PICTURE TRADE TEST ME'THOD 225 PICTURE 13
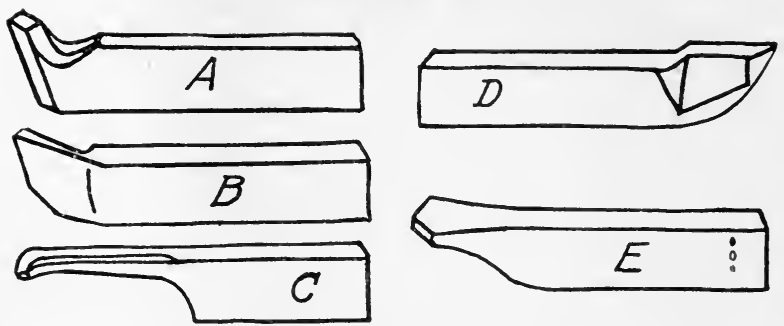

16. Q. Name the tools in that picture.

A. (a) Diamond point.

(b) Cutting-off (Parting).

(c) Boring Tool.

(d) Side Tool (Facing).

(e) Centering Tool.

(All required)

\section{PICTURE 14}

17. Q. What is the purpose of the part F?

A. Counterbalance (Balance).
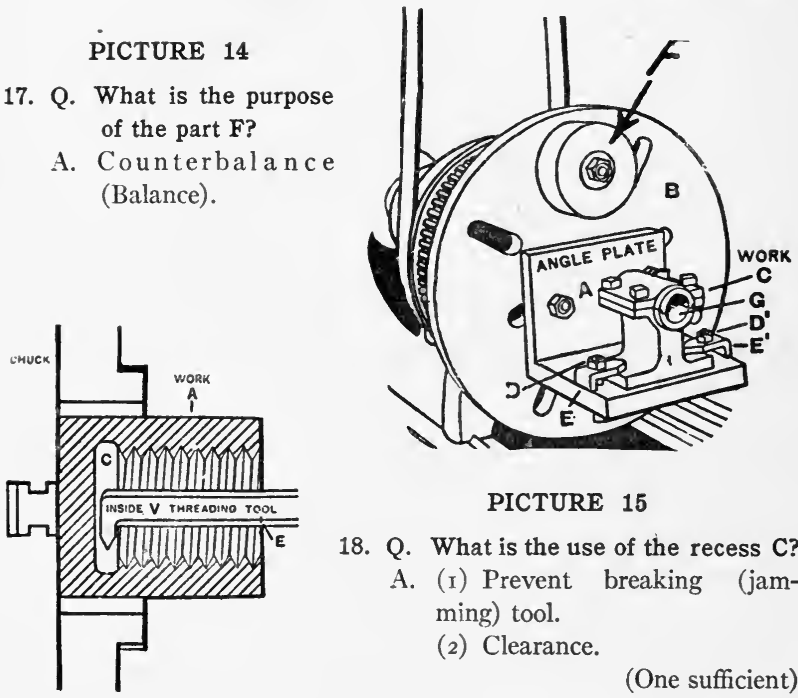

PICTURE 15

18. Q. What is the use of the recess C?

A. (I) Prevent breaking (jamming) tool.

(2) Clearance.

(One sufficient) 


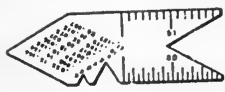

A
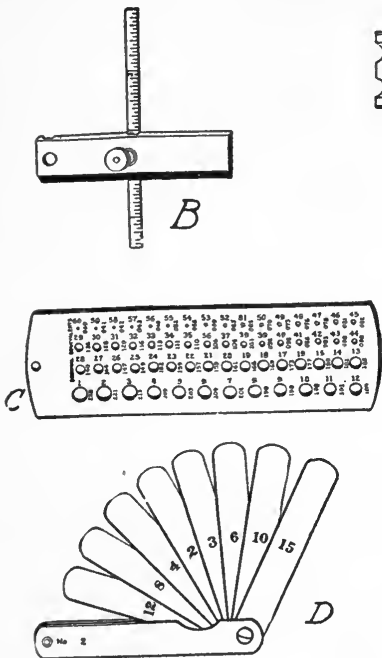
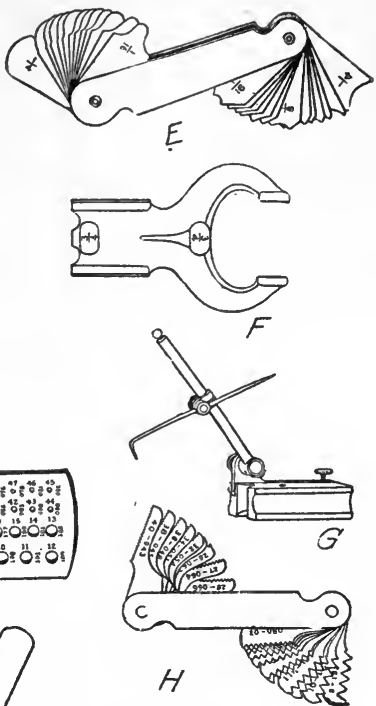

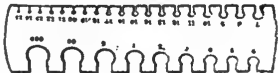

\section{PICTURE 16}

19. Q. Name the gages in that picture.

A. (a) Center Gage.

(b) Depth Gage.

(c) Drill Gage (Wire Gage).

(d) Feeler (Thickness) Gage.

(e) Radius (Curve) Gage.

(f) Snap Gage.

(g) Surface Gage.

(h) Thread Gage.

(i) Wire Gage. 
THE PICTURE TRADE TEST METHOD 227

\section{RATING THE CANDIDATE}

Score

$\circ$ to $\mathrm{I} 6$ inclusive.................... Novice

20 to 40 inclusive..................... Apprentice

44 to 60 inclusive ..................... Journeyman

64 to 76 inclusive.................... Expert 


\section{TRADE TEST \\ BLACKSMITH. - Horseshoer \\ PICTURE}

COMMITTEE ON CLASSIFICATION OF PERSONNEL IN THE ARMY

Trade Test Division

Reproduced by permission of the Adjutant General

\section{PICTURE 1}

1. Q. What is the difference between those shoes?

A. "A" is fullered (creased).

" $\mathrm{B}$ " is hand made (stamped).

(Both required)

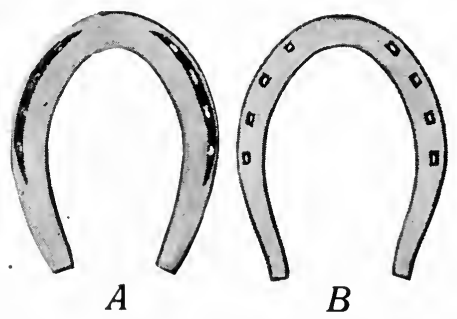

PICTURE 2

2. Q. Why do you put on that kind of shoe?

A. To prevent interfering.

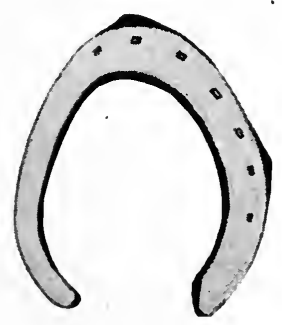


THE PICTURE TRADE TEST METHOD 229

\section{PICTURE 3}

3. Q. What kind of a shoe is that?

A. Toe weight.

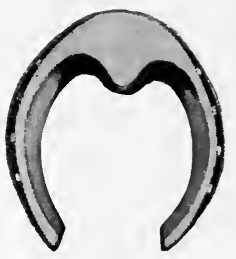

PICTURE 4

4. Q. What do you call that?

A. Pad.

5. Q. Why are they used?

A. Sore feet.

PICTURE 5

6. Q. When do you use a shoe like that?

A. Mule.

\section{PICTURE 6}

7. Q. What do you call that?

A. (I) Racing plate.

(2) Trotting.

(One sufficient)
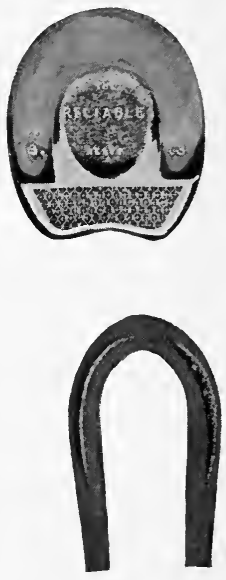


\section{PICTURE 7}

8. Q. What is the difference between those shoes?

A. "A" is front shoe. " $\mathrm{B}$ " is hind shoe.

(Both required)

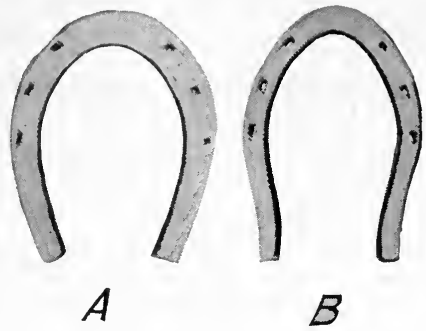

\section{PICTURE 8}

9. Q. That is a picture of a hoof plate. What is it made of?
A. (I) Canvas.
(2) Leather.
(3) Rubber.

(One sufficient)

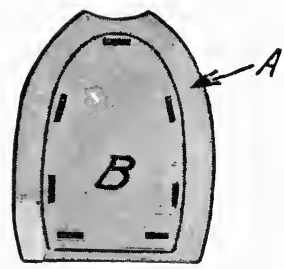

PICTURE 9

10. Q. What do you call that?

A. Trotting plate.



PICTURE 10

11. Q. When do you use that kind of shoe?

A. Winter.

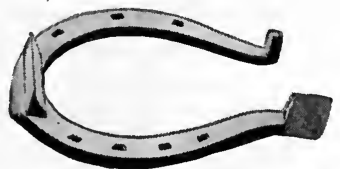


THE PICTURE TRADE TEST METHOD 231

\section{PICTURE 11}

12. Q. What do you call that?

A. Pritchel.

\section{PICTURE 12}

13. Q. What do you call that tool?
A. (I) Clinch tongs.
(2) Clinch puller

(One sufficient)

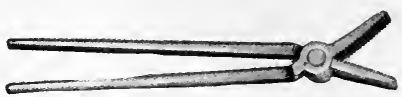

\section{PICTURE 13}

14. Q. What kind of hammer is that?

A. (I) Fitting hammer.

(2) Sharpening hammer.

(One sufficient)

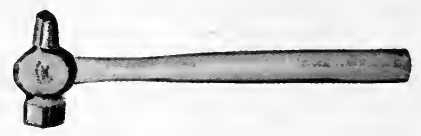

\section{PICTURE 14}

15. Q. What kind of hammer is that?

A. Driving.

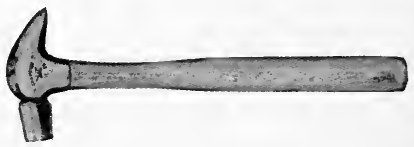

\section{PICTURE 15}

16. Q. What do you call that? A. Tongs.

\section{PICTURE 16}

17. Q. What do you call that?

A. Buffer.

18. Q. What is that used for?

A. Cut clinches.

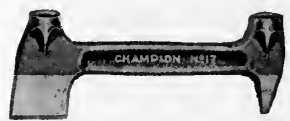




\section{PICTURE 17}

19. Q. What do you call those tools?

A. Hardies.

20. Q. What is the difference between them?

A. (I) A is straight hardie.

(2) $\mathrm{B}$ is round hardie.

(Both required)

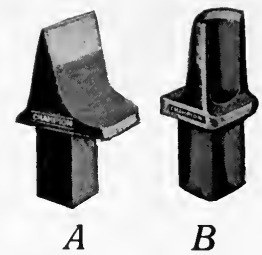

PICTURE 18

21. Q. What do you call those tools?

A. Chisels.

22. Q. What is the difference between those tools?

A. (I) A is cold chisel.

(2) B is hot chisel.

(Both required)

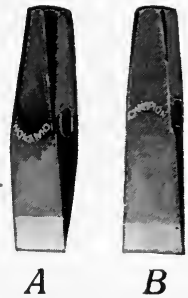

PICTURE 19

23. Q. How should that foot be shod?

A. (I) Concave shoe.

(2) Wide shoe.

(3) Bar shoe.

(One sufficient)

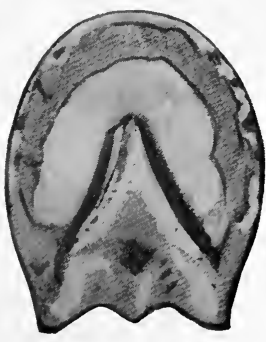


THE PICTURE TRADE TEST METHOD 233

\section{PICTURE 20}

24. Q. What part of the foot is at 1 ?

A. Frog.

25. Q. What part of the foot is at 3?

A. Bar.

26. Q. What part is at 4 ?

A. Wall.

PICTURE 21

27. Q. What is the condition of that foot?

A. Contracted foot.
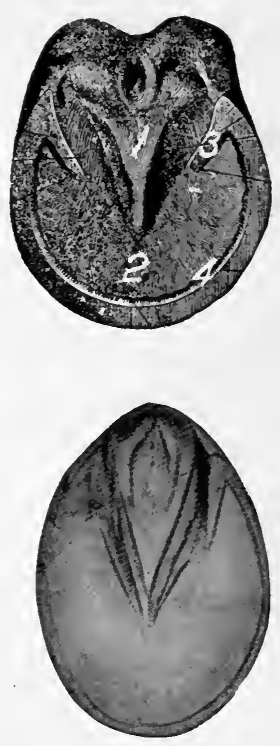

PICTURE 22

28. Q. What do you call that device inside the hoof?

A. (I) Hoof expander.

(2) Spring.

(One sufficient)

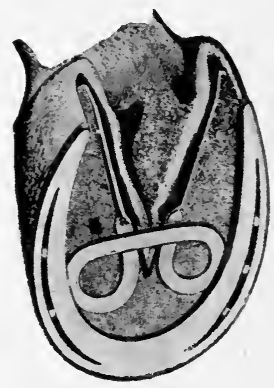




\section{PICTURE 23}

29. Q. What is the condition of that foot at " $A$ "?

A. Quarter crack.

30. Q. What has been done at "A"?

A. Clamped.

31. Q. What has been done at "B"?

A. Nailed.

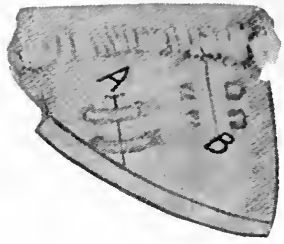

\section{PICTURE 24}

32. Q. How should those feet be shod?

A. (I) Outside of foot weighted.

(2) Side weight.

(One sufficient)

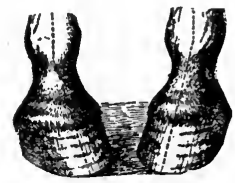

PICTURE 25

33. Q. What is the condition of that foot?
A. (I) Foundered.
(2) Laminated.

(One sufficient)

34. Q. How should that foot be shod?

A. (I) Concave shoe.

(2) Bar shoe.

(3) Remove pressure on sole.

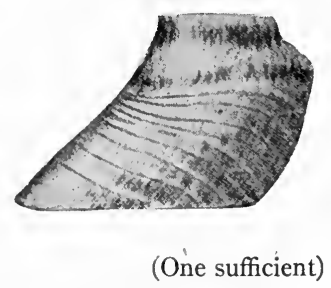

PICTURE 26

35. Q. What is the condition of that foot?

A. (I) Cracked walls.

(2) Seedy.

(One sufficient)

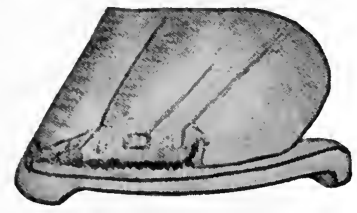


THE PICTURE TRADE TEST ME'THOD 235

\section{PICTURE 27}

36. Q. What is that?

A. (I) Toolbox.

(2) Shoeing box.

(One sufficient)

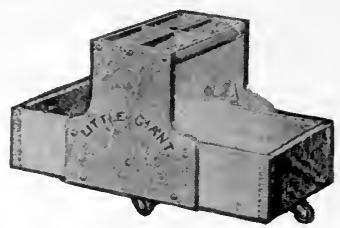

PICTURE 28

37. Q. What do you call that?

A. Stocks.

38. Q. When are they used?

A. Unruly horses.

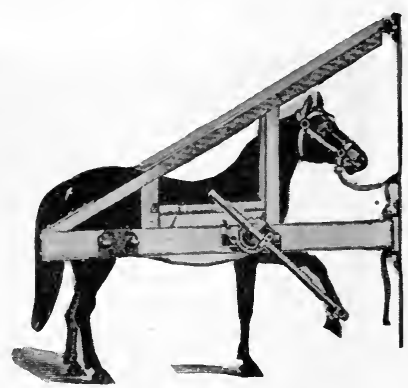

PICTURE 29

39. Q. What is that?

A. Toe calk.

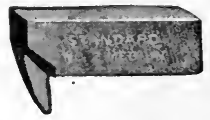

\section{RATING THE CANDIDATE}

\section{Score}

Rating

o to 52 inclusive.................. Novice

$5^{6}$ to 76 inclusive................... Apprentice

80 to 108 inclusive. .................. Journeyman

II 2 to I $^{6} 6$ inclusive . . . . . . . . . . Expert 


\section{TRADE TEST}

\section{BOILERMAKER. - Locomotive}

\section{PICTURE}

COMMITTEE ON CLASSIFICATION OF PERSONNEL IN THE ARMY

Trade Test Division

Reproduced by permission of the Adjutant General

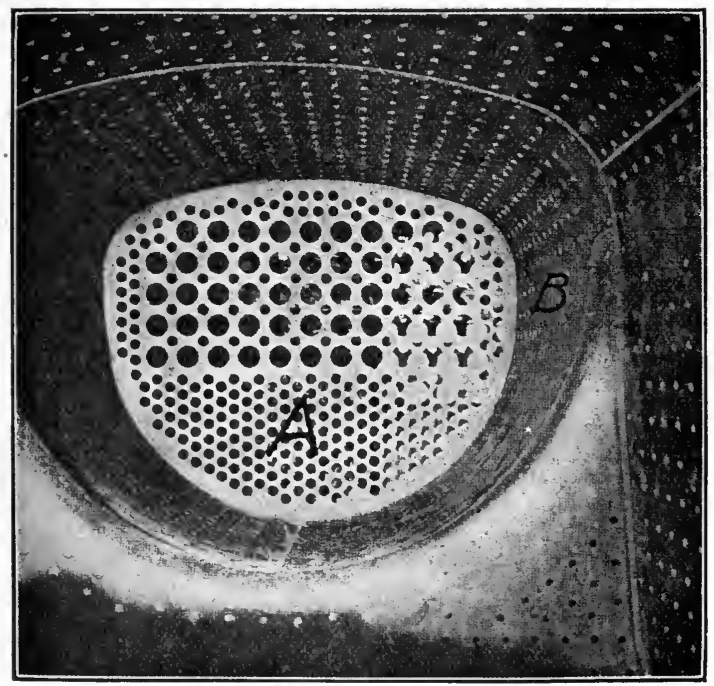

PICTURE 1

1. Q. What are the large holes in that sheet for?

A. Superheater tubes (flues) (units). 
THE PICTURE TRADE TEST METHOD 237

2. Q. What do you call the space between the holes?

A. (I) Bridges.

(2) Pitch.

(3) Ligaments.

(One sufficient)

3. Q. How do you repair a crack in that sheet?

A. (I) Cut (chip) (V) out and weld.

(2) Weld.

(3) Patch (plug).

(One sufficient)

4. Q. What part of that is the combustion chamber?

A. (I) $B(\dot{A})$.

(2) From flue sheet back.

(3) Between flue sheet and firebox.

(One sufficient)

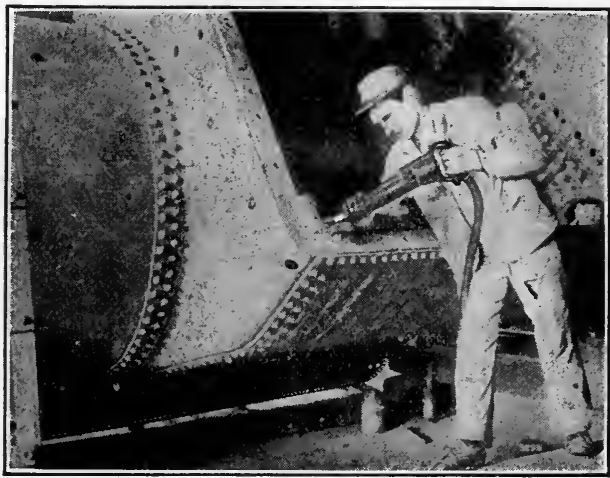

PICTURE 2

5. Q. What is that man doing?

A. Caulking.

6. Q. What is that operation for?

A. (I) Make it steam tight (stop leak).

(2) Tighten sheet.

(One sufficient)

7. Q. What must you usually do to the edge of a sheet before caulking it?

A. (I) Chip.

(2) Bevel.

(One sufficient) 
8. Q. What may happen if the holding rivets are too far from the edge of the sheet?

A. (I) Cause leakage.

(2) Caulking edge (lap) lift (sheet turn up).

(3) Drive sheet off ring.

(4) Undermine sheet (sheet loosen).

(One sufficient)

9. Q. What part of the boiler is that man working on?

A. (I) Mud ring.

(2) Right front corner.

(One sufficient)

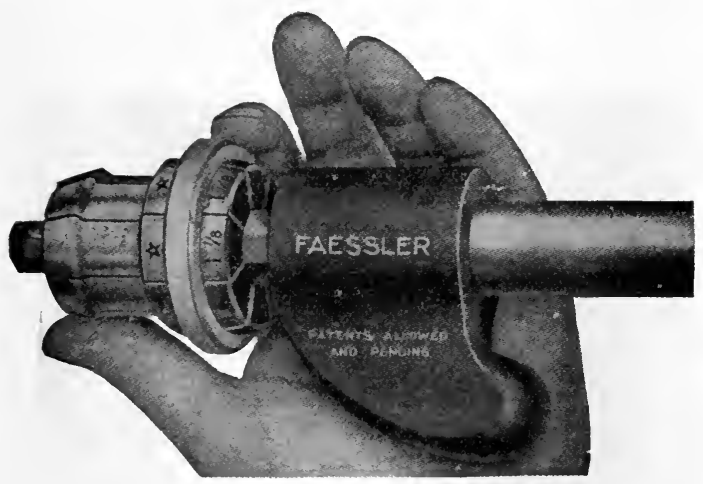

PICTURE 3

10. Q. What do you call that tool?

A. (I) Expander.

(2) Prosser.

(One sufficient)

11. Q. At what point on fig. 5 would that tool be applied?

A. (I) $G(\mathrm{~K})$.

(2) Firebox end.

(3) Rear (back) end (of flue).

(One sufficient)

12. Q. What risk is there in using that tool on running repairs?

A. (I) Break (crack) (fracture) tubes.

(2) Burst flues.

(One sufficient) 


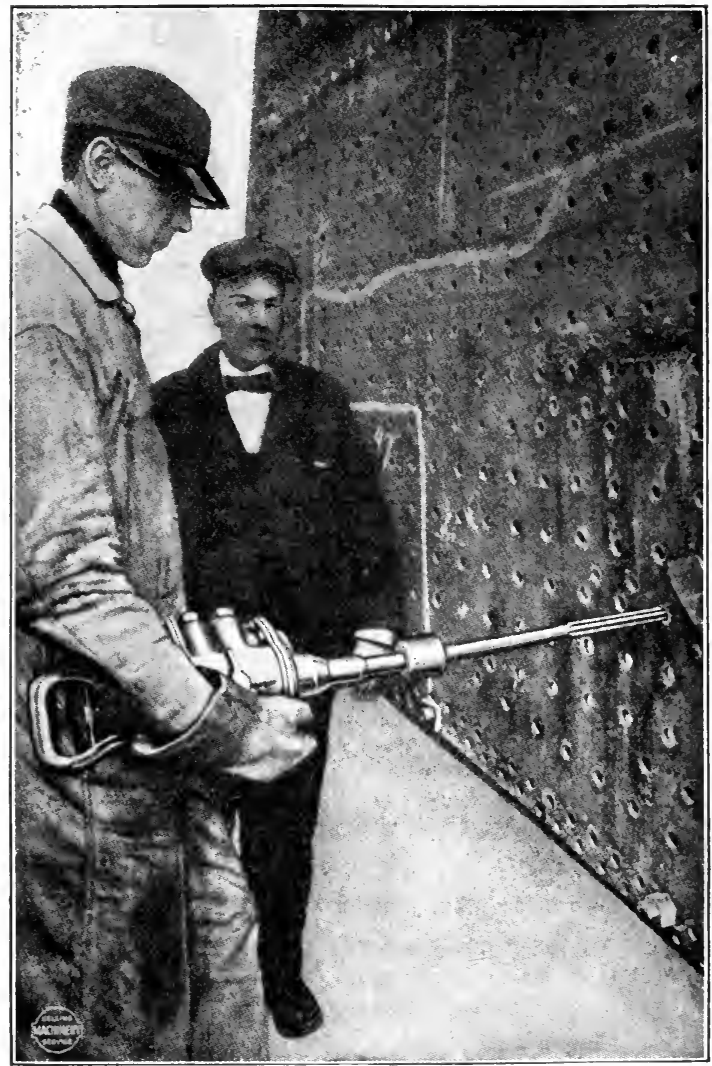

PICTURE 4

13. Q. What are those men tapping?

A. Staybolts.

14. Q. What part of the boiler does that show?

A. Side sheet. 


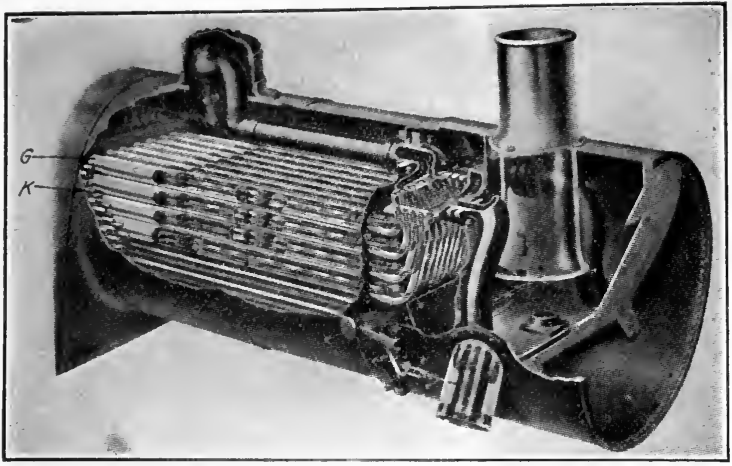

\section{PICTURE 5}

15. Q. What special equipment is shown there?

A. Superheater.

16. Q. What change must be made in the boiler to put in that special equipment?

A. (I) New flue sheets (heads).

(2) Change front and back flue sheets.

(round head and $\mathrm{V}$ head)

(One sufficient)

17. Q. Why are those tubes smaller at G?

A. (I) Not room enough (large hole takes too much of sheet).

(2) Give larger bridge space (not to weaken sheet).

(3) Large size not necessary (no superheater units at G).

(4) Copper ferrule.

(One sufficient)

18. Q. What are the small pipes inside the large ones for?

A. (I) Superheat steam.

(2) Dry steam.

(One sufficient) 
THE PICTURE TRADE TEST METHOD 241

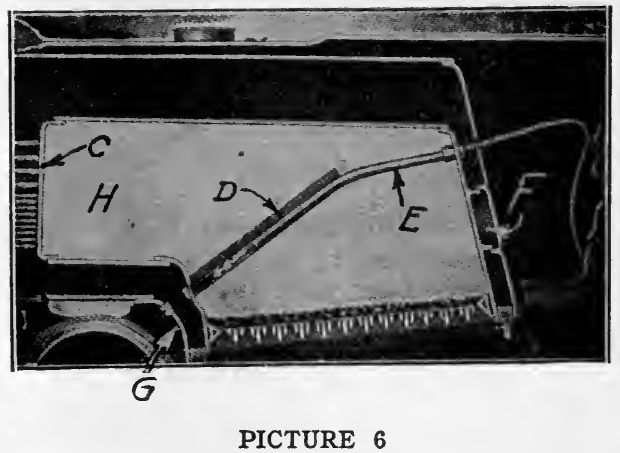

19. Q. What is the purpose of tube E?

A. Arch (bridge).

20. Q. What is being done in that picture?

A. Cleaning.

21. Q. What is the part at D which rests on the tubes?

A. (I) Brick arch.

(2) Arch brick.

(3) Brick.

(One sufficient)

22. Q. How can you tell from that picture that the locomotive has a superheater?

A. (I) Large (superheater) flues (tubes).

(2) Brick arch.

(3) C.

(4) Spacing of tubes.

(One sufficient)

23. Q. What tool would be used for applying tube $\mathbf{E}$ to a firebox?

A. (I) Roller.

(2) Expander.

(3) Beading.

(One sufficient)

24. Q. What do you call the part at G?

A. Throat sheet.

25. Q. What do you call the part at F?

A. (I) Back head.

(2) Door.

(One sufficient) 
26. Q. What causes tubes to blister?

A. Dirt (mud) (sediment) (scale):

27. Q. When tubes become blistered, what must be done?

A. Replace (renew) (remove).

\section{(ORAL)}

28. Q. In testing a boiler, why is it better to use water than steam?

A. (I) Find leaks better.

(2) Safer.

(Both required)

\section{RATING THE CANDIDATE}

I. Score each answer 4 or 0 . Give no partial credits.

2. Rate the candidate according to the following table:

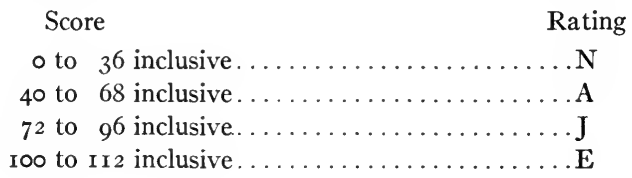


THE PICTURE TRADE TEST METHOD 243

\section{TRADE TEST,}

\section{LEATHER WORKER. - Cobbler}

\section{PICTURE}

COMMITTEE ON CLASSIFICATION OF PERSONNEL IN THE ARMY

Trade Test Division

Reproduced by permission of the Adjutant General

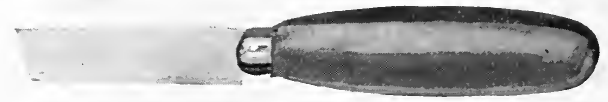

PICTURE 1

1. Q. What is this knife used for?

A. (I) Rounding sole (welt).

(2) Trimming sole (welt).

(One sufficient)

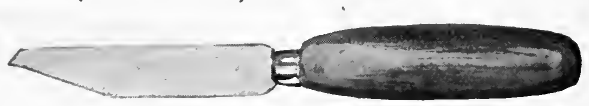

PICTURE 2

2. Q. What is this knife used for?

A. (I) Skiving.

(2) Uppers.

(One sufficient)

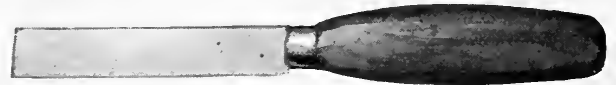

PICTURE 3

3. Q. What is this knife used for?

A. (I) Soles.

(2) Skiving.

(One sufficient) 


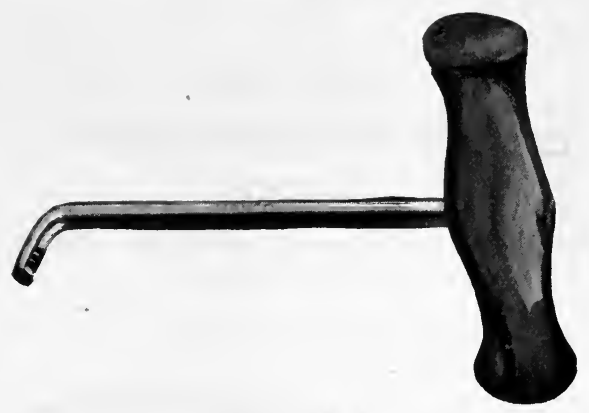

\section{PICTURE 4}

4. Q. What is the name of this?

A. Last hook.

5. Q. What is it used for?

A. Pulling (taking) out lasts.

\section{PICTURE 5}

6. Q. What kind of an awl is this?

A. (I) Sewing. Score 4

(2) Stitching. Score o
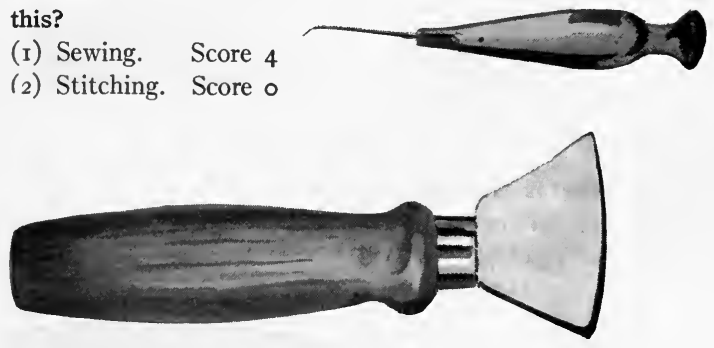

PICTURE 6

7. Q. What is this?

A. (I) Burnisher.

(2) Heel iron.

(3) Burnishing iron.

(One sufficient) 
THE PICTURE TRADE TEST METHOD 245

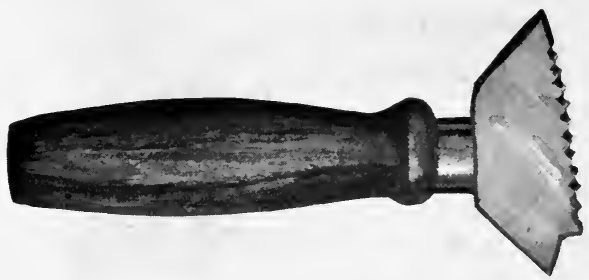

PICTURE 7

8. Q. What is this used for?

A. (I) Burnishing heels.

(2) Finishing heels.

(3) First (roughing) work.

(One sufficient)

\section{PICTURE 8}

9. Q. What is this?

A. (I) Cutter.

(2) Biter.

(3) Nail cutter.

(4) Nail nippers.

(One sufficient)

10. Q. What is it used for?

A. (I) Cutting nails.

(2) Breaking nails.

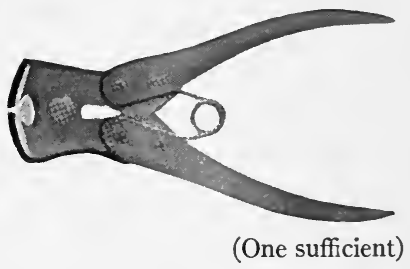

PICTURE 9

11. Q. What do you use this for?

A. (I) Closing uppers.

(2) Hand stitching.

(3) Sewing soles.

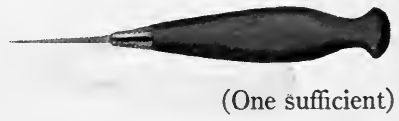

PICTURE 10

12. Q. What is this?

A. Peg (pegging) awl.

13. Q. What is it used for?

A. (I) Making holes for pegs.

(2) Wood pegs.

(3) Wood nails (tacks).

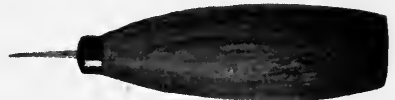

(One sufficient) 


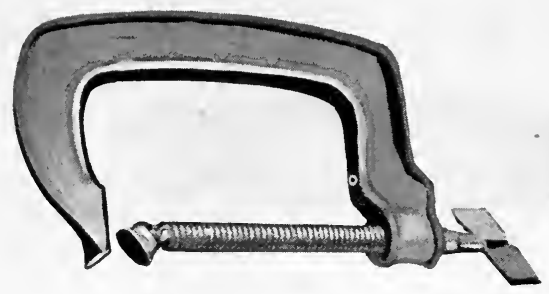

\section{PICTURE 11}

14. Q. What do you use this for?

A. (I) Clamping heels.

(2) Holding heels.

(3) Wood heels.

(One sufficient)

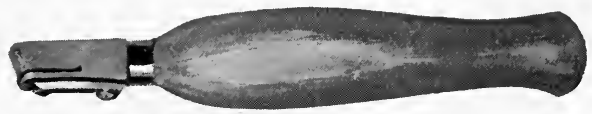

PICTURE 12

15. Q. What is this used for?

A. (I) Finishing heel (seats).

(2) Marking heel (seats).

(One sufficient)

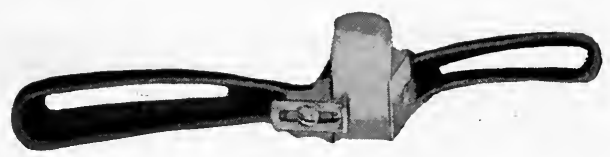

\section{PICTURE 13}

16. Q. What is the name of this?

A. (I) Edge shave.

(2) Edge trimmer.

(3) Shave.

(One sufficient) 
THE PICTURE TRADE TEST METHOD 247

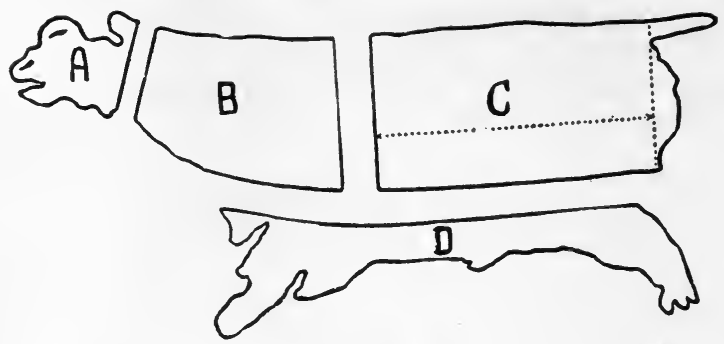

PICTURE 14

17. Q. This is a side of leather,

(a) From what part do you get heel stock?

(b) From what part do you get light soles?

(c) From what part do you get insoles?

(d) From what part do you get prime soles?

A. (a) A. and D. (b) B. (c) A. and D. (d) C. (Any 3)

PICTURE 15

18. Q. This picture shows shoe cut across.

What part of the shoe do you call part at " $\mathrm{A}$ "?

A. Upper (vamp).

19. Q. What is the name of the part of the shoe at "B"?

A. Lining.

20. Q. What do you call , "C"?

A. Insole.

21. Q. What is " $\mathrm{D}$ " called?

A. Welt.

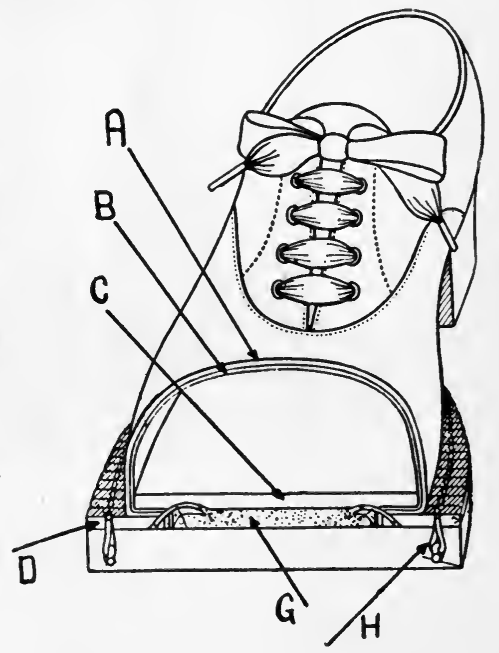


22. $\mathrm{Q}$. What is " $\mathrm{G}$ " called?

A. Filling.

23. Q. What parts does stitch " $\mathbf{H}$ " fasten together?

A. Outsole to the welt.

\section{RATING THE CANDIDATE}

Score

Rating

$\circ$ to 20 both inclusive................. Novice

24 to 40 both inclusive................. Apprentice

44 to 72 both inclusive............... Journeyman

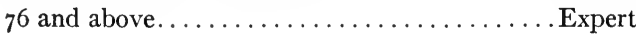


THE PICTURE TRADE TEST METHOD 249

\section{TRADE TEST}

\section{WELDER. - Gas Welder}

PICTURE

COMMITTEE ON CLASSIFICATION OF PERSONNEL IN THE ARMY

Trade Test Division

Reproduced by permission of the Adjutant General

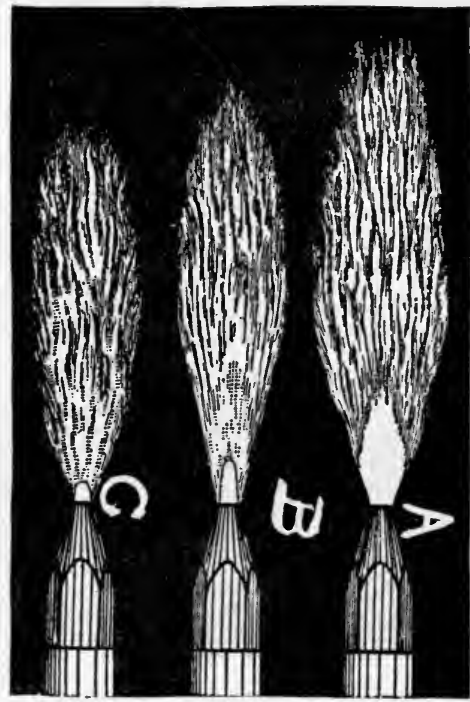

PICTURE 1

1. Q. What kind of flame is shown at $\mathbf{A}$ ?

A. (I) Carbonizing.

(2) Excessive acetylene.

(3) Crystallizing.

(One sufficient) 
2. Q. What kind of flame is shown at B?
A. (I) Neutral.
(2) Welding.

(One sufficient)

3. Q. What kind of flame is shown at C?

A. Oxidizing (oxygen).

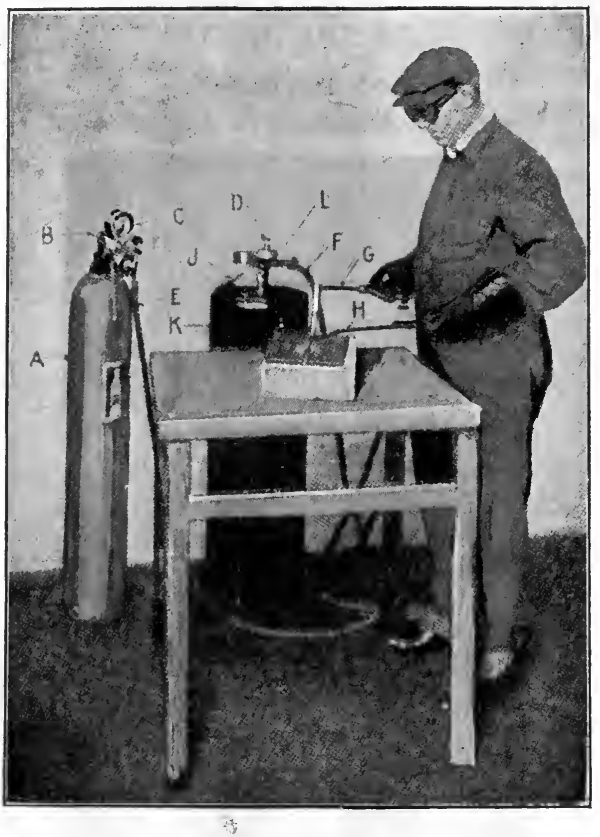

\section{PICTURE 2}

4. Q. Why is flux used in welding cast iron?
A. (I) Clean.
(2) Reduce oxide (remove scale).

(One sufficient) 


\section{THE PICTURE TRADE TEST METHOD 251}

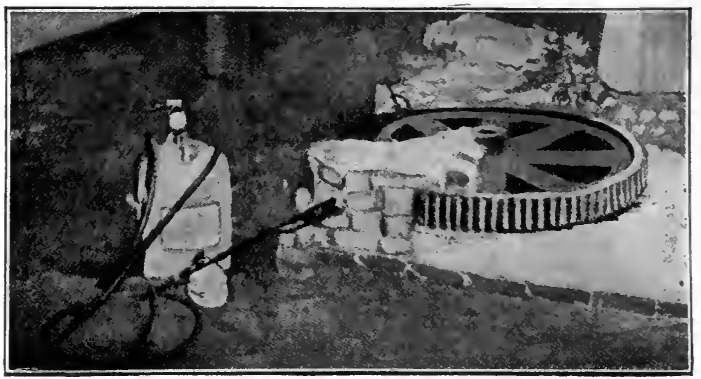

\section{PICTURE 3}

5. Q. Why is the operation in that picture necessary?

A. (I) Expansion and contraction.

(2) Crack.

(One sufficient)

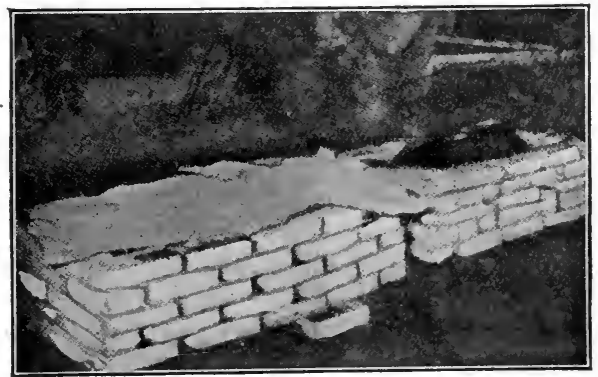

PICTURE 4

6. Q. What kind of pre-heating is being used there?

A. Charcoal. 


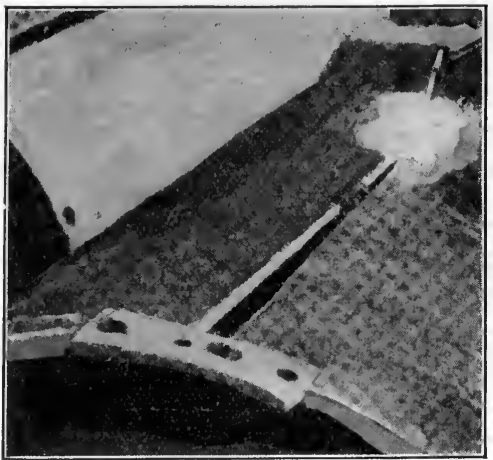

PICTURE 5

7. Q. What would happen if that plate were not held open during welding?

A. (г) Over-lapping (lap).

(2) Warp (buckle).

(One sufficient)

PICTURE 6

8. Q. What is the material around the blow pipe on that fender?

A. (I). Asbestos.

(2) Clay.

(One sufficient)

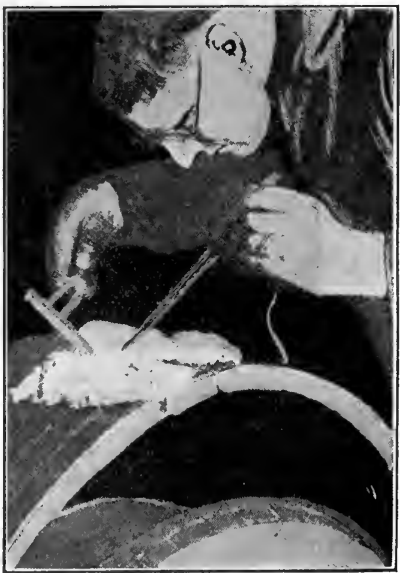


'THE PICTURE TRADE TES'T NETHOD 253

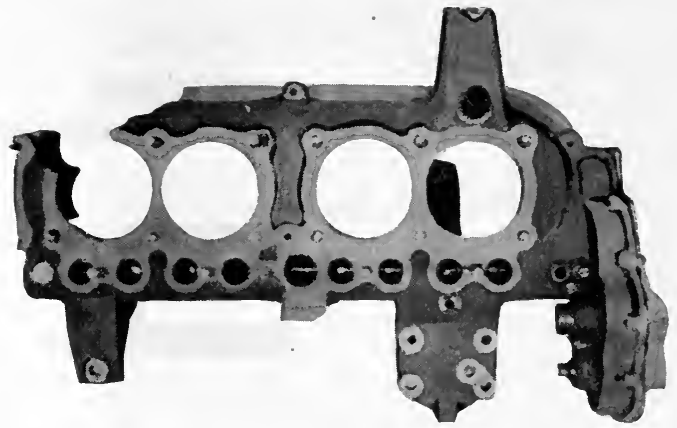

PICTURE 7

9. Q. What must be done in preparing that casting for welding?

A. (a) Line up case (fit piece).

(b) Pre-heat.

(Both required)

10. Q. What would result from over-heating that casting?

A. (I) Collapse.

(2) Crumbles.

(One sufficient)

PICTURE 8

11. Q. What is wrong with the welding at $\mathrm{B}$ ?

A. Burned (Oxidized).

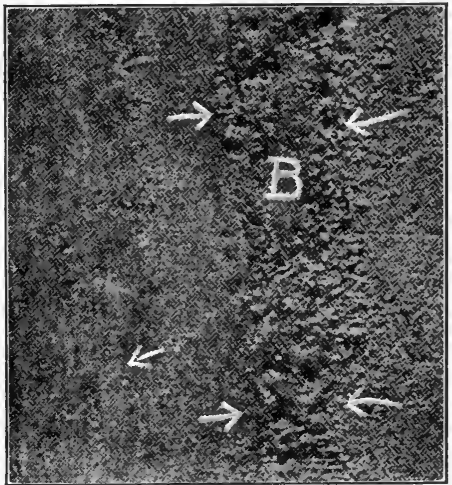




\section{PICTURE 9}

12. Q. What kind of weld is shown at $\mathbf{A}$ ?.
A. Lap.

\section{A}

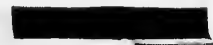

13. Q. What kind of weld is shown at $B$ ?

A. Butt (end to end).

14. $\mathrm{Q}$. With what thickness of metal may the weld at $\mathrm{C}$ be properly used?
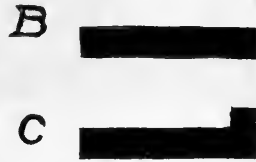

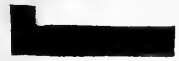

A. Thin. (Light.)

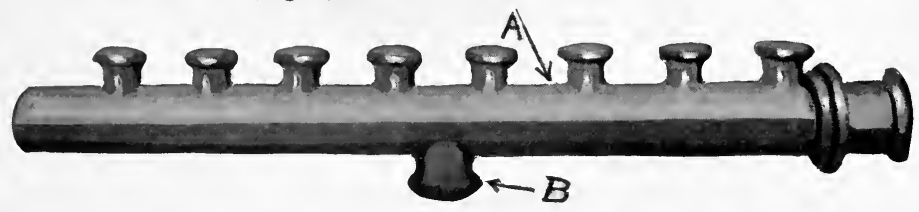

PICTURE 10

15. Q. What metal should be used as a filler rod in welding parts A and B together; A being of cast iron and B of steel? A. Cast iron.

\section{PICTURE 11}

16. Q. What is the relation between the pressures of the gas and air in that blow pipe?

A. Air (oxygen) greater. 


\section{THE PICTURE TRADE TEST METHOD 255}

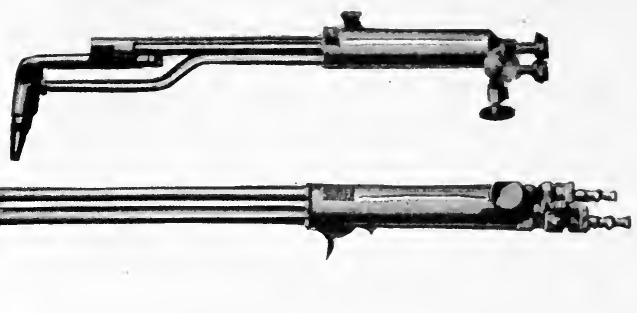

PICTURE 12

17. Q. What are those blow pipes used for?

A. Cutting.

RATING THE CANDIDATE

Score

Rating

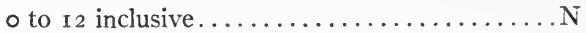

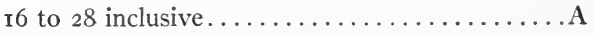

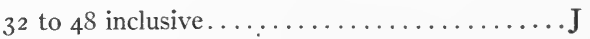

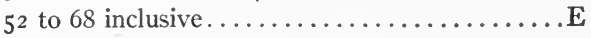





\section{SECTION IV \\ TIIE PERFORMANCE TRADE TEST}




\section{CHAPTER VI}

\section{THE GENERAL NATURE OF THE PERFORM- ANCE TEST METHOD}

THE performance test is nothing more than a standardized, practical trade job, involving the use of blue prints, material and tools characteristic of the trade. The word performance is here used in an arbitrary but definite way. It means the carrying out, with the help of tools and equipment, of certain processes of the trade. Strictly speaking, the oral and picture tests are just as much performances as an actual operation of the trade. In one case the performance is largely mental - the answer being oral; in the other case the performance is largely manual - the operation of the hand. It will, however, for the purpose of presentation, be convenient to limit the use of the word performance exclusively to actual work done under conditions essentially similar to those found in the trade.

This method of testing is more closely related to that which has been used in industry than any of the methods previously described. The most common method, after the preliminary interview has taken place, is to refer the applicant to that department in which he claims to have skill. On reaching this department the actual test for skill may be of two kinds. In one case the tradesman is actually put to work, using the tools of the trade in the actual job for which he is hired. His success or failure during the first two or three days determines whether he has the necessary skill. Another device, less frequently employed, is to try the man out on a single representative opera- 
tion of the trade. His success or failure in this one typical job is used as an index for estimating his total trade ability. The advantage of this second method is found in the fact that it gives a much more rapid estimate of general ability, it enables a large number of bluffers to be rapidly eliminated, and it saves a good deal of waste material and damaged machinery. It is obviously very wasteful to put a man directly on a complex job, involving the use of expensive machines and much material, when a representative sample job, involving few tools and a small amount of material, can be used for the same purpose.

When it became necessary to give some form of test to tradesmen in the army, naturally this method of examination was thoroughly investigated to see in what way it could be applied to meet army requirements. In order to give such a performance test two conditions are necessary: on the one hand the tools and the material, and on the other, an expert to judge the success with which the task has been performed. While these conditions are automatically secured in any industry, the reproduction of these conditions for hundreds of trades in all the army camps obviously presented great difficulties. It will be remembered that the chief requirements of the army situation were:

I. The method must be such that it can be employed by an intelligent examiner who has no knowledge of the trade.

2. The method must yield a rating which is objective.

3. The method must be rapid and inexpensive.

The question, therefore, facing those working on the feasibility of the performance test was to construct a general method whereby the tradesman could be tested in a straightforward, significant job which would require a sufficiently simple equipment to admit of its being employed without undue expense in many centers. In addition, it was absolutely necessary to work out a system which would enable an intelligent examiner 
who had no specific trade skill, to rate the candidates' performance in an objective manner. It can readily be seen that much greater difficulties had to be met than those encountered in the construction of the oral or picture test.

\section{The Advantages of the Performance Trade Test Methods}

The performance test method possesses so many advantages that it was well worth the time to investigate whether or not the obstacles could be surmounted. Many occupations exist in which it is almost wholly a question of degree of skill rather than range of information which distinguishes between different degrees of ability. The oral and picture tests measure trade skill indirectly by ascertaining the amount of information possessed by the tradesman. This method, however, breaks down completely when there is no high correlation between information possessed and trade usefulness. In the case of stenog- raphy, the distinction between the poor typist, or even the learner in typewriting and the trained expert does not lie in the information possessed. Both know, as far as any oral test could reveal the fact, the position of the keys on the machine, the forms in which a letter or document should be written, etc. The distinction lies in the speed possessed by the expert as compared with that found in the slower typist. To differentiate between these two kinds of trade usefulness, the performance test, where the individual is actually given a piece of work to do, is the only possible resort. The same is true for such occupations as truck driver, computer, clerical worker, and countless other occupations where information is a minimum and skill a maximum. This condition is found to a great extent in modern production methods of industry, where the process upon which the tradesman is engaged is exceedingly specialized, demanding a minimum of knowledge and a maximum of speed. 
The performance test is also indispensable in the examination of tradesmen who are unable to speak the English language. In certain important occupations in many parts of the country the skilled work is being done almost exclusively by men who are incapable of being tested by any method involving language to the degree called for by the oral and picture test. For example, in the city of Cleveland it was extremely difficult to standardize, under fair conditions, the oral test for cabinet makers; eighty per cent of the men who by trade standing were qualified to take the examination were prevented from doing so by language difficulty. Where this situation exists, the oral or picture test is much more a measurement of language facility than it is of trade information, and for these reasons, where the tradesmen are not English speaking, the findings are very misleading.

A further advantage of the performance test is found in its obviously practical nature. It has already been emphasized that, other things being equal, any trade test is advantageous . to the extent to which it reflects the shop conditions under which the ordinary workman follows the trade. The performance test possesses this great merit, and on this account establishes the confidence of the tradesman both in himself and in the method of examination. The considerations enumerated above made the use of the performance test method indispensable as part of the army selective machinery.

\section{The Difficulty of Procuring an Adequate Sample of Trade Ability by a Single Performance Test}

In connection with the oral method of examination the question of the random sampling of trade information and trade ability has been discussed. In general the complex which is referred to as trade ability consists of many elements of information and a large number of skills. It has been proved that 
fifteen to twenty questions, so chosen as to cover different processes of the trade, can be used as an adequate sampling of total information. It is obvious, however, that as the number of questions is reduced, the assumption that the test will give an indication of general trade information and ability, becomes increasingly dangerous. To attempt to measure the ability of a tradesman with a single question is, on the face of it, absurd. One question might be merely a matter of accidental information, which might conceivably be possessed by an individual who had no knowledge of any operation other than that concerning which the question was asked. It is around this question of the sampling of total trade ability that one of the great difficulties of the performance method centers.

If, with twenty questions, involving twenty different phases of the total occupation, there is difficulty in ensuring a random sampling, how much greater is the difficulty in the case of a single operation! The reader may be tempted to ask, "Why was it necessary to restrict the performance to a single job? Why could not the performance test cover a large number of different operations of the trade?" The reason that many operations could not be included in one composite test lay in the limitations as to time and expense fixed by the army situation. To administer twenty oral or picture questions was a matter of ten to fifteen minutes. The simplest form of performance test in the majority of trades would occupy from one to three hours. A sampling including a number of jobs would involve not only a great deal of equipment, but would also take two or three days to furnish a rating. When it is considered that the army required a test which could be given in all the camps in a minimum of time, the impracticability of a long performance test is patent.

It may be mentioned in passing, however, that this was prac- 
tically the only method employed by the British Army. Owing to the geographical conditions and general methods of operation of their army, it was possible to assemble all men claiming trade skill in one or two large centers. At these centers were found the tools and materials of a fully equipped shop, with trade experts in charge having full knowledge of army requirements. The recruit in passing through one of these stations was assigned a number of jobs. While working on these various jobs, his dexterity and familiarity with the processes were observed. It was possible under these conditions to note the points of strength and weakness, and on this basis to make recommendation for further training or assignment to a suitable unit. This examination, which often extended over a period of from two days to a week, failed, in spite of its thoroughness, to yield an objective rating. The estimate made of the man's ability was of course dependent upon the subjective judgment of the particular examiner who observed his work. This method of examination will, however, be discussed more fully when we consider the applications of trade test methods to modern conditions.

The restriction as to the time allowed for the examination made it necessary to select a single operation of the trade which could be completed in one or two hours at the most, and which would furnish a reliable index of general trade efficiency. Naturally, a single operation in the trade might well involve the use of a considerable number of tools and the handling of various kinds of material. For example, the total operation of making a small tin cup according to specifications, as a performance test for sheet metal workers, involves efficiency in a large number of contributing minor operations. Other things being equal, that total operation is of the greatest value from the standpoint of testing which involves the largest number of significant minor processes. 


\section{Kinds of Performance Test}

For present purposes it is convenient to distinguish between the process and the product of a trade operation. While the two, in many cases, are very closely related, and in fact almost indistinguishable, in other cases the product may be considered apart from the process. As an illustration of process and product being almost inseparable, an operation such as that of truck driving may be cited. There is in this case no possibility of drawing the line at any time during the operation between the process and the product. The "product" of turning a difficult corner is virtually the "process" of turning a corner. In the case of the construction of a tin cup, the processes involved in the choosing of materials, their cutting, shaping, soldering, etc., can all be observed, even though the final product, the completed cup, is never seen.

In the case of a process performance test the candidate would be watched during the progress of the examination. His familiarity with tools and material, his skill and dexterity would be judged, even though the examination was not carried to a point where any tangible final product was evolved. The way in which the man went about his work, the tools that he chose, the remarks that he made, the order in which he tackled the various steps, all this could be observed without reference to the final product.

In the case of the product test, there need be no observation of the man while he is performing the task. A carpenter might be given the necessary specifications, materials and tools for the construction of a joint. He would then be set to work at the bench, no further attention being given except to insure the absence of outside assistance. At the end of the trial, the quality of the product could be examined and rated according to previously formulated objective standards. 
The last illustration brings us to the consideration of the question of speed of operation. It may well be that a very simple product, which could be turned out even by an apprentice would, when the time factor is considered, differentiate between men of varying trade experience. It would not be a matter of the quality of the product, but rather the facility and dexterity possessed by the tradesman, as indicated by the time he took to perform the task. In illustration of this, the case of the distinction between the poor and good typist may be cited. If both are given the same copy, it may well be that they would both hand in identically the same final product, but whereas, in the first case, the time taken might be twenty-eight minutes, the corresponding time of the expert might well be thirteen minutes. The distinction between the two levels of ability is, therefore, in this case, one that admits of being measured by a time factor. It is not to be inferred that the process by which the final copy is produced is the same in the two cases. An observation of the two typists at work would show at once that the processes differ much more than in mere speed. The operations of a skilled individual in a particular process are different operations, not merely more rapid ones than those of the unskilled worker.

There are, then, several elements from which the performance test is evolved. These are,

I. Observation of tradesman while engaged in the processes of the trade.

2. Examination of the resulting product.

3. Consideration of the time taken, either for a particular process, or for the producing of a particular object.

In addition, combinations of the first and second factors, second and third factors, and of all three may well be used in the construction of a performance test. . Simple illustrations of each of these possibilities are given. 


\section{Process Test}

In a test for chauffeur truck driver, the candidate would be scored, according to the way in which he handled a truck, under standard conditions, when under the observation of the examiner.

\section{Product Test}

In a test for an expert toolmaker, a very difficult part might be given, the tradesman being required to produce to within a few thousands of an inch a part from raw stock, similar to the sample. Here time might not be considered, the fact that the workman was capable of reproducing the part furnishing sufficient evidence for rating.

\section{Process Time Test}

In a test for a machinist, the speed with which a machine could be changed from doing one job to another requiring a different set-up might be measured; the examiner would rate the workman according to the correctness of the various steps, as well as on the basis of his speed in passing through the several stages.

\section{Product Time Test}

In a test for typist, not only would the quality of the final copy be examined, but also the speed at which a definite amount was produced.

\section{Process-product-time Test}

This is a common type of informal test used in industry, where the workman, say an automobile radiator repair man, is given a radiator, damaged in a known way, to repair. His performance is judged partly by the way in which he handles and chooses the implements of his trade, partly by the quality 
of the final job turned out, and partly on the basis of the time taken for the carrying out of the operations.

As to which one of these methods shall be employed, the decision depends on the conditions for which the test is designed. To meet army requirements of speed and objective scoring by non-tradesmen the product-time method is usually the most useful. In certain cases, however, as in the auto driver, the process test can be used to greater advantage. With reference to the process method, it may be noted that although time may not be actually measured it is not wholly neglected, for the conditions of the experiment naturally set a limiting time for the carrying out of the operations. Provided the procedure is gone through within this time, which is ample, no note is made of the speed of the operation.

\section{Guiding Principles in Determining Selection of} Performance Test

The first requisite of the performance test is that the nature of the task should be, as far as possible, typical of the actual work of the trade. Where a trade, particularly in its higher branches, becomes very specialized, the actual task chosen for the performance test must be such that it is common to the maximum number of these specialized branches. It is also exceedingly desirable to arrange the test so that it can be used as an examination for all tradesmen, irrespective of their trade status. The rating of the tradesmen as apprentice, journeyman or expert should be determined by the time required for the completion of the task, by the quality of the workmanship, or by both. While for other than army conditions it may well be desirable that three performance tests be given, one being suited to those of apprentice standard, another to journeyman standard, and the third adapted to the expert group, yet this 
method was not feasible for the rapid examination of men of unknown trade status in the army.

The process test has certain merits. The most frequent and insistent contention of experts in the field is that it is necessary, in order to judge the skill of a tradesman, to watch him at work. Only by actually observing him on the job is it possible to get a full idea of the way in which he handles his tools, his material and himself. A judgment of this kind tends to include more than merely manual skill. It also gives a basis for estimation of general intelligence, physical strength, perseverance and the like.

The chief demerit of the process test is that the judgment rendered by the examiner, even when an expert in the trade, is subjective. In a large majority of the cases where unskilled examiners must be used, it is impossible to obtain an adequate objective judgment. In opposition to this method of examination, let us contrast the "product-time" test. Here the final object produced has to be rated, and not the operations which led to its production. The examination of the object, with a view to rating, can be leisurely. It can be judged by reference to certain standard samples or objects, and it can also be scored by several examiners, thereby greatly increasing the reliability of the judgment. The product test is also far superior to the process test from the standpoint of administration. The process test calls for continuous observation by the examiner, his time is apt to be taken up exclusively by one tradesman, whereas in the product time test, the examiner, after assigning the task and distributing the material and tools, has merely to note the time at which the candidate hands in the finished product. Consequently many examinations can be given simultaneously. It may be urged by some readers that an unduly fine line has been drawn between the process and the product form of examination. There is, in the last analysis, little distinction be- 
tween the two. In many cases they are so interrelated that even for purposes of presentation there are certain dangers in making such a clear differentiation. Whenever the final product of an operation, together with the time taken for its perform-

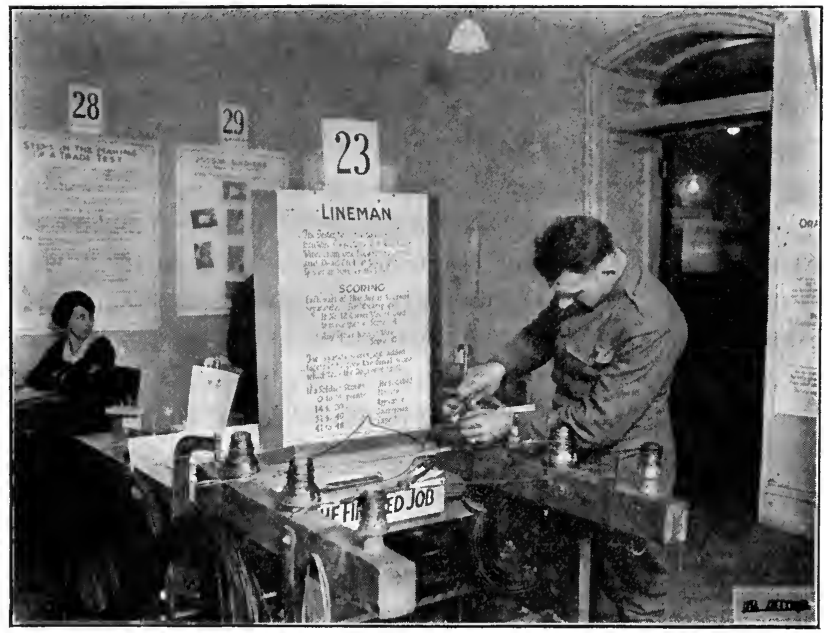

Sample page of performance test in operation (Lineman).

ance, is judged, this judgment applies also indirectly to the process leading to the product.

The more this relationship is analyzed, the clearer becomes the fact that the product-time test covers almost everything involved in a process test.

Assuming, therefore, the general advisability of using the product-time test, the question as to which operation should be chosen depends on a number of factors. Among these the following need special mention. 
I. The operation should be sufficiently exact, so that time and product admit of accurate standardization, thereby enabling objective judgments to be made.

2. The combined ratings of time and quality of product should differentiate between men of different levels of trade ability.

3. The task should be of such a nature as to command the respect and establish the confidence of the tradesman.

4. Equipment, material and tools must be reduced to the smallest practical quantity, and must be capable of standardization, so that all tests can be given under the same conditions.

5. The operation must not require undue length of time for its completion, and should contain within itself as little repetition of procedures as possible.

To summarize, a performance test is a standardized practical trade job, involving the use of blue prints, material and tools characteristic of the trade. The purposes of a performance test are:

I. To measure the ability of the candidate in the actual handling of the equipment, and material of his trade.

2. To check the rating given by any of the ordinary interview methods. Discrepancies between the candidate's performance ability and his rating by any oral interview method may be due to (a) language considerations, (b) coaching, (c) technical school training.

3. To give an objective rating when the nature of the trade is such that an oral examination cannot be satisfactorily given. 


\section{CHAPTER VII}

\section{THE CONSTRUCTION OF A PERFORMANCE TEST}

The Construction of a Performance Trade Test

When, for any of the above reasons, it was tentatively decided to construct a performance trade test, the stages through which the test passed were as follows:

I. Inquiry concerning feasibility of this type of test.

2. Collection of trade information and material.

3. Preliminary testing on not less than three experts, three journeymen and three apprentices.

4. Revision and final formulation.

5. Final testing on a larger group of apprentices, journeymen and experts.

6. Statistical treatment of results and calibration of the test.

It will be seen that these stages closely correspond to those through which the oral and picture test pass. In describing these processes for a performance test it will only be necessary to show where the differences in procedure exist, and to discuss the peculiar difficulties arising in connection with the construction of such a test.

\section{Inquiry Concerning Feasibility of This Type of Test}

The first point of investigation concerns the relationship existing in the trade between information and manual skill. This inquiry consists of a review of: 
I. The equipment, materials and tools with which a man works.

2. The kind of work produced.

3. Trade processes, such as laying out, cutting, etc.

(a) An enumeration and description of the significant elements.

(b) A classification of these elements, particularly with reference to whether they belong primarily to the work of an apprentice, journeyman or expert.

The sources of this information are:

I. Suggestions from experts.

2. Suggestions from employers.

3. Literature of the trade, which may be in the form of text books or catalogs.

4. The methods of training in trade schools.

5. Trade investigations.

\section{Collection of Trade Information and Material}

Using the methods and facilities above described, by looking at products and processes in the shop, a compilation is made of that material which might contribute to the construction of the performance test. This compilation is made in conference - with several expert tradesmen in different plants, working under different conditions. From what has already been said concerning the difficulties of securing a single job which may be representative of trade ability and trade skill, it will be apparent that these performances have to be selected with the greatest degree of care. An operation is of no service as the basis of a performance test unless (I) it will differentiate between different levels of trade ability; (2) it can be administered with fairly simple equipment; (3) it can be administered and be rated in an objective manner by a non-tradesman. All of 
the above considerations have to be taken into account in the selection of the final performance which is to be used in the test. A particular job may conform to one or two of the requirements and yet be useless because it fails to satisfy others. Again, the contribution made by the tradesman is found in the information furnished with regard to the suitability of the performance as a measure of trade ability. The contribution made by the compiler lies in the decision as to whether the job can be made to conform to the requirements of an objective test, suited to the other demands of the examination. Of the several possible jobs selected, all but one or two are eliminated by consultation with expert tradesmen or by rapid try-out.

For the jobs which still appear to be suitable when all available information has been obtained, the necessary tools and materials have to be collected. This involves in many cases the assembly of blue-prints, drawings, and detailed instructions. The final stage of the compilation process is the reduction of the test to a tentative form in which specific instructions to the candidate are formulated, together with definite instructions to the examiner with regard to the administration and scoring of the test. There must also be a complete statement of the equipment and facilities necessary for the carrying out of the process. While these requirements cannot be completely met at this early stage the general nature of the test procedure must be outlined before the passage can be made to the next stage, that of the preliminary testing on tradesmen of different known levels of ability.

\section{Preliminary Testing of Tentative Form of Performance Test}

When the performance test has been reduced to a fairly definite form, particularly with regard to the instructions given to the tradesman and the equipment necessary for the process, 
the preliminary sampling takes place. This consists of administering the test to not less than three experts, three journeymen and three apprentices, the different grades of ability being taken alternately. The functions of this preliminary experiment are manifold. The most essential information which is secured has reference to the differentiating value of the test, answering the question as to whether the performance, scored by any possible objective means, can be expected to differentiate between tradesmen of different abilities. It also serves to bring out the administrative difficulties of the test, and gives an approximate idea of the time consumed. Furthermore, it provides information from which the scheme of scoring can be more fully constructed. In addition it furnishes a more accurate basis for the compilation of the necessary equipment, material and tools. It also reveals the extent to which the preliminary instructions to the candidate are adequate. Finally, it gives information with regard to the extent to which this particular test conforms or fails to conform to the other criteria of performance tests which have been mentioned. If the above requirements can be met and the difficulties avoided, the test now passes to the next stage.

\section{Revision and Final Formulation}

On the basis of the full records of the nine men tested, together with the finished products (when the test is of this type), the process of revision now takes place. Some elements of the test, which prove to have no differentiating value, are eliminated; other elements are altered and occasionally new elements, which the preliminary experiment brought to attention, are added. These changes necessitate the drawing up in final form, collecting the instructions to the candidate, a full statement of the test equipment, and also detailed instructions to the examiner 
as regards administration. The performance test is now in its final form and it remains hereafter unchanged. Following these precise directions, the test is now administered in a routine manner, for the purpose of final testing and calibration.

\section{Final Testing on Larger Group of Apprentices,} JOURNEYMEN AND EXPERTS

Using the criteria of apprentice, journeyman and expert which have already been given in the description of the oral test, fifteen apprentices, fifteen journeymen and fifteen experts were now subjected to the standardized form of examination. These tradesmen were taken from different plants, working under different trade conditions. Ideally the examination should have been given in different localities, as was the case in the oral and picture tests, but this was not found to be practicable. During these examinations the fullest notes were taken, the times of performance noted, and the finished products labeled. These records furnished the basis for the last stage through which the test passed.

\section{Statistical Treatment of Results or Calibration of Test}

The method of evaluation varies so much from test to test, that it is impossible to describe, except in the most general terms, the process whereby the final method of scoring in each test was evolved. The procedure in the case of the oral test standardization was always the same, and eventually it developed into a purely routine statistical procedure. This was not the case with the performance test. Here there was room for the utmost ingenuity in the selection and weighting of the different elements which comprised the whole examination. It will be necessary to refer to the methods of scoring shown in the tests themselves, to realize the significance of this state- 
ment. The following, however, gives in a general way an account of the procedure. The object of the evaluation was to pick out certain elements of the test, usually qualities of the product, and to weight these qualities in such a manner that when combined with the time factor, the most marked differentiation between the three levels of tradesmen was obtained. In other words, a numerical expression had to be worked out, in which the various elements of the test were so appraised that the test would exert its maximum differentiating power. To accomplish this purpose, it was necessary to single out those aspects of the test which, in addition to differentiating, were also capable of being scored on an objective basis. The extent to which objectivity of marking was secured was discovered by framing standardized directions for scoring, and then noting the variation which existed between the marks given by various examiners. When reasonable objectivity of scoring was obtained with reference to a particular aspect of the test, a full description of what constituted the various scores was compiled. It can readily be seen that certain phases of the operation are of much greater importance than others. This was recognized in the marking by assigning different scores to different elements. This is what is meant by "weighting" the various parts of the test. In deciding the amount of these weightings, graphs were drawn, somewhat similar to that which has been presented in the corresponding stage of the oral test. The combined scores on all aspects of the tests were thus determined for the forty-five tradesmen to whom the test was given, and from this distribution the critical scores corresponding to apprentice, journeyman, and expert status were then determined, the lines of demarcation of the three levels being so chosen as to secure the maximum correspondence between the verdict of the test and the known trade abilities of the workmen. This completer 
the stages through which the performance test passed from the initial inquiry concerning its feasibility to the final determination of norms of performance.

\section{Divisions of a Performance Test in Its Final Form}

I. The first part consists of the test specifications, which are described under thiree heads:
A. Equipment.
B. Material.
C. Tools.

II. The second part consists of instructions to examiners. These instructions may be divided into two parts:

A. Those instructions which are necessary for the preparation of the test.

B. Instructions to be given to the candidate. These instructions are usually of an oral nature, and explain to the candidate the nature of the task; making the necessary reference to blueprints, diagrams and specifications. They are given in a perfectly standardized way. It is merely a matter of reading the directions. The examiner is not allowed to deviate in the least degree from the printed form. When these instructions had been given, it was customary to say to the candidate: "Now just to make sure that you understand what is wanted, suppose you tell me what you are going to do." The examiner at this stage was allowed to repeat all, or any part of the instructions, but he was not allowed to alter or add to them in any way. If during the performance the candidate asked any questions, the examiner was restricted to repeating merely that part of the prescribed instruction which covered the question asked. If the question covered a field not touched upon in the instruction, 
the examiner answered: "I have given you all the instructions which are allowed in this test."

III. Instructions to examiner with reference to scoring.

These may be divided into two parts:

A. Detailed instructions with regard to scoring the various qualitative aspects of the product. As full an account as possible of the requirements of each aspect necessary to receive a certain credit is given.

B. Full directions are also given as to the manner in which the time factor should be treated, when it enters.

C. Final rating of candidate. When the total score of the candidate, which may be in terms of time, in terms of quality, or in both, has been calculated, the examiner has merely to follow the directions given under "Basis for scoring" to decide whether the candidate is an expert, journeyman, apprentice or novice.

IV. Method of administering performance test.

The following are the general instructions, issued to the examiners for giving the Performance Test.

\section{Giving the Tests}

I. Before giving a test, the examiner will make a statement to the candidate which must cover and be limited to the following points:

(a) Name of the trade.

(b) Reason for giving the test.

(c) Importance of working carefully or rapidly, or both.

2. The exact wording is not prescribed because of the obvious difficulty of making it suit all examiners under varying conditions.

Note the following sample statement: "We are going to give you a practical job in Pattern Making to find out how much 
you know about your trade. Work as quickly and as well as you can." Follow with the specific instructions.

3. Specific instructions for every performance test are different. Therefore examiners will study carefully each performance test before attempting to give it.

4. A performance test consists of five parts:

I. Test equipment.

II. Instructions to the examiner.

III. Instructions to the candidate.

IV. Instructions to the scorer.

V. Instructions to the rater.

\section{Test Equipment}

I. Equipment, materials and tools are described in detail. There should be no departure from these specifications.

2. In some tests the layout or arrangement of equipment before the candidate, determines the character of the test. The exact position of each part in relation to the other parts of the test is specified. Any deviation from the prescribed arrangement destroys the value of the test.

3. All cutting tools, such as chisels, drills, saws, and the like, must be sharp and in good condition for each test.

\section{Instructions to the Candidate}

I. Instructions which the examiner is to give the candidate are specified in each test. These' instructions must not be changed or added to in any way.

2. After the candidate has received these instructions the examiner will ask him, "Are there any questions?"

3. The examirier may repeat, when necessary, all or any part of the instructions. The examiner will answer no questions 
the candidate may ask during the test except by repeating the printed words which relate to the question asked.

4. When time is an element of the test, the examiner will record the time required by the candidate to do the work. The time spent in giving the original instructions will not be included.

\section{Scoring}

I. Before attempting to score the product, the examiner must be familiar with the "Basis for Scoring."

2. Partial credits will be given only when permitted by "Requirements."

3. Owing to the time and care required to score certain products, it is advisable in these cases to dismiss the candidate and to forward the product to special scorers.

4. In these cases when the product is not scored by the examiner administering the test, he shall enter the candidate's name and organization upon a tag or upon the product itself and on an accompanying form forward the product to the special scorers.

5. The candidate will be rated according to the instructions given in each test.

\section{Sample Performance Tests}

On the following pages are reproduced several performance tests. These are taken as typical of the various methods employed in the construction of the tests. No attempt is made to analyze the description of the method of administration or the method of scoring. If these are not obvious to the reader in those trades in which he has adequate information, it is a condemnation of the instruments. 


\section{TRADE TEST}

CARPENTER. - Pattern Maker, Wood

PERFORMANCE

COMMITTEE ON CLASSIFICATION OF PERSONNEL

IN THE ARMY

Trade Test Division

Reproduced by permission of the Adjutant Gieneral

\section{TEST EQUIPMENT}

Equipment :

I Woodworker's bench vise.

5 Feet of bench space, "with bench stop.

Material :

I Piece of white pine $\frac{3}{4} \times 5^{\frac{1}{2}} \times 12$ inches.

I Piece of $\frac{1}{4}$ inch tight doweling, 6 inches long.

I Piece of $\frac{3}{16}$ inch leather fillet, 6 inches long.

I2 $1 \frac{1}{4}$ inch brads No. I 7 .

I2 $1 \frac{1}{2}$ inch brads No. I7.

I $\frac{1}{2}$ pint bottle of LePage's glue.

Tools :

I Jack plane.

I Smooth plane.

I $\frac{3}{4}$ inch paring chisel.

I lb. claw hammer.

I Cross cut saw, I8 inch blade.

I $2 \frac{1}{2}$ inch dividers (H \& S No. 83 or No. 8 ro).

I Marking gauge.

I 9 inch combination square, with bevel protractor.

I Ratchet brace, ro inch sweep.

I $\frac{1}{4}$ inch wood bit, square shank.

I $\frac{5}{8}$ inch wood bit, square shank.

I $\frac{3}{4}$ inch wood bit, square shank. 


\section{A PERFORMANCE TEST}

I No. I nail set.

I Contraction rule for cast iron and steel.

I Fillet iron, length $6 \frac{1}{2}$ inches.

I 6 inch try square.

I I foot rule.

\section{INSTRUCTIONS TO THE EXAMINER}

I. Make certain that the TEST EQUIPMENT is complete and ready for the test.

2. Record the time required by the candidate to do the work. Do not include the time spent in giving preliminary instructions.

3. Use Plate 8-p, to identify the parts and measurements referred to in the BASIS FOR SCORING. Do not permit the candidate to see this plate.

4. Hand the candidate blue-print 8-p, No. I.

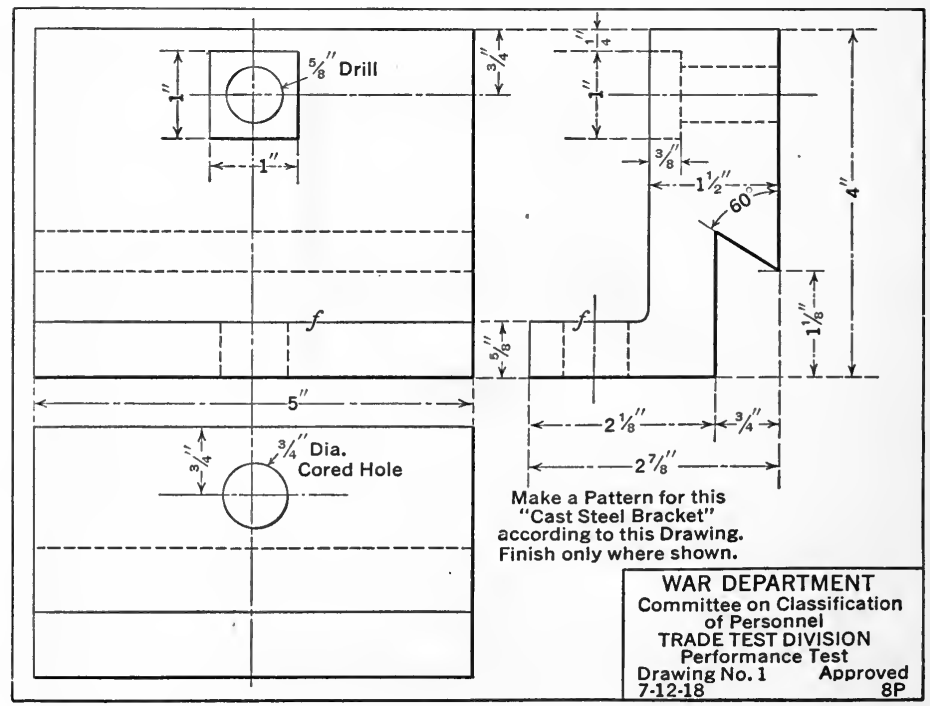




\section{INSTRUCTIONS TO THE CANDIDATE}

I. Say to the candidate: "Look at the instructions on this blueprint while I read them." Read distinctly and slowly all legends and measurements. Point to each thing as you read it.

2. Say to the candidate: "Are there any questions?"

3. Repeat, if necessary, all or any part of the instructions on the blue-print. Do not change them in any way.

4. Answer any questions the candidate may ask during the test by re-reading the instructions printed on the blue-print.

\section{INSTRUCTIONS TO THE SCORER AND RATER}

Study carefully Plate 8-p.

Figure IA pictures a correct product.

Figure IB shows the same product in its approximate moulding position. Two sets of doweling are shown. Either the two dowels

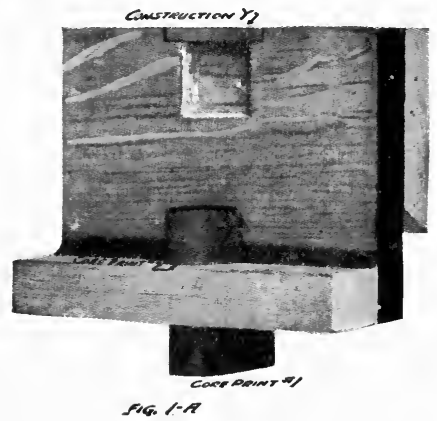

at right angles to Block \#I, or the two dowels parallel to Block \#2, are acceptable, but both sets on one product are wrong. Core prints may be attached at different places; (I) c.p. (Core print) \#I or \#2 may be omitted; (2) with c.p. \#2 omitted, c.p. \#I may be reversed, i.e., point M may be at point N; (3) c.p. \#3 may be substituted for c.p. \#I with or without c.p. \#2. Measurement $\mathrm{O}$, angle $\mathrm{P}$ and the 
tightness of the fit of Block \#4 to Block \#2 are not significant in the scoring of this test.

Figures $2 \mathrm{~A}$ and $\mathrm{B}$ show a partially incorrect product. Reference will be made to this product to illustrate incorrect procedure.

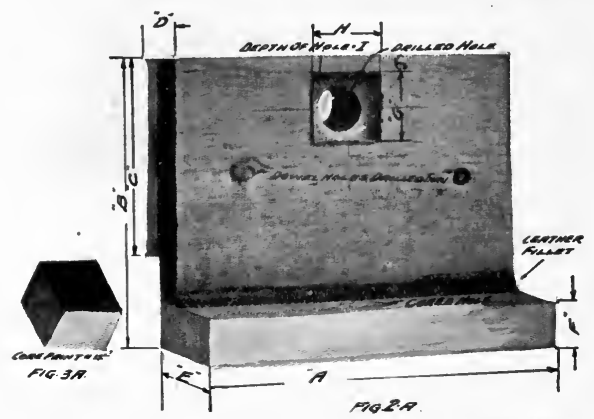

Plate 8-p

Rate a candidate A whose product has one of the following defects; (except under the condition described in the special note at the end of the following list):

DIMENSIONS (in inches) Fig. 2A.

Less Than More Than

I. Fig. $2 \mathrm{~A}$ "A" $\ldots \ldots \ldots \ldots \ldots \ldots \ldots \frac{1}{5 \frac{1}{32}}$ $5 \frac{2}{16}$

2. Fig. $2 A$ " $B " \ldots \ldots \ldots \ldots \ldots \ldots \ldots \ldots$

3. Fig. $2 \mathrm{~A}$ "C" $\mathrm{C}$. . . . . . . . . . . . $2 \frac{14}{16}$ $4 \frac{1}{16}$

4. Fig. $2 A$ "D" $D \ldots \ldots \ldots \ldots \ldots \ldots \ldots \frac{8}{16}$

5. Fig. $2 \mathrm{~A}$ " $\mathrm{E} " \ldots \ldots \ldots \ldots \ldots \ldots \ldots \ldots \ldots$

6. Fig. $2 \mathrm{~A} " \mathrm{~F} " \ldots \ldots \ldots \ldots \ldots \ldots \ldots \ldots . \ldots \ldots \ldots$

7. Fig. $2 A$ " $\mathrm{G}$ " and " $\mathrm{H} " \ldots \ldots \ldots \ldots \ldots . \frac{15}{16}$

8. Fig. $2 A$ " $I " \ldots \ldots \ldots \ldots \ldots \ldots \ldots \ldots . \frac{15}{16}$

9. Fig. $2 \mathrm{~A}$ "J" $\ldots \ldots \ldots \ldots \ldots \ldots \ldots$. $\frac{9}{16}$ $2 \frac{1}{1} \frac{5}{6}$ $\frac{9}{16}$ $2 \frac{3}{16}$ $\frac{1}{1} \frac{3}{6}$ $\frac{17}{16}$ $\frac{17}{16}$ $\frac{9}{16}$

BLOCK \#I.

I0. Figs. IB, 2B. Grain in direction at right angles to grain shown. II. Fig. IB. Absence of loose angle block, as Block \#4. (See note at end of list.) 
I2. Fig. IB. Entire Block \#I attach solidly. (See note at end of list.)

I3. Fig. IB. Entire Block \#I doweled.

I4. Fig. 2 B. Angle between Blocks \#I and \#2 other than $60^{\circ}$.

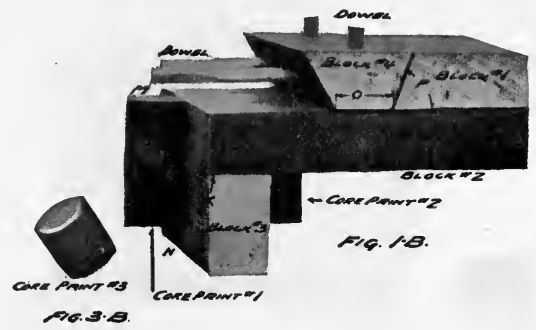

BLOCK \#2.

15. Figs. $\mathrm{IB},{ }_{2} \mathrm{~B}$. Grain in direction at right angles to grain shown for Block \#2.

I6. Fig. 2A. "Drilled hole" drilled through.

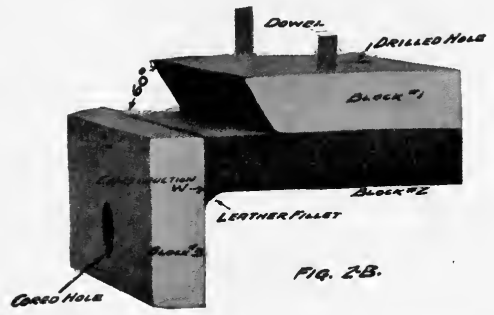

Plate 8-p.

17. Fig. 2A. Dowel holes drilled through.

18. Figs. 2A, 2B. Absence of fillet.

BLOCK \#3.

19. Figs. $1 \mathrm{~B},{ }_{2} \mathrm{~B}$. Grain in direction at right angles to grain shown for Block \#3. 


\section{A PERFORMANCE TEST}

20. Fig. 2 B. Block \#3 attached to Block \#2 as shown by construction $\mathrm{W}$ is not acceptable. The correct method is shown by construction X, Fig. IB.

2I. Fig. IB. Absence of core prints \#I, 2 or 3 from Block \#3. (See note at end of this list.)

22. Core print split.

23. Fig. 2B. "Cored hole" drilled through. Block \#3. (See note at end of this list.)

24. Fig. IA, IB. Core print \#3 substituted for core print \#2.

NOTE: Fig. IA construction $\mathrm{Y}$ shows an alternate correct method of making this pattern. If the small piece, such as indicated by construction $\mathrm{Y}$, is left loose, the following methods of construction are acceptable:

(I) Absence of loose angle block as Block \#4.

(2) Entire Block \#I attached solidly.

(3) Absence of core print I, 2 or 3 from Block \#3.

(4) "Cored hole" drilled through.

Rate a candidate $\mathrm{J}$ whose product does not have one of the above twenty-four defects and who completes the work between 120 and 7 I minutes inclusive.

Rate a candidate $\mathbf{E}$ whose product does not have one of the above twenty-four defects and who completes the work in 70 minutes or less.

Rate a candidate $\mathbf{N}$ whose product does not consist of three or four blocks: Nos. I, 2, 3, 4 . 


\section{TRADE TEST}

\section{PIPE FITTER. - Steam Fitter}

\section{PERFORMANCE}

COMMITTEE ON CLASSIFICATION OF PERSONNEL

\section{IN THE ARMY}

Trade Test Division

Reproduced by permission of the Adjutant General

\section{TEST EQUIPMENT}

\section{Equipment :}

I Mitre radiator coil ${ }^{1}$ to consist of the following parts:

2 I inch 4-pipe headers ( $1 \frac{1}{4}$ inch inlets).

$4 \mathrm{I}$ inch right and left elbows.

I I inch nipple $13 \frac{7}{8}$ inches long.

I I inch nipple $1 \mathrm{I} \frac{3}{8}$ inches long.

I I inch nipple 9 inches long.

I I inch nipple $6 \frac{1}{2}$ inches long.

I I inch right and left nipple $14 \frac{1}{8}$ inches long.

I I inch right and left nipple I $1 \frac{3}{4}$ inches long.

I I inch right and left nipple $9 \frac{3}{8}$ inches long.

I I inch right and left nipple $6 \frac{3}{4}$ inches long.

\section{Replacement Material :}

$4 \mathrm{I}$ inch right and left elbows.

\section{Maintenance Material :}

I 2 lb. can of Dixon's graphite. (This is to be mixed with oil to keep the pipes in good condition.)

\section{Tools :}

I 18 inch genuine Stillson wrench with metal handle.

I 2 foot rule.

${ }^{1}$ All threads on the nipples should be run down so that three full turns can be made by hand. 


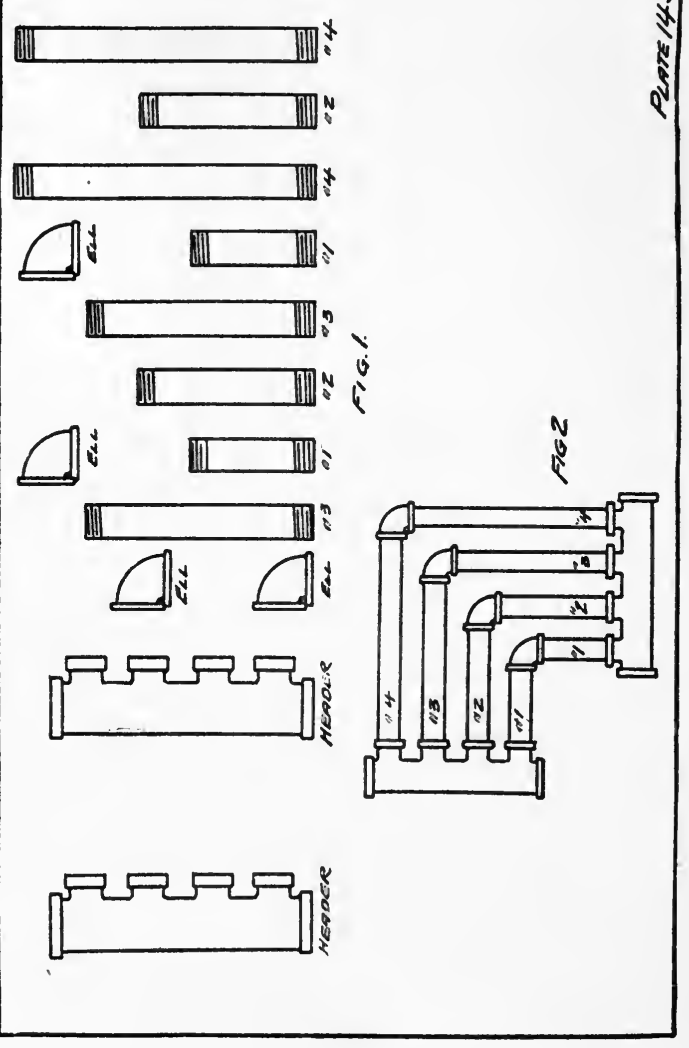


I Piece of colored crayon.

I Piece of paper approximately 24 inches square.

\section{INSTRUCTIONS TO THE EXAMINER}

I. Make certain that the TEST EQUIPMENT is complete and ready for the test.

2. Place all the parts of the Radiator Coil on the floor exactly in the manner indicated on Plate $14^{-}-\mathrm{s}$, No. 2.

3. Record the time required by the candidate to do the work. Do not include the time spent in giving preliminary instructions. Since time is the only criterion for judging the candidate's ability in this test make certain that the time is recorded accurately.

4. In no case permit the candidate to see the assembled coil or to see another candidate taking this same test.

\section{INSTRUCTIONS TO THE CANDIDATE}

I. Say to the candidate: "Make up this Radiator Coil. Make it up snug - a little tighter than by hand. Don't make it up too tight because it must be used over and over again."

2. Say to the candidate: "Are there any questions?"

3. Repeat, if necessary, all or any part of the above instructions. Do not change them in any way.

4. Answer any questions the candidate may ask during the test by repeating the above instructions.

\section{INSTRUCTIONS TO THE RATER}

1. Rate a candidate on the basis of the time required to put the coil together. In order to be rated at all on the basis of time the candidate must at least have each of the pipes tighter than can be turned by hand. If any one of the nipples is omitted or if any one of the nipples is loose rate the candidate $\mathrm{N}$.

2. Rate a candidate's proficiency in this trade according to the following standards: 
Score

Rating

I8 minutes and less.....................

r9 to 34 minutes inclusive.............. J

35 to Ir 5 minutes inclusive................

Ir6 minutes or longer...................

Coil imperfectly assembled as stated in para-

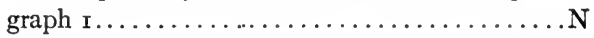




\section{TRADE TEST}

\section{SHEET METAL WORKER. - General}

\section{PERFORMANCE}

COMMITTEE ON CLASSIFICATION OF PERSONNEL IN THE ARMY

Trade Test Division

Reproduced by permission of the Adjutant General

TEST EQUIPMENT

\section{EQUIPMENT}

4 feet of bench space. Bench with holes adequate to mount hatchet stake and beakhorn.

I Block of wood $4 \times 4 \times 4$ inches.

\section{MATERIAL}

2 Pieces of No. 24 plain (not ingot) galvanized sheet iron $4 \times 7$ inches.

$6 \mathbf{I} \frac{1}{2}$ pound tinners rivets.

\section{TOOLS}

I Tinners snips: straight: length of jaws from pivot $3 \frac{1}{8}$ inches.

I Tinners riveting hammer: weight $\mathrm{I} \frac{1}{2}$ pounds; size of face $\mathrm{I}$ inch.

I Rivet set for $\mathrm{I} \frac{1}{2}$ pound rivets.

I Tinners solid rivet punch to make $\frac{1}{8}$ inch hole.

I Tinners grooving tools to make $\frac{1}{4}$ inch grooved seam.

I Tinners mallet: face diameter $2 \frac{1}{2}$ inches.

I Tinners hatchet stake: length of blade 7 inches.

I Tinners beakhorn: end diameter (largest) 2 inches; weight 28 pounds.

I I foot rule. 


\section{INSTRUCTIONS TO EXAMINER}

PREPARING THE TEST:

I. Hand the candidate the two pieces of galvanized iron specified in TEST EQUIPMENT.

2. Use the accompanying picture to make certain that the candidate's product fulfills the requirements, but do not permit the candidate to see this picture.
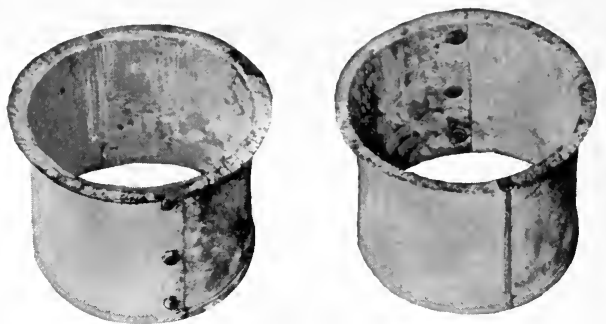

INSTRUCTING THE CANDIDATE:

I. Say to the candidate: "Connect these two pieces with a lock seam, grooved at the 4 inch side. Make into a 'cup' about 4 inches in diameter, with top turned over twice to the outside of the 'cup.' Seam with three rivets. Turn out bottom edge $\frac{1}{4}$ inch ready for sealing on the bottom."

2. Say to the candidate: "Now just to make sure that you understand what is wanted, suppose you tell me what you are going to do."

3. Repeat all or any part of the instructions above, if necessary, but neither alter nor add to them in any way.

4. Answer any questions the candidate may ask during the test by repeating that part of the prescribed instructions which covers the questions asked.

\section{INSTRUCTIONS TO SCORER}

SCORING THE CANDIDATE'S PRODUCT:

If the candidate completes the "cup" as instructed and if all the operations shown by the picture have been performed, 
rate him on the basis of the length of time required to make the "cup."

\section{RATING THE CANDIDATE:}

Rate a candidate "J" (journeyman or skilled tradesman) who completes the "cup" in 26 minutes or less.

Rate a candidate "A" (apprentice or partly skilled tradesman) who completes the "cup" in less than 60 minutes.

Rate a candidate " $\mathrm{N}$ " (novice) who requires more than 60 minutes or who omits any of the required operations; i.e., a "cup" shape, grooved seam, riveted seam, top turned over and bottom edge turned out. 


\section{TRADE TEST \\ ELECTRICIAN. - Interior Wireman \\ PERFORMANCE}

COMMITTEE ON CLASSIFICATION OF PERSONNEL IN THE ARMY

Trade Test Division

Reproduced by permission of the Adjutant General

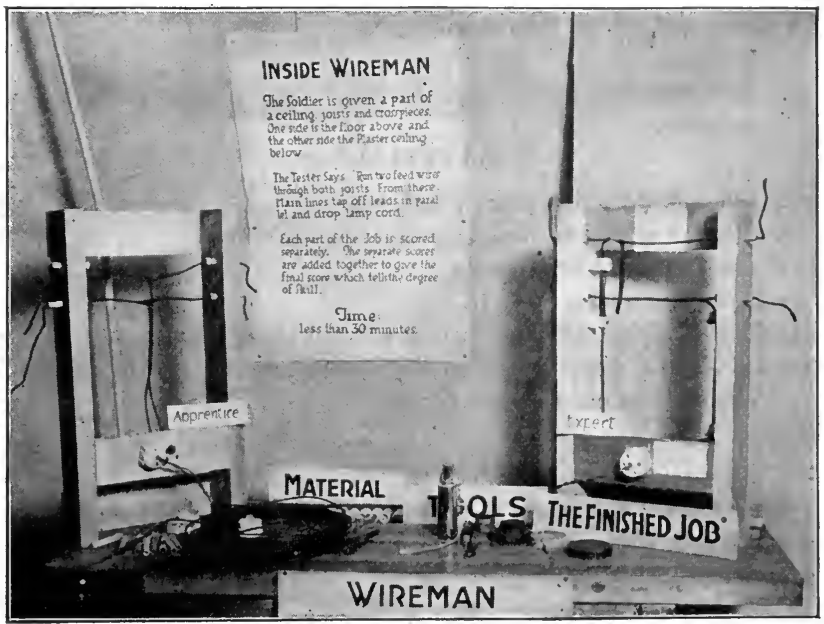

TEST EQUTPMENT

\section{EQUIPMENT}

I Jig. ${ }^{1}$

I Alcohol torch and blow pipe (Bernz No. Io).

${ }^{1}$ This jig consists of joists and cross pieces to resemble a part of a ceiling, and is constructed as shown in bluebrint ro W-I. 
I2 Standard Porcelain insulating tubes, five-sixteenths of an inch wide and three inches long.

6 Standard Porcelain insulating split knobs.

I Cleat rosette - Bryant, catalog No. 965.'

I Moulding rosette - Bryant, fuseless "Junior," catalog No. 299.

I Concealed rosette - "Junior" concealed, catalog No. 298.

12 No. 9 Flat Head bright wood screws $2 \frac{1}{2}$ inches long.

I 2 No. 7 Flat Head bright wood screws $1 \frac{1}{2}$ inches long.

3 feet of bench space.

80 inches of $\frac{3}{8}$ inch circular insulating loom cut to the following dimensions:

I piece 4 feet long.

2 pieces each of the following lengths:

2 inches,

- 5 inches,

9 inches.

MATERIAL ${ }^{2}$

I $\mathrm{I}$ lb. roll of friction tape, $\frac{3}{4}$ inch wide.

I I lb. roll of rubber insulating tape, $\frac{3}{4}$ inch wide.

I 2 oz. can of soldering paste.

I lb. of wire solder.

Io ft. B. \& S. No. 18 gauge cotton covered twisted lamp cord.

$400 \mathrm{ft}$. No. I4 gauge single strand electric light wire (insulated). Western Electric List No. 6600r3.

\section{TOOLS}

I screw driver with blade 6 inches long and $\frac{1}{4}$ inch wide.

I pair 8 inch Kline side cutting pliers.

I ordinary pocket knife.

\section{NSTRUCTIONS TO EXAMINER}

PREPARATION FOR THE TEST:

Place the jig (the section of joists and supports) upon the bench with the floor-side up.

1 Catalog numbers refer to Western Electrical Supply Year Book, I9r8.

${ }^{2}$ Sufficient to test 50 men. 


\section{A PERFORMANCE TEST}

\section{INSTRUCTIONS TO CANDIDATE:}

I. Say to the candidate: "This is part of a ceiling: joists and cross pieces. This side is the floor above (examiner points to this) and this side (examiner points to opposite side) is the

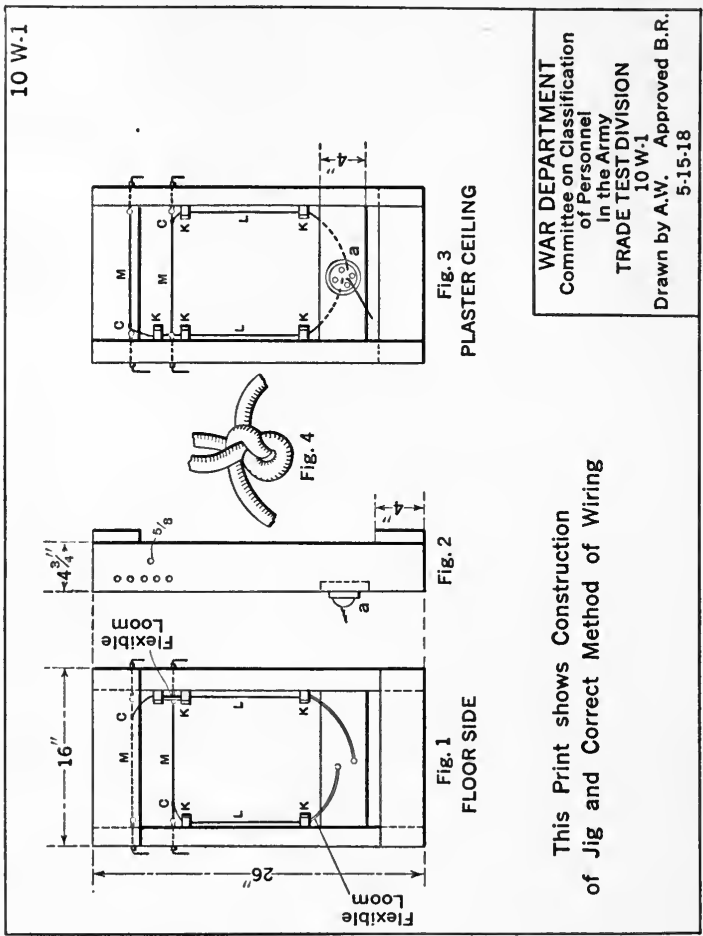

plaster ceiling below." (Examiner should hold the jig slightly above the level of his head so that the candidate can see the resemblance to the situation described.) "Run two feed wires ACROSS and THROUGH both joists, using holes al- 
ready drilled. From these main lines tap off leads in parallel and drop a lamp cord from this support (examiner points to the support). Use any material necessary, but do not use any more than you have to. Do your work as if it were a regular finished job."

2. Say to the candidate: "Now tell me what you are supposed to do."

3. Repeat all or any part of the instructions above, if necessary, but neither alter nor add to them in any way.

4. Answer any questio s s the candidate may ask during the test by repeating that part of the prescribed instructions which covers the question asked.

\section{SCORING THE CANDIDATES PRODUCT:}

I. After the candidate has f nished the test, and before attempting to credit any part of the product, read through carefully the entire BASIS FOR SCORING and check each requirement against the corresponding part of the product, so that you will understand thoroughly how to give proper credit.

2. In all cases score the candidate's product on the basis of the REQUIREMENTS provided in BASIS FOR SCORING, not on what you think the finished product is worth.

3. For that product which agrees with the definition of "perfect".................... Score I

4. For that product which agrees with the definition of "failure" ........................ Score o

5. Give credit to each SCORING UNIT in accordance with the REQUIREMENTS enumerated in the BASIS FOR SCORING.

6. Add up the credits which the candidate obtains on the individual scoring units. This is the candidate's Performance Test Score.

7. Record the time when the candidate actually begins and finishes work.

RATING THE CANDIDATE:

Rate a candidate "J" (journeyman or skilled tradesman) who fulfills both the following requirements: 


\section{A PERFORMANCE TEST}

I. Score: 9 points or more.

2. Time: 30 minutes or less.

Rate a candidate "A" (apprentice or partly skilled tradesman) who fulfills both the following requirements:

I. Score: Between 2 and 8 points inclusive.

2. Time: More than 30 minutes.

Rate a candidate " $\mathrm{N}$ " (novice) who scores less than 2 points.

\section{BASIS FOR SCORING}

\section{SCORING UNIT}

\section{REQUIREMENTS}

CREDIT

I. Wiring

Wires drawn through joists, leads tapped off and lamp cord dropped from ceiling support, although incorrectly done...................... I

Failure to do any one of these things...........

2. Installing Main

Wires drawn through the two outside holes ( 5 inches apart) through both joists................ I

Wires drawn through any pair of holes less than 5 inches apart

3. Connections, Main

Connections on main lines located as on blueprint Io w-I, Fig. I, parts c,c..................

Connections located elsewhere... ............ o

4. Knobs

Insulating knobs located as shown on blueprint io w-I, Figs. No. I and No. 3; parts k,k.......... I

Insulating knobs located elsewhere...........

5. Insulation from Main

Insulation of lead wire from main lines by means of flexible conduit or porcelain insulator taped to wire. I Absence of such insulation.................

6. Tape

Friction tape covers entirely the rubber tape and rubber tape wrapped tightly around all open wires..... I Rubber tape or open wire exposed............ 
7. Solder

Connections on main lines soldered tightly........ I

Loose connections or absence of solder..........

8. Loom

Circular loom extends from last knob to, and projects . through ceiling support to rosette............ I

Absence of or length of conduit less than from last knob to support

9. Rosette

Use of rosette with concealed connections.......... I

Use of either of the other rosettes............

Io. Knot

"Underwriter's knot" (see blueprint to w-I, Fig. 4) or wires taped to prevent pulling through rosette..... I

Absence of knot or tape................

II. Screws

Connections, screws and rosette tight ........ I

Connection screws loose ................. ○

I2. Lamp Cord

Lamp cord ends twisted and soldered.......... I

Ends not twisted or not soldered............. o 


\title{
TRADE TEST
}

\section{MACHINIST AND MECHANIC. - General}

\author{
(Bench Hand and Assembler)
}

PERFORMANCE

COMMITTEE ON CLASSIFICATION OF PERSONNEL IN THE ARMY

Trade Test Division

Reproduced by permission of the Adjutant General

Equipment :

\section{TEST EQUIPMENT}

I Machinists' Bench Vise; 4 inch jaw, to weigh not less than 40 pounds.

4 Feet of bench space.

\section{Material :}

I piece of cold rolled steel $\frac{1}{8} \times$ I $\times 3^{\frac{3}{4}}$ inches.

\section{Tools :}

I Miller Falls adjustable hack saw frame.

38 inch Star hack saw blades.

I 8 inch flat file, \#oo cut. ${ }^{1}$

I 8 inch flat file, \#o cut. ${ }^{1}$

2 Wooden File Handles.

I 9 inch Starrett combination square. ${ }^{2}$

\section{INSTRUCTIONS TO THE EXAMINER}

I. Make certain that the TEST EQUIPMENT is complete and ready for the test.

${ }^{1}$ This is the Nicholson size and cut of file, but another make of file, with equivalent size and cut, may be used.

${ }^{2}$ This square will also be used to score the test product. 


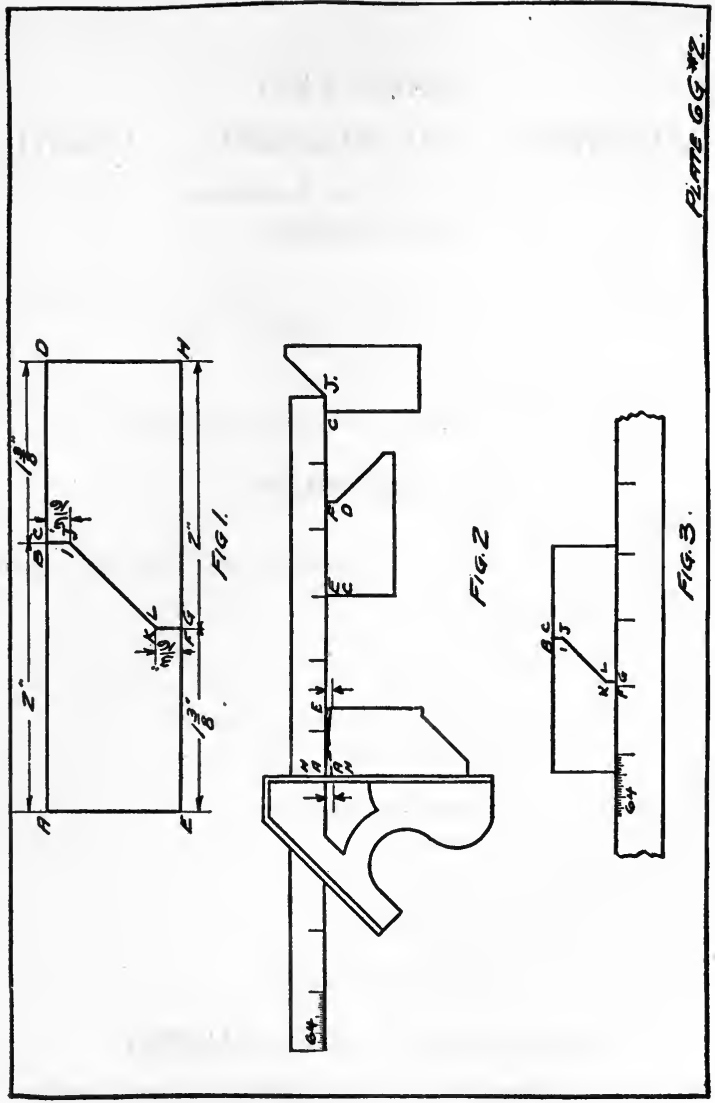



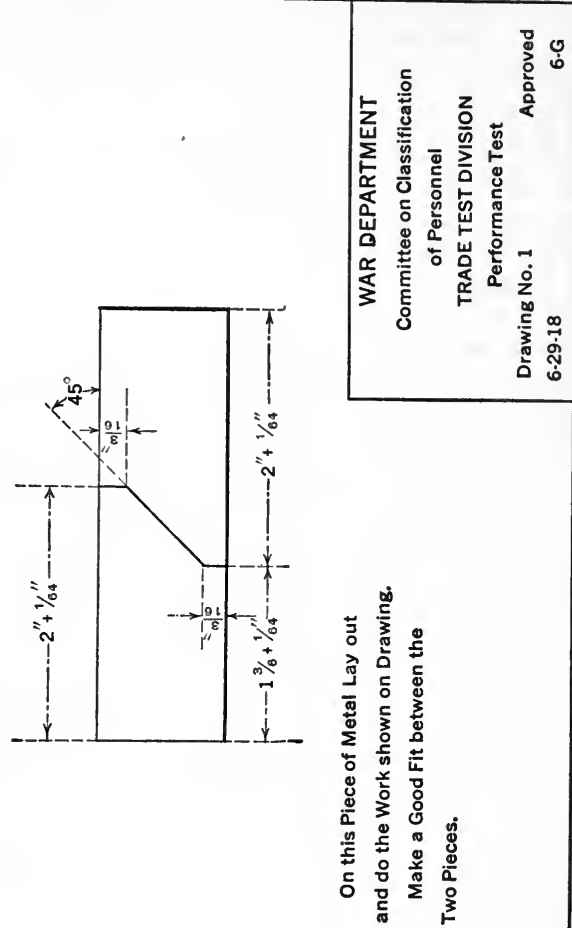

2. Record the time required by the candidate to do the work. Do not include the time spent in giving preliminary instructions.

3. Use Plate 6-g, No. 2, to identify the parts and measurements referred to in the BASIS FOR SCORING. Do not permit the candidate to see this plate.

4. Hand the candidate blue-print 6-g, No. r. 


\section{INSTRUCTIONS TO THE CANDIDATE}

I. Say to the candidate: "Look at the instructions on this blue-print while I read them." Read distinctly and slowly all legends and measurements. Point to each thing as you read it.

2. Say to the candidate: "Are there any questions?"

3. Repeat, if necessary, all or any part of the instructions on the blue-print. Do not change them in any way.

4. If the candidate approaches the examiner after he has commenced work and informs the examiner that he has made a mistake and asks of the examiner what he shall do, say: "Go ahead and make a good fit any way."

5. Answer no other questions the candidate may ask.

\section{INSTRUCTIONS TO THE SCORER}

I. Before attempting to score any part of the product, read through carefully the entire BASIS FOR SCORING.

2. Identify each Scoring Unit with the corresponding part of the product so that you will understand what parts of the product are to be scored.

3. Identify each condition described in the Requirements with the corresponding part of the product. Use plate 6-g to facilitate this identification.

4. Consider each Scoring Unit singly and in the order specified. Make certain you can identify the conditions which receive full, partial, or zero scores.

5. Score each part of the product separately and in the order specified.

6. Score each Scoring Unit strictly in accordance with the printed Requirements.

7. Add up the credits which the candidate obtains on the individual Scoring Units. This is the candidate's Quality Score.

8. Study carefully Figures 1,2 and 3 on Plate 6-g, No. 2. When recording read all measurements to the nearest 64 th of an inch. Record the actual measurement first - then determine its variation.

Fig. I shows the assembled product. 
Fig. 2 shows how to obtain the measurements $\mathrm{CD}-\mathrm{EF}, \mathrm{CJ}, \mathrm{KF}$, and the squareness of the pieces at $\mathrm{A}$ and $\mathrm{H}$.

Fig. 3 shows how the pieces should be placed on the steel rule of the square to obtain measurements BC, IJ, IJ-KL, i.e., the distance between the two pieces at these points when fitted together.

\section{BASIS FOR SCORING}

Scoring Unit

Requirements

Score

I. CD-EF. Record distances $\mathrm{CD}$ and $\mathrm{EF}$ to the nearest 64th of an inch. Fig. 2 shows how these measurements are to be obtained. Allow a variation (from $\mathrm{I}_{\frac{3}{8}}$ inch) on each $\mathrm{CD}$ and $\mathrm{EF}$ of $\frac{1}{64}$ th of an inch plus or minus without recording it as a variation, i.e., an actual variation of $\frac{4}{64}$ ths will be called $\frac{3}{64}$ ths. Sum the variations for both pieces, disregarding the signs, i.e., plus or minus.

$\frac{1}{64}$ th inch or less variation (allowing for $\frac{1}{64}$ th inch plus or minus) ................. 4

Between $\frac{2}{64}$ ths and $\frac{10}{64}$ ths inclusive......... 3

Between $\frac{11}{64}$ ths and $\frac{20}{64}$ ths inclusive......... 2

Between $\frac{20}{6}$ ths and $\frac{32}{6}$ ths inclusive......... I

Beyond $\frac{32}{6} t_{4}$ ths....................

2. CJ. Record the distance CT to the nearest 64 th of inch. Fig. 2 shows how to obtain this measurement. Allow no variation.

Less than $\frac{1}{64}$ th inch variation from $\frac{3}{16}$ ths inch.......................... 4

$\frac{1}{64}$ th variation, plus or minus............. 2

More than $\frac{1}{6 !}$ th inch variation............

3. KF. Record distance KF to the nearest 64 th of an inch. Fig. 2 shows how to obtain this measurement. Allow no variation.

Less than $\frac{1}{64}$ th inch variation from $\frac{1}{16}$ ths inch. 4 $\frac{1}{64}$ th variation, plus or minus............. 2

More than $\frac{1}{64}$ th inch variation............. 
4. A. Fig. 2 shows how the squareness at $\mathbf{A}$ and $\mathrm{H}$ are measured. Place corner $\mathrm{A}$ in the angle of the square so that side $\mathrm{AB}$ rests squarely against the hand piece. If the angle is less than $90^{\circ}$ read (to nearest 64 th inch) distance from rule edge to Point $\mathrm{E}$. If angle is greater than $90^{\circ}$ permit point $\mathrm{E}$ to rest against rule and read distance from point $A$ to the rule. Use the 6-inch steel scale to obtain these measurements. Allow no variation.

Less than $\frac{1}{64}$ th inch variation. ......... 6

$\frac{1}{64}$ th inch variation................ 2

$\frac{2}{64}$ ths inches or more variation..........

5. H. The squareness at $\mathrm{H}$ is obtained in the same manner as the squareness at $\mathrm{A}$.

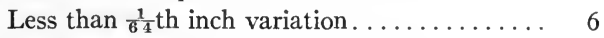

$\frac{1}{64}$ th inch variation. . . . . . . . . 2

$\frac{2}{64}$ ths inches or more variation..........

6. BC-IJ. How the accuracy of the fit between the two pieces is obtained is shown in Fig. 3. Place edges $\mathrm{EF}$ and $\mathrm{GH}$ against the straight edge of the rule and press the two pieces together. Use the small steel scale to obtain the distances between $\mathrm{BC}$ and IJ. Make certain that the $45^{\circ}$ angle runs upward to the right.

Less than $\frac{1}{64}$ th inch space between the two pieces..................... 8

$\frac{1}{64}$ th inch space between the two pieces... 2

$\frac{2}{64}$ ths inch space between the two pieces... 0

7. IJ-KL. Obtain the distance between the edges IJ-KL while the two pieces are in position described Scoring Unit 6.

Less than $\frac{1}{64}$ th inch space between the two pieces ....................... 8

$\frac{1}{64}$ th inch space between the two pieces..... 2

$\frac{2}{64}$ ths inch space between the two pieces... 


\section{INSTRUCTIONS TO THE RATER}

I. Rate a candidate's proficiency in his trade according to the following standards:

2. Rate a candidate $\mathrm{E}$ who scores 33 points and above.

3. Rate a candidate $\mathrm{J}$ who fulfills both the following requirements:

(I) Score: to to 30 points inclusive.

(2) Time: I 20 minutes or less.

4. Rate a candidate $\mathrm{A}$ who fulfills one of the following requirements

(I) Score: $\mathrm{I}$ to 20 points inclusive, or

(2) Time: I2I minutes or longer.

5. Rate a candidate $\mathrm{N}$ who scores less than one point. 


\section{TRADE TEST}

\section{MACHINIST AND MECHANIC. - Lathe}

Operator

PERFORMANCE

COMMITTEE ON CLASSIFICATION OF PERSONNEL

IN THE ARMY

Trade Test Division

Reproduced by permission of the Adjutant General

\section{TEST EQUIPMENT}

Equipment:

I Cast iron surface plate $7 \times 7 \frac{1}{2}$ inches, weight approximately ro lbs.

I Cadillac steering spindle. ${ }^{1}$

Tools :

I 6 inch Outside spring caliper, Brown \& Sharpe No. 806 .

I 6 inch Inside spring caliper, Brown \& Sharpe No. 807.

I 9 inch Combination square.

I $\circ$ to I inch micrometer caliper with ratchet stop.

I I to 2 inch micrometer caliper with ratchet stop.

i Pencil.

\section{INSTRUCTIONS TO THE EXAMINER}

I. Make certain that the TEST EQUIPMENT is complete and ready for the test.

2. Hand the candidate blue-print 6-L, No. I.

\section{INSTRUCTIONS TO THE CANDIDATE}

I. Say to the candidate: "Look at the instructions on this blue-print while I read them." Read distinctly and slowly all legends and measurements. Point to each thing as you read it.

${ }^{1}$ Cadillac Price List of Parts, 1919. Part number KK 3063. 
2. Say to the candidate: "Are there any questions?"

3. Repeat, if necessary, all or any part of the instructions on the blue-print. Do not change them in any way.

4. Answer any questions the candidate may ask during the test by repeating the instructions on the blue-print.

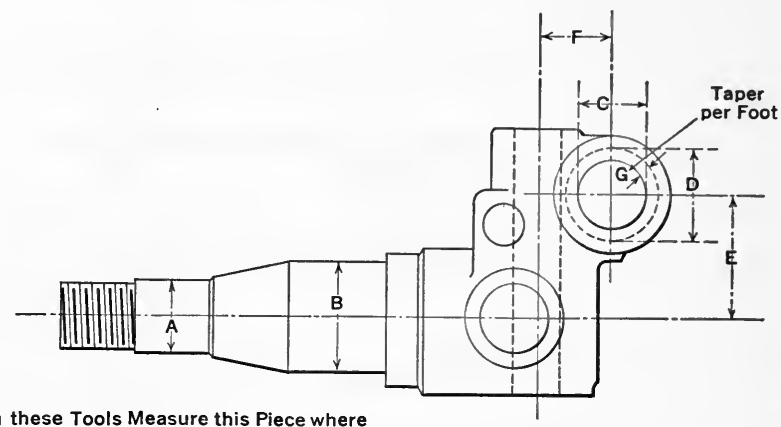

With these Tools Measure this Piece where shown on this Drawing by Letters " $A$ "." $B$ "." $C$ "'-etc.

Give all Measurements to the One Thousandth

Part of an Inch.

Write these Measurements on a separate

Piece of Paper.

\begin{tabular}{|c|}
\hline WAR DEPARTMENT \\
Committee on Classification \\
of Personnel \\
TRADE TEST DIVISION \\
Performance Test \\
$\begin{array}{cc}\text { Drawing No. } 1 & \text { Approved } \\
7.10 .18 & 6-L^{2}\end{array}$
\end{tabular}

\section{INSTRUCTIONS TO THE SCORER}

I. Score the candidate upon the Basis of the Measurements which he writes on the slip of paper supplied. All measurements are in inches. "Variations" in the BASIS FOR SCORING refers to variation from the correct measurement.

2. Candidates will be scored in terms of variations from the correct measurements of the parts of the piece. A set of correct measurements will be furnished with each steering spindle. 
3. Before attempting to score any measurement, read through carefully the entire BASIS FOR SCORING.

4. Identify each Scoring Unit with the corresponding measurement so that you will understand what measurements are to be scored.

5. Identify each condition described in the Requirements with the corresponding measurement.

6. Consider each Scoring Unit singly and in the order specified.

7. Score each measurement separately and in the order specified. Make certain of the degrees of variation which receive full, partial and zero scores.

8. Score each Scoring Unit strictly in accordance with the printed Requirements.

9. Add up the credits which the candidate obtains on the individual Scoring Units. This is the candidate's Quality Score.

\section{BASIS FOR SCORING}

Scoring Unit

Requirements

Score

I. A.

Measurement A.

Less than .0005 variation........... 8

.0005 variation, plus or minus......... 2

Greater variation................

Measurement recorded in fractional form. o

Measurement not recorded.......... o

2. 8 Measurement B.

Less than .0005 variation........... 8

.0005 variation, plus or minus........ 2

Greater variation................ .

Measurement recorded in fractional form. $\circ$

Measurement not recorded...........

3. C. Measurement C.

Less than .005 variation........... 4

.or variation................... 2

Greater variation.................

Measurement recorded in fractional form. .

Measurement not recorded............ o 
4. D. Measurement D.

.002 variation.................... 8

.005 variation................... 2

Greater variation.................. ०

Measurement recorded in fractional form. .

Measurement not recorded..............

5. E. Measurement E.

$.0 \mathrm{I} 2$ variation................... 8

Greater variation................. ०

Measurement recorded in fractional form o

Measurement not recorded............. $\circ$

6. F. Measurement F.

. .I variation..................... 4

.3 variation ..................... 2

Great variation.................. 。

Measurement recorded in fractional form. .

Measurement not recorded..............

7. G. Measurement G.

.2 variation less than correct measurement. 8

Greater variation..................

Measurement not recorded..............

(If measurement is recorded in fractional form transmute to decimal.)

\section{INSTRUCTIONS TO THE RATER}

I. Rate a candidate's proficiency in his trade according to the following standards:

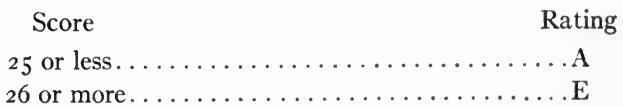

2. Rate a candidate $\mathrm{J}$ who receives

(I) Rating A on this performance test and a

(2) Rating J or higher on Picture Trade Test.*

* See Picture tests, p. 218 . 


\section{TRADE TEST \\ BLACKSMITH. - General}

PERFORMANCE

COMMITTEE ON CLASSIFICATION OF PERSONNEL IN THE ARMY

Trade Test Division

Reproduced by permission of the Adjutant General

Equipment :

\section{TEST EQUIPMENT}

I Blacksmith's forge.

I Blacksmith's anvil.

I ten quart pail.

Material :

2 pieces $\mathrm{B} B$ square rod iron $\frac{3}{8}$ inches square and 4 inches long. Coke.

Water.

Tools :

I Ball Peen Hammer, 2 lbs.

I Round eye punch, size of point $\frac{1}{4}$ inch with handle.

I Pair Blacksmith's 'Tongs; Cast Steel, I8 inches straight lip.

I Straight Hardie, shank to fit anvil.

I Pair 6 inch outside calipers.

I I2-inch metal blacksmith's rule.

Scoring Tools :

I 6-inch Steel Scale, sixty-fourths.

I 6-inch outside spring caliper.

\section{INSTRUCTIONS TO THE EXAMINER}

I. Make certain that the TEST EQUIPMENT is complete and ready for the test. 
2. Record the time when the candidate begins to work on the hook and when he finishes it. Do not include the time spent in giving preliminary instructions.

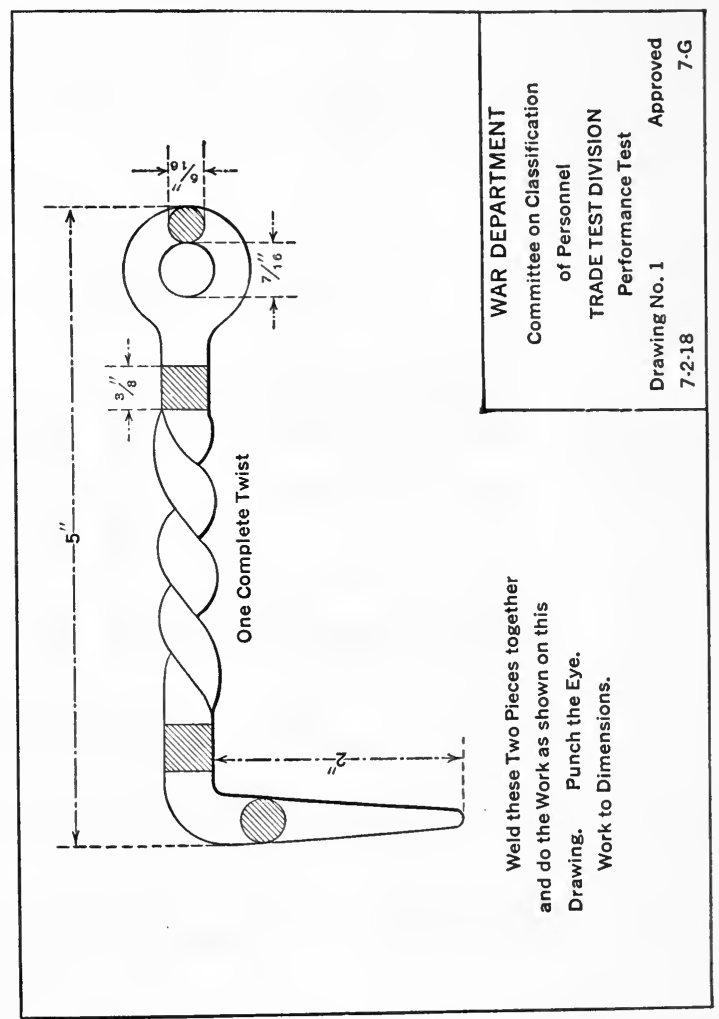

3. Use Plate 7-g to identify the parts and measurements referred to in the BASIS FOR SCORING. Do not permit the candidate to see this plate.

4. Hand the candidate blue-print 7-g, No. I. 


\section{INSTRUCTIONS TO THE CANDIDATE}

I. Say to the candidate: "Build a fire in that forge." Do not include the time required to build the fire in the time recorded to make the hook. (A fire is usually built in 15 minutes or less.)

2. When the candidate has built the fire, say: "Are you ready to take this test?"

3. Say to the candidate: "Look at the instructions on this blueprint while I read them." Read distinctly and slowly all legends and measurements. Point to each thing as you read it.

4. Say to the candidate: "Are there any questions?"

5. Repeat, if necessary, all or any part of the instructions on the blue-print. Do not change them in any way.

6. Answer any questions the candidate may ask during the test by repeating that part of the prescribed instructions which relate to the question asked.

\section{INSTRUCTIONS TO THE SCORER}

I. Before attempting to score any part of the product, read through carefully the entire BASIS FOR SCORING.

2. Identify each Scoring Unit with the corresponding part of the product so that you will understand what parts of the product are to be scored.

3. Identify each condition described in the Requirements with the corresponding part of the product. Use plate $7-\mathrm{g}$ to facilitate this identification.

4. Consider each Scoring Unit singly and in the order specified. Make certain you can identify the conditions which receive full, partial, and zero scores.

5 Score each part of the product separately and in the order specified.

6. Score each Scoring Unit strictly in accordance with the printed Requirements.

7. Add up the credits which the candidate obtains on the individual Scoring Units. This is the candidate's Quality Score.

8. Subtract from 60 the time required by the candidate to make this hook. This is the candidate's Time Score. Add the Time Score to the Quality Score. This is the candidate's Performance Test Score. 


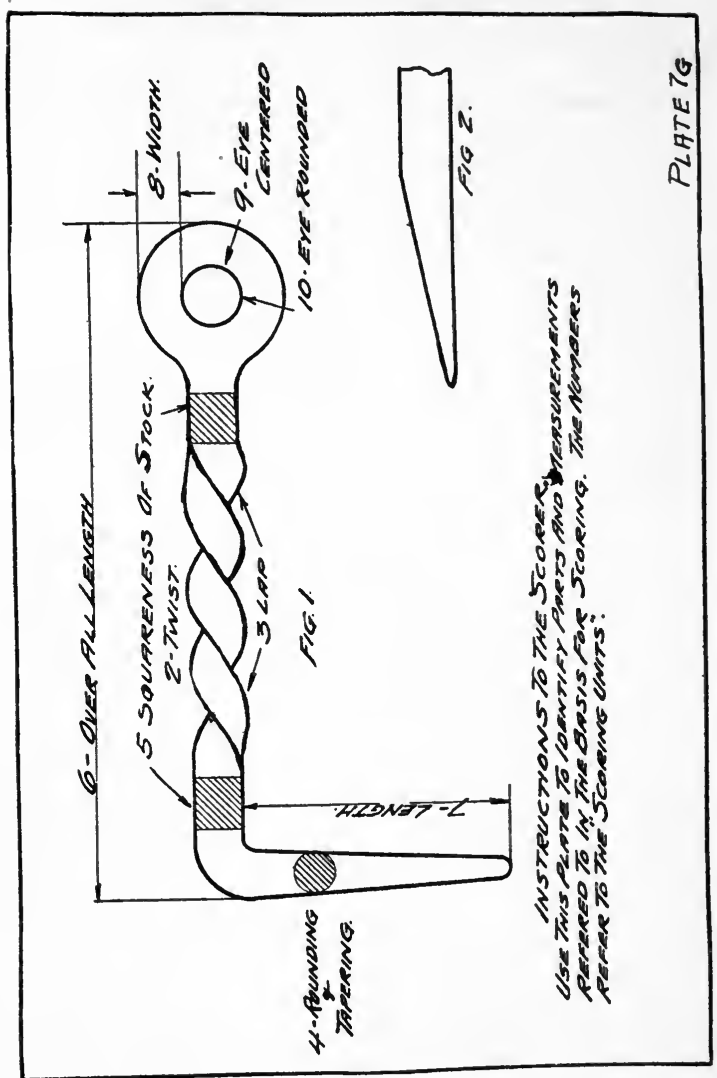




\section{BASIS FOR SCORING}

Scoring Unit

Requirements

Credit

I. Operations. Forging this hook involves five operations. For all operations performed, although incorrectly.............. 74

For each operation omitted subtract scores according to the following schedule: Subtract

(I) Preparing the weld (Fig. 2). This is the minimum acceptable performance for rating a candidate "A"

(2) Welding............... I 2

(3) Twisting. ............. I2

(4) Punching the eye............ 24

(5) Bending the hook........... 24

2. Twist. Follow through one surface of the twist. Score One-half twist has been made if the twist finishes upon the side opposite from the surface where it began (Fig. I, No. 2).

One-half twist or more.......... 4

Less than one-half twist........... o

Twist not at place of welding.......

Surfaces of twist so irregular that number of quarter turns is doubtful...... ०

Twist not made................. o

3. Lap. At both ends of the weld the metal should be joined (welded) so as to make the surface continuous. A lack of union (a gap between the two pieces such that the shank of a pin will readily go in) between the two parts of the forging is called "lap." (Fig. I, No. 3, indicates where this lap is likely to be found.)

Weld shows no lap............. 4

Lap at one end of twist.......... 2

Lap at both ends of twist......... 。

Less than $\frac{1}{2}$ turn in the twist....... o

Weld not made................. o 
4. Rounding Rounding and Tapering of Hook Bend. Tapering. Bend of the hook is tapered and rounded (Fig. I, No. 4).................. 8

Bend of the hook is tapered but not rounded, or

Rounded but not tapered, or

Neither rounded nor tapered, or

Hook not bent

5. Squareness The stock should be square at points S-I of Stock. and S-2. This scoring unit should not be credited unless (I) the hook has been bent, (2) twist has been made, (3) eye has been punched. Add the maximum variations (in sixteenths of an inch) from squareness for both dimensions at both points (Fig. 2, No. 5).

Total variation $\frac{1}{16}$ of an inch or less from square $\ldots \ldots \ldots \ldots \ldots \ldots \ldots, 4$

Total variation more than $\frac{1}{16}$ of an inch from square................

Any of the above three operations omitted

6. Length Overall length of hook (Fig. I, No. 6). overall. Credit this scoring unit $\circ$ if one of these operations has been omitted: (I) Twisting, (2) Punching eye, (3) Bending hook.

From $5 \frac{4}{16}$ to $5 \frac{6}{16}$ inches inclusive... 4

From 5 inches to $5 \frac{3}{16}$ inches inclusive.. 2

From $5 \frac{7}{16}$ inches to $5 \frac{12}{16}$ inches inclusive 2

Shorter or longer than these dimensions 0

Any one of above three operations omitted...................... o

7. Length: Length of hook under bend (Fig. I, No. 7).

2 inches to $2 \frac{2}{16}$ inches inclusive...... 8

$\mathrm{I} \frac{14}{16}, \mathrm{I} \frac{15}{16}, 2 \frac{3}{16}, 2 \frac{4}{16}$ inches......... 4

Shorter than $1 \frac{14}{16}$ or longer than $2 \frac{4}{16}$. 。

Hook not bent.................. 0 
8. Width. Width of metal encircling eye. Record this dimension for the narrowest part of the eye between the lines limiting the $\frac{3}{4}$ circumference indicated in Fig. I, No. Io. Take this measurement with an outside calipers.

$\frac{4}{16}$ or $\frac{5}{16}$ inch $\ldots \ldots \ldots \ldots \ldots \ldots \ldots$

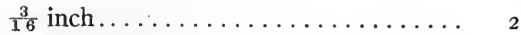

Less than $\frac{3}{16}$ inch............. o

Eye not punched.............. o

9. Eye Center of eye on center line of stock centered. (Fig. I, No. 9) .............. 8

Center of eye more than $\frac{1}{16}$ of an inch off center line of stock .............. o

Eye not punched............... o

ro. Eye rounded. rounded.

Encircling metal rounded for $\frac{3}{4}$ of its circumference (i.e. disregard part at stock and immediately adjacent) (Fig. r, No. ro) . . . . . . . . . . . . . .

Encircling metal is not rounded or only a feeble attempt has been made to round it.................. o Encircling metal not rounded.......

\section{INSTRUCTIONS TO THE RATER}

I. Rate a candidate's proficiency in his trade according to the following standards:

Score

Rating

I44 and above.................E

$\mathbf{I} 43$ to $\mathbf{3} 32$ inclusive ............... J

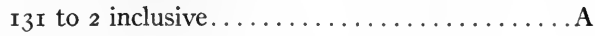

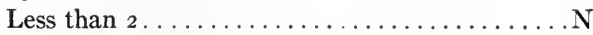

Inability to build fire............... 


\section{TRADE TEST \\ STENOGRAPHER AND TYPIST. - Typist}

\section{PERFORMANCE}

\section{COMMITTEE ON CLASSIFICATION OF PERSONNEL IN THE ARMY}

Trade Test Division

Reproduced by permission of the Adjutant General

\section{INSTRUCTIONS TO THE EXAMINER}

I. Make sure that the typewriter is in good condition. The only form of supplies needed is typewriter paper, $8 \frac{1}{2} \mathrm{x}$ Ir.

2. Say to the candidate: "Be seated at this typewriter. Insert paper and adjust the typewriter for single space."

3. When these instructions have been complied with give to the candidate the loose sheet of test copy and say: "Copy this as rapidly as possible, making no erasures and as few mistakes as possible, and report to me as soon as you are through."

4. Record the starting time in minutes and seconds. This represents the time at which the copy is handed to the candidate, not necessarily the time that he begins to write.

5. Record the time when the candidate gives to the examiner the finished typewritten copy.

6. Record on the candidate's individual score card his name, and the total time in minutes. Ignore the fractional part of a minute.

7. Determine the number of errors. An error is any error in a word or the space or punctuation immediately following a word. A word which has several errors is counted as one error. Record the number of errors on the score card.

\section{COPY}

The truck company is normally organized into three sections of nine trucks, each section under command of an assistant truckmaster. 
The service trucks not forming an integral part of the cargo sections are usually kept under the immediate orders of the truckmaster. When the company is not operating as a train, or when gasolinesupply trucks are not needed, these trucks may be assigned to cargo work, and in such case should be attached to sections.

The administration of a truck company is identical with that of a company, troop, or battery. The company commander is responsible for the operation, supply, and discipline of his command. He is assisted by the truckmaster, whose duties are analogous to those of a first sergeant. The truckmaster is the executive, and sees that all orders or instructions are properly carried out.

Each assistant truckmaster is responsible for the discipline of the men of his section, and for the proper operation and up-keep of the equipment assigned thereto. All orders or instructions to various members of a section should be given to the assistant truckmaster in charge thereof and he should be held rigidly accountable for the condition and operation of his section.

The assistant mechanics are under the supervision of the mechanic, who should be under the immediate supervision of the truckmaster. They perform such mechanical work as the company commander may direct.

The mess sergeant has general charge of the mess, and the cooks are under his supervision. He has control of all materials and supplies for the company, and is accountable for their proper issue and use. He is assisted in care and issues of property by one of the assistant chauffeurs, usually by assis ant chauffeur of the light repair truck or cargo truck clerk, etc. The company clerk keeps all records of personnel, property and operation, and performs such other duties as the company commander may require.

\section{RATING THE CANDIDATE}

I. Multiply the number of minutes by ten. Ignore the fractional part of a minute. 
2. Add the number of errors.

3. This sum is the candidate's score. Rate the candidate according to the following table:

Expert: $\quad$ o to 85 inclusive with not more than five errors Journeyman: o to 86 inclusive with more than five errors. Apprenice: 87 to 150 inclusive. Novice: $\quad$ I5I and above. 


\section{TRADE TEST}

\section{STENOGRAPHER AND TYPIST. - Stenographer}

\section{PERFORMANCE}

\section{COMMITTEE ON CLASSIFICATION OF PERSONNEL IN THE ARMY}

Trade Test Division

Reproduced by permission of the Adjutant General

\section{INSTRUCTIONS TO THE EXAMINER}

I. Make sure that the typewriter is in good condition. The necessary supplies are typewriter paper $8 \frac{1}{2} \mathrm{x}$ II, a stenographer's notebook, and pencil.

2. Say to the candidate: "Be seated at this table." Give him the notebook and pencil.

3. Give the candidate the loose sheet of copy and say, "Copy this in shorthand as rapidly as you can without making mistakes."

4. Record the starting time in minutes and seconds. This represents the time at which the copy is handed to the candidate, not necessarily the time that he begins to write.

5. Record the time when the candidate gives to the examiner the finished notes and the sheet of test copy.

6. Record on the individual score card the candidate's name, and the total time. Ignore the fractional part of a minute.

7. Say to the candidate: "Be seated at this typewriter. Insert paper and adjust the typewriter for single space."

8. When these instructions have been complied with, give to the candidate his stenographic notes and say: "Copy this as rapidly as possible, making no erasures, and as few mistakes as possible; and report to me as soon as you are through."

9. Record the starting time in minutes and seconds.

ro. Record the time when the candidate gives to the examiner the finished typewritten copy. 
II. Record on the candidate's score card the total time of transcribing in minutes. Ignore the fractional part of a minute.

12. Determine the number of errors. An error is any error in a word, or the space or punctuation immediately following a word. A word which has several errors is counted as one error. Record the number of errors on the score card.

\section{COPY}

This is the kind of ambition which creates things and which pushes the world along; an ambition to do or to be, to produce or to master something, and which never for an instant loses sight of the point first aimed at unless it be to aim at some point which is still higher and still harder to hit. That sort of ambition consists of only two elements, work and purpose; all men have had it who have striven with a definite end in view, even though some of them might not be willing to call it by that name. The dictionary gives several meanings of the word, but it matters very little which you accept, for the end is always the same; if you work with a desire to make a name for yourself, or if you try to establish an idea which you know to be right, you follow the same lines, and the method you adopt has for its basis ambition; there is no other word which can take its place and no other which has even a similar meaning.

Ambition may be counted as one of the best qualities of the human race; to be sure it has led to evil a great many times, or to what has seemed at first to be such, but I doubt if there has ever been a case where a great ambition did not in the end result in great good to all mankind. Napoleon has been called the most ambitious man that ever lived and crimes without number have been laid at the door of that ambition, all of which may be true, but today the world is better in many ways because he lived in it and because he was ambitious. An ambition to make money, to have a large pay envelope, has been sneered at as unworthy the thought of any young person; that is entirely wrong, for say what you will there are a thousand and one things that make for the best good of everybody which can only be had through the medium of hard cash; we should dress well and read good books; we should surround ourselves with a certain amount of what have been termed luxuries but which are fast becoming neces- 
sities; all these things cost money and to get money we must earn it; therefore the ambition for a large pay envelope is simply an ambition for better conditions in life, than which there can be no more worthy ambition.

\section{RATING THE CANDIDATE}

I. Add the two time scores. Multiply the sum by ten. This is the candidate's time score.

2. Add to the time score the number of errors. This sum is the candidate's final score.

3. Rate the candidate according to the following table:

Expert: Score o to 225 inclusive with less than 13 errors.

Journeyman: Score o to 225 inclusive with more than I2 errors and less than 26 errors

or, score 226 to 300 inclusive with less than 26 errors. Apprentice: Score $\circ$ to 300 inclusive with more than 25 errors or, score 301 to 500 .

Novice: $\quad$ Score 501 or more. 


\section{TRADE TEST}

\section{CHAUFFEUR. - Truck Driver}

\section{PERFORMANCE}

COMMITTEE ON CLASSIFICATION OF PERSONNEL IN THE ARMY

Trade Test Division

Reproduced by permission of the Adjulant General

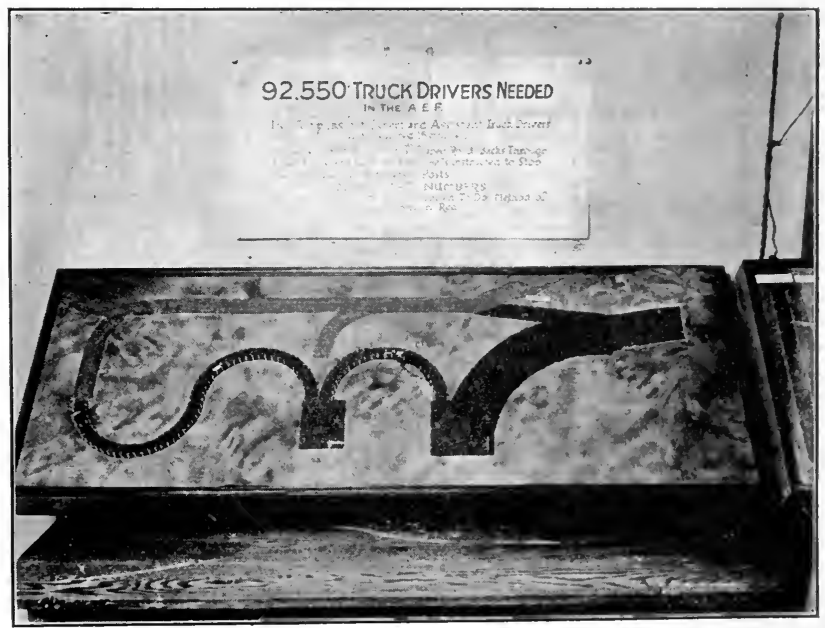

\section{TEST EQUIPMENT}

\section{Equipment :}

I. Area. The course for the truck driver's trade test requires:

a. A plot of fairly level ground $330 \mathrm{ft}$. long and $\mathrm{I} 25 \mathrm{ft}$. wide.

b. A hill grade between $\mathrm{I} \frac{1}{2}$ and $2 \frac{1}{2}$ inches to the foot, with a surface not less than $50 \mathrm{ft}$. long (with grade) and $36 \mathrm{ft}$. wide. 
2. U.S. Army truck, Type B, specifications for which are as follows:

a. Left hand drive.

b. Steering radius, $28 \mathrm{ft} .3$ in.

c. Tread: front, 64 in.; rear, $64 \frac{1}{2}$ in.

d. Wheel base, $160 \frac{1}{2}$ in.

e. Overall length of body: $\mathbf{I}_{52} \frac{7}{8}$ in.

f. Overall width of body: $86 \frac{1}{2}$ in.

g. Sun hood over driver's seat.

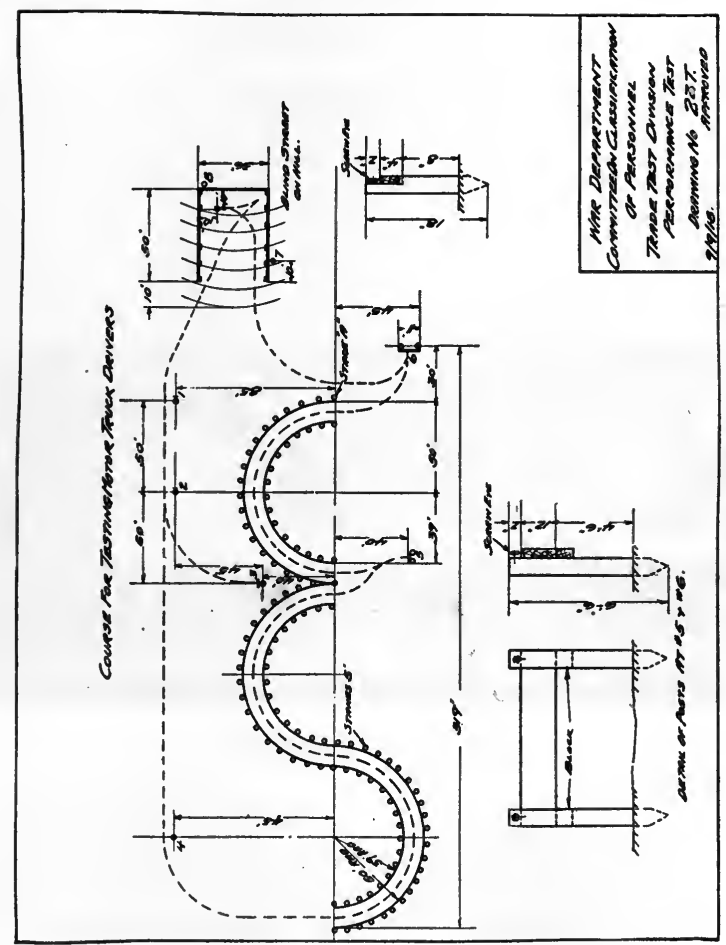




\section{A PERFORMANCE TEST}

3. Course construction. (See Plate 23-t)

a. All parts of the course between posts $I$ and 6 inclusive will be located according to the accompanying blueprint dimensions. The hill may be placed where practical for the topography of the space available and consistent with giving the different parts of the test specified.

b. The entire course will be covered with 2 to 4 inches of cinders. (Finely crushed stone may be substituted.) :

"c. The "S" road will be marked off by white stakes, $5 \mathrm{ft}$. apart, $\mathrm{I} \frac{1}{2}$ inches (approximately) in diameter or diagonal and $4 \mathrm{ft}$. 6 in. or higher above the ground. These stakes will be driven into the ground so that they will fall down readily when hit by the truck.

d. Numbered posts will carry white signs with appropriate numbers in black. Signs will be $8 \times$ ro inches (approximately). The bottom of the sign will be $4 \mathrm{ft} .6$ inches (approximately) from the ground.

e. Posts 5 and 6 consist of $\mathrm{I} \times \mathrm{I} 2$ inch boards supported by $2 \times 4$ inch posts or larger. The bottom of the board will be $4 \frac{1}{2} \mathrm{ft}$. from the ground. The boards should be attached loosely (screw eye and nail) so that they can readily be knocked off.

f. Blind street will have curb of white board. For dimensions and construction see Plate 23-t. The curb will be attached loosely (screw eye and nail) so that it can be readily knocked down.

g. A post will be driven io feet from post No. 8.(as shown on Plate $23-t$ ) flush with the ground, to guide examiner in scoring error No. 27 .

\section{Materials :}

5 Posts $2 \times 4$ inches (or larger) $\mathrm{x} 6 \mathrm{ft}$. (For sign posts I, 2, 3, 4, 8.)

4 Posts $2 \times 4$ inches (or larger) $\times 6 \mathrm{ft} .6 \mathrm{in}$. (For posts 5 and 6.)

I5 Posts $2 \times 4$ inches (or larger) $\times$ I 8 in. (For white board curb.)

I Post $2 \times 4$ inches (or larger) $\times 30$ in. (For post 7.)

8 Boards I $\mathrm{x} 8 \times$ io inches. (For numbered signs.)

3 Boards $\frac{3}{4} \times 4$ inches $x_{12}$ feet. (For curbing blind alley.) 
Io Boards $\frac{3}{4} \times 4$ inches $\times$ io feet. (For curbing blind alley.)

I Board I $\mathrm{x}$ I 2 inches $\mathrm{x}$ i I feet. (For post 6.)

I Board I X 12 inches $\times 5$ feet. (For post 5.)

95 Stakes $1 \frac{1}{2} \times 1 \frac{1}{2}$ in. $\times 5$ feet.

The thickness of these boards may approximate the dimensions given.

Whitewash.

Black paint.

Whitewash brush.

Small brush for sign painting.

Tools :

Hammers.

Cross cut saw.

Rip saw.

Axe.

Shovels.

Mallet - ro lb. wood.

Nails.

Measuring tape.

These tools are used in the construction and maintenance of the course.

\section{INSTRUCTIONS TO THE EXAMINER}

I. Give this test only with a U.S. Army Truck, Type B, of above specifications.

2. Make certain that the truck is in good running order before the test begins. Care will be taken to have the accelerator working properly. Guard against scoring the candidate for racing the engine when the accelerator is at fault.

3. Empty the truck; let down the tail board; roll up back and side curtains of sunhood.

4. Have each candidate begin the test at post No. r. The truck will be at the right side of post No. I, with engine running ready for the candidate to drive.

5. Permit only one candidate at a time to ride on the truck. 
6. If a candidate quits the test at any part of the course bring the truck to post No. I. Under no circumstances will a candidate be permitted to get on the truck at any part of the course other than at post No. I.

7. Stop the test if the candidate is obviously incompetent.

\section{INSTRUCTIONS TO THE CANDIDATE}

I. When the candidate is in the driver's seat ready for the test at post No. I, say:

a. "Do you know this gear shift?"

b. "Shift to first. Shift to second. Shift to third. Reverse." Have the candidate shift to each speed as you instruct him.

c. "Which is the spark? Which is the gas?" Have the candidate operate each of these levers.

d. "Do you know how to work that accelerator?" Have the candidate use the accelerator.

2. The examiner or an expert truck driver acting as assistant will occupy the seat to the right of the candidate and give him all instruction necessary concerning gear shift, ignition, throttle and acceleration. In no case will this expert or examiner give instruction after preliminary practice.

3. During the preliminary practice do not shift gears or regulate spark or throttle for the candidate. Force the candidate to learn how to handle the truck here by having him do all the necessary operations.

4. At the posts listed under INSTRUCTIONS AND BASIS FOR SCORING, give the candidate the instructions indicated.

5. Repeat if necessary any or all of the prescribed instructions. Do not change them in any way.

6. If a candidate asks a question involving a choice between driving one way or another, say: "Do what you think best."

7. Point out to the candidate the posts or parts of road referred to in the instructions.

8. When the candidate has driven from post No. 8 to post No. I, permit the engine to run, so that the succeeding candidate may start driving. 


\section{INSTRUCTIONS TO THE SCORER}

r. The candidate's score is the number of errors he makes. Each kind of error is tabulated in the BASIS FOR SCORING.

2. Before attempting to score any part of the performance, read through carefully the entire BASIS FOR SCORING.

3. Score each error singly and at the time of performance.

4. Score each error strictly in accordance with the printed Errors.

5. Be careful to put the score in the appropriate space on C.C.P. 577. Guard against putting the score for error No. I 2 in space No. 13 .

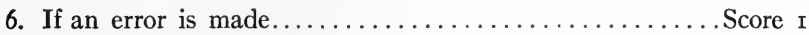
If an error is not made. . . . . . . . . . . . . . . . Score o

7. If, because of demonstrated inability the candidate has not been permitted to complete the test, score each subsequent Scoring Unit as an error.

8. If a candidate makes error II he also makes errors I 2 and I3.

\section{INSTRUCTIONS TO THE RATER}

I. Rate a candidate's proficiency as truck driver according to the following standards:

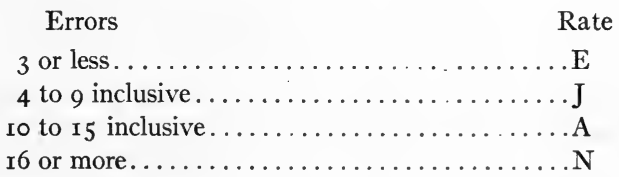

2. An expert (E) is capable of handling a truck with great efficiency and skill.

A journeyman $(\mathrm{J})$ is an acceptable driver competent for ordinary driving.

An apprentice (A) should not be trusted with a truck until given further instructions. 


\section{INSTRUCTIONS AND BASIS FOR SCORING}

No. I. "The first part of this is preliminary practice and does No scoring. not count. Drive to the right side of post 2 , over to post 3 and then back up again to post 2."

No. 2. "Now back up to the right side of post 2."

No scoring.

No. 3. "Drive to the right side of post 4 and then through that ' $S$ ' shaped road without touching any stakes. Drive at the speed you think best."
From Post 2 to Post 4.

I. Races engine when starting or shifting.

2. Abrupt start-truck jumps, acceleration uneven.

3. First speed from post 2 to 4 .

4. Grinds gears in shifting.
No. 4. At the exit of the "S" shaped road, say: "Drive your hood up into the center of No. 5."
From Post 4 to Post 5 .

5. Knocks down stake in first half circle.

6. Knocks down stake in second half circle.

7. Jerky driving.

8. Stops truck.

9. Hits any part of No. 5 .
No. 5. As soon as the candidate has driven up to the board, say:

"Back through that curved road without knocking down any stakes."

If the candidate knocks down four stakes in the first quarter of the circle, say:

"Drive out and drive into the other end."

(Indicate clearly that he is to drive front end in - into the other end of this third half circle.)
From Post 5 to Post 6 .

Io. More than one direct backing to enter third half circle.

II. Knocks down more than one stake.

12. Stops truck or drives forward more than once.

I3. Jerky driving.

14. More than one backing to reach platform No. 6.

15. Hits platform.

I6. Truck not square with platform.

r7. Sides of truck off to one side of posts. 
Have the truck driven inside the stake at " $A$," i.e., in that position where it would have been had the candidate backed through successfully. At the exit from this road, say:

"Back up to platform No. 6 as if you were going to load your truck."

No. 6. "Turn to the right without hitting those stakes."

When the candidate passes stake "A," say

"Drive up to post No. 7 and stop with your step next to the post."
From Post 6 to Post 7

r8. Hits stake at "A."

I9. Takes one backing to clear "A."

20. First speed from post 6 to 7 .

2I. Stops with front step directly in front of post 7 .

22. Truck rolls down hill more than one foot.
No. 7. "Drive to end of street marked by post No. 8 and turn around. Do not back any more than necessary." When candidate has turned around, say: "Drive down to the right side of post No. I."
From Post 7 to Post I.

23. Truck rolls down hill more than one foot when starting.

24. Emergency brake on when driving up hill.

25. Jerky driving.

26. More than one backing in turn.

27. Turns further than io feet from post 8.

28. Wheels touch curb.

29. Races engine or grinds gears on turn.

30. Turns steering wheel more than $\frac{1}{2}$ turn when truck is stationary.

Note: Add I error each time the candidate stalls the engine, at any part of the course after preliminary practice.

\section{The Place of the Performance Test}

The main criticism of the performance test method as used in the army concerns itself with the difficulty of securing a 
single task which is sufficiently typical to be taken as indicative of general trade ability. The restrictions of time imposed by army conditions prevented the examination from covering a large number of trade operations. There is, however, no reason why the tests when applied in industry could not be much more lengthy than those used in the army. A day, or even two days, spent in systematic examination of the abilities of a skilled tradesman would be well spent. The general method of assigning standardized, typical jobs of various degrees of difficulty is infinitely superior to the haphazard methods which are now commonly used.

There is little doubt, however, that for rapid examination by unskilled examiners, ${ }^{*}$ the oral or picture method, except for a few special occupations, is the more advantageous, as the initial selecting agency. Where further information is required, which the oral test does not furnish, the performance test may well be employed. It is also an indispensable instrument, (I) where there is great language difficulty; (2) where there is fear that previous coaching has taken place; (3) where the oral method has been rendered void because the trade information has been obtained in a purely theoretical way. In both the oral and picture methods it cannot be too clearly realized that manual skill is only indirectly measured; the success of the rating depends on the close correlation between degree of information and amount of skill. In the performance test no such assumption is made. The latter form of test, if of a wide enough order, measures both elements of trade ability, namely, technical information and manual dexterity. The performance test is merely a more refined and inclusive measuring device. It is impossible, without considering the reasons for an exami-

* The examiners for performance tests underwent specific training for their work. 
nation, that is, without a consideration of the importance of the decision to be made as a result of the test, to weigh the respective merits of the oral and performance method. Where, however, a thorough knowledge is required, not only of the strong points of the workman, but also of his weaknesses in the trade, a series of performance tests has undoubtedly a great field of usefulness, in spite of the fact that they are more difficult to construct and more expensive to administer. Some of the ways in which the performance test method can be used, not primarily for selecting, but rather for training workmen, will be discussed in a later chapter. 
SECTION V

A WRITTEN GROUP TRADE TEST 



\section{CHAPTER VIII}

\section{THE WRITTEN GROUP TRADE TEST METHOD}

ThE Army Trade Test Division was, on a priori grounds, extremely skeptical of written trade examinations. For this reason, in the theoretical examination, oral tests alone were used. Such tests demand an individual examination; an examiner must give the whole of his attention to a single man throughout the entire test. When there is no pressure of time, such a procedure is advantageous, but when time is limited, there are many advantages in being able to give group examinations. Among these advantages are: (I) conservation of examiner's time; (2) reduction of scoring time and increase of scoring accuracy through the use of stencils, etc.; (3) elimination of subjective judgments; (4) the possibility of rapidly eliminating the trade "bluffer," leaving only those who show evidence of some knowledge for further consideration or examination by means of oral, performance, or picture tests.

In connection with the work of this division, it was possible before the signing of the armistice to experiment with a group examination in only one trade. It is, therefore, premature to make any estimate of the group test, but there is little doubt that great possibilities lie ahead of the general method. The examination was constructed on the well-known multiple-choice plan, i.e., to each question asked four answers are appended, and the examinee is instructed to underline the correct answer. 


\section{Assembly of Questions}

In conference with expert tradesmen, sixty-two questions were prepared, each question having four possible answers, of which one was correct. Nearly all the questions of the army oral test for bricklayers were adapted to this form of examination, the remainder being secured from other sources. Trade terms were used almost exclusively in the four answers from which the choice was to be made, on the supposition that a person might be able to recognize a trade term from among a number of terms not applicable to the trade and yet have no real knowledge of its significance. A part of this test is here reproduced by the courtesy of the Editor of the Journal of Applied Psychology, from an article written by one of the authors with Mr. H. A. Toops.

\section{BRICKLAYERS' TEST ${ }^{1}$}

\section{Directions :}

In the sentences below, there are four choices for a correct sentence. Only one of the four choices is correct. Draw a line under the one choice which makes the best sentence. If you are not sure, guess; an omitted answer will count as a wrong answer in determining your score. The first two sentences, A and B, are answered correctly as a sample for you. Read them carefully; then go on to question I, question 2, and so on to the end of the list.

\section{Samples :}

A. A half of a brick is called a: chunk, block, heel, bat.

B. Fire-bricks are laid in: concrete, cement, fire-clay, mortar. Questions:

I. The top course of stone on a wall is called: coping, bond-stone, clip-course, capstone.

2. A brick set on end is called: upright, soldier, rowlock, stud.

1 These eighteen questions are samples of the original set of sixty-two which constituted the examination. 


\section{WRITTEN GROUP TRADE TEST}

3. Before plumbing up a corner, you should lay: 3-courses, 6courses, 9-courses, I 2 -courses.

4. A brick that is set on the narrow edge is called: stretcher, oarlock, rowlock, header.

5. In coming to a height, if there is a course of brick difference in the level, you would call it a: haunch, filler, line-level, hog.

6. Filling-in the space between a front and back course of brick is called: slushing-up, tempering, tuck-pointing, plastering.

7. Bricks laid across the wall reaching to the face are called: stretchers, headers, layers, fillers.

8. A fire stop around a flue is formed by a coping, skew-back, corble, indent.

9. If you have no metal ties, in plain bond work; the front work of a building is tied-in with: king-course, clip-course, projection course, belt.

ı. In backing a 4-inch ashlar stone wall, you would tie it with: tie-joint, binder, brace, anchor.

II. A brick cut in half lengthwise is called: filler, soap, bat, chunk.

12. To keep the line level in the middle of a long wall you use: level, plumb-line, square, trigger.

I3. In cutting a brick you would use a: chisel-bar, striker, brick-set, cutter.

I4. The distance above the frame for a lintel should be: $\frac{1}{4}$ inch, $\frac{3}{4}$ inch, $\mathrm{I}$ inch, $\mathrm{I} \frac{1}{2}$ inches.

15. An ordinary stone sill should be bedded on the: front, back, solid, two ends.

I6. To locate a building you use: water-level, sighter, transit, line-level.

I7. A skutch is used in cutting: cement, glazed-brick, stone, firebrick.

I8. Another name for a blind header course is: belt-course, clipcourse, dental-course, hidden-course.

The answers to the above questions with the percentages of experts passing each are as follows:
I. Coping $-98 \%$.
4. Rowlock - $100 \%$.
2. Soldier $-98 \%$.
5. $\mathrm{Hog}-100 \%$.
3. 3 -courses $-88 \%$.
6. Slushing-up $-98 \%$. 

7. Headers $-98 \%$.
13. Brick-set - 100\%.
8. Corble $-85 \%$.
I4. $\frac{1}{4}$-inch $-88 \%$.
9. Clip-course - 100\%.
I5. Two-ends $-93 \%$.
I0. Anchor $-85 \%$.
I6. Transit $-88 \%$.
II. Soap $-85 \%$.
I2. Trigger $-93 \%$.
I7. Fire-brick - 100\%.
I8. Clip-course $-93 \%$.

\section{The Subjects of the Experiment}

The examination was given without time limit to IOI persons, distributed as follows: 35 novices without trade experience, 4 apprentices, and 62 trade union members. Of the novices, 29 were soldiers in an army training school, being instructed in other trades at the time, but inexperienced in the bricklayers' trade. These men were mechanically inclined, and above average in intelligence and education. It is obvious, therefore, that the questions were subjected to much more intelligent guessing than ordinary conditions of their application would furnish. Of the other six novices, 3 were stenographers who had had several days' experience, immediately preceding this test, in taking and transcribing stenographic notes relating to the general subject of bricklaying. The other 3 novices were clerical workers. These subjects were well informed concerning the technique employed in assembling such tests, and used various methods of "suggestion, inspection, and elimination" in efforts to make as high scores as possible.

Owing to the great scarcity of apprentices, only four could be examined. The length of their trade experience ranged from one month to five years. In view of experience and performance in the army oral test, the lowest apprentice can be considered little better than novice, while the best apprentice perhaps deserves to be ranked as a low journeyman.

The tradesmen, being all members of the union, more than 
fulfilled the minimum entrance requirements in point of years of trade experience and skill. On the basis of their own written statements in regard to years of trade experience, type of work, and foremanship ability, these 62 men were divided by the authors into the two following groups: (a) 36 journeymen (hereafter called J.) or men of medium amount of skill and knowledge; (b) 26 experts (hereafter called E.), men of superior skill, knowledge and foremanship ability. This rather arbitrary classification was made in an effort to determine from the results of the examination whether a set of questions could be so selected as to differentiate not only nontradesmen from tradesmen, and apprentices from skilled men, but also journeymen from journeymen experts, so divided.

\section{Presentation of Results}

Four points were allowed for each correct answer; there were no partial credits. Four points were selected as an arbitrary value because of army custom. A graph for each question was drawn, showing the average score made by novices, apprentices, journeymen and experts. Samples of such graphs are shown in Fig. r. Since little was known as to the most desirable combination of questions to make up the best set for an examination, five methods of combining varying numbers of questions were tried; only one of these methods is here described, that in which the entire set of 62 questions is used.

The distribution of scores is given in the Graph. By inspection, arbitrary lines of demarcation of $\mathrm{N}-\mathrm{A}$, and $\mathrm{A}-\mathrm{J}$ may be made, corresponding to the number of questions correct as follows:

$\begin{array}{lr}\text { Novice score, } & 0-30 \\ \text { Apprentice score, } & 3{ }^{\mathrm{I}-42} \\ \text { Skilled tradesmen, } & 43^{-62}\end{array}$



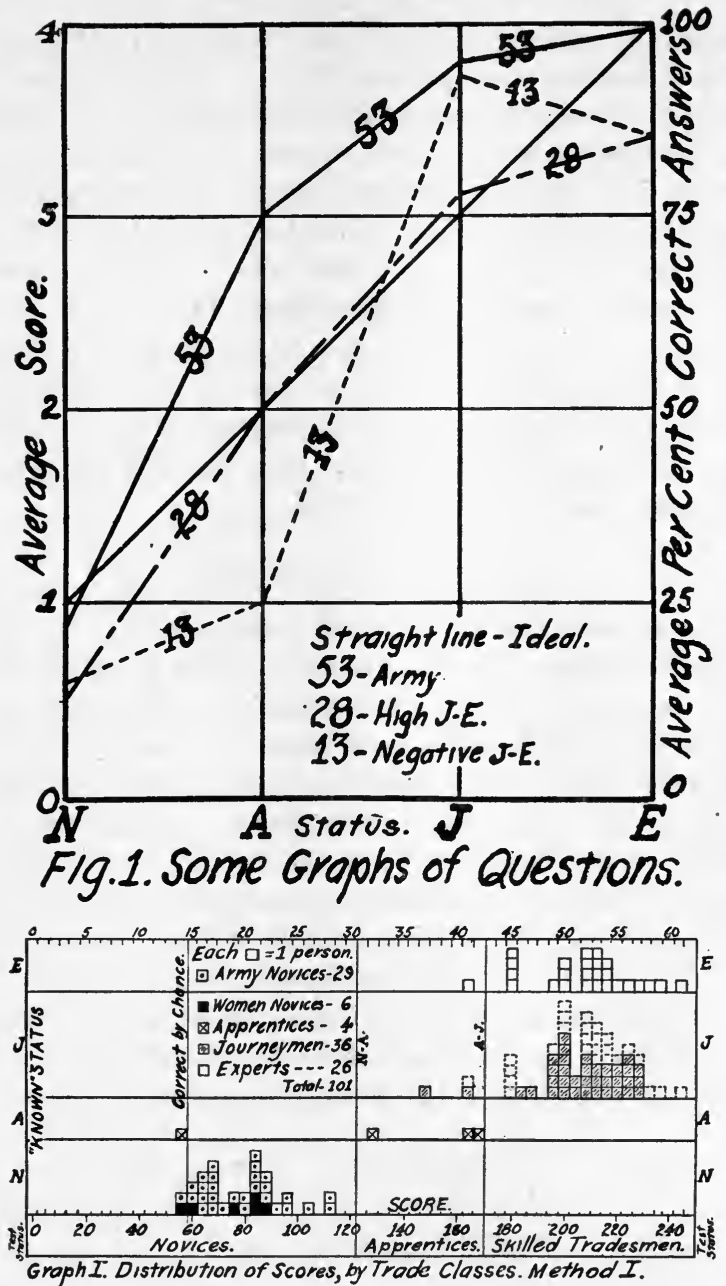
It can be seen at once that the test does not differentiate between the journeyman and expert classes. Either the division into these two classes by judgments based on the written statements of the men has nothing to do with men's ability to answer this form of question, or the test as given is not sufficiently difficult to differentiate among skilled tradesmen. The homogeneity of the skilled tradesmen class as to scores can be easily seen from the Graph, where the expert distribution has been added to the journeyman distribution by means of the dotted squares.

With the two arbitrary critical lines just mentioned, only three skilled union men out of 62 , or less than 5 per cent, are displaced out of this larger class into the apprentice class. We can assume that all union men have had four years' trade experience and possess a certain minimum requirement of ability. The apprentice with only one month's experience is here rated with the novices, as is only fair under the conditions. His guessing ability is as poor as the poorest novice, from which we can assume that he has learned next to no trade terms in one month of trade experience. Our own judgment is to the effect that intelligence is a better single measure of trade skill than are years of trade experience, after a certain minimum time for learning has elapsed.

By chance alone, the poorest novice should theoretically be able to answer 15 of the 62 questions correctly (one out of every four). Here, only two novices fail to come up to this standard, and they fail by only a single question each, both answering I4 questions correctly. The average novice answers a little better than 19 qúestions.

If the object is merely to separate skilled tradesmen from the apprentices, or the tradesmen of experience from the "trade bluffers," this type of examination offers great promise, but much more work will have to be done to decide whether it has a place in the employment machinery. 



\section{SECTION VI \\ THE PLACE OF THE TRADE TEST IN INDUSTRY}


. 


\section{CHAPTER IX}

\section{THE ANALOGY BETWEEN THE ARMY AND THE INDUSTRIAL EMPLOYMENT PROBLEM}

\section{The Location of the Trade Test in the Mechanism of Placement in the Army}

THE trade test methods which have been described were devised to meet the requirements of the army problem. The trade tests themselves were constructed to fit into a personnel system peculiar to the army. Nothing is more certain than the fact that the tests and methods will have to be modified to meet the varying conditions under which they will be employed in industry. To apply the army tests directly in industry would be to court disaster, unless it happens that the industrial situation presents the same type of problem as that which was faced in the army. The experimental work undertaken by the Committee on Classification of Personnel is much more valuable on account of the general methods, the validity of which it has established, than on account of any specific instruments of measurement which it has actually evolved. As the work progressed from month to month, the general theory and nature of the examination became more clearly formulated, but in only a few cases was it possible to return to the tests which had already been constructed in order to modify them to meet in a more satisfactory manner the principles which had been evolved.

The improvement in the form of oral examination employed 
is well illustrated by the development of the general carpenter interview as it passed from its first form in the "Aids to Interviewers" to the trade test form in September, 1918. Both these tests are here reproduced as an illustration of progress.

\begin{tabular}{|c|c|}
\hline & $\begin{array}{l}\text { CARPENTER } \\
\text { Page } 1 \quad \text { (GENERAL) }\end{array}$ \\
\hline \multirow{2}{*}{$1: A$} & \multirow{2}{*}{$\begin{array}{l}\text { Q. (a) State names of planes commonly used and (b) purpose of } \\
\text { each. } \\
\text { A. (a) (I) Jack, (2) fore, (3) smoothing, (4) block, (b) (I) The jack } \\
\text { plane is for removing surplus wood and (2) to prepare material } \\
\text { for the fore and smoothing planes. (c) (I) The fore plane to } \\
\text { "joint up" the material, (2) to straighten edges of material } \\
\text { so as to obtain a perfectly tight joint, (3) to take material } \\
\text { "out of wind." (d) (I) Smoothing plane is chiefly used for } \\
\text { finishing, (2) to give material a smooth surface, (3) and pre- } \\
\text { pare it for paint or varnish. (e) (I) Block plane is used for } \\
\text { small work and (2) for end planing. }\end{array}$} \\
\hline & \\
\hline \multirow{2}{*}{ 2:A } & \multirow{2}{*}{$\begin{array}{l}\text { Q. What other ordinary tools does a carpenter need in addition to } \\
\text { saws and planes? } \\
\text { A. (I) Hammer, (2) screw driver, (3) chisel, (4) brace, (5) auger } \\
\text { bits, (6) steel square, (7) tri-square, (8) bevel, (9) marking } \\
\text { gauge, (I0) compass, (II) oil stone, (I }) \text { oil can. }\end{array}$} \\
\hline & \\
\hline \multirow{2}{*}{ 3: A } & Q. What is meant by taking a piece of lumber "out of wind"? \\
\hline & A. (I) Making the surface a true plane, or (2) a straight line. \\
\hline \multirow{2}{*}{$1: \mathrm{J}$} & Q. What is a square mitre joint? \\
\hline & $\begin{array}{l}\text { A. (I) Joining two pieces together, (2) first cutting each piece on } \\
\text { an angle of forty-five degrees, (3) when joined together the } \\
\text { two pieces form an angle of ninety degrees. }\end{array}$ \\
\hline \multirow{2}{*}{ 2: J } & $\begin{array}{l}\text { Q. (a) Which edge should be used for the top in setting a floor joist? } \\
\text { (b) Why? }\end{array}$ \\
\hline & $\begin{array}{l}\text { A. (a) The crown. (b) Because the joist has a tendency to sag from } \\
\text { its own weight }- \text { and should have a little crown to overcome } \\
\text { this and the added weight of the floor. }\end{array}$ \\
\hline
\end{tabular}




\begin{tabular}{|c|c|}
\hline & $\begin{array}{l}\text { CARPENTER } \\
\text { (GENERAL) }\end{array}$ \\
\hline \multirow[b]{2}{*}{ 3: J } & $\begin{array}{l}\text { Q. (a) What is a good height for a step riser and (b) width for the } \\
\text { tread? }\end{array}$ \\
\hline & A. (a) Six inches. (b) Twelve inches. \\
\hline \multirow{2}{*}{$4: \mathrm{J}$} & $\begin{array}{l}\text { Q. What is the usual size of a " two by four" after it has been } \\
\text { "dressed and jointed"? }\end{array}$ \\
\hline & A One and three-quarter inches by three and three-quarter inches. \\
\hline \multirow{2}{*}{$1: \mathrm{JE}$} & Q. What is meant by quarter-sawed lumber? \\
\hline & $\begin{array}{l}\text { A. (I) The original log is first cut into quarters and (2) each quarter } \\
\text { into slabs, (3) the saw out radiating from the center of the log } \\
\text { on each cut, or (4) at right angles to the medullary rays. }\end{array}$ \\
\hline & $\begin{array}{l}\text { Q. How many shingles will be required to cover one hundred square } \\
\text { feet, if laid four inches to the weather? }\end{array}$ \\
\hline & $\begin{array}{l}\text { A. Four inches by four inches equal sixteen square inches, or one- } \\
\text { ninth of a square foot, which each shingle will cover to the } \\
\text { weather, therefore: (I) one square foot will require nine } \\
\text { shingles. (2) One hundred square feet will require nine hun- } \\
\text { dred shingles. }\end{array}$ \\
\hline & $\begin{array}{l}\text { Q. Give the names of the various parts of frame of a simple frame } \\
\text { house. }\end{array}$ \\
\hline . J4 & $\begin{array}{l}\text { A. (I) Sill, (2) plate, (3) corner posts, (4) studding, (5) floor } \\
\text { beams, (6) ribbon strip, (7) girth, (8) tie beams, (9) rafter, } \\
\text { (I0) collar beams. }\end{array}$ \\
\hline & $\begin{array}{l}\text { Q. (a) Is it necessary to know the location of door hardware in setting } \\
\text { door? (b) Why? }\end{array}$ \\
\hline & A. (a) Yes. (b) To block solidly back of butts and lock strike. \\
\hline & $\begin{array}{l}\text { Q. How many lineal feet of joists of ordinary dimensions can two } \\
\text { men place on the different floors in a five-story brick building, } \\
\text { including anchoring and leveling, in eight hours? }\end{array}$ \\
\hline JE & $\begin{array}{l}\text { A. (I) First, second and third floors, four hundred feet, (2) fourth } \\
\text { floor, three hundred and fifty feet, (3) fifth floor, two hundred } \\
\text { and seventy-five feet. }\end{array}$ \\
\hline
\end{tabular}




\section{TRADE TEST \\ CARPENTER. - General}

ORAL

COMMITTEE ON CLASSIFICATION OF PERSONNEL IN THE ARMY

Trade Test Division

Reproduced by permission of the Adjutant General

QUESTION 1

Q. What are the timbers called on which the flooring rests in a frame building?

A. Joists (beams).

Score 4

QUESTION 2

Q. What do you do to a nail after it has been driven on varnished work?

A. Set.

QUESTION 3

Q. What is the part of the window frame called which projects beyond the wall at the bottom?

A. Sill.

Score 4

QUESTION 4

Q. What do you call the cross bracing which is put between floor beams?

A. Bridging.

Score 4

QUESTION 5

Q. What plane do you use to plane the end of a small board across the grain?

A. Block (butt).

Score 4

QUESTION 6

Q. What do you call the timber which goes on top of the studding?

A. Plate.

Score 4

QUESTION 7

Q. What does the number of a saw near the handle mean?

A. Number of teeth to the inch.

Score 4 


\section{QUESTION 8}

Q. What figures on the square would you use to make a square-miter joint?

A. Equal figures.

Score 4

Note: Any two specific equal figures such 6-6, 9-9, I0-10, I 2-I 2 accepted.

\section{QUESTION 9}

Q. How are the ends of the floor joists cut on a brick building?

A. (I) Beveled (angled) (diagonally) (mitered).

Score 4

(2) Fire cut.

\section{QUESTION 10}

Score 4

Q. What is the name of the largest plane commonly used?

A. Joint (joiner) (jointer) (fore).

Score 4

\section{QUESTION 11}

Q. What method of nailing is used in putting down a hard-wood floor?

A. Toe (tongue) (blind) (secret).

Score 4

\section{QUESTION 12}

Q. What are two ways of joining base boards in the corner of a room?

A. Butt (square).

Dado.

Miter.

Cope.

Any two, Score 4

\section{QUESTION 13}

Q. What do you call a rafter which runs from an outside corner of the building to the ridge at an angle other than 90 degrees? A. Hip.

\section{QUESTION 14}

Score 4

Q. What are two ways of cutting-in mold faced door stops?

A. (I) a. Miter.

Score 4

b. Cope.

Note: Both required. No partial credits. 


\section{QUESTION 15}

Q. What do you call the end post used to support stair rails?

A. Newel.

Score 4

QUESTION 16

Q. What kind of hinges are used in hanging an inside door?

A. Butt.

Score 4

\section{QUESTION 17}

Q. What do you call planing off the corner of a heavy timber?

A. Chamfer.

Score 4

\section{QUESTION 18}

Q. What attachment is used to keep a bit from going beyond a given depth?

A. Gauge (stop).

Score 4

\section{QUESTION 19}

Q. What do you call the method of marking a board to fit into an irregular space?

A. Scribe.

Score 4

\section{QUESTION 20}

Q. What figures do you use on the square for laying out the top and bottom cuts on a hip rafter for a one-to-one or half pitch roof?

A. 12 and 17 .

Score 4

RATING THE CANDIDATE

Score

Rating

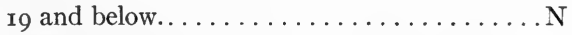

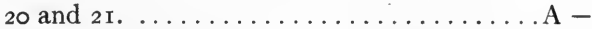

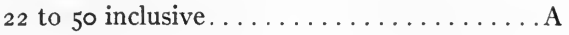

$5^{\mathrm{I}}$ and $52 \ldots \ldots \ldots \ldots \ldots \ldots \ldots \ldots \ldots \ldots \ldots \ldots \ldots \ldots \ldots$

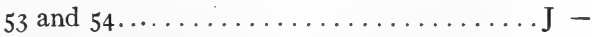

55 to 68 inclusive.................. J

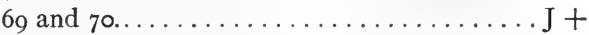

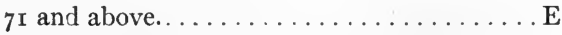

There is no $\mathrm{E}-$ or $\mathrm{E}+$ rating. 
A comparison of the two will show, better than any words can describe, the evolution of the single-answer question and the approach to the ideal of objective rating.

It is probably true to say that were the compilation of tests to be made afresh, starting with the knowledge that is now possessed, not a single test would remain in its present form, although in the later tests, the alteration would not be considerable. After the first few months of work little change was made in the general plan of construction, but technique in carrying out this plan improved greatly and was steadily advancing when the work of compilation ceased with the signing of the armistice.

To get a true perspective of the trade test instrument, it is necessary to consider the general scheme of which it furnished an essential part. While only the roughest outline can be given of the general army method, even this will be of great service as an introduction to the consideration of the industrial applications of trade tests. It is obvious that any method of determining trade qualifications is meaningless unless coincident with it there is adequate information concerning trade needs. Strictly speaking, before a trade test covering any particular occupation can be constructed, it is necessary to know in some considerable detail the precise duties and skill demanded by the occupation.

One of the first personnel problems which had to be faced centered around the trade requirements of the army. To most of those who were unacquainted with modern methods of warfare it was a source of perpetual wonder to learn how large a number of trades were required within the limits of the army proper. However remote might be the occupation, with a few exceptions, somewhere in the army was a place where, under certain conditions, that occupation might profitably be followed. Each platoon, company, regiment or other unit, whether infan- 
try, cavalry, engineers, medical, etc., made its own particular demands for skilled workmen. The determination of the exact nature of these demands led to the compilation of Tables of Occupational Needs of Personnel Specifications. These were prepared in order to provide a definite and organized method of placing the supply of specialists in organizations and to secure their equable distribution throughout the army.

They served the double purpose of showing the organization commander how best to utilize the trade ability at his disposal, and in addition guided him in the further selection of men. Below is given an illustration of such a table of organization of a Rifle Company (Infantry Regiment).

It was while the Tables of Occupational Needs for an Infantry Division were being revised that the fact was driven home with so much emphasis it could no longer be neglected that men could not be classified by occupations alone; and that by the very nature of these tables, which specified an occupationalist for a duty which had at best only a few essentials of a vocation in it, the tables were becoming too rich in occupational specialists. In consequence the necessity arose for taking into consideration qualifications other than occupational in order properly to make the best utilization of the personnel coming into the Army. Work was then commenced upon real personnel specifications which would take into account other factors upon which a man's assignment should be based, such as his physical, educational, intellectual, and leadership qualifications. Furthermore, in order to keep the relation between the qualifications a man possessies and the duties he performs foremost in the minds of those who are makng the initial and subsequent assignments of men to Army units, the personnel specifications set forth in concise but comprehensive style the duties of each of the Army grades for which it describes the qualifications. 
OCCUPATIONAL NEEDS

RIFLE COMPANY

INFANTRY REGIMENT

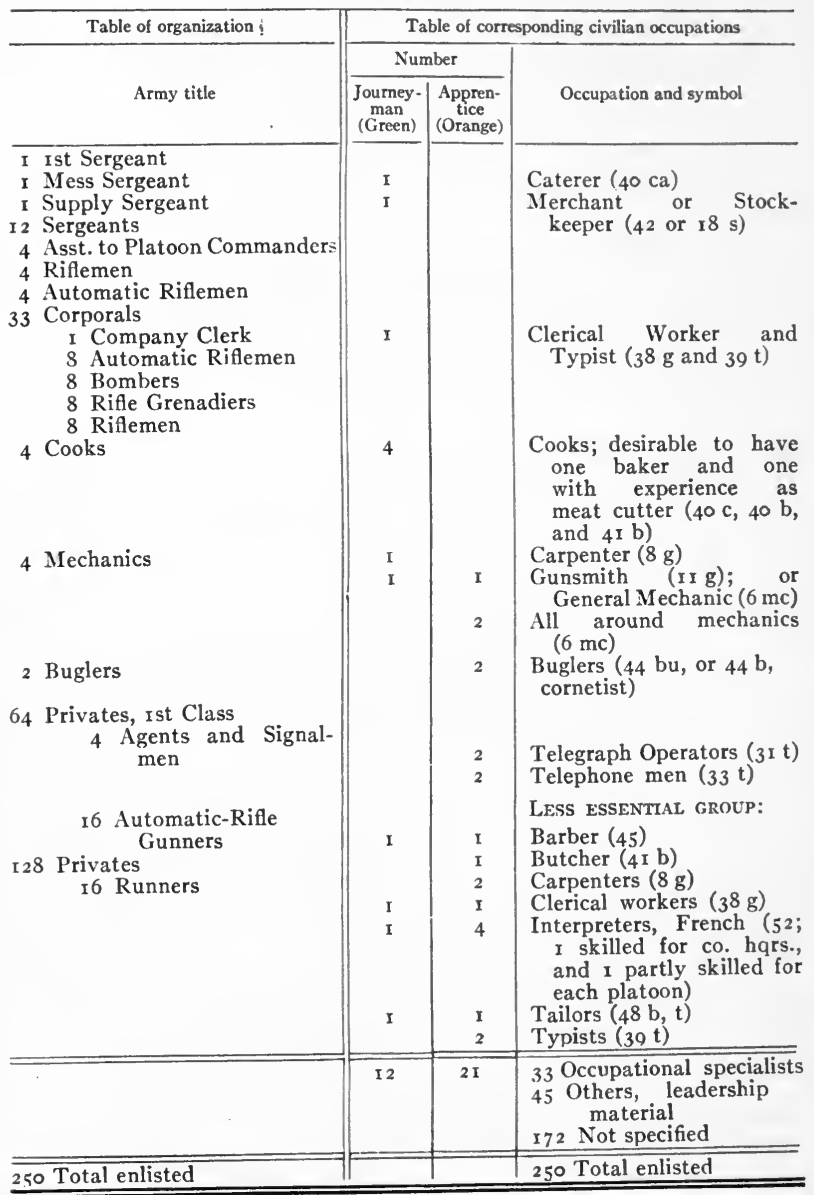




\section{Value of Personnel Specifications}

The immediate value of personnel specifications is four-fold: (I) The Army is given the benefit of civilian experience gained at the soldier's expense; (2) the need for Army schools to develop specialists out of raw material is minimized; (3) the training period of units is shortened inasmuch as only military instruction is necessary and not both military and occupational instruction; and (4) the man is much more likely to be contented because of being continued at work he enjoys.

The most important service which these personnel specifications rendered was that it enabled a central planning board to determine how specialists should be used, and how the supply of skilled men should be husbanded, particularly in cases where the demand far exceeded the supply. The tables furnished the requisite information, not only of what trades were useful to the army, but just where and in what number tradesmen of varied degrees of ability could be used.

As will be seen from the table on page 355 the occupational needs of each unit were expressed in the statement that a certain number of men in various occupations were required. These occupations were given the army title, which may, or may not, conform to that usually employed in civil life. It soon became apparent that there was urgent need for precise definition of the duties which the various types of army tradesmen were expected to fulfill. This need was met in a small degree by appending information in the Tables of Occupational Needs, regarding the general duties of the various occupations, but the most vital step towards precision in the specification of personnel requirements was taken when the volume of "Trade Specifications" was published, containing statements of the duties and specifications in each of the 714 civilian trades and occupations which 
DUTIES

1. Operation of standard types and various kinds and sizes of forging ma. chines. such as bulidozes and hydraulic presses on general work.

\section{QUALIFICATIONS}

2. Should have thorongh knowledge of rivet and bolt forging machines, screw, toggle and liydraulie presses for heading stayboits, forms, and

Should have a practical knowledge of coal, gas, and ofl types of forge furnace, and the proper heating of various material for forglngs. Must be able to set and adjust dies and maintain same and be able
to turn out uniformly dimensioned product.

SUBSTITUTE OCCUPATIONS

3. Drop forge operator, press operator, heavy forge blaeksmith, blacksmith.

$\begin{array}{lll}\text { HADGA the HEAT TREATEJ3 } & \end{array}$

DUTIEs
1. Heat treatment in general of steel forgings, finished parts and eastings.

\section{QUALIFICATIONS}

2. Must be thoronghly experienced in the besting and oll treatment of various grades of stcel for annealing or toughening for any kind of work. Must be capable of annealing, quenching and drawing of all kinds of steel forgings and castings, either rough or after being machined. Must be capabie of judglng temperature by the ege, and $f a$ miliar with the nse of pyrometers.

Must thoroughly onderstand the construction and operation of standard types of coke. oil, gas or electric turnace equipment, and quencling tanks, and have a working knowledge of the metallurgy of steel. at least sufficlent to know how it should be heated, treated and cooled, under instruction or by test.

Should have had similar experience in forge shop of any industrlal. plant.

SUBSTTUTE OCCOPATIONS

3. Annealer, heater, forge beater.

\section{HAEWS}

F-h

HORSESIOER

DUTIES :

1. Shoeing horses and males.

QUALIFICATIONS

2. Must be a practical horseshoer, capable of forging, shaping and panching horse or mule shoes from standard stock or bar material. Capable of removing shoes, paring and dressing hoofs, welding caulks, shaping shocs for correction of diseased or malformed feet.

Should have soine veterinary knowledge, enabling him to care for and correct hoof troubles.

Must be able to handle and shoe anbroken horses ander rough feld conditions, and handle heavy harses and wules.

Should have some knowledge of blacksmithing and beiable to make weids and do light blacksmith work.

Experienced as commerckal horseshoer or as horseshoer in construetion camp. or employee of company having considerable stock.

SUBSTITUTE OCCUPATIONS

3. Farrier, country blacksmith, blacksmith.

the army utilized. Samples of these specifications are shown above.

It was the introduction of these specifications that furnished a common language and a working basis of standard terminology. 
The Table of Occupational Needs and Personnel Specifications, together with the Trade Specifications and Index of Occupations, furnished information concerning:

(I) The trade needs in each branch of the army.

(2) The actual duties involved in the various trades.

This compilation of information corresponds to the process of job analysis in industry.

The only other procedure of army placement which need be mentioned as essential to the understanding of the trade test movement is that involving the compilation of an occupational history of each recruit. While many other lines of achievement were of interest, the trade achievement is the only one of importance in the present discussion.

Occupational History. The experience of the army has been that a very reliable statement of what the man has done in an occupational way can be obtained when he is properly interviewed. According to personnel procedure a complete record of just what he had done from the time he left school until he entered the Army was recorded first of all in the form of notes on a pad. After the interviewer was satisfied he had a complete statement, he determined what was the man's main civilian occupation and then filled in the space on the Qualification Card as to

(I) Name of main occupation.

(2) Details of just what he did at that job.

(3) Years of experience.

(4) The army symbol. For example, carpentry was subdivided into 22 subdivisions, i.e., block maker, pulley, 8 bl; boat carpenter, $8 \mathrm{~b}$; bridge, timber carpenter, $8 \mathrm{br}$; cabinet maker, $8 \mathrm{cb}$; etc.

(5) Interviewer's estimate of his skill at the trade, expressed as apprentice, journeyman, or expert. (Skill less than that of 


\section{ARMY AND INDUSTRIAL PROBLEM}

an apprentice was ignored as not of sufficient value to warrant transferring a man on that basis.)

(6) Firm worked for.

(7) Dejartment, shop or branch.

(8) Kind of business (the industry; e.g., shipbuilding, textile, etc.).

(9) Address of firm.

(Io) Weekly wages.

Items $\mathrm{I}^{-} 5$ and to were recorded similarly for the $2 \mathrm{~d}$ best and $3 \mathrm{~d}$ best occupations and occasionally the 4 th best.

The main object of that part of the qualification card shown on page 360 was to elicit all possible information concerning the trade ability of the recruit, with a view to filling the requirements of the army as detailed in the Tables of Occupational Needs and the Trade Specifications. The qualification card was merely a means to an end - the correct placement and correct follow-up of the recruit. It will be noticed that item (5) in the list above calls for the interviewer's estimate of the trade skill of the recruit. This estimate must be expressed in terms of an apprentice, journeyman, or expert rating. Upon the accuracy of the estimate of this skill depended the success of the whole scheme of trade placement. It was at this point in the involved mechanism that the need for the trade test arose. The trade test is a device which serves as an accurate measuring instrument for determining the degree of trade skill with a view to the correct placement of this skill within an organization, the precise needs of which have been previously determined by exhaustive study and detailed analysis. Without some form of qualification card, which could guide the examiner and serve as a permanent record, without an accurate knowledge of the trade requirements of the army, it would have been impossible to derive the full benefit from the trade tests 

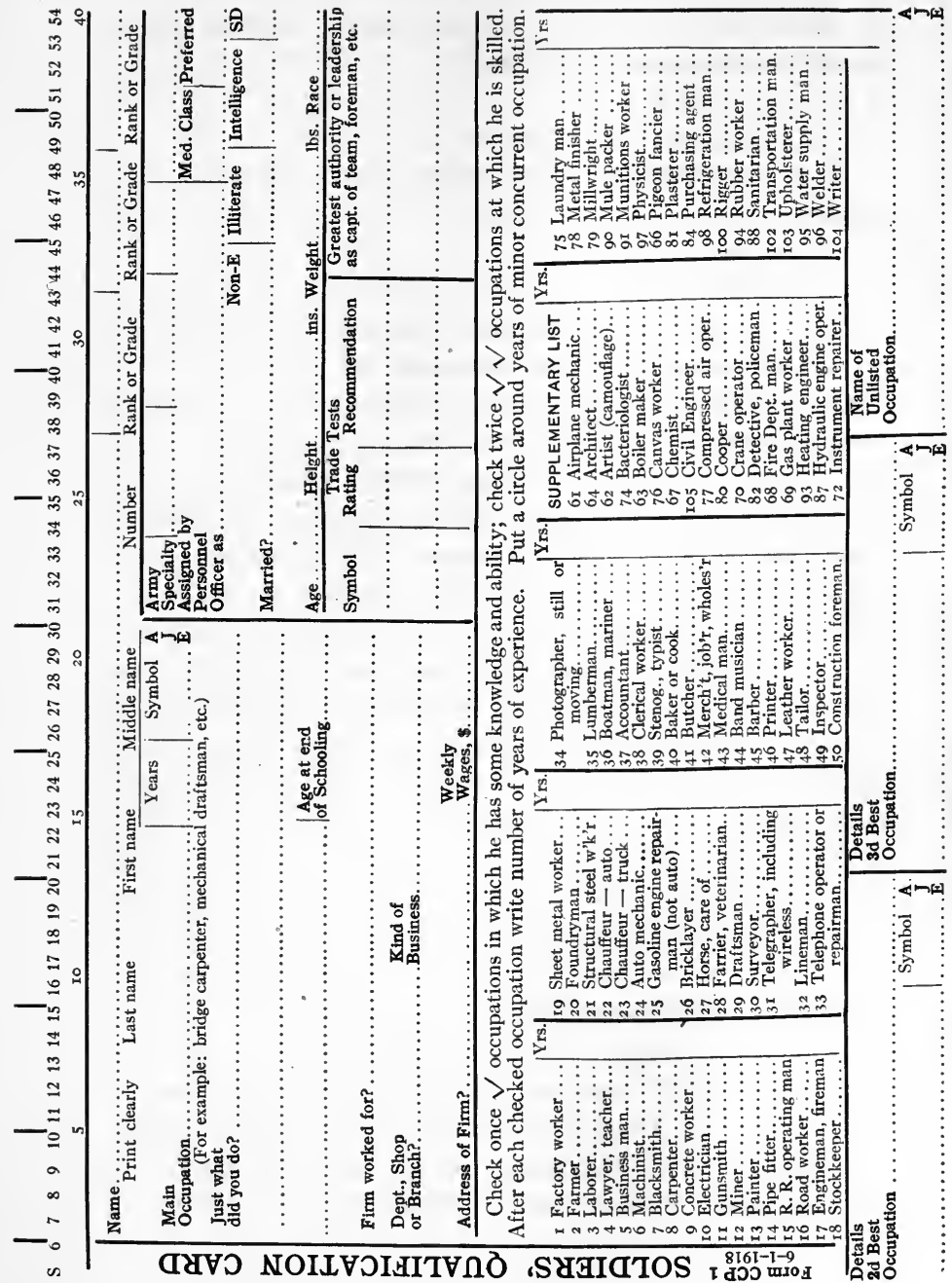
themselves. Only as the trade test forms part of an organic unit can it be used to the best advantage.

\section{Analogy between the Army and the Industrial Problem}

The question of the extent to which the present measuring devices of the army can be applied directly to industry depends upon the extent to which the conditions of an industry coincide with those of the army. In a very real sense, the effective utilization of the available skilled personnel within the army was essentially a similar problem to that which is faced by the employment office in large industrial plants. The army on a large scale, the employment manager of an industry on a smaller scale, must function to bring man and job together with due regard to the qualifications of the former and the demands of the latter. Trade tests in one form or another will accomplish this purpose, if they are made an integral part of the total mechanism of placement. Just as in the army it was necessary to know the number of men with various trade skills that were required, together with an exact knowledge of the duties within each of the trades, so it is necessary in the industry, before any system of trade testing is set up, to conduct a thorough survey of occupational needs and requirements.

This introduces an idea which is rapidly gaining favor in industry. Adequate knowledge of the employment situation within a plant necessitates, at its inception, a complete analysis of the various occupations represented. Job analysis, or occupational specification, is the forerunner of the construction of an accurate placement scheme.

It is obviously a waste of time to attempt to analyze the human element when there has been no corresponding analysis of the jobs to which the human material is to be assigned. The analysis of the man and the analysis of the job are interwoven 
throughout the whole process of placement. One of the lines along which there is a possibility for a great saving of human material lies in the direction of much more detailed investigation of the various occupations within the confines of the industrial plant.

If one considers the way in which the processes of industry have become more specialized during the past twenty-five years, how new trades have come into existence and older trades have been split into various minor trades, the necessity for this step becomes apparent. Thirty or forty years ago, trades and occupations were limited in number and fairly definite in content. A carpenter was a general carpenter, a machinist, a general machinst. A particular product passed through all its stages in the hands of one man; starting with the raw material it passed to the finished stage in the hands of a single tradesman. The procedure necessitated all round skill and knowledge on the part of each tradesman. To-day, under production methods, this same product may pass through the hands of ten or fifteen men, each one performing a single operation, and possibly being skilled in this operation alone.

Again, the growth in the size of plants, in many cases, has made the old method of hiring through the shop foreman unwieldy. It has become necessary to centralize the employment operations, with the result that a single office must hire men for all types of work within the plant. In this. respect the conditions within the industry resemble the army situation. When it was possible for foremen to do the hiring, their first-hand knowledge of trade operations enabled them to give a very searching examination, covering the most involved operations of the trade. Even under these conditions there were, however, numerous disadvantages, of which the most important must be mentioned. In the first place the rating that was given was the 
result of a general estimate made by a particular person. This resulted in an absolute lack of standardization of rating. A foreman and an assistant foreman, interviewing the same applicant in the same shop, would give very different judgments with regard to ability. Even when the same judgment was arrived at, there were no objective terms in which it might be expressed. Foremen were influenced also by many extraneous elements, quite apart from the skill possessed by the applicant. In many cases the questions given or the jobs assigned were of a catch nature, calculated rather to impress the applicant with the knowledge of the examiner than to elicit information with regard to the skill of the tradesman. Herein lay the great weakness of the method. The foreman was chosen on the basis of considerations other than those of skilful interviewing. He was much more likely to be a skilled workman than a skilled interviewer. It would be absurd to say that this method of employment is unworkable. It is claimed, however, that under ordinary conditions it is a very wasteful procedure. This method of decentralized employment has been abandoned, not because the foreman was not a skilled examiner, but because of the growth of the industries themselves. In the interests of reduction of labor turnover and in the interests of production, it became necessary to have the hiring done by a small group of men. When this centralizing takes place, intimate knowledge of the operations of the trade can no longer be expected of the examiner. While it may be possible in a few of the most important occupations of the plant to have specialists within the employment office, it is utterly out of the question to have experts in all of the occupations concerned. The work of employment, therefore, has had to be handed over to a small group of specialized men who can have, from the nature of things, only the most superficial knowledge of the jobs for which they are doing the hiring. 


\section{Common Methods of Interview in the Centralized Employment Office}

The use of a corps of trade experts within an employment office is a possible solution, but it is an exceedingly expensive method of operation. There is an old saying, "Never let a superior mind do what an inferior mind can do equally well," which this method openly flaunts. Superior knowledge and superior skill do not exist in such quantity that industry can afford to use such skill except in strategic places where it is demanded.

Another practice which is very common is for the employment office staff to give a general interview, and on the basis of this refer the applicants for a specific trade interview to the foremen of the various shops. To this procedure, the same objection may be raised. It is exceedingly wasteful to use the time of a skilled foreman in interviewing a large number of unsuitable applicants. His attention should be, as far as feasible, concentrated on what is taking place within his shop. He should be distracted to the minimum degree by matters of hiring. Before using a workman it is, of course, necessary for the foreman to be satisfied that he is efficient, but this does not mean that he should interview all applicants. The foreman should receive for further testing only those who by their trade examination within the employment office have shown sufficient knowledge and skill to give promise of being suited to the job. Simply because a man claims trade ability and succeeds in passing an unskilled interviewer is not sufficient ground for reference to the foreman. If this method of hiring is used, production and efficiency within the shop are bound to suffer. Any simple form of trade test, administered by an intelligent interviewer, would eliminate ninety per cent of the useless references. 
There is still another method which is commonly employed, where the interviewing within the central employment office is done by the same group of men for all trades. This consists in allowing the interviewers to visit the departments or shops for which they are doing the hiring. During slack periods in the employment office work, or in some cases, for a stated period before they enter upon their duties in the central office, they are given opportunities to study and in certain cases to perform some of the more typical operations of the shop. They are also encouraged to get a few "stock questions" from the foreman, with which they can at least detect the trade bluffer. Here we have the first beginnings of the trade test idea. While this scheme is far better than that in which the interviewer has no trade knowledge, the obvious criticism to which it is subject lies in the well-known fact that a little knowledge is a dangerous thing. The author has seen interviewing done by young men in the employment office, where the whole object of the procedure seemed to be to prevent the "interviewer" from appearing to lack thorough trade knowledge. When the examiner is out of his depth, the skilled workman is the first to detect the fact. Under these conditions he feels that he is either passing through a purely formal examination, or else that he is being made a fool of. Both of these situations are unfortunate for the reputation and effectiveness of the employment office. All who have worked in industry know how important it is that a good understanding exist between the various shops and the office, an understanding that should not be confined merely to the foreman, but should extend to each man in the plant.

From what has already been said, the use of the methods of job analysis and the application of trade tests, are not theoretical ideas which will have to fight for a hearing. The situation in almost all large industries is crying out for some device which 
will meet the present difficulties of operation. Every large employment office, either through its follow-up work, when using methods of general interview, or else through its expensive office payroll, when the examinations are conducted by experts, knows how necessary is some radical change to better the mechanism of placement. Just as in the army the occupational specifications and trade tests came into existence to meet urgent demands of the personnel officers, who saw that their own methods were completely breaking down, so also in industry . job analysis and trade tests will enter to fill a want, the magnitude of which is best known to the employment office itself. 


\section{CHAPTER $\mathrm{X}$}

\section{PROBLEM OF OCCUPATIONAL ANALYSIS}

\section{The Problem of Occupational Analysis}

THE general purpose of this book does not admit of any description of the way in which a plant should conduct analyses and construct sets of specifications for each job.

The problem of job analysis, while simple enough as far as the idea is concerned, becomes very complex when the work is commenced. It may, however, be pointed out that from the very beginning of time, implicitly at least, there have been rough forms of analysis. Plato's "Republic" gives us an admirable example of job analysis on a large scale. All that is proposed is to conduct these analyses in a much more scientific and detailed manner, making common property what often is the mental property of a single man.

Any analysis of a job can be made from two viewpoints:

(I) the human qualities and properties for which it calls,

(2) a detailed account of the actual operation and skills characteristic of the job.

Of these two types the second is by far the more useful. It is exceedingly difficult with reference to any particular job to decide just what are the human qualities required. Whenever an analysis of this kind is attempted, the common list of human qualities such as perseverance, patience, adaptability, thoroughness, etc., gets rapidly used up and the result is a meaningless jumble. It is often found that for twenty or thirty entirely 
different jobs within the plant the same basic human qualities are required. The only difference existing between the jobs is found in the different skills which are required, and only in these terms can the job be accurately defined. Industry should be extremely skeptical of any method for selecting personnel based on observation of different basic human qualities. Applied psychology has been brought into great disrepute by charlatans who have claimed to be able, by mere observation, to rate employees for all important traits. The author knows in particular of two or three cases of exploitation of this kind, where the individual in question rated each member of the employment force in twenty to thirty important human traits, without spending, on the average, more than five minutes with each individual. To measure human qualities, in fact, to discover any objective scales upon which honesty, perseverance, adaptability, loyalty, coöperation can be reported is work which lies in the distant future of psychology, work which will of necessity be slow and disappointing, taxing human ingenuity and patience to the uttermost. While it is true that fairly accurate methods of measuring certain forms of intelligence have been evolved, and are now applied with great success in industry, too great warning cannot be given against the supposition that the success of these methods for measuring intelligence, which have been the result of twenty years of labor, will lead to the immediate evolution of methods for measuring these more complex human traits. In fact the beginnings of measurements of this kind practically are not yet in sight. Especially must the employment manager be wary of those persons who claim heaven-sent skill, and methods which savor more of witchcraft than of the scientific laboratory. Even if it were possible to conduct a job analysis upon the basis of the human qualities required, such an analysis would be of little service, until an 
accurate method of measuring these human qualities had been devised.

When, however, we pass from the job analysis in terms of human qualities to actual analysis of the skills and duties of the job, we pass from the shifting sand of human judgment to the firm foundation of concrete fact. Whatever may be the form and the details in which these analyses are made, there seems to be general agreement that three distinct characteristics of the job must be analyzed.

I. The physical characteristics of the job.

2. The mental characteristics of the job.

3. The economic aspects of the job.

The essence of a good analysis is to pick out the essential elements under each of these aspects, and to describe them in standard terms, which will mean the same to all men at all times. Under the physical aspects of jobs, the precise nature of the work, in so far as it requires a particular physical organization, will be described. Thus, for example, whether it is heavy work, whether it involves sitting, standing, climbing, hauling, etc. Under mental characteristics will be included an account of the educational requirements, the necessary training defined as far as possible by stating the actual operations which the job demands, that is, the actual tools which must be employed, the machines which must be run, or the procedures which must be followed.

In large numbers of specialized shops it may be advisable, in constructing these specifications, to distinguish clearly between the general duties of the occupation and the specialized duties which are called for by the particular nature of the work in that shop or plant. For example, in a particular machine shop, the basic duties of the occupation might be those of the general machinist, which would be listed. In addition to these, 
however, there would be specialized duties characteristic possibly of this shop alone. These two types of duties should be distinguished in order to simplify the problem of the employment office. The trade test or any form of interview must be based on the general duties or operations, since no applicant, unless he had previously worked in the plant, could be expected to be familiar with the specialized duties.

Under economic aspects all such questions as methods of payment (by time, piecework), hours of work, basis and avenues of promotion are included.

These specifications, as has already been said, will introduce a common language upon which exchange can take place. When requisitions come from a foreman, there will be no chance for vague general terms. Instead of six machinists being called for, the foreman will ask for two men to fulfill the requirements of job 27 , and four men to fulfill the requirements of job 36 . No misunderstandings can arise under these conditions, such as those often found in the army. Thus, for example, an amusing case arose in response to a call for a pipe cutter. The qualification cards were consulted, and a "pipe cutter" was assigned to work. When he reported and was put to work on a sewer in the camp, it appeared that he was a carver of meerschaum pipes! While this is an extreme case, any industry in the course of a week could duplicate equally useless references, due to the fact that no common language is used in making requisitions. With the entrance of job specifications and the application of trade tests, all such ambiguities automatically disappear. 


\section{CHAPTER XI \\ WHAT THE TRADE 'TEST IS NOT}

The Trade Test is Not an Intelligence Test nor does it Serve to Predict the Rate at which Șkill can be Acquired by Training

WHEN the various occupations within a particular industry have been analyzed, the next step is to decide on those trades or occupations for which it is advisable to construct some form of trade test. Obviously, in the case of unskilled occupations, and in a large number of other occupations, for which skill can be acquired in a few hours, there is no need for any form of trade test. It is necessary to distinguish very clearly, at this point, between the function of trade tests and two other types of examination which are entering the industrial field.

The first of these is the mental intelligence test. Here no attempt is made to measure any specific skill which has resulted from trade experience. The examination confines itself to an attempt to measure general mental adaptability. In so far as any particular job requires this mental equipment, rather than any specific trade skill, the mental test can be used with great advantage, but it should never be confounded or combined with the trade test proper. Intelligence is dependent almost wholly on a native endowment; trade knowledge is primarily the result of specific training which has for its object the development of this particular trade skill.

The second type of test which must not be confused with a 
trade test is that for skill prediction. For a large number of occupations very little training is required; in fact, many industries prefer to take on "green hands," and to train them for the particular operations which they are to perform. The performance of these operations may, however, be dependent upon certain qualities or traits within the individual, which vary greatly from person to person. These qualities are not the basic human qualities to which reference has been made, namely, honesty, pliability, perseverance, etc., but much more specific traits. For example, for certain kinds of work it is known that good eyesight, keen visual and tactual discrimination, a good memory, quick reaction, accuracy of movement, steadiness of attention are necessary. No claim is made that all these traits are required for any particular occupation, but even the most superficial analysis of some occupations reveals the necessity for certain of these traits in more than average amounts. Thus, for example, in the case of the telephone operator it may readily be seen that a quick reaction to a certain type of stimulus, and a ready memory for certain kinds of material are a sine qua non for success. Or again, for a great deal of inspection work where very minute flaws in parts have to be detected, good eyesight and keen visual and tactual discrimination are essential assets. Experiments on large numbers of individuals, performed in different places and at different times, have all agreed in one respect, that there are enormous individual differences in the degree in which these traits are possessed by various individuals. Perhaps the most outstanding contribution during the last twenty-five years of the application of psychology to human behavior has been the revelation of these extreme individual differences. These differences, as they exist, are not due primarily to the training which the person has received, but are much more fundamental in so far as the 
traits are the result of the inheritance of a definite nervous mechanism. Training has, of course, some effect upon the final skill which the person acquires, but the extent to which he profits by the training is very dependent upon the particular nervous mechanism which he brings to the learning process. It is by no means merely a question of perseverance. In some cases, though perseverance be unstinted, and the period of training as long as possible, skill in tactual and visual discrimination will be poorer than it is in other cases before the period of training is commenced. In fact, in a large number of what are called elemental traits, the amount of improvement with practice is very small. It is patent that it is extremely wasteful for industry to hire for a particular operation requiring very keen visual or tactual discrimination applicants who do not possess this trait in a fairly high degree. Failure in a large number of employees cannot be attributed to the employee himself, but is due to the faulty method of selection used by the employment office. A particular applicant, who in all general respects may be competent for a hundred and one jobs, may have such a low degree of the trait essential for a specific process that it is absolutely futile to attempt to train him. Under these conditions, it is very desirable to have some form of tests which will distinguish between individuals of different degrees of native endowment. Such tests are in no sense trade tests. They make no attempt to measure skill which has been acquired in a specific occupation. They are essentially "skill prediction" tests, or "vocational aptitude" tests, as they have been sometimes called. They do not measure skill and information which the individual actually has acquired when following a trade, but they attempt to measure the suitability of the applicant for entering upon a process of training.

While these two forms of test, the mental test and the skill 
prediction test, both have a great sphere of usefulness in industry, it is very essential to precise thinking on the subject of industrial testing not to confuse these with the trade test proper. The trade test makes no pretence at measuring intelligence directly; it makes no attempt to measure the native endowment of the subject, with a view to predicting the degree of success to be expected as a result of training in a specific trade; the trade test furnishes a rating, in objective quantitative terms, of the degree of trade ability already possessed as a result of practice in the trade.

Nevertheless, in a very real sense, a trade rating can, under certain conditions, be used as a help in predicting the future capability of a tradesman. This point will now receive attention.

\section{Interpretation of the Trade Status Rating}

A rating of a tradesman cannot, under all circumstances, be taken at its face value. It must in many cases be interpreted in terms of his previous educational experience, the amount and variety of his previous industrial experience, and such other social and personal data as are significant. For example, two men, both rating as apprentices when given the same test, are of totally different trade value, if one has earned the rating as the result of six months' experience whereas the other has been engaged in the trade for five years and still earns the same rating. In the last-named case, owing to lack of intelligence or lack of interest, in spite of considerable experience in the trade, the learning process has been so slow that little prospect can be entertained of any considerable advance with further training. The man is an apprentice and will probably remain an apprentice all his life. In the first case, however, the achievement in the test is such that rapid progress may be expected as 
WHAT THE TRADE TEST IS NOT 375

the result of further experience. For present purposes both men may be of equal value, but from the standpoint of future usefulness they have totally different worth. A trade rating is a measure which must be interpreted in the light of other factors than those of present performance. 


\section{CHAPTER XII}

\section{THE USE OF THE VARIOUS TYPES OF TRADE TESTS}

\section{The Use of the Oral Test}

THE question as to which form of trade test shall be used, oral, picture, performance or written, depends wholly on the nature of the trade and the particular purpose of the test within the plant. Certain general factors have to be taken into consideration in making the final choice. While it is possible, of course, to use all three forms of test in the initial stages of the introduction of the idea, it is more than likely that such duplication of measuring instruments will not be expedient. Where the trade under consideration is one which requires a considerable amount of information, and where the class of workman that is hired is English speaking, it will usually be wise to start with some form of oral or picture test. The simplicity in construction combined with the ease in administration are points which favor the oral and picture method to such an extent that only where these forms of test are out of the question will the performance method be resorted to as a first type of selective examination. When it has been decided to use either of these two forms of trade test, the problem of compilation of the question closely resembles that already described in the army process. There are, however, one or two factors which commonly enter into the industrial situation to complicate the issue. The first of these concerns the problem of the type of question, the second concerns the coaching factor. 


\section{The Non-specialized Question}

One of the dangers to be avoided in the compilation of groups of questions for specific trades within a particular industry is the possibility of securing a number of questions which are dependent entirely on a purely local condition. To illustrate, within a particular shop twenty or thirty general machinists might be found working on the same class of work, one confined wholly to this particular shop. In spite of the fact that this process was very specialized and remote from the ordinary run of work of a machinist, there would be grave danger in making the assumption when compiling the questions that information in regard to these processes must be possessed by all general machinists who apply for work at the employment office. Provided such men existed, it would be perfectly legitimate to frame a test which demanded the precise information, important for that particular shop. Usually, however, the employment manager under such conditions is perfectly satisfied to have a good general machinist, knowing that his trade ability can be rapidly adapted to the specialized jobs of the shop. Unless, therefore, the attempt is being made to hire very specialized labor, which is already skilled in the particular processes, it is very necessary to avoid questions which are not representative of the general trade. This difficulty was obviated in the army by visiting a large number of plants in three geographical centers. The selection of the plants within a particular center was based primarily upon differences of work performed by men following the same trade. Where two plants employed men of the same occupation, doing almost identically the same work, an attempt was made, in the process of compilation and standardization, to avoid using the men in both these plants. In this way all localisms of the trade and all highly specialized processes, 
confined to one or two plants, were avoided. When the questions are compiled, not within a dozen plants but within a single plant, this point will have to be very carefully watched. Invariably in the army procedure it was found that a number of the questions furnished by the experts within the first plant visited were incomprehensible to experts in other plants.

There are several ways of avoiding highly specialized questions. Usually within a plant of any size there are a large number of men who have not grown up there. In fact, the usual lament of industry is its rapid labor-turnover. It is an ill wind that blows no good - these very men can furnish valuable information to the compilers of questions. The application of doubtful questions to such men will decide whether the process around which the question is framed is local or common to many plants. Not having grown up within the plant, these men will also suggest questions of a general nature which would not arise as the result of study of the processes in a particular shop. A further device for eliminating questions of this type is by consulting standard text books and trade journals. One important warning, however, must be issued. In the attempt to get away from specialized questions, there is a danger that the compiler may also get away from the practical conditions of the trade. Generally speaking, his only source of thoroughly practical information is the shop itself. It is far better to have an occasional specialized question than it is to have a series of questions which do not reflect general shop conditions. In the case of small shops where there are but few men representing any one trade, the only method of constructing satisfactory trade tests will be by coöperative experiments with other plants. Without wide diversity in operators and a sufficient number for the process of try-out and standardization it is out of the question 'to manufacture a rigid trade test. 


\section{Factor of Coaching}

Within the army the danger of previous coaching of the recruit was reduced to a minimum, by giving the examination at the time of entry. It formed but a small part of a larger process of examination. The recruit at the end of the whole examination had little chance of remembering the details of any part of it. Even if information were retained by a recruit, it was almost impossible to transfer this information to other men who at a later time would come up for examination. When the trade tests were first constructed, the danger of coaching was felt to be so real that supplementary questions were added, which did not form part of the examination upon which the man was rated. The instructions with regard to the use of these supplementary questions called for their administration, if by any chance the suspicions of the examiner were aroused, causing him to think that the candidate had been coached for the examination. The whole group of 'supplementary questions was never given to any one candidate. It was discovered, however, that coaching was not taking place, with the result that in the later forms of test the supplementary questions were omitted.

The assumption that in industry the coaching factor will not enter would be erroneous. A method of oral or picture trade testing must be devised which will frustrate any attempts in this direction. There is only one way in which the danger can be avoided, i.e., by having a large number of questions which can be used in a more or less random order. There is probably no trade so barren that it cannot furnish several hundred questions conforming to the requirements which have already been cited. There is no reason why the more complex trades should not furnish several thousand satisfactory questions. In compiling and standardizing these questions, a good mechanical 
device for securing the necessary information is to use a filing system. Then each question which arises can be placed on a single card, on which the results of the preliminary try-out and the final try-out can also be recorded. If the question is suitable for the purpose for which it was constructed, by a simple statistical method its degree of difficulty can be calculated and noted on the card. Another alternative is to construct several groups of questions combining, let us say, fifty questions of known degree of difficulty into twelve or fifteen sets of ten to twelve questions each. The score that may be expected on each one of these sets can then be deduced from the material furnished by the original cards. The advantage of the filing system is that questions can be added from time to time, thereby maintaining a cumulative system of examination.

\section{Standard of Achievements in Industry}

The question of establishing standards of achievement raises a further point concerning the contrast between army and industrial conditions. When a recruit claiming skill was examined in the camp to which he was sent, his rating in the trade examination was in many cases the sole criterion for transfer to meet trade requisitions in other camps or in France. It was absolutely necessary to have a form of examination which yielded a very accurate rating of the degree of skill possessed. A trade test, carelessly standardized, might easily result in the transfer of men to France who were entirely unsuited to perform the work for which they. were requisitioned. Again, the necessity for fine differentiation between degrees of ability arose because of the extreme value of highly skilled tradesmen. Where the army specifications called for an apprentice workman, it was obviously wasteful to send a journeyman or expert unless the two last named could not be used in any other place to greater 
advantage. This differentiation between apprentice, journeyman and expert and particularly between journeyman and expert necessitated very accurate standardization. Generally speaking, the accuracy which is sought in any instrument varies directly with the importance and finality of the decision which results from the measurement. In the case of the army, where transfer involving time and money was dependent upon the decision, it was very advisable to use every care in calibrating the test. The importance of the army decision was infinitely greater than that of the same decision usually made in industry, where failure or success merely results in rejection or reference to a foreman. Furthermore, the distinction between journeyman and expert, which made the process of standardization somewhat laborious for the army, is rarely called for in industry. The three essential classifications in ninety per cent of the interviews in an employment office are (I) novice or bluffer, (2) a helper or learner, (3) journeyman (skilled man). Usually these three classes are so well separated by any form of test that the process of standardization can be much curtailed. It is impossible to lay down any general rule. The feeling of the author is, however, that particularly at the time of introduction of trade tests into industry it is very easy to spend too much effort in accurate calibration of questions and tests. Each question must of course be administered to a sufficient number of men of different degrees of trade standing to insure its conformity to the requirements of a good oral or picture test. Too much time can hardly be spent in acquiring facility in constructing the question yielding the right type of answer; too much time cannot be spent in confirming the fact that the content of the question is satisfactory, but it will be very easy to waste time by attempting to calibrate the tests to make fine distinctions when the tests themselves, under the 
actual conditions of the employment office, will never be called upon to make such fine differentiations.

\section{The Use of the Performance Trade Test}

If for language reasons or because the nature of the trade does not lend itself to oral or picture methods it is decided to use a performance test, great care must be taken in the choice of the performance or performances. The operation must be typical of the trade as it is carried out in various plants. It must be of such simplicity that on the basis of time taken and product produced the applicant can be rated objectively. Finally it must differentiate between those levels of trade ability which at a later time it will be used to measure. Generally speaking, unless a particular performance reveals a marked difference in skill between the apprentice and journeyman, it will be of no wide service in industry. Whether the test need distinguish between the ordinary journeyman and the so called expert, is much more doubtful. In those plants with which the author is familiar, such differentiation is not usually demanded.

The scope of the performance test is unlimited; its main advantages and disadvantages have already been touched upon. It may, however, be interesting to note how the performance trade test differs from the usual try-out given to an applicant by the foreman. In the latter it is commonly a matter of chance what operation is used as the test; it depends on the machines that are free, the time of day and the caprice of the foreman. Particularly, if a foreman takes a dislike at sight to an applicant, the operation assigned for performance is apt to be an extremely difficult one, with failure almost certain. No detailed standard directions or specifications are given with reference to the job itself. If the foreman has free time, the applicant has a much better chance for receiving full explanations than if the shop is 


\section{USE OF THE, VARIOUS TYPES}

busy and the foreman rushed. Another essential difference is that in the usual try-out there are no standards of achievement laid down; the foreman uses his own personal judgment, not rating by the time factor or by attention to certain details of the process or qualities of the product, the importance of which have been already determined and correspondingly weighted in the final score. In other words the whole examination suffers from all the disadvantages which are the concomitant of a haphazard process as opposed to a scientific process. The result is that justice is not done to the applicant, the plant or the foreman. The foreman is not to be blamed for the arbitrariness of his judgment; with such a process of examination no other form of judgment is possible. Contrast this with the scientific performance test chosen after due experimentation with various procedures of the trade. Here every applicant is given the same job to perform, to each are given precisely the same tools and equipment, precisely the same directions; every applicant finally is judged according to fixed standards, on the basis of time consumed and certain qualities of the final product. There is the same chance for all, and ability can be judged and rated in terms which are objective and, therefore, comparable with the ratings of all other applicants. The standards are the same from month to month and are independent of the examiner giving the test. The arbitrary and subjective judgment is replaced by the scientific measuring rod.

The drawbacks which attend the performance method, from the standpoint of their industrial application, are:

(I) the greater time consumed in examination,

(2) the equipment necessary for the examination, i.e., tools, machines, material,

(3) the room required for administering tests to several applicants at the same time,

(4) the greater difficulty in constructing the test. 
If these points do not render the oral method the more advantageous, the introduction of the performance test brings with it many incidental advantages. The attitude of the applicant towards this type of examination has already been considered; there is no doubt that a well-chosen performance test gives the workman a feeling of satisfaction with regard to the fairness of the selective method which in certain cases is lacking when the oral tests are used. It is, however, rather easy to overestimate the importance of this point. In examining several hundred men each day for several weeks, in eighty trades, in a large employment office, the author can only remember four cases in which the applicant openly expressed his skepticism and disapproval of the oral examination. In a large number of cases, where the oral test revealed little ability, the applicant would make statements such as the following: "Well, I guess you called my bluff." "As a matter of fact, I never worked at the trade, but my father was in it and I thought I knew a good bit about it." "To tell the truth, I have only been on production work, but I thought I could get by as a machinist." In addition, the performance test, if well chosen, is almost free from the danger of coaching. Words may be learnt readily, but to master knacks and acquire skill is a very different matter. The claim cannot be made that an appl cant cannot be coached for the examination, but it is much more difficult and requires much greater time than in the case of the oral tests. In a large plant it might be well to have several alternative tests, where there is any suspicion of special training taking place.

There is of course no reason for an employment office limiting itself to one form of examination; presumably within the same office, oral, picture and performance tests will be employed according to the nature of the trade for which hiring is done. Under certain conditions even for the same trade, it may be 


\section{USE OF THE VARIOUS TYPES}

advisable to have all types of examination. The first rough selection might well be based on rapid oral examination; if this was passed with a certain degree of proficiency, the applicant would then be given a systematic performance test to determine his final rating. Even where the oral test gives a sufficiently accurate rating of skill, as is usually the case, a performance test may be necessary if large numbers of foreigners have to be handled, a condition found in certain localities, in specific trades, such as cabinet making, etc. 


\section{CHAPTER XIII}

\section{THE ADAPTATION OF THE TRADE TEST METHODS TO THE TRAINING OF EMPLOYEES}

\section{The Use of the Trade Test Method in the Training of EMployees}

MANY large corporations, to fill their demand for skilled men, have installed or are installing their own trade schools, vestibule schools or educational departments. Within these schools a more formal type of instruction is given than that which can be expected in the shop itself. The advantage of this method of training is apparent. In the shop the main consideration is production; to this end all processes must lead. In so far as instruction is given, it is merely a means, within this unit, to increase the production. Under these conditions the efficiency of the learning process is sacrificed to the routine of the shop. The instruction is almost entirely confined to the actual processes which the workman is called upon to perform; there is little attempt to choose typical processes which contribute to a broad understanding of the trade. Furthermore, the foreman who is in charge of what incidental instruction is imparted is more often chosen on account of his trade skill, or power of handling men, than on any consideration of his ability as a teacher or trainer.

The specialization of departments, which on the production side has yielded such ample returns, is now extending to this 
phase of plant operation, namely the training of employees. It is not necessary to discuss whether the school is whole time or part time, but it is important to realize clearly the contrast between the training which is incidental to the shop and the school training which exists solely for the purpose of imparting instruction. Within the school there is no bogey of production, there is no need to sacrifice the learning process to other factors, though of course in the last analysis the school itself must by the efficiency and the rapidity with which it teaches justify its existence, as a factor in increased production of the entire plant. However, the school during the training period can direct all its energies to devising and formulating educational methods and devices. The nature of these is dictated solely by the needs of the learners in the light of the occupations for which they are being trained.

Within the educational department the three fundamental problems which arise are the old problems of the school.

r. What shall be taught?

2. How shall it be taught?

3. How shall the efficiency of instruction be measured?

In the solution of these problems the usefulness of trade tests and allied devices is apparent. What shall be taught is largely determined by job analyses, the results of which supply accurate information concerning the actual knowledge and skills demanded by the various jobs. For certain purposes it may be necessary to consider the whole process of instruction as contributing to the turning out of a skilled mechanic, but from the standpoint of the teacher the more enlightened view analyzes the total process into its elements. While it may be true that general trade ability is the final goal, the more immediate aims by which the goal can be reached are very definite and specific in their nature. To recognize this tool, to know its 
name, to know when and how it is used, to understand just how much heat must be applied, to understand the working of this machine when doing a particular process, to know how to use a micrometer, how to mix solder, what stock is suited to the job under consideration, etc., are the immediate aims of instruction.

The first procedure, therefore, before any attempt at imparting trade instruction is made, must be to discover what are the essential tools, the important processes and the common materials of the occupation. When this information has been secured, the next problem is - How shall the various elements of information and the various kinds of skill be taught? The problem is that of devising a scheme of training which will accomplish its ends in the minimum of time and with the minimum expense. The total body of information which has to be learned and the various skills which have to be acquired being known, the question is to construct a plan whereby the unskilled worker is converted into the competent tradesman. In what order shall the various processes be taught? Where shall the different elements of information be emphasized? What shall be the method of teaching each process? In what way is the necessary information most readily acquired and retained? All these are questions which press for solution. In the solving of these problems an adaptation of the methods of the trade test can be employed to great advantage.

In the description of the oral tests it has been-shown that a series of questions can be devised which cover, by sampling, a range of knowledge of the whole trade. This was for the purpose of measuring with the maximum speed, the general trade ability of the workman. There is, however, no reason at all why this method, instead of being applied to the whole trade, should not be confined to first one element of the trade, then to 
another, until all the significant phases of the occupation have been covered. Thus, instead of having a series of twenty questions concerning twenty representative elements of the machinist trade, there might well be twenty to fifty questions on each of forty, let us say, essential processes of the trade. By way of illustration, we can consider a number of characteristic jobs of the machine trades, compiled by the Committee on Education and Special Training of the War Department and reproduced by special permission.

WAR DEPARTMENT

COMMITTEE ON EDUCATION

AND SPECIAL TRAINING

\section{NUMERICAL LIST OF JOB SHEETS}

\section{General Tools and Operations}

I. Use a file properly on work furnished by instructor.

2. Use a hack saw properly on work furnished by instructor.

3. Grind a cold chisel.

4. Use a properly made screw driver in the right way.

5. Use a caliper.

16. Chip a flat surface.

7. Use properly the wrenches required on the job assigned.

8. Lay out work according to blue print.

9. Lay out and chip a keyway.

Io. File a keyway to size and fit the key.

II. Grind cutting tools (lathe, shaper or planer).

I2. Use properly the taps required on the job assigned.

I3. Use properly the threading dies required on the job assigned.

I4. Measure accurately with a micrometer.

15. Scrape a surface.

r6. Measure and classify tapers of various sizes.

17. Use properly the hand reamer required on the job assigned.

${ }^{1}$ I 8 . Solder a piece of brass to a piece of steel.

${ }^{1}$ Not published in advance edition. 
${ }^{1}$ I9. Babbitt a bearing.

20. Build a fire in the forge.

21. Cut off stock at the anvil.

122 . Draw out a piece of iron.

23. Forge, harden, temper and grind a cold chisel.

${ }^{1}$ 24. Forge a U clamp.

${ }^{1} 25$. Forge a bolt blank.

${ }^{1} 26$. Forge a nut blank.

${ }^{1} 27$. Join two pieces of stock by welding.

\section{Lathe}

Ior. Put a lathe through its paces.

I02. Drill and ream center holes.

I03. Face a piece to a given length.

I04. Turn a piece to a given diameter.

105. Turn shouldered work.

Io6. Determine the proper use of lathe chucks.

107. Finish a hole in a lathe (drill, bore and ream).

I08. Turn a taper.

Io9. Cut a thread in a lathe.

${ }^{1}$ I IO. Face and turn work held on a mandrel.

${ }^{1}$ I I I. Turn an angle, using the compound rest.

${ }^{1}$ I 2 . Bore a taper hole.

${ }^{1}$ II3. Use a steady rest for turning.

${ }^{1}$ II4. Use a steady rest for boring.

${ }^{1}$ II 5. Cut a square thread.

${ }^{1}$ I 6 . Cut a metric thread.

${ }^{1}$ II 7 . Cut a metric thread.

${ }^{1}$ I 18 . Cut an inside thread in a lathe.

${ }^{1}$ I I9. Set up work on a face plate.

\section{Drill Press}

20I. Put a drill press through its paces.

202. Grind a twist drill.

203. Hold work on the drill press.

${ }^{1}$ Not published in advance edition. 
204. Drill holes as per layout.

205. Use a machine reamer in a drill press.

${ }_{1}^{1} 206$. Use a counterbore in a drill press.

${ }_{1207}$. Use a boring tool in a drill press.

${ }^{1}$ 208. Use a tap in a drill press.

WAR DEPARTMENT

COMMITTEE ON EDUCATION

AND SPECIAL TRAINING

Shaper

30r. Put a shaper through its paces.

302. Finish a rectangular piece in a shaper.

${ }^{1} 303$. Plane a bevel surface in a shaper.

${ }^{1} 304$. Plane a tongue and groove.

${ }^{1} 305$. Plane an irregular surface.

${ }^{1} 306$. Plane a keyway in a shaft.

${ }^{1} 307$. Plane a keyway in a gear.

\section{Planer}

${ }^{1} 40$. Put a planer through its paces.

${ }^{1} 402$. Hold a piece of work on the planer table.

${ }^{1} 403$. Plane a horizontal flat surface.

${ }^{1}$ 404. Plane a vertical surface and a bevel surface.

\section{Milling Machine}

5or. Put a milling machine through its paces.

${ }^{1} 502$. Select a milling cutter.

${ }^{1} 503$. Mill a plane surface.

${ }^{1} 504$. Mill a rectangular piece.

${ }^{1} 505$. Mill a keyway.

${ }^{1}$ 506. Face mill a surface.

507. Put a dividing-head through its paces.

${ }^{1}$ 508. Mill a bolt head square.

${ }^{1}$ 509. Cut a spur gear.

${ }^{1} 5$ ro. Cut a reamer.

${ }^{1} 5$ Ir. Mill the square on a tap.

${ }^{1}$ Not published in advance edition. 


\section{Grinding Machine}

${ }^{1} 60$ r. Put a grinding machine through its paces.

${ }^{1} 602$. Select an abrasive wheel.

1603 . Grind a cylinder.

${ }^{1} 604$. Grind a taper.

1605 . Grind a hole.

${ }^{1} 606$. Grind a face.

${ }^{1} 607$. Grind a cutter.

Within the field of each one of these operations, a series of directions and questions covering the essential elements of information has been constructed. These questions serve to bring out within each operation what are the points of importance with which the skilled tradesman must be acquainted. One of the great weaknesses of present methods of instruction both in the public schools and in industry is that the pupil does not know, and at present has no way of finding out, what are the really fundamental elements which must be given attention. When attempting for the first time a particular job, each part of the operation appears to the learner to be of equal importance; minor details are given just the same attention as the essential parts of the process. There is no assessment of relative values. In a great many cases the learner is so overpowered by the details and the secondary factors that the main points escape attention. How often after failure to benefit by instruction we hear the learner say, "I did not realize at the time that it was essential; if only I had known I would not have overlooked it."

It is just this difficulty that a series of well-chosen questions will obviate. Each question will call attention to some aspect of the work, an understanding of which is essential to future success in the trade. Concerning the minor parts, which may

${ }^{1}$ Not published in advance edition. 
well be left for a future occasion, there will be no questions. The attention of the learner will be directed wholly to the elements of vital importance.

The questions will not only tell the learner what are the essential elements, but they will also call for definite answers. The workman from the very beginning will have to talk the language of his trade. It is a remarkable fact how limited the trade language of many skilled workmen is; especially is this true in respect to the names of tools and processes. Again and again when compiling the army tests, it was necessary to eliminate a question for the simple reason that even skilled men did not know trade names. A tool or operation which had a perfectly definite and simple name would be referred to as a "hickey" or "the job the foreman does." In fact in one plant the employer was so impressed with the ignorance in this respect of even his best men, as revealed by the preliminary set of trade test questions, that he informed the author that he was going to do a "little schooling on his own," in order to remedy a state of affairs which could not but cause confusion in the stockroom and shop. This condition is produced by a system of haphazard instruction, in which the learner is told to use this tool or to perform that job without ever having a chance to hear the exact language of his trade.

No mention has yet been made of the form in which the instruction within each important aspect of the trade shall be given. The series of questions will merely call attention to certain fundamental elements; it yet remains to discuss the manner in which the learner is introduced to the operation under consideration.

One common method is to assign the learner to work with a skilled tradesman or teacher, virtually a modification of the old apprentice system. In other cases, the learner is put through 
his paces in a more or less systematic fashion by the foreman. Both these methods are exceedingly wasteful for reasons already discussed, but until recent times, no other recognized method has been available.

Under either of the above forms of instruction, the whole process was haphazard, depending to too great a degree on the workman, teacher or foreman. If the pupil was sufficiently curious to "worm out" the necessary information, or the teacher sufficiently attentive and conscientious in the imparting of knowledge, the process might be reasonably satisfactory, but in the large majority of cases the instruction was of a perfunctory nature, from which the pupil derived the minimum of skill and information. Moreover the jobs or tasks were as a rule not well chosen for the purpose of teaching the essential elements of the trade, and even where the operation was well chosen the teacher did not allow the learner sufficient first-hand experience to perform the processes or to become acquainted with the tools and machines. A more systematic method of instruction was badly needed.

The fundamental principles upon which the performance test was constructed furnishes a valuable method of attacking this training problem. Instead of the training operations being performed under chance and varying conditions, a device for training is necessary where every operation is performed under controlled conditions. Now from what has already been said, it is obvious that the essence of the performance trade test method lies in the controlled conditions under which each job was executed.

The scientific procedures of the examining device as found in the performance test must be adapted to the construction of an equally scientific training device. It is a well-recognized fact that we learn by doing. Especially in the acquirement of skill, 
the laboratory method is the only possibility. This being the case, the problem of instruction within any particular trade resolves itself into the determination of what are the most appropriate tasks for the learner. While job analysis determines the general nature of these tasks, there are several important considerations which must be borne in mind in the selection of the detailed operations. In the first place, each operation must include within itself the maximum number of useful elements. It must also be an operation which is essential or fundamental to the trade. Moreover, the jobs should be arranged in an order of increasing complexity. Commencing with a simple process basic to the trade, the job should gradually increase in difficulty until the final tasks are such as to demand the knowledge and skill required of an expert workman. All theoretical training should be given incidentally in connection with these assigned specific tasks. No workman should be allowed to pass from one job to another until he has shown the requisite amount of skill in the first operation. The manner in which the trade test ideas can be used in connection with each one of these tasks must now be discussed.

It will be noted that the phrases "specific tasks" and "learning under controlled conditions" have been used. The problem is largely one of making these various operations specific and controlled. In the description which has been given of the construction of a performance test, the way in which an operation is standardized was made clear. The essential elements of this procedure are:

I. Very accurate statement of the practical problem.

2. A clear enumeration of the tools and material necessary for the carrying out of the job.

3. A specific statement of the essential qualities in the product obtained or essential activities in the process performed. 
These three elements are necessary when the purpose of the operation is to measure the ability of the tradesman. Where, however, the purpose of the process is not to examine but to train, a further element will have to be added. Besides giving clear directions with regard to the required product, it will be necessary to give in great detail the problems to be met before this final product is obtained. In the description of the process there will be included a statement of the tools which have to be employed, and an account of the way in which the material must be handled, and any other incidental information which is essential to the satisfactory performance of the operation. These detailed specifications of the problem, covering what has to be done, the equipment necessary, the methods of doing it, and the essential quality of the final product, will be collected into a single job sheet for that operation. It may well be that included in this job sheet there will be oral questions and even pictures which call attention to the salient features of the job. Each learner will be responsible for seeing that he understands and follows out in detail the exact operations called for by the job sheet. When one of these jobs has been completed, the learner will then pass on to the next, and so on until he has gone through all the typical operations which are necessary for success in the trade. There is of course the greatest room for skill in deciding the nature and sequence of these jobs. They should follow one another in an order which is conducive to rapid learning and each one should present real problems, the working out of which will equip the man with first-hand knowledge of practical details of construction or operation and provide a background for the understanding of scientific principles. A few typical job sheets in tentative form are here reproduced by permission of the War Department. 
WAR DEPARTMENT

COMMITTEE ON EDUCATION

AND SPECIAL TRAINING

\section{MACHINISTS}

\section{INTRODUCTION TO USE OF JOB SHEETS}

\section{The Purpose of the Job Sheets.}

The purpose of the Job Sheet is to draw the attention to the underlying principles and important features wit : which familiarity should be attained through the doing of the job.

\section{Directions for Using the Job Sheets.}

General directions sufficient for beginning the job are given in the first few questions of each job sheet. Start the work according to these directions, and, as the work progresses, determine from the remaining questions what other things should be done, the order in which they should be done and the method of doing them. Refer to the sheet from time to time as you progress in the work in order that you may be sure of observing the details which are important and may become familiar with the reasons for doing the job in a particular manner. It is only by thoroughly understanding the underlying principles of this job that you will be able to undertake, intelligently, similar jobs depending upon the same principles. In this way, the knowledge gained from doing one job can be used to advantage in doing others.

\section{Sources of Information.}

There are several available sources from which you may obtain the information to which the questions relate.

First: A study of the machines and tools which you are to use will furnish a fund of information that will be of value, not only in the job at hand, but in any similar job.

Second: Copies of Text Books, Hand Books, Data Sheets, Manufacturers' Catalogues and Instruction Books are available in the shop library. These should be consulted frequently.

Third: Some of the men working with you may have had previous experience which will enable them to help you. Do not hesitate to discuss the questions with the other men in the shop. 
Fourth: The instructor may be appealed to for such information as you are unable to get in any other way. However, he will generally prefer to tell you where the information can be found, and correct any misinformation which you may have obtained from other sources.

\section{Note Particularly.}

It is of utmost importance that you know the answer to every question on the Job Sheet and it is equally important that you obtain this information by your own exertions rather than have the instructor pass it out to you. Information obtained by experience is likely to be retained and become a part of your personal knowledge, while information obtained from the instructor is readily forgotten. Students should regard the instructor not so much as a source of information as a court of last appeal, who can settle discussions and rectify mistakes. It is much better to have the instructor judge as to the correctness of the information which you have obtained by your own efforts than to have him give you the information himself.

WAR DEPARTMENT COMMITTEE ON EDUCATION AND SPECIAL TRAINING

\section{MACHINISTS}

Job No. I

\section{Use a File Properly on Work Furnished by Instructor}

[Obtain a convenient piece of flat or rectangular stock say about $2^{\prime \prime}$ wide, and catch it in the vise. This piece may be scrap if one side is flat and smooth. Get a $12^{\prime \prime}$ bastard file from the tool-room and lay it across the piece.]

I. Can you see between the file and the piece?

2. Is the file thicker in the middle than at the ends?

[Grasp the handle of the file in the right hand, thumb on top and end of handle against palm. Place the heel of the thumb of the left hand on the other end of the file and curl the fingers under. Do not bear too hard on the file, but try to file a spot in the middle of 


\section{ADAPTATION TO TRAINING}

the work without touching near the edges. One or two careful strokes are enough.]

3. What is one reason for having the file slightly convex or "bellied "?

4. If the file were not bellied, and warped in hardening, would its usefulness be impaired? Explain.

5. If the file were not bellied, would it be easier to "take hold" or harder? Why?

6. Grasp the file properly as directed above; make a dozen or more strokes and test the surface. Is it flat? Is it convex?

7. What is the effect when filing if the right hand tends to go down and the left hand raises slightly?

8. What is the effect when filing, if the right hand tends to raise and the left to go down?

9. Is it easy to file the edges and produce a convex surface?

Io. It may be stated that in order to produce a flat surface with a $\mathrm{IO}^{\prime \prime}$ or a I $2^{\prime \prime}$ file, a harmonic movement of the arms, body and legs is necessary. What does this mean?

II. What do you mean by a "knack"? Is filing a flat surface a knack? How is a knack acquired?

I2. What is meant by crossing the cut in filing?

I3. Should the file be lifted from the work on the return stroke? What is the reason?

14. When making the forward stroke in filing, should the side tendency be to the right or to the left? Why?

[Obtain from the tool-room a flat bastard file, a hand bastard file, a second cut file and a mill file; sizes $\mathrm{I}^{\prime \prime}$ " or $\mathrm{I} \mathrm{o}^{\prime \prime}$, if convenient.]

15. What are the differences between a flat file and a hand file?

I6. What is the difference between a bastard file and a second cut file?

I7. In what way does the mill file differ from the other files?

I8. What do you understand by bastard? Second cut? Smooth?

19. How is the length of a file measured?

20. What is the difference between a "double cut" file and a "single cut" file?

2I. What is the difference between a "double cut" file and a "second cut" file?

22. Which is the easier metal to cut with a file, cast iron or wrought iron? 
23. How should the scale on castings be removed before filing the surface?

24. What is the reason a file should not be used to remove the scale from cast iron?

25. Why should not a new file be used on cast iron?

26. When should the coarser files be used? When should the finer files be used?

27. On narrow work, should an old file or a new file be used? Why?

28. What can be done to keep cast iron filings from clogging the file?

29. How is the handle properly fitted on the tang of a file?

[Obtain from the tool-room the following files and place them on the bench in the order named: $10^{\prime \prime}$ half-round; $8^{\prime \prime}$ pillar No. $\infty$; $8^{\prime \prime}$ pillar No. $2 ; 8^{\prime \prime}$ round second cut; $8^{\prime \prime}$ square second cut; and $6^{\prime \prime}$ three-square slim.]

30. What is meant by "safe edge" on a file? When is it advisable to use a file with a safe edge? If advisable could you grind a safe edge on a file?

3r. What commonly used file has two safe edges?

32 . Is a half-round file half round?

33. On what kind of surfaces is a half-round file used? What is the purpose of having teeth cut on the flat side?

34. How is the cut of a file designated in the smaller sizes?

35. Are the terms coarse and fine as applied to files relative for all sizes of files?

36. What $\mathrm{I}_{2}$ " file would you use to remove stock rapidly? What file would you use for finishing?

37. What number $8^{\prime \prime}$ pillar file would you use for roughing? For finishing?

38. What is a file card? How may a piece of brass or copper rod be made into a most efficient file cleaner?

39. What causes "pinning"? How may the pin be removed?

40. How many different shapes (cross section) of files are you able to find?

41. What is a riffle? What is a "needle handle" file?

42. In your judgment, why should a single cut file be best for filing in a lathe? 
WAR DEPARTMENT

COMMITTEE ON EDUCATION

AND SPECIAL TRAINING

\section{MACHINISTS}

Job No. 23

\section{Forge, Harden, Temper and Grind a Cold Chisel}

[Obtain a piece of chisel steel of the size and length required, build a good, deep charcoal or coke fire and heat the steel to a forging heat.]

[It is very necessary in forging to hammer with well-directed, snappy, solid blows, and the hammering should be fast enough to "keep up the heat" of the steel. In forging it is advisable to keep in mind the general shape desired and forge along these lines. For example, in forging a chisel, cracks are often caused if the chisel is allowed to get too wide and afterwards forged back to width. In order then to forge a chisel in the right way and to have the effect of the hammer blows evenly distributed, it is necessary to alternate the operation on the flats and on the sides of the chisel.]

I. What is the purpose of keeping the fire fairly small in circumference?

2. Why is it necessary to have a deep fire?

3. How far above the tuyere is the chisel placed in the fire? How deep in the fire is it buried?

4. What is the disadvantage in having too much blast? In not keeping up enough blast?

5. In what way will it injure tool steel to overheat it?

6. What are the reasons for not hammering tool steel when the heat is lost?

7. What do you understand by the terms white heat, yellow heat, red heat, welding heat, forging heat?

8. How is a piece of steel heated "thoroughly"?

9. How heavy a hammer should you use when forging?

ro. What general shape of tongs is best? Why?

II. How and where do you grasp the hammer? Why not choke it?

Why not squeeze it? 
12. What is meant by the term "annealing"? What two effects may annealing have on steel?

13. Why is it advisable to anneal a forged tool before hardening it?

14. How may steel be annealed? What is meant by "water anneal"? What heat is suitable for annealing?

15. What heat is suitable for hardening? What care must be taken in heating? Why?

16. What is meant by hardening on a rising heat? Why is this advisable?

17. How far back should a cold chisel be hardened?

I8. What is the proper temper color for a cold chisel? Why?

I9. Is a chisel harder or softer than a file? Why?

20. What do you mean by running the color? By drawing the temper?.

2r. How is the chisel held against the grinding wheel? Why not rest the chisel on the tool rest?

22. When the face of the grinding wheel is grooved, how may the facets of a cold chisel be ground flat?

23. What is the best cutting angle for a cold chisel? Why not 90 degrees? Why not 50 degrees?

24. Are the facets of a cold chisel flat? Is the cutting edge straight? 25. When grinding a cold chisel, what precaution should be taken regarding the temper?

26. How would you make a cold chisel if no fire suitable for forging is available? How could it be hardened and tempered?

27. If no grinder is available, how may a cold chisel be sharpened? 28. What is a cold chisel? What is a flat chisel? Cape chisel? Gouge chisel?

WAR DEPARTMENT

COMMITTEE ON EDUCATION

AND SPECIAL TRAINING

\section{MACHINISTS}

Job No. IOI

\section{Put a Lathe Through Its Paces}

I. Move the carriage along the top of the bed by hand. What are the ways used for? How are they shaped? How are they finished? Why? 
2. Explain how the carriage is moved along the ways by hand. What is the feed rack? What is the feed rack pinion? Why is it called a pinion?

3. How are the ways cleaned and oiled properly? What will occur if they are allowed to become dry?

4. A large proportion of lathe work is done "on centers." Where is the "live center" located? Where is the "dead center" located?

5. Why are the centers called "live" and "dead"? Which is hard? Which is soft? Why? .

6. Move the tail-stock along the bed. What other lengthwise adjustment may be given the dead center?

7. If through carelessness the tail spindle is run off the screw, what caution must be taken regarding the keyway?

8. How is the dead center removed? What caution must be observed?

9. How is the tail-stock adjusted sideways? Why is it necessary to first loosen the clamping bolts? Where are the "witness marks"?

Io. How is the tail spindle tightened? Will a quarter of a turn of the binding screw loosen it? Why turn the binding screw around three or four times?

II. Where is the main spindle of the lathe? Why must it he substantial and accurate? Why must the hearings be substantial and accurate?

I2. What establishes "the center line of a lathe"? What is it parallel to? When is the dead center, "in line"?

I3. How is the live center removed? What is the use of the "witness mark"?

14. Why is the face plate removable? What is the proper method of removing it? What is the danger of starting it on when the machine is running? What is the diameter of the "large face plate"? What size lathe is this?

15. What are two advantages of the hollow spindle?

I6. When do you clean and oil the thread and shoulder of the spindle? Why?

17. What part of the carriage is called the saddle? The apron? The tool rest? 
18. How is the top of the saddle finished? Why must it be kept clean and well oiled?

I9. Find, along the front of the bed, the lead screw and the feed rod; and on the apron, the split-nut handle and the longitudinal feed control.

20. Close the split-nut on the lead screw. Can you now move the carriage by hand? Give reason.

2I. Open the split-nut and tighten the feed control knob. Can you now move the carriage by hand?

22. Loosen the feed control and tighten the carriage clamp screw. Can you move the carriage?

23. Why does a machinist, before starting to work on a lathe, always try the carriage to make sure it moves freely?

24. Be sure the carriage moves freely by hand and start the lathe. How is motion transmitted from the main spindle to the lead screw? To the feed rod?

25. Arrange the tail-stock well back toward the end of the lathe and the carriage about midway between the head stock and tailstock; have the feed rod turning and "throw in the feed." How far does the carriage move while the lathe spindle makes 25 revolutions? Divide by 25 and tell how far it moves in one revolution.

26. What do you understand by the term "feed" in lathe work?

27. How do you obtain a "coarser feed" or a "finer feed" in this lathe?

WAR DEPARTMENT

COMMITTEE ON EDUCATION

AND SPECIAL TRAINING

\section{MACHINISTS}

Job No. $5 \circ 7$

\section{Put a Dividing Head Through Its Paces}

I. Turn the index crank ro turns (revolutions) and note what part of a revolution the work spindle makes. How many turns of the index crank are necessary to make one complete turn of the work? 
2. The work spindle is turned by an enclosed worm wheel. In certain other machines, possibly on the drill press, the action of the worm and worm wheel may be seen. Find an example.

3. How can you determine the number of teeth on the worm wheel in the dividing head?

4. If it takes 40 turns of the index crank to revolve the spindle once, what part of a revolution will the spindle make with 20 turns? With 5 turns? With ro turns? With $6 \frac{2}{3}$ turns?

5. How many turns are necessary to index for a gear of 20 teeth? For 40 teeth? For 80 teeth?

6. In each casé, as above, a certain number divided by the number of teeth required gives the number of turns of the index handle. What is this number?

7. State a rule for determining the number of turns or the fractional part of a turn of the index handle to be made for any given number of divisions.

8. How many turns for to divisions? For 5 divisions? For 8 divisions? For 6 divisions?

9. How many circles of holes has the index plate that is now on the head? How many of these circles are divisible by 3? How would you obtain two-thirds of a turn?

Io. Are there any index plates, other than the one now on the head, furnished with this machine?

II. If the index pin is not in a circle divisible by 3 , how may the index crank be adjusted radially to permit the pin to enter a hole in the desired circle?

I2. What do you use to save counting the holes for every move? How are the arms adjusted and set to include the desired number of holes?

13. If two-thirds of a turn is required and an I8-hole circle is used, how many holes are included between the arms of the sector? Why not twelve?

I4. What part of a turn will you make to cut a gear of 42 teeth? What circle will you use? How many holes will be included between the arms of the sector?

I5. In which direction should the index crank be turned? Why? 
I6. What keeps the index plate from turning when the crank is turned?

[The worm and worm-wheel and the spindle are arranged within a casting more or less cylindrical in form, which is so mounted on the base plate of the head, as to permit of its being set and securely locked at any angle from $5^{\circ}$ below the horizontal to $30^{\circ}$ beyond the perpendicular.]

17. Tip the head to a vertical position. Can indexing be accomplished? Tip the head to 45 degrees. Are you able to index in this position?

I8. In some makes of index heads a plate with 24 divisions is keyed to the spindle just back of the drive. What is the purpose of this plate?

19. How may the worm be disengaged from the worm wheel? When is this necessary? Why?

20. Before disengaging the worm why is it necessary to take out the stop-pin?

2I. What advantage has direct indexing? Why are there 24 holes in the direct index plate? How are these holes numbered?

22. Rearrange the dividing head for simple indexing. How do you know when the worm properly engages the worm wheel?

23. How is the center removed from the dividing head spindle? What standard taper has the spindle hole?

24. Why is a cap screwed on the nose of the spindle when the center is being used? How is a chuck mounted on the spindle?

25. What plate is needed in order to set the dividing head at any other angle than parallel with the table?. How do you set this plate square? How do you set it at any other angle?

Reference has already been made to the third problem in the educational process, namely, How shall the efficiency of instruction be measured? Given a certain training process, how can we be sure that the ideas or skill which it was devised to impart are "getting over"? The application of the performance test idea to the job sheet method of instruction makes this question comparatively simple. Whether the man has fulfilled 
the requirements of the job sheet will readily be determined by the consideration of two of the essential elements of the job sheet itself.

In the first place, can the learner, as a result of performing the process, answer the various questions which are included in the job sheet? Secondly, does the product exhibit those standard qualities which are the necessary resultant of the correct performance of the job? If the learner can answer a predetermined proportion of the questions, if the product that he has turned out, when rated by standard methods, scores a reasonable percentage of the maximum, then, and not until then, will this particular stage in the process of learning be passed. The accomplishment of the job, with a reasonable degree of success, success being defined in purely objective terms, is the signal for advancement to the operation next in sequence. The job sheet, if properly constructed, will decide the three questions:

r. What shall be taught?

2. How shall it be taught?

3. Has the learning process taken place?

It is impossible here to go into further detail as to the exact construction and methods. of use of these job sheets, which would form the basis of instruction. The exact function which the teacher would perform would vary with the nature of the operation and the ability of the learner. The extent to which the theoretical information should be introduced in the form of questions would also have to be determined with great care. Each element would be introduced in connection with that process with which it had the most intimate relation. One of the discoveries which is made as soon as this device of teaching is adopted is that the old distinction between what is practical and what is theoretical tends to disappear. Precisely the same element of information nay be theoretical if given at one time 
and essentially practical if given at another. One of the great advantages which will be reaped from the use of the job sheet method will be the scientific determination of the exact point at which each element can be most advantageously introduced in the solving of the practical problems outlined in the sheet.

The general directions which will be given to the learner before commencing work on any job sheet series will cover such points as the object of the method; it will be pointed out that its aim is to draw attention to the fundamental principles and important features by actually doing the job. The instructions for using the job sheets will be of the simplest order; the learner will simply be told to solve the problems as they arise; only when the workman is absolutely brought to a standstill will he consult the instructor. The questions themselves and the nature of the job will determine what has to be done and the order in which it shall be done. Constant reference must be made to the questions, for the purpose of these is to insure the observation of the important details. The workman will be informed that these tasks have been chosen and arranged in a certain order, and that success in the operations involved in the later sheets will be strictly dependent on the manner in which the underlying principles of the preceding jobs have been thoroughly mastered. While most of the questions will be such as can be answered directly from observations of the process and trial and error in the use of tools and machine, a few of the questions demand further outside trade information. This can be obtained from either text books or handbooks, placed in the shop library, which the learner will be encouraged to consult. Others may be answered by discussion with fellowstudents who are also learning the trade. Only in the last resort shall appeal be made to the instructor. Even then, it shall be the business of the instructor, if the information can 
be procured in reasonable time, to refer the learner to the correct sources. The sterling virtue of this method of instruction lies in the extent to which it places the responsibility in all the various stages upon the student himself. From the very first job sheet the student will know that he is responsible for performing the operation; that the answering of every question depends on his own exertion; that only when all other methods have failed will he be given direct information. Lastly, he will know that at the end of the process he will be held to a strict account in which there can be no shuffling and no bluffing. If he is unable to furnish intelligent answers to a reasonable proportion of the questions, if the final product does not show the necessary standardized qualities, he will not be allowed to pass on to the next operation. Shoddy work will mean, in the first place, a reduction of the speed of the learning process, and in the last analysis, rejection. In this way, within each important occupation for which the industry gives specialized instruction, there will be created a series of hurdles which become increasingly difficult as time advances. These hurdles will automatically create a barrier to the student who cannot benefit by the instructions, but to those who can negotiate them the hurdle itself will furnish both the exercise and the check. The speed with which these hurdles can be passed depends wholly upon the learning ability of the pupil. It may reasonably be expected that the best will be advanced at from five to ten times the rate which the slowest will attain. Just as the performance test is a standardized, scientifically constructed examining device, so the job sheet will be a standardized, scientifically constructed training device.

Up to this point the general implication has been that the training device above described is to be used merely for the breaking in of new employees. This of course is only one of 
the functions. It will also be used with great effectiveness in the case of employees, who for some reason - either the transfer from one department to another, or promotion within the same department to more difficult work - need specialized training. Herein will lie one of the great merits of the job sheet method in which the scheme of instruction is in well-defined and separated units. Where an unskilled hand is receiving training he will pass through the whole series of training units, but where a man, already partly skilled, is receiving further training, he will merely pass through those units which are new to him, and which are contributory to the final trade ability required.

It is a platitude to say that the essence of the problem of placement is to know just what knowledge and skill is in the possession of each employee. The above scheme presents a method of determining and recording this information in a very precise manner. The training record of all employees within the plant will furnish a permanent register, which, together with information in other lines, will form the basis of promotion or transfer from one operation to another. In the case of new employees, very slight modifications of the job sheet will convert them into what are essentially oral and performance tests. When these sheets are arranged in a more or less definite order of ascending difficulty, it will be possible to assign the man on the basis of the general interview to that testing job which is about his level of attainment. There will be no need in many cases to cover the preceding sheets, and even if doubt exists, a few well-directed oral questions will give the necessary information.

Another important contribution which will be made by this system will result from its usefulness in determining points of weakness in the trade ability of a particular man. One of the great merits of the British system of Trade Tests lay in the 
fact that the testing device also gave very valuable information with regard to the elements in which further instruction was needed. Their administration being centralized, it was possible to have the tests much longer and more elaborate than those found in our own army camps. The examiners were trade experts who knew exactly the army requirements in skill. By watching the recruit perform a long series of processes, they were able to make a detailed analytic measurement of the trade ability of each candidate. Thus they knew that a particular recruit was strong in certain directions and very weak in others. Consequently he could be transferred to training schools where the necessary instructions could be given along just those lines in which the candidate had shown weakness during the examination. The devices of standardized examinations and standardized performances above described will accomplish this same purpose. They will also have the great advantage, which the British system lacked, of furnishing standardized ratings of the ability of the workman.

What has been said must not be interpreted to mean that the instruction centering around the job sheets will always take place in the school laboratory rather than in the actual producing shops of the plant. Whenever possible the job sheets should be constructed from operations chosen because they are actually contributory to the production of a common product. This close connection between the learning process and production gives a zest and significance to the former which exerts a most beneficial effect on the student. There is, however, a very marked difference between the state of affairs when carefully chosen jobs within the industry are used as methods of instruction and the old type of haphazard instruction commonly found in the shops. The differences in the two methods are found in (I) the nature of the problem selected for learning purposes, 
(2) the manner in which the student is allowed to solve the problem for himself, (3) the absence of meaningless routine and drudgery. In a shop working under production conditions, where these three points can receive adequate attention, instruction may well be given, but where the conditions of production do not admit of such attention, the special school shop should be the place of learning. 


\section{CHAPTER XIV}

\section{THE INSTALLATION OF TRADE 'TESTS}

THE precise manner in which the training and selection function will be performed cannot be described in any detail. The essential factor for success of any method or device depends on the extent to which it is incorporated into, and articulated with, the various other devices for personnel placement. No idea such as that of the trade tests can be worked out and reduced to a standardized form, which can be applied directly to all industries. Generally speaking, the author is extremely skeptical of methods that are introduced from the outside by consultants. Nearly always this results in the plants being saddled with numerous appliances which are not adapted to their specific needs. The consultant or efficiency expert creates a device to meet a general need, which may in only the remotest way coincide with the particularized need of the specific industry. Methods such as have been described must be applied by men who have a first-hand knowledge of conditions, knowledge only found in those who are permanent members of the personnel division.

What then is the function of the consultant or expert? From a wide acquaintance with the application of these methods in large numbers of industries it may be supposed that the consultant will have a wider point of view, and will be more able to diagnose roughly the general needs of the plant. Having determined whether these methods can be successfully applied, it is the business of the consultant to train individual members of the personnel force in the methods of test construction and administration. That is, the work of the expert will be that of 
training in personnel methods, and not that of installing certain devices. If the latter procedure is allowed, the firm will never free itself from the necessity of constant reference to the original consultant. Whenever the actual device installed has to be modified to meet new conditions, the outside services will be needed. While this, of course, is very profitable to the consultant, and to a certain extent is his salvation, it is very expensive, and even wasteful, for the firm. It is much more advantageous to have a single personnel member of the organization trained under careful supervision of those familiar with trade test ideas, than to have a thousand and one personnel devices of which the underlying principles are not clearly understood. One of the objects of this presentation of the trade test ideas is to give an intelligent employment specialist the fundamental principles and the necessary information so that he may be enabled, without undue wasteful experimentation, to install his own methods. The construction of oral tests, picture tests and performance tests, is a matter of trial and error; provided the individual starts with a few basic ideas, it does not take long to acquire the skill and technique of construction. With the person who has, by one method or another, acquired a knowledge of trade test methods there will be associated a group of men, the number of which varies with the size of the plant. This experimental group will be responsible for:

(I) Deciding as to the advisability of the trade test method in the various occupations.

(2) Deciding with regard to the type of test used.

(3) Construction of the tests.

(4) Keeping the tests up to date.

(5) Application of the trade test methods to the problems of training and transfer.

(6) General supervision of the administration of the tests. 
In the larger industries it will be a matter of considerable economy to separate the research group that constructs the test and advises with regard to their application from the larger group, consisting chiefly of clerical workers, who administer the tests. The research group should be responsible for seeing that the general methods of administration are followed in order to reap the full benefits of the testing method, but in so far as their work is highly specialized, they should not be held responsible for the routine of hiring within the employment office, or for the routine of teaching in the shop or school. It is of course necessary that they should keep in the closest touch with the employment office and the school, in order to test the general efficiency and workability of the methods they devise, but the routine work should be handled by the lower paid group.

With the introduction of oral trade tests into the employment office, certain alterations of the office arrangement, while not absolutely necessary, will contribute greatly to their success. The fact that an oral test is given makes it highly desirable that the conditions of an individual examination be established. This can usually be accomplished by a different system of routing, or by constructing small booths or office partitions at convenient places. The army in its interview work, when a trade examination was necessary, used partitions, such as those shown in the illustration. Where the existing arrangements cannot be altered, the oral tests can be given with reasonable success provided one applicant is called up at a time. The common practice of allowing all that takes place between the interviewer and the applicant to be heard by a number of men, who in many cases are pushing and shoving for the next hearing, is exceedingly bad. In a well-constructed employment office, sufficient order should prevail to enable at least a semi-private interview to be given. In the case of the performance test, naturally, 
somewhat elaborate facilities are necessary. Whether these facilities shall be placed in the employment office itself, in the school, or in assigned places within the shops themselves, is a matter which can only be settled by a consideration of the

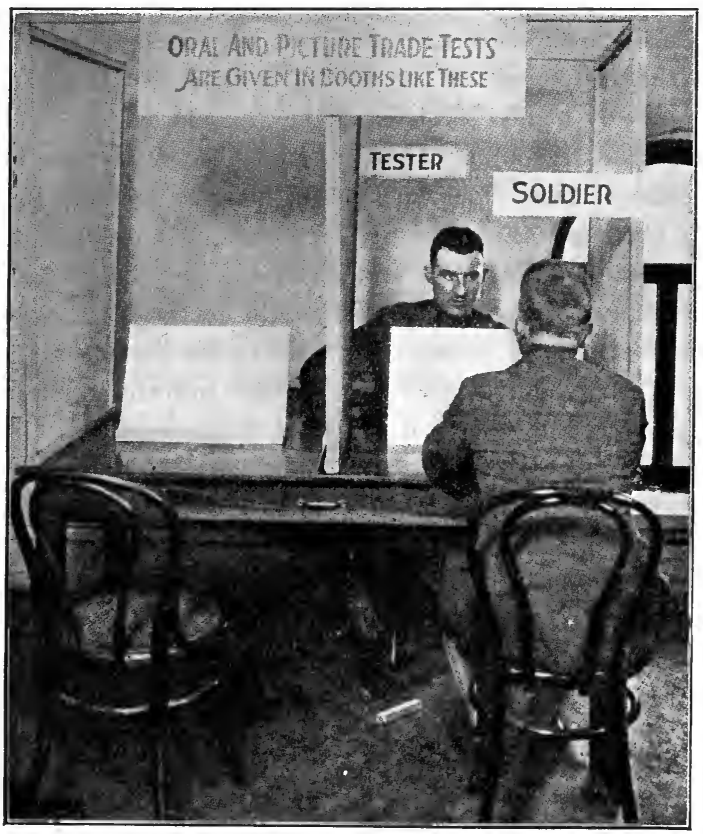

nature of the tests and the possibilities of the particular plant.

The introduction of the trade tests will of course be gradual. At first only the more important occupations will be studied; only for those occupations where a good deal of selection is necessary will tests be devised. The author would strongly 
recommend that the first experimental work be done, wherever possible, with the oral question method. When this method, for any reason, is not applicable, resort must be had to the picture or performance devices. In the interest of a rapid return for the effort expended in construction, and also for the purpose of establishing confidence in the tests, administered by interviewers who are not tradesmen, the oral tests should be the first in the field.

A further purpose for which trade tests will eventually be employed, even in those industries where no formal instruction is given, will be to determine from time to time the manner in which the various employees are becoming acquainted with the general processes of the trade. It is probably true that for many years to come the old method of breaking in workers will be employed, where the applicants after a preliminary interview are sent into the shops and assigned odd jobs, assisting skilled workers in the various places in which they can be useful. Under these conditions the degree of benefit which is derived varies greatly from learner to learner. Let us consider two applicants who, after the preliminary interview, pass into the same shop and both work on numerous routine jobs. At the end of a year, if the foreman is asked concerning the relative merits of these two employees, he might answer that both are equally useful, in his opinion, which may indeed be true as far as the work upon which they have been put enables the foreman to make a decision. As a matter of fact, one of the applicants is extremely interested in his trade. In his odd moments he has watched the other workmen in the shop, he has attended night classes, and he has read up on the processes of his trade. The other workman has conscientiously performed the tasks which he has been called upon to do, but his interest has not been sufficient to make him acquire other information except 
that which was essential to his trade. While in the majority of such instances the foreman will discover such facts as have been mentioned, it is quite possible in the case of a large shop and a reticent employee for merit of this kind to pass unnoticed. In other cases, even when some workmen in the shop may know of this difference in attitude of the two employees, it may easily happen that such information is not known to those who control promotion and transfer. That this is not a purely hypothetical state of affairs, the following illustration will prove. In a large plant in the neighborhood of Pittsburg, priding itself on its personnel work, the author was standardizing a set of questions for a certain type of machine trade. One of the apprentices when brought in for a try-out and given the questions, astounded the examiner by securing a score which was slightly better than that of the average expert in the trade. This rather disconcerting fact stimulated curiosity as to possible coaching, since this particular applicant was the fifth or sixth in order of examination. Investigation, however, proved coaching out of the question. An experience of this kind naturally called for further inquiry, as the whole success of the army trade tests depends on such cases not arising unless there is a very adequate cause. The foreman was at once called in and interrogated with regard to this particular boy. The facts were that he had served an apprenticeship of a year and a half. In the opinion of the foreman, his trade knowledge was on a par with the other apprentices who were also given the examination. Nothing that had happened within the shop had caused either the foreman or the assistant foreman to single out this particular apprentice.

The foreman being unable to give any light, the boy himself was recalled, and he was asked if, as far as he could tell, there was any reason why he knew more about the trade than the average apprentice of one and one-half years' standing. Then 
the fact revealed itself that his father was a skilled machinist, having a small shop of his own in the neighborhood. The boy from the time that he went to school had been around the shop, helping his father and the other men. He had also been given definite instructions in an informal way, but his training had not been of that systematic kind which would enable him to claim journeyman ranking. His father, desiring him to work in a large shop, sent him to the plant where he applied for work as a helper, and not explicitly claiming any special skill he was placed in the ordinary routine fashion. It was not until the trade test was given, one and one-half years after his entry into the shop, that his real trade ability was known. The examiner left the plant and thought no more of the incident until three weeks later he was again in a different department of the same concern, and happened to run across the aforementioned foreman; who at once made the significant remark: "You know that boy that you picked out? We have already promoted him, raised his wages, and I intend to keep my eye on him, for he is the kind of workman I need." While this is undoubtedly an extreme example, there were several other cases in which the employer made very interesting discoveries with regard to differences between his workmen which he had never suspected. The application of trade test methods cannot help but reveal the extraordinary differences in the rate at which individuals learn when working under precisely the same conditions. The fact that from time to time the workman will be given a chance to show just exactly what he has learned, and that a record of this will be kept in the hands of those who control his promotion, will serve as an incentive of the highest order. 


\section{CHAPTER XV}

\section{SOME FURTHER APPLICATIONS OF TRADE TEST METHODS}

IN addition to finding their place in the employment offices of large industrial plants, the trade tests will also fill a keenly felt want in general employment offices, whether private or public. A very significant experiment with the oral tests was performed from December, I918, to March, I919. When the armistice was signed, and there was no longer need for the army tests to be used solely in the army, it was felt that the results should be applied to other government offices where skilled workers were handled. The most obvious field for their operation lay in the U.S. Employment Service, conducted as a part of the Department of Labor. Considering that at that time it was the intention to use the U.S. Employment Service as one of the important agencies which was to relieve the pressure of demobilization, it was particularly incumbent upon the War Department to see that this Service was given every facility. With this in view a group of men was lent by the Army Trade Test Division to the Labor Department. The function of this group was to adapt the army methods to the needs of the Employment Service. These needs were so essentially similar to those of the army, that it became immediately apparent, from a preliminary try-out in several cities, that the oral trade test could be used to good advantage. It was, however, felt that a complete trial, on a large scale, of the trade tests necessitated the creation of a special type of employment office.

At this particular time there was also a demand for enlarging the employment service in New York City. This fact enabled 
a specialized employment office to be created, which would handle only skilled labor. As no such office existed, it was necessary not only to procure the site, but also to devise an office plan and to gather the necessary personnel. There is no need to describe at any length its general plan. The lay-out of the office enabled each examiner to occupy a section; within this section there was the examiner's desk and the clerk's desk, and a number of chairs. There were in all five examiners, each examiner handling a group of trades. The applicant on entrance was given a rapid interview in order to discover the trade in which he claimed to have skill. When this was ascertained, he was then referred to that section where the trade was handled. Here the man was seated, and waited until he was called by the examiner for an interview at the desk.

This interview was absolutely private. The men who were waiting were so placed that they could not hear the conversation. At this point the applicant was given a form of trade test specially adapted to the uses of the U.S. Employment Service. There was felt an urgent need for such a device to solve one of the great problems of the Employment Offices. The common criticism which was made of the system of reference used prior to this time was that the method of interviewing enabled a large number of trade bluffers to "get by" and thus secure references to industrial plants. From the standpoint of the skilled mechanic the employment office must operate to bring the man into contact with the job; from the standpoint of the employer it must serve to furnish a likely group of men from which choice may be made, thereby minimizing the wearisome and wasteful task of personally investigating the qualifications of men who have not had the necessary training for the work. It was in the latter respect that the mechanism was breaking down. Many employers made the complaint that the men sent 
from the employment office had no skill in the trades in which they had claimed knowledge when interviewed in the employment office. The lack of trade knowledge on the part of the interviewers was bound to create this situation. In order to obviate this situation, within this experimental office two methods of interview were worked out:

I. The standardized trade interview.

2. The selective trade interview.

The results which had been previously obtained by the Army Trade Test Division were used at once to construct the standardized trade interview. The factor of coaching and speed made it necessary to alter the form of examination; also the rigidity of the army scheme made it unsuitable for use in an employment office. The final form of standardized interview consisted of ten questions, the degree of difficulty of which was known. Any six of the questions were to be asked, and the individual rated upon the basis of his score on these six questions. The questions within the test were so chosen that any six which were selected would be of approximately the same degree of difficulty. Whereas in the army four levels of ability were recognized, in the Employment Service there seemed to be no useful purpose served by making the distinction between the journeyman and the expert. For this reason, only three levels were used:

I. The nontradesman, who was defined as a man with no trade experience.

2. The helper, a man who has had experience in learning the trade, but not sufficient to make him a tradesman.

3. Tradesman, a man who has passed through the helper or apprentice stage, and is given full tradesman's rating.

The examinations, though of a simpler order, and not so highly differential, were so essentially similar to the army 
trade tests, that there is no need to reproduce any of them. With extensive trial of this simplified standard test, it was discovered that the definite standards of achievement prescribed for novice, helper and tradesman made the use of this type of examination rather dangerous, unless examiners could be well supervised and trained in the methods of giving the oral tests which have already been detailed. The object of this experimental office was to devise a method which could be applied to all offices throughout the country. There is no doubt that within a specialized office the standardized test, with prescribed levels of achievement, is by far the most satisfactory. For general uses, however, in offices where it was impossible to control conditions, another type of interview was called for, which would be more flexible and, therefore, more adaptable to the needs of the general run of employment offices.

To meet this need a device known as The Selective Trade Interview was constructed. The questions comprising a Selective Interview were compiled in precisely the same manner as was described in the army procedure; the same degree of care was employed to see that they were typical questions and that the answers were complete. They were, however, not standardized in any formal manner, they were merely administered to a sufficient number of tradesmen of different degrees of ability to ensure: (I) that they represented different degrees of difficulty, (2) that they were genuine trade questions. No standards of achievement were prescribed. The interview furnished the examiner with a series of questions carefully worded, with all possible answers which he could use, in any manner, to discover the suitability of the applicant for the position. The examiner merely judged by the ease and fluency of the workman whether he was a tradesman, helper, or novice. In general the examination consisted of ten questions, any six of which might be used. 


\section{PAPER HANGER}

\section{TRADE INTERVIEW QUESTIONS}

Ask at least six questions; more if necessary to judge accurately the candidate's ability. Score only the results of the six questions you ask first. Vary as much as possible your selection of the first six questions.

1. Q. What do you call the paste or glue you put on a plastered wall before papering?

A. Size (sizing).

2. Q. What other brush does a paper hanger use besides a pasting brush?

A. Smoothing.

3. Q. What do you call the muslin covering which is put on a board partition before sizing?

A. Lining.

4. Q. What kind of joint is generally used in hanging heavy oatmeal or embossed paper?

A. Butt.

5. Q. What do you call the waste edge which is cut off in making a butt-edge joint?

A. Selvage (trim).

6. Q. What do you put into sizing to kill the gloss when papering over a painted wall?

A. Potash (soda) (pearl ash) (ash).

7. Q. What do you call the joint where only one selvage edge is trimmed off?

A. Lap (slap-work).

8. Q. What do you call a joint where one edge and all but about $\frac{1}{8}$-inch of the other edge is trimmed off?

A. Wire (hair-stripe). 
9. Q. What do you call the space on the wall between he chairrail and baseboard?

A. Dado.

10. Q. What is put into paste to make it stick better when you hang lincrusta or heavy paper?

A. Molasses (turpentine), (venetian), (turps). 


\section{GLAZIER}

\section{TRADE INTERVIEW QUESTIONS}

Ask at least six questions; more if necessary to judge accurately the candidate's ability. Score only the results of the six questions you ask first. Vary as much as possible your seleztion of the first six questions.

1. Q. What liquid do you generally use on the drill point when drilling through glass?

A. Turpentine (kerosene), (coal-oil).

2. Q. What tool do you use to remove the sharp edge from glass? A. Roller.

3. Q. What do you call the small triangular pieces of metal that hold-in the glass when puttying?

A. Points.

4. Q. What do you do to a wooden sash to make the putty stick in longer?

A. Paint (prime), (oil).

5. Q. What common kind of pu ty is there besides linseed-putty? A. White-lead.

6. Q. What do you generally use to drive in points on a window which is in place?

A. Chisel.

7. Q. What do you call puttying the sash before putting in the glass?

A. Bedding (back-puttying).

8. Q. What do you call the narrow strips of wood used to hold plate-glass in?

A. Beading (molding).

9. Q. What is placed in skylight glass to make it fireproof?

A. Wire.

10. Q. What kind of glass, besides wired, is usød in skylights?

A. Ribbed. 
While this method is by no means as complete as the standardized, calibrated form of examination, it has the great advantage that it can be used by any examiner even though he has not been trained in the technique of administering the oral tests. What is more, a series of adequate questions can be prepared very rapidly. This type of exam nation certainly serves to eliminate the man who is attempting to deceive and in nine cases out of ten enables the examiner, with the help of the general interview concerning nature of previous work, length of experience, etc., to decide whether the applicant is a helper or tradesman. It should, however, only be used when for any of the reasons above mentioned the other more accurate forms of calibrated tests are impractical.

This experiment was such a success and resulted in so much more accuracy in the placement of men, that it was decided to extend these methods to a number of representative offices throughout the country. This work was already under way when the curtailment of the United States Employment Service, as a result of the lack of appropriation by Congress, brought this interesting experiment to an end. The abandonment of the idea did not take place, however, before the trade test methods had demonstrated their efficiency and applicability to the problem of a large employment office, working under peace conditions.

Trade test methods have also been effectively employed in examinations given for Civil Service positions. The conditions under which the Civil Service appointments are made make some form of objective rating extremely desirable. The examinations for a large number of positions must be conducted in various places by a single examiner. Absolute freedom from any suspicion of favoritism or "pull" is a necessity. Slight adaptations of the trade test methods will provide a ready 
means for securing a type of examination which will meet these requirements. In fact at the present time the Civil Service Commission of Ohio is constructing examinations directly based upon trade test ideas.

It is also true that in certain trades, even fairly large plants require only one or at the most two skilled tradesmen. Thus for example a single electrician or power-house man may be sufficient to meet the needs of that particular kind of work within the plant. When hiring for these jobs there is no chance for reference to a foreman, there is no chance of comparison with other types of workmen. Under these conditions this form of trade test, devised in plants where large numbers of such workmen are handled, would be of the greatest service in the correct selection of an applicant.

A further fact of interest may be cited, as showing the advantages which may be derived from even a limited use of trade tests. Supposing that in only a few of the more important trades it is feasible to construct trade tests for use in the employment office, the introduction of tests in these few trades will alter the attitude of men who are applying for openings in those trades for which no tests have been constructed. Practical experience within a large employment office has definitely proved that knowledge on the part of the applicant that some form of trade interview may possibly be given is sufficient to eliminate the greater number of bluffers. The presence of a few good trade tests gives a tone to an office which is noticeably lacking under present conditions, where not only the employment officials but also the tradesmen themselves realize how slip-shod are the methods of judging trade skill.

While it is true that these standardized methods of selecting personnel have passed, by one stride, out of the realms of theory, it would not be wise to make claims which at this time would 
appear extravagant. Industry is in a position to take advantage of the result of a huge experiment, but these benefits will be reaped more by continued experiment with the general methods, than by any immediate application of present devices. The great contribution of the Army Trade Test Division is found in its rigid adherence, at every step, to the strictest scientific principles. It has shown that the principles of measurement, devised in other fields, can be applied with equal advantage to the field of selection and training in industry. A great step has been made, but progress will only be secured by following the leads which have been given. There is always danger that when new laboratory ideas are applied, the desire for immediate results in the practical field will lead to an attempt to eliminate some of the less showy but absolutely necessary scientific steps upon which the success of the whole process is dependent. If industry will use the experimental method, the standardized methods which have been described cannot fail; if, however, it hastily constructs measuring devices, without regard to the fundamental foundation upon which such measurements depend, failure will be certain. It will not be true, as may be claimed, that the trade test is "too theoretical," but that those who attempt to use it are "too practical."

There is, however, one goal towards which the ideas and methods of the trade test have at least pointed the way. The trade test as employed in the various camps of the army established uniform standards of achievement, standards of achievement which did not vary with place, time, or examiner. If as a result of the further application of these methods, upon an infinitely wider scale, unchanging standards which will be nationwide can be established, the results to be obtained from such standardization can hardly be overestimated. If within each trade and occupation there was a common language and a 
common quantitative basis for measurement, a great advance could be made. The present chaos of trade standards created at will, by this union, or by that union, cannot long be tolerated. Trade standing must finally be determined, not by number of years of training, but by the absolute amount of knowledge and skill possessed by the tradesman. Why should a learner be made to serve a five-year apprenticeship, when a six months' course, scientifically planned, and well administered, can produce a better workman than five years of haphazard experience? In the realms of physical measurement the necessity for never changing standards is accepted. No elaborate commercial or scientific work could be done in the absence of the Bureau of Standards. Is it too much to expect that the application of scientific measurement in the field of human knowledge and human skill will demand the creation of a similar institution? 


\section{SELECTED BIBLIOGRAPHY}

I. The Personnel System of the U. S. Army. Published by War Department, Adjutant General's Office, Washington, D. C.

(History and development of the army personnel system)

2. Army Trade Tests. W. T. Bawden. Bureau of Education, Industrial Education Circular No. 4. April, I9r9.

(Report of Conference)

3. Trade Specifications and Index of Professions and Trades in the Army. War Department Document No. 774, Government Printing Office, Washington, D. C.

4. Description of Occupations. A series of bulletins published by the Bureau of Labor Statistics. U. S. Department of Labor. Washington, D. C.

5. Personnel Management. J. J. Coss and L. Outhwaite. War Department, Washington, D. C.

(Topical outline and bibliography of most phases of personnel work)

6. Publications of the Committee on Education and Special Training.

War Department, Washington, D. C.

(Instruction Manuals)

7. The Extension of Selective Tests to Industry. By B. Ruml. Annals of the American Academy of Political and Social Sciences, Vol. 8I, r9I9.

(Short statement of trade test method)

8. Measuring a Workman's Skill. W. V. Bingham. National Society for Vocational Education, Bulletin No. 30 .

(A short statement of the use of trade tests)

9. A Written Trade Test. J. Crosby Chapman and H. A. Toops. (Multiple Choice Method)

Journal of Applied Psychology, Vol. III, No. 4, I9r9.

(An account of a written group form of examination)

Io. Trade Test Enters Industry. J. Crosby Chapman. Finance and Industry, Vol. XXXIX, No. Io.

(A short statement of trade test method) 



\section{N D E X}

Ability, definition of, I2; sampling of, 80

Aids for interviewers, demerits of system, 5I, 53; general directions, 35; tests reproduced: auto repairer, 38 ; bricklayer, 46; carpenter, 348 ; inside wireman, 5०; machinist, general, 36; motion picture operator, 40; sheetmetal worker, 48 ; surveyor, 42 ; tire repairer, 44

Apprenticeship, period of, 56,430

Army requirements for testing devices, 8

Army requisitions, 6,355

Army trade names, caution, $6 \mathrm{I}$

Attitude of tradesman, 175

Basic human qualities, difficulty in measurement of, 368

Bluffing, 6, 343, 427; in commerce, 33

British trade test method, 264, 410

Civil Service, trade tests in, 427

Coaching, 333, 384; method of elimination, 379 ; use of supplementary questions, II 3

Committee on Classification of Personnel, $\mathrm{I} 3$

Consultants, $4 \mathrm{I} 3$

Differentiating power of test, I8; defined, 56; method of testing, 57, 59, 97

Differentiation in industry, 380

Educational department, problems of, 387
Educational measurements, application to trade test, 17

Efficiency expert, $4^{\mathrm{I}} 3$

Employment office, I3; centralized, 362 ; lack of skilled examiners, 32; methods of interview, 364 ; weaknesses of, $42 \mathrm{I}$; use of clerical assistance, 15

Examination, by experts, 7,364

Examiner, no trade knowledge needed by, 16,30

Follow up questions, 9I

Foreman, method of handling applicants, 13,364

Hiring out of town, 34

Industrial methods, adaptation of, I6 Industrial problem, similarity to army problem, 36I

Industry, achievements in, 380 ; centralized employment office in, 364 ; existing methods in, 13 ; exploitation of, 368 ; installation of trade tests in, 413; place of tests in, 376

Information, relation to skill, 23, 24

Intelligence test, distinguished from trade test, $37 \mathrm{I}$

Interview, aids for, 35 ; methods in industry, 7,364 ; private interview necessary, 4I 5

Job analysis, $36 \mathrm{r}, 367,387$; method of, 369

Job sheets, 389 ; advantages of method, 409; directions for, 408; introduction 
Job sheets, continued -

to, 397; samples reproduced - dividing head, 404 ; file, 398 ; forging cold chisel, 401 ; lathe, 402 ; use of, 410

Labor turnover, 4,363

Language difficulty, I89, 262, 333

Measuring instruments, skepticism with regard to, $\mathrm{XI}$

Motor-mindedness, 24

Multi-answer questions, 29, 30, 52, 54

Multi-choice method, 337

Objective ratings, 9; of trade test, I9 Objective scale, definition, 9; for school subjects, 17

Occupations, in army, $7,353,355$; specialized duties in army, 370

Occupational analysis, method of, 367 , 369

Occupational history, $35^{8}$

Occupational needs, tables of, 354,356

Occupational specialists, 354

Oral question, assumption underlying, 23; compilation of, 83,87 ; faults of, 86; elimination of, 93 ; key word, 94 ; nature of, 27; multi-answer vs. single answer, 29, 30, 52, 54; relation of information to skill, 23; scoring of, 94; selection of, $3 \mathrm{I}$; standardized followup question for, $9 \mathrm{I}$; statistical treatment of, 96; testing of, 90, 92, 94; types of, 27, 99; what it measures, 24

Oral trade test, alternative method of construction, 176; assembly of, 107; calibration of, ro3; differentiating power of, 55 ; genesis of, 16 ; improvement in, 348; instructions for giving, I66; scope of, I79; scoring of, I74; tests reproduced - acetylene cutter, 163; automatic screw machine, I34; auto repairer, 72; brass melter, I3I; bricklayer, I09; butcher, 144; cableman, I25; cabinet maker, 69; car- penter, 350; compositor, 150 ; cook (selected questions), I8I; cupola tender, I28; die-sinker, I38; dropforger, I4I; electrician, D.C., I 22; hammersmith, 66; ironworker erector, II9; painter, 63; pipe-fitter (low pressure), II2; plumber, II6; radio operator, $\mathrm{I}_{59}$; surveyor, 53 ; tailor, 156; telephone repairer, 76; typewriter repairer, I47; use of, 376

Performance trade test, administering, 279; advantages of, 26r; advantages for foreigners, 262 ; calibration of, 276 ; construction of, 272 ; demands of, 260; divisions of, 278 ; drawbacks of, in industry, 383 ; equipment for, 280; feasibility of, 272 ; final formulation of, 272 ; final testing of, 276 ; genesis of, 13 ; instructions to candidate, 280; instructions to examiner, 278 ; kinds of, 265 ; meaning of, 259; picture of, 270; place of, 268 ; practicality of, 384 ; preliminary testing of, 274 ; relation to industrial method, 259; scoring, $28 \mathrm{I}$; selection of, 268 ; specifications of, 278 ; stages of, 272 ; standardized vs. unstandardized, 382 ; tests reproduced: - bench-hand, 30I; blacksmith, 312; interior wireman, 295; lathe operator, 308 ; pattern-maker, 282 ; sheet-metal worker, 292 ; steamfitter, 288 ; stenographer, 322 ; truckdriver, 325 ; typist, 319 ; use of, 382 ; weighting, 277

Personnel, army problem, 5; organization in industry, 4I4; research vs. administrative groups, 4I5; specifications, 354,356

Picture trade test, advantages of, I88, I93; construction of, 190, 192; difficulties of, I9I; instructions for, 192; method, 183 ; reasons for, $\mathrm{I}_{3}$; practicality of, 187; scoring of, 193; 
source of, I89; tests reproduced: battery expert, 212; boilermaker, 236; carpenter, 198; cobbler, 243; gas welder, 249; generator tender, 203; horse-shoer, 228; lathe operator, 220; use of, 376

Progress of employee, measurement of, 4I7

\section{Qualification card, 360}

Questions, avoiding theoretical, I9I; compilation of, 87 ; formal, 15 ; single answer, 29, 30, 52, 54; specialized vs. non-specialized, 377 ; supplementary, 379

Ratings, in army, 56; lack of standardized, 7 ; subjective, 9

Sampling of ability, random, 80

Scientific method, 27, 429

Scoring, 60

Selective trade interview, 423; interviews reproduced: paper-hanger, 424 ; glazier, 426; single-answer question, 29, 30, 52, 54

Skill prediction test, distinguished from trade test, 372 .

Skill, relation to information, 23, 24

Skilled tradesman, disadvantages of use as interviewer, 14; present method of securing information concerning, 13

\section{Toops, 338}

Trade ability, definition of, I2; gradations in, 84 ; mistake in estimating, 6; need for more exact knowledge of, 3,4 ; sampling of, 263

Trade, change in, 362 ; definition of, I I Trade information, compilation of, 273 Trade interview methods, 422
Trade names in army, 6I

Trade qualification record, 6,360

Tradesman, attitude of, 175 ; motorminded, 24

Trade specifications, 356,357

Trade status, 93, 422; definition of, 56; interpretation of, 374

Trade test, criteria, I8; decision from, I0; definition of, 8; installation of, 43, 4I7; method in U. S. Employment Service, 420; not an intelligence test, $37 \mathrm{I}$; not for skill prediction, 372; place in general employment scheme, 353; specialized vs. non-specialized questions, 377 ; use of, $374,426,347,376,428$; selection of men for, 93; standardization of, 58 ; stages in construction of, 83 ; types of, I9

Training of employees, 386 ; formal vs. informal training, 387 ; haphazard instruction, 394; job sheets listed, $38_{9}$; measurements of results, 407; oral test applied, 388; performance method applied, 394; plan for, 388; rate of, $4 \mathrm{I} 7$; trade test methods applied, 386; technical, 26; weakness of present methods, 392

U. S. Employment Service, 420, 427; experimental office of, 420 ; forms of interview in office of, 422

War Department, Committee on Education and Special Training, 389

Written group trade test, advantages of, 337 ; assembly of, 338 ; differentiation by, 343; graphs in, 342; method of, 337; test reproduced:bricklayer, 338; results of, 34I; scores in, 341 ; subjects in, $34{ }^{\circ}$ 

. . 


\section{.}


IJAN 231

University of California 405 HIIgard AvenEGIONAL LIBRARY FACILITY JAN 26 ic $\begin{gathered}\text { Return this material to the library } \\ \text { from which it was borrowed. }\end{gathered}$

APR 2319

Jili. $1+51993$

MAY $6 \quad 1 !$

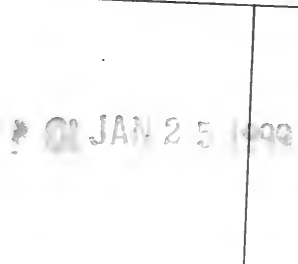

JAN 18

FEB 1

\section{DUll 8:}

Form 1 190 - 10 : 


$$
\begin{gathered}
\text { WHEERTH OF CALI } \\
\text { LERARY: }
\end{gathered}
$$

$T$

23

c $36 t$ 


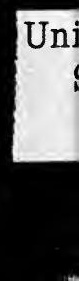

